Portland State University

PDXScholar

1993

\title{
An Implementation Analysis of the Water Resources Development Act of 1986
}

James Joseph Rich

Portland State University

Follow this and additional works at: https://pdxscholar.library.pdx.edu/open_access_etds

Part of the Environmental Policy Commons, Public Policy Commons, and the Social Policy Commons Let us know how access to this document benefits you.

\section{Recommended Citation}

Rich, James Joseph, "An Implementation Analysis of the Water Resources Development Act of 1986" (1993). Dissertations and Theses. Paper 1267.

https://doi.org/10.15760/etd.1266

This Dissertation is brought to you for free and open access. It has been accepted for inclusion in Dissertations and Theses by an authorized administrator of PDXScholar. Please contact us if we can make this document more accessible: pdxscholar@pdx.edu. 
AN IMPLEMENATION ANALYSIS OF THE WATER RESOURCES

DEVELOPMENT ACT OF 1986

by

JAMES JOSEPH RICH

A dissertation submitted in partial fulfillment of the requirements for the degree of

DOCTOR OF PHILOSOPHY

in

URBAN STUDIES

Portland State University

1993 
TO THE OFFICE OF GRADUATE STUDIES:

The members of the Committee approve the dissertation of James Joseph Rich presented December 11, 1992.

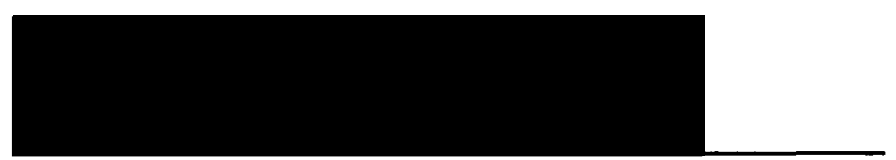

Sheldon Edner, Chair
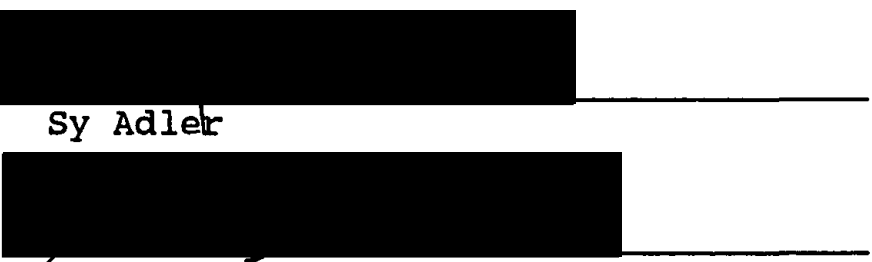

James G. Strathman

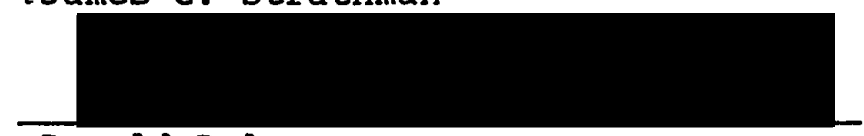

Donald Balmer

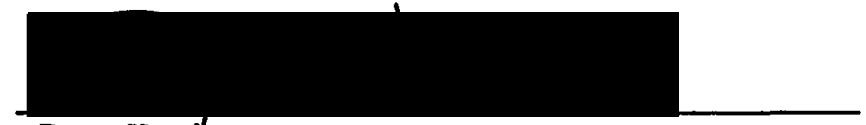

Roy Koch

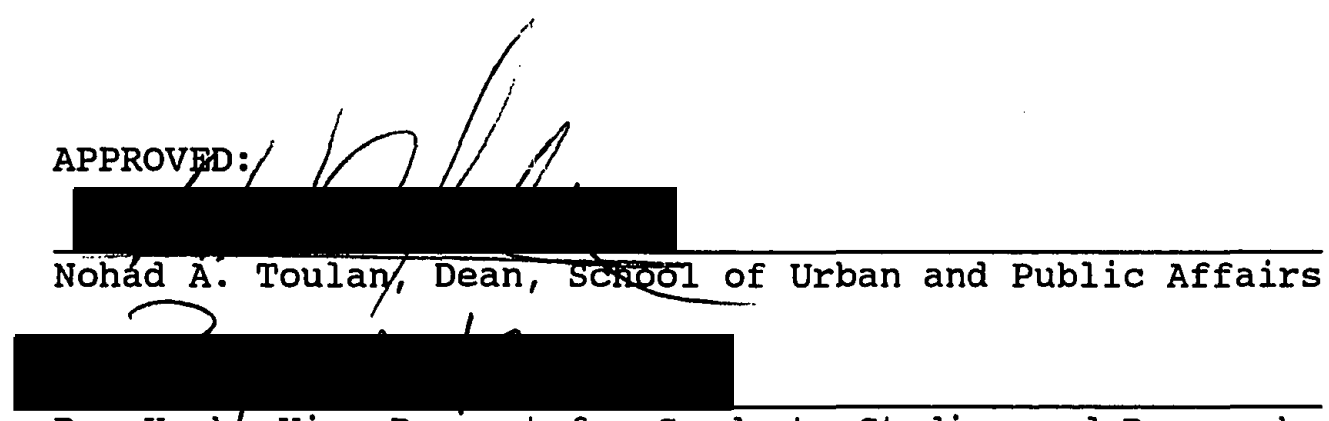

Roy Koch/, Vice Provost for Graduate studies and Research 
AN ABSTRACT OF THE DISSERMATION OF James Joseph Rich for the Doctor of Philosophy in Urban Studies presented December 11, 1992 .

Title: An Implementation Analysis of the Water Resources Development Act of 1986

APPROVED BY THE MEMBERS OF THE DISSERTATION COMMITTEE:

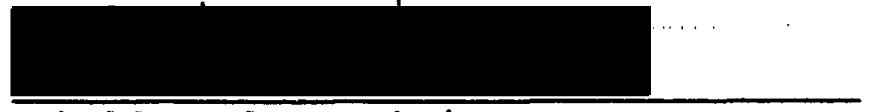

Sheldon Edner, Chair

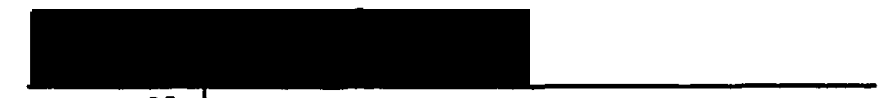

Sy Adler

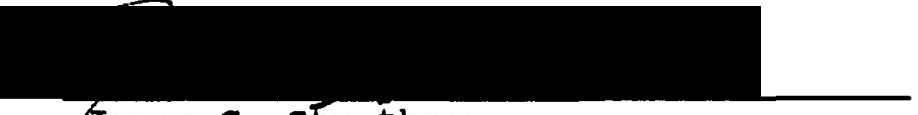

Tames G. Strathman

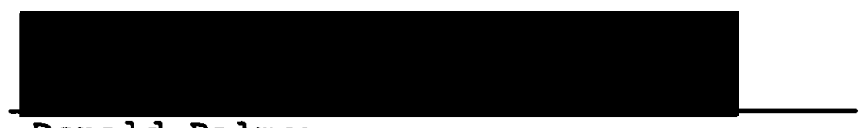

Donald Balmer

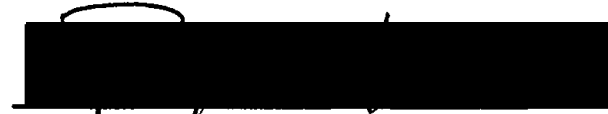

Roy Koqh

Implementation research, an area once largely ignored in favor of policy design and impact assessment, now constitutes a significant portion of the policy analysis literature. One of the key issues addressed by the theory building portion of that literature is the necessity of precisely identifying implementation variables, conditions or actions that measurably contribute to the success or 
failure of implementation efforts over a broad range of policies and programs, and to then suggest some order of significance. In order to test the validity of a variable set proposed by the literature, a multivariate implementation model was employed as the basis of a case study designed to conduct both a process and impact analysis of the implementation of the Water Resources Development Act of 1986 (WRDA 86).

Implementation of the WRDA 86 was selected for this research as it offered an opportunity to investigate implementation of a significant policy change in an established policy arena, the water resource development industry. Following ten years of failure to achieve agreement on an omnibus water resource appropriation, passage of the WRDA 86 was widely perceived to have signaled a new era of water resource development for the nation. It will likely be a period characterized by the transfer of the financial burden of planning, construction, and maintenance of water resource projects from the Federal government to the non-Federal sponsor/beneficiary. The transfer will be achieved by application of cost-sharing formulas contained in WRDA 86 and affirmed in subsequent biannual omnibus water resource development legislation.

Cost-sharing and similar beneficiary-pay principles had long been considered as an efficient alternative to water resource programs which relied principally on Federal 
funding owing to the long held assumption that the benefits from such projects were so "widespread and general" as to be in the national interest. Incorporation of cost-sharing principles in water resource legislation ensured that appropriation language would require local project beneficiaries to assume a larger portion of project costs. In addition to the assumption that application of the principles would lead to economically efficient projects it was also argued that cost-sharing and increased local sponsor input would lead to smaller projects that better reflected local need, projects with greater emphasis on environmental concerns, and the construction of projects in stages or phases.

The research proceeded with an implementation process analysis to test the model's assumption that specific variables or conditions may be identified as having the greatest significance in the achievement of successful implementation. Furthermore, the study attempted to determine whether identified groups at different "levels" of the implementation hierarchy would rank specified variables consistently or result in a finding that variable criticality rankings tend to reflect one's position within the hierarchy.

Study outcomes did not confirm the model's assertion with respect to which variables were most critical. This 
finding may have reflected the fact that conditions thought to be most critical by the model, clear legal directives and legislation that reflects sound theory, were largely issues that had been thoroughly discussed and resolved prior to enactment of the legislation. Position within the hierarchy appeared to influence the rater's assignment of variable criticality though not to a statistically significant degree. The differences, however, were intuitively consistent and their basis supported by secondary survey data. This finding suggests that future implementation studies need to carefully examine the role of hierarchical position and intergovernmental interdependencies in theory development.

With respect to the impact analysis, it was determined that cost sharing would have a demonstrable impact on resulting projects in a variety of areas. Future costshared water resource development projects will likely be smaller on average than past projects though the precise impact of cost-sharing is indeterminable. Projects may result in less impact on the environment but largely as a result of reduced size rather than the additional environmental input of local sponsors. Phased and staged construction of large projects will be more likely, particularly where project benefits and revenue streams may be partially captured by incremental construction. 
Dedicated To

ANASTASIA

(1983-1991)

My Best Friend Forever 


\section{ACKNOWLEDGEMENTS}

I am deeply indebted Dean Nohad A. Toulan and to the faculty of the School of Urban and Public Affairs, Portland State University, for their patience and guidance in this endeavor. I am particularly grateful to my committee chairman, Dr. Sheldon Edner whose devotion to this effort extended far beyond his professional obligation. Special thanks also to Dr. Jim Strathman, Dr. Sy Adler, Dr. Donald Balmer, and Dr. Roy Koch for their support, their advice, and their cooperation.

I would also like to thank specific staff members of the University without whose help and friendship I would not have been able to complete my dissertation in absentia. For the assistance rendered by Ms. Eloise Bates of the SUPA and Ms. Maureen orr Eldrud of the office of Graduate studies I am truly grateful. Their caring attitude and professionalism are a credit to the University.

Many members of the U. S. Army Corps of Engineers participated in this research offering their time, their advice, and their institutional memory. I wish to specifically acknowledge Mr. Kyle Schilling, Water Resources Support Center, for his assistance in getting the research off the ground, Dr. Martin Reuss, office of History, for his invaluable assistance in the area of public history 
research, and Mr. Thomas Carter, Alaska District COE, for his sense of humour through it all.

Lastly I wish to thank Ms. Deanna bell whose patience, love, support, and willingness to spend extra time with the dog got me through the hard times. 
TABLE OF CONTENTS

PAGE

ACKNOWLEDGEMENTS. . . . . . . . . . . . . . . . . iii

LIST OF TABLES. . . . . . . . . . . . . . . . . vii

LIST OF FIGURES. . . . . . . . . . . . . . . . . . . ix

CHAPTER

I INTRODUCTION. . . . . . . . . . . . 1

II REVIEW OF THE IITERATURE. . . . . . . . . 12

An Overview of Policy Implementation:

The Literature.... . . . . . . 13

Cost-Sharing: Literature on the

Theoretical Foundations. . . . . . 35

WRDA 1986: A History of Water Resource

Development Policy. . . . . . . 53

The Army Corps of Engineers and the

History of cost Shared Water Resource

Development. . . . . . . . . 61

Conclusion. . . . . . . . . . 105

Endnotes. . . . . . . . . . . 108

III RESEARCH METHODOLOGY AND HYPOTHESIS

DEVELOPMENT. . . . . . . . . . . . . . 109

Hypothesis Development: Analysis of

Implementation Variables. . . . . . . 110

The Conditions of Effective

Implementation. . . . . . . . . . 126

General Design Considerations. . . . 132

Data Analysis and Hypothesis Testing. • 137

Endnotes. . . . . . . . . . . 152 
PAGE

IV SURVEY DATA ANALYSIS. . . . . . . . . . . 153

Respondent Assessment of Variable

Importance. . . . . . . . . . . 153

Conclusion. . . . . . . . . . 183

Endnotes. . . . . . . . . . . 185

$\checkmark$ THE IMPACT OF COST SHARING ON PROJECT

DEVELOPMENT. . . . . . . . . . . . . 186

Impact on Project Size. . . . . . . . 187

Data on Physical Impacts. . . . . . . 213

Cost-Shared Project Development and

Environmental Impacts. . . . . . . . 237

Summary. . . . . . . . . . . 260

Endnotes. . . . . . . . . . . . 264

VI SUMMARY FINDINGS. . . . . . . . . . . 265

Endnotes. . . . . . . . . . . . 286

SELECTED BIBLIOGRAPHY. • . . . . . . . . . . . 287

APPENDICES

A

SURVEY INSTRUMENT. . . . . . . . . 302

B

NATIONAL ASSOCIATION OF FLOOD AND STORMWATER MANAGEMENT AGENCIES (NAFSMA)

SURVEY. . . . . . . . . . . . 306

C

INDEX OF ACRONYMS. . . . . . . . . . 312 


\section{LIST OF TABLES}

TABLE

PAGE

I Major Federal Legislation Authorizing Cost Sharing By Project Purpose. . . 56

II Summary: Implementation and OM\&R for NonFederal cost Sharing for 20 Agencies. . 59

III Nonfederal Mean, Effective, Composite Cost Share by Project Purpose (In Percents) 60

IV Army corps of Engineers cost Sharing

Allocation Prior to WRDA 1986. . . 85

$\mathrm{V} \quad$ Cost Sharing Allocation Under WRDA 1986. • 86

VI Traditional cost Sharing of Water Resource Development Projects. . . . . . 87

VII Project Finance options. . . . . . . . 92

VIII Project cost Comparison. . . . . . . 95

IX Model Flow Diagram. . . . . . . . 121

$\mathrm{X}$ Mean Distribution Scores For

Implementation Variables . . . . . 154

XI Relative Variable Rankings Based on

Mean By Group. . . . . . . . . . 156

XII Frequency Distribution Table of Variable Rankings. . . . . . . . . . 157 
XIII One Way ANOVA: Implementation Variable By Group. . . . . . . . . . . . 164

XIV Project Manager Survey For Cost Shared Planning. . . . . . . . . . . 173 One Way ANOVA: Comparison of Center And Periphery. . . . . . . . 176 XVI Cost Comparison Estimate For Flood Control Project With Cost Shared Design Changes. . . . . . . . . 216

XVII Water Resources Development Act of 1986

Authorized Channel Improvement Projects. . . . . . . . . . . 218

XVIII Cost Share Impacts on Navigation projects. . . . . . . . . . 221

XIX

Cost Shared Deep-Draft Harbor Projects Under Construction. . . . . . . . 223 $\mathrm{XX}$ Corps of Engineers Construction General Expenditures. . . . . . . . . . . 224 XXI Reconnaisance Studies started In FY 1986-87. . . . . . . . . . . 233

XXII Impact of cost Sharing on Environmental Mitigation. . . . . . . . . . 252 XXIII Non-Federal Interest Data on Cost Shared Planning. . . . . . . . 281 


\section{LIST OF FIGURES}

FIGURE

PAGE

1. Output of Public Goods. . . . . . . . . . 42

2. Demand for Project Benefits. . . . . . . . 48

3. Indifference Curves for Public Goods. . . . 209

4. The Rise and Decline of Federal Aid, 1958-88

(as a Percentage of State-Local Outlays) 226

5. Federal Aid To state and Local Government

per $\$ 100$ of Personal Income, 1970-1987

$(1987=100)$. . . . . . . . . . 227

6. Changes in Federal Aid to State and Local

Government (1957-1986). . . . . . . 229

7. State and Local Tax Effort by Level of

Government (1957-1986). . . . . . . 229

8. Capital and Operating Outlays for Water

Resource by All Level of Government. . . 235

9. Output of Environmental Quality. . . . . . 244

10. Patterns of Effective Implementation. . . . 267 
CHAPTER I

INTRODUCTION

The focus of this research involves an implementation analysis of the Water Resources Development Act of 1986 (which shall hereinafter be referred to as the WRDA 1986) by the United States Army Corps of Engineers with specific treatment of the development and execution of the Act's cost sharing provisions. The signing into law of the WRDA 1986 on November 17, 1986 by President Ronald Reagan was widely and correctly perceived to have signaled a new era of water resource development, a period characterized by:

1. The further transfer of the financial burden of water resource planning, development, and maintenance from the Federal government to non-Federal project sponsors (beneficiaries);

2. The emergence of a Federal Interest/Sponsor "partnership environment" that promised to substantively modify the qualitative dimension of intergovernmental resource development relationships;

3. A tenuous resolution of the struggle between the executive and legislative branch of the Federal government to control Federal water resource development policy.

The WRDA 1986 was a singularly important legislative act for a variety of reasons. As the first Omnibus water 
appropriation in ten years, the Act authorized 377 projects for construction or study including 43 port projects, 7 inland waterway projects, 115 flood control projects, 24 shoreline protection projects, 61 water resource conservation and development projects, 38 studies, and 63 project modifications (Reuss 1990). Notwithstanding the importance of the authorized projects, the overriding significance of the Act rests with the perception that, with its passage, Federal water resource development was brought "back on track" following a decade of often acrimonious controversy over the appropriate role of Federal investment in water resource development and the relationship of Congress and the Executive branch in the development and execution of water resource development policy. Owing to disagreement between the Executive and Congress on such broad but interrelated issues as project selection criteria, geographic distribution of capital investment, and cost sharing requirements for non-Federal beneficiaries no omnibus water resource legislation had passed since 1976 . The result was a significant "backlog" of projects awaiting either authorization or funding. The loss of consensus between the executive and legislative branches on priorities and the role of beneficiaries had effectively stopped the great water projects engine.

It was widely acknowledged that the corps had fallen on hard times in the 1970 s as it struggled to meet its mission 
in the "constrained needs of a postindustrial, debt ridden, and service based economy" that was experiencing the rise of the environmental movement compounded by the decline of development interests (National Journal 1986, 2822). Immediately prior to the passage of the WRDA 1986, the Corps of Engineers noted that of the 106 ongoing construction projects only six were begun after 1979 with $\$ 16$ billion of authorized projects awaiting construction funding and \$13 billion in projects awaiting authorization (Wall 1985, 22). By 1983, the Corps for the first time in its history spent more money on operation and maintenance of projects than on new start construction. Over the course of this era, cost sharing emerged as the dominant intergovernmental water resource development issue requiring resolution.

As advocated by the Administrations of both President Carter and Reagan, cost sharing by the non-Federal beneficiary represented a best alternative, a practical and efficient method of determining: 1) a beneficiary's true desire for a given project as evidenced by willingness to invest, 2) optimal project size as mediated by the beneficiaries willingness to pay, 3) a more economically efficient method of allocating scarce Federal resources while reducing the actual size of the Federal obligation. As it was an Executive initiative it came as no surprise that cost sharing, in the form it came to assume in the WRDA 1986, also expanded the direct involvement of the Executive 
branch, particularly the office of Management and Budget (OMB), in establishing broad project selection criteria, authorization of cost ceilings, and approval of all cost sharing arrangements reached with non-Federal interests. While the economic logic of cost sharing realized the support of a broad and eclectic range of interests, some of which favored the measure for little more than its potential to act as a constraint on development, it was not without it detractors. The concept of cost shared planning was soundly rooted in applied microeconomic theory. Alas, that same body of work noted that the efficiencies achieved by application of cost shared planning principles came at the expense of reduced subsidization of marginally efficient public works. Predictably, institutional interests which had enjoyed a long history of delivering subsidized public works projects to their constituencies and those interests which benefited from such Federal largess were opposed to dramatically changing the traditional water resource development calculus.

As is often the case, the removal or reduction of a longstanding subsidy is perceived not so much as a move toward a more rational and equitable method of financing but as a method of indirectly raising taxes. A discussion of this phenomena is offered in that section of chapter II which deals with the nature of public goods and their 
efficient provision.

As is so frequently the case, the opposing point of view on a policy matter is not muted by "losing" in or being excluded from the legislative arena. The implementation phase of public policy provides such "losers" an opportunity to revisit issues in hopes of influencing this stage of the policy process (Rein, 1978). Indeed, as late as June, 1985 OMB expressed concern that congress would fail to require cost sharing and user fees in the omnibus authorization (S 366) that was to become the WRDA 1986 (Congressional Quarterly 1985, 1239) and requested that the legislation expressly prohibit the expenditure of funds for any authorized project until a cost sharing agreement had been executed. The concern was shared by cost share advocates in the Administration and Congress who fought to strictly limit the number of projects that could be legislatively excluded from cost share provisions. This was done to preclude the gradual erosion of the policy initiative by anti-cost share legislators who might attempt to exempt projects, individually or by class, from cost share requirements in subsequent legislation.

While the enactment of cost sharing provisions in the WRDA 1986 was perceived by many as a tentative first step toward establishing cost share principles as critical planning elements in water resource development, it also represented a significant change in the Army Corps of 
Engineers' (COE) approach to project planning and development. The "Partnership in Planning" model, occasioned by the additional financial contribution now required of the non-Federal partner, presented a variety of opportunities and challenges to the corps and the nonFederal interests. Not the least of these involved addressing the negotiation of "engineering and design" issues which had heretofore been the express domain of the Corps; a fact attested to by the thousands of pages of regulations, circulars, pamphlets, and guidelines authored and compiled by the agency over the years. Absent local budget constraints, the corps had typically designed to the highest engineering standard. The engineering solution proposed by local interests promised to offer a somewhat more austere approach given the limited financial capacity of most non-Federal interests and their desire to design a project which met their specific needs rather than one which necessarily met national benefits criteria. What was to be the role of the new partner in deciding which engineering solution was right?

From the perspective of non-Federal interests, the issue of financing capital water resource development projects in an environment of cost estimate uncertainty, largely a non-problem when construction was financed $100 \%$ by the Federal government, presented an equally complex 
challenge. Unlike the Federal government, the non-Federal interest typically had strictly limited financial resources, a far shorter project planning horizon, and an interested constituency. For better or worse, all parties concerned agreed that the WRDA 1986 promised to offer a unique experience in intergovernmental cooperation.

In an attempt to offer a multi-perspective evaluation of the implementation of the WRDA 1986 and its impact on the water resource development planning process this research focuses on two fundamental aspects of the implementation: 1) a process analysis which attempts to evaluate how well specific theory based implementation models explain or account for the inter-interest dynamics of the implementation process, and 2) an impact analysis which attempts to reveal the actual and likely project impacts of implementing cost shared planning and development.

This approach was adopted to provide a broad understanding of the "end-product" impact of implementing significant policy change in the water resource development arena and to expand upon that understanding by evaluating the process in the context of models that reflect what we know (or believe we know) about the implementation of public policy. This effort is undertaken primarily to contribute to the further refinement of the body of knowledge on conceptual approaches to policy implementation. Additionally, it is hoped that the findings of this research 
may be utilized more generally to provide a rational basis for the practitioner to determine strategy alternatives with regard to limited resource allocation in the design of an optimal implementation strategy.

To provide a foundation for the process analysis, the research examined the literature on implementation and selected from several existing implementation models a series of variables that have been identified as important in the successful implementation of public policy. These variables, in combination with variables identified by this researcher, were combined in a survey instrument designed to elicit from participants involved in the implementation process data on the relative significance of various identified aspects (hereinafter referred to as conditions) of implementation. For the purpose of the survey and statistical analysis, the participants were grouped into cohorts in accordance with the criteria set forth in the selected implementation model. This structure provided an opportunity to test the statistical significance of recorded differences between groups identified as being at different "levels" of the implementation process. This aspect of the research was undertaken both to test the explanatory capacity. of the model and its underlying theory and, hopefully, to thereby expand our working knowledge of inter and intragovernmental policy implementation. 
The project impact analysis focused on the identification and assessment of how distinguishable features of projects were modified or re-scoped as a result of planning under cost share principles. This approach was selected to illustrate the empirical impact (scope, size, feature, etc.) of cost sharing on projects originally planned or conceived under traditional Federal funding guidelines and to determine the probable impacts on future projects developed under cost shared planning principles.

The analysis for this effort proceeded with a straightforward comparison of a sample of projects originally authorized and planned prior to the enactment of the WRDA 1986 which subsequently required reauthorization under the Act and were thus subject to project plan renegotiation with the non-Federal interest. These projects, which represent a unique sample of projects planned under both traditional and cost shared planning principles, provide data that establishes a basis for examining the existence and characteristics of empirical differences between cost shared projects and those fully funded by the Federal government. Comparable data from projects authorized under subsequent omnibus water resource development legislation (the WRDA 1988 and the WRDA 1990) is then analyzed to see if confirming evidence exists to support the predicted impacts.

While it is not the intention of this research to 
provide the reader with a definitive history of either the role of the Army Corps of Engineers in water resource development or the development of intergovernmental cost sharing as public policy, it will be necessary to offer some background on both surjects to provide context for the ensuing discussion. With that historical context in place, the analysis will then provide a multi-perspective examination of the projects, people, and processes that comprised the implementation of the WRDA 1986.

It is the intention of this research to contribute to an understanding of the extent to which cost sharing has affected Federally assisted water resource development since the passage of the WRDA 1986. Moreover, data are offered to suggest the impact cost sharing will have on the future of water resource development in this nation and to provide some idea of the predicted footprint of that impact as regards the size, configuration, and geographical location of future projects.

The research strives, through the analysis of existing implementation models, to offer insight regarding the dynamics of the policy implementation process. Particular attention is afforded the possibility of identifying the foundation of the implementation process as a set of variables/conditions which may be ordered based on their relative importance or significance to the process. If there exist independent implementation variables that can be 
so ordered, policy makers, faced with designing implementation strategies for new policy, should be capable of utilizing such information to make a more informed and rational allocation of organizational resources in pursuit of successful program implementation.

Lastly, data on the existence of intergovernmental differentials in the ranking of implementation variables will be evaluated to determine the origin, nature, and magnitude of the differences. The existence of differences of opinion between Federal interests and state/local interests as to what contributes most significantly to a successful implementation effort, though not intuitively surprising, has both practical and theoretical implications. The research will here address those implications by examining the evolving relationship between the corps of Engineers and non-Federal interests as the partnership is shaped by the influences of the implementation environment and the impact of that process on the transformation of law to applied policy. 
CHAPTER II

REVIEW OF THE LITERATURE

This chapter provides a review of the literature and relevant history of implementation research and cost shared water resource development. While the topics are integrated for evaluative purposes in this research, implementation research and water resource development policy are clearly discrete fields of study, and as such, possess a unique literature and history. To more clearly establish the theoretical and/or historical antecedents of the individual areas of research, this chapter is set forth in four primary subdivisions:

1. A review of the literature on implementation research and resultant theory;

2. A review of the theoretical foundations of cost sharing as a method of planning for and funding public works projects;

3. A review of the history of water resource development policy within the Army Corps of Engineers leading to the implementation of the WRDA 1986;

4. An analysis of the key issues established by the literature that will be the subject of investigation in this research. 
AN OVERVIEW OF POLICY IMPLEMENTATION: THE LITERATURE

It is now well understood that the establishment of major policy goals and directions in legislation does not ensure the success of those initiatives. Indeed, the recent literature on implementation would appear to suggest that the tortuous route the execution of legislation to on-site implementation of the program or policy more often than not is characterized by a commingling of complexity, confusion, and compromise. Perhaps this appears to be the case because the first significant implementation studies, and so much of the ensuing literature in the field, is devoted to an analysis of failed programs (Pressman and Wildavsky 1973; Derthick 1972) and the research itself, "an exercise in concentrated pessimism" (Bardach 1977). As a result, implementation research has tended to focus generally on the constraining rather than the enabling variables or conditions; and much has been written of the complexity and dynamic instability of the process. Here a likely explanation is that it is somewhat easier to suggest why a policy tailed in some important respect than why it succeeded well in others. Typically, someone (or group) did not do something, or did less than was required, thus providing some explanatory basis for the resulting underperformance of the policy initiative. Contributing to this phenomenon is the observation that 
almost nothing, let alone a social policy, works as well as we had hoped. Thus, there appears always to be a rich array of policy failures available for research. It is frequently the failure of policy over time that leads to an interest in examining the process of policy implementation in hopes of determining whether "mechanical failure" rather than bad policy was the culprit (Goggin et. al. 1990, 9). For whatever reason, there exists a significant body of implementation research that is openly critical of the research process itself and the resultant literature which is found wanting for, among other deficiencies:

1. A failure to produce a body of coherent theory (O'Toole 1986; Berman 1980; Goggin et. al. 1990);

2. A tendency to produce findings that are little more than routine restatements of long observed phenomena (Salamon 1981);

3. Research findings that are long on description and short on prescription (Williams 1982, 18);

4. Methodology characterized by a multiplicity of approaches without an integrating framework (Alexander 1985).

Fox $(1987,138)$ suggests that the problem rests more with the positivistic bias of the research than the poverty of the implementation effort. There is a suggestion by some researchers (Alexander 1985) that the field of study may be inherently intractable or that the target behavior, 
implementation, is an essentially political act, always present and ever illusive (wittrock 1986, 46).

Indeed, there is persuasive argument made for not considering implementation during policy formulation lest policy options be constrained by perceptions of administrative feasibility leading to a situation where "we only attempt to do that which we know we can do well" (Iinder and Peters 1987), or design feasible rather than optimal policies (Majone 1975, 50). These observations have normative implications which Linder and Peters note may be highly undesirable and contribute little to a theoretical understanding of how to effectively implement "difficult" policy.

Other scholars have inveighed against such constraints arguing that unless implementation research generates a product that is policy relevant and of utility to policy makers it will never achieve status outside the established work on organizational theory and management (Williams 1982, I). Pioneering studies in the area of implementation analysis featured an emphasis on ascertaining the feasibility of policy success of a given policy in a known environment. While such research advanced an appreciation for the implementation component of policy success it did little to suggest answers to the broader theoretical concerns of researchers interested in what made 
implementation work or not work (Wittrock and De Leon 1986). Authors such as Jones (1977, 137-158) and Anderson (1975, 99-115) tend to dismiss the field of implementation research as a unique body of study by incorporating the process of implementation into a broader framework of analysis which they respectively refer to as the "administrative process" or "public policy making." still, there appears a formidable body of research that argues for implementation analysis as the critical link in appreciating observed inconsistencies between the promulgation of policy objectives and the delivery of policy outcomes. Absent knowledge of whether or not a policy was implemented substantially as designed, it is virtually impossible to assess the correctness of a policy direction.

In recognition of this, the policy implementation process, which was once largely ignored in favor of analysis of policy design and policy impact assessment, now constitutes a significant portion of the policy analysis literature (Pressman and Wildavsky 1973, 166). The literature on implementation has, beginning with Pressman and Wildavsky's "classic", Implementation (1973), tended to emphasize almost exclusively the case study approach (Fox 1987, 129). The case study is typically used to: 1) descriptively. identify and distinguish the character of the "implementation problem" (as was largely the case in Pressman and Wildavsky 1973 and Derthick 1972), 2) focus on 
the influences that affect policy making and implementation (Allison 1971 and Bardach 1977) or, 3) attempt to isolate the factors or variables in the process so that the individual components of the process may be evaluated (Edwards 1980, Mazmanian and Sabatier 1983).

The use of the case study method has provided a rich narrative literature examining the event sequencing (and re-sequencing) of the implementation process. It has, however, also contributed to the observation that various methodological approaches to analysis are "partial and incomplete" and that each is exclusive of any other perspective because the data set of each case study is unique unto itself (Alexander 1985, 407). This latter criticism is particularly significant to those researchers engaged in theory building exercises for whom nonstandardized case studies provide no research platform for replication (Goggin et. al. 1990, 15). Moreover, the case study comparative approach has frequently resulted in a "small N" or "degrees of freedom" problem in which the number of variables exceeds the number of cases thus making inferential generalization a methodologically difficult proposition (Yin 1982, Goggin 1986, Goggin et. al. 1990). Van Horn lends support to such criticism noting that case study analysis provides no coherent framework for analysis as the findings appear idiosyncratic, variables and 
explanations being typically tailored to the single case under investigation $(1979,9)$.

The very decision as to where to initiate analysis is both seminal and itself open to question. Various scholars have noted that the hierarchical geography of implementation suggests that one can initiate measurement and evaluation from the "top down" or begin the analysis with an assessment of implementation outputs and work back toward a resolution of intent and outcomes. The "top down-bottom up" controversy, the dominant research protocol issue of the 1980s, remains unresolved. Linder and Peters identify the "top down" and "bottom up" approaches as the current schools of thought in implementation analysis with the former being more phenomenological and the latter positivistic (Linder \& Peters 1987,116$)$. While a number of models would arguably fall neither entirely into one camp or the other, the general groupings offers an attractive first order classification of proposed research strategies. Moreover, the distinction is not trivial because selection of an approach to analysis, when the alternative employs different units of measurement and evaluation criteria, may lead to quite different results, even when competing research models are tasked with evaluating an identical sequence of events. Thus, while the empirical impacts of an implementation effort may generally be agreed upon (a risky assumption at best) the measured "success" of 
an implementation effort may vary with the orientation of the analysis.

Top down analysts emphasize the legitimacy of goals and policies established by elected officials, a reasonable and seemingly normative assumption. The focus is generally on national policy or policy goals set forth by a central government (Goggin et. al. 1990, 11). The analysis begins with a set of policy decisions and seeks to identify a measurable differential between actual outcomes and anticipated outcomes. The incremental difference between stated expectation and actual outcomes, if negative, is ascribed, at least in part, to implementation deficiencies.

The straightforward nature of such analysis has a certain intuitive charm. Policies are frequently announced with associated goals, though such goals are seldom quantified with any degree of specificity. Indeed, the general lack of quantification in the implementation research process has been a longstanding criticism of those who see such imprecision as severely limiting the ability of the research to identify precise relationships between the various elements and outcomes (Goggin et. al. 1990, 11). Measurement of goal attainment thus becomes a basis for meaningful implementation analysis. If one assumes that the policy is prescriptively correct and the goals realistic, the measurable difference between goal and goal achievement 
should be largely ascribable to what did or did not happen in the implementation process.

Interestingly, as implementation research has progressed the position of the top down analyst has generated numerous critics. A number of studies have offered evidence that policy makers have little practical influence on the behavior of implementors (Berman 1975, 22-47; Lipsky 1980, 16-28). This is so, it is argued, because outcomes are primarily dependent upon the resources, initiative, and commitment of first order implementors. Hence, it is methodologically appropriate to initiate analysis at the bottom of the implementation hierarchy and work backwards (Elmore 1978, 212-213). Moreover, the role of the state and its agents as autonomous rational actors must be accounted for when evaluating national/state intergovernmental implementation efforts (Goggin et. al. 1990, 13.) Critics of the top down approach cite the inherent necessity of consensus building and accommodation in the implementation process and suggest that to ignore their role and significance is tantamount to "denying and renouncing the very existence of politics" (Winter 1983, 2).

Perhaps the first systematic reordering of the top down policy flow perspective was Elmore's backward mapping model which traced the development of policy initiatives by first order implementors, whom he argues, should formally share responsibility for the policy development process (1979). 
This view is generally shared by a number of researchers who either actually attempt to identify policy development origins, as did Elmore, or who argue that policy, while generally evinced at the top of the hierarchy, is dynamic, iterative, and subject to a wide variety of modifying pressures (Elmore 1978, 1979; Lipsky 1978; Hjern et. al. 1978). Stone $(1980,13)$ suggests that implementation is an integral part of the policy development process rather than an administrative follow on and so has no one set of authors but is the product of a "multiplicity of actors and agencies involved and the linkages between them" (Barret and Hill 1984, 220; Berman and McLaughlin 1975).

Elmore, in addition to advancing our understanding of the shortcomings of using traditional bureaucratic models to explain implementation has noted that implementation is instrumental in nature and so employs policy instruments which he identifies as: 1) mandates, 2) capacity building, 3) inducements and, 4) system changing. The instruments are a means to accomplish a desired policy end or purpose and are employed to elicit a predictable response from policy makers. Their utility, then, is that certain instruments may fit a particular policy problem or objectives better than others permitting the analyst to introduce strategic implementation concerns in the policy design process by recommending a particular instrument or combination (Elmore 
$1987,175)$.

Edwards notes that a critical emphasis in continuing implementation research must involve identification of the preconditions of successful policy implementation and the primary obstacles to its achievement (Edwards 1980, 9). This argument is extended by Goggin who, while affirming the need to devote attention to the identification of process variables, argues that the constants, the patterned regularities of the implementation context require equal consideration (Goggin 1987, 27). General criticism of rigid bureaucratic top down implementation analysis addresses the deficiency of the perspective for failing to recognize or measure significant intangible effects of the implementation process (Rossi and Wright 1985, 328). Indeed, a significant portion of implementation research is criticized as confusing policy implementation research with evaluation research which is more appropriately concerned with a straightforward comparison of outputs in relation to expectations (Goggin 1987, 27; Edwards 1980, 8).

These approaches enjoy an intuitively obvious advantage in that they immediately move one beyond simply descriptively documenting the process of implementation. Serious questions remain, however. How, for instance, is one to be sure that either the preconditions or patterned regularities observed in conjunction with a particular policy application would apply across policy types, let 
alone jurisdictional environments? Fox notes that implementation impacts, negative or positive, may appear ahistorically general when they are, in fact, specific to the times and particular environment (Fox 1987, 137). Moreover, assuming that a set of general variables (proxies for the referenced preconditions and obstacles) could be identified, how does one order the set so that limited administrative resources can be rationally applied?

The criticism of "top down" implementation models is both weighty and compelling but far from sufficient to fully discredit the approach. In fact, the persistence of "textbook policy process" as Nakamura refers to it, may be attributable to the fact that, while inaccurate, it is superior to the next best alternative $(1987,152)$. Whereas the "bottom up" perspective adds greatly to our understanding of the obstacles and forces that impede or redirect the implementation of mandated policy it errs on the side of the "practical," accepting, in Linder's words, "an empirical difficulty as both a normative statement and the sole basis of analysis ... " (1987, 459).

While we achieve an appreciation of the dynamics of a particular process based on a purely descriptive network analysis. we learn listle of theoretical significance that would have empirical or normative significance for subsequent applications of the technique. Indeed, there is 
a persuasive and disturbing argument made for not considering implementation during policy formulation lest policy options be constrained by perceptions of administrative feasibility so that "we only attempt to do that which we know we can do well" (Linder and Peters 1987), design feasible rather than optimal policies (Majone 1975), or adopt policies (driven from the bottom up) that are inconsistent with the fundamental values of society at large (Hoggwood and Peters 1983).

Distinct from the focus on identifying the direction of policy flow within an organizational hierarchy and the correspondingly appropriate methodological perspective, a body of research in the last decade has sought to examine the development of models that identify the institutional "mechanics" of implementation. These models, once again generally through. case study, attempt to provide a schema of how the actors, forces, and organizations interact to produce outputs that are more or less consistent with the stated policy initiative; in effect, the physics of policy implementation. This initiative is in response to the early criticism of implementation research as lacking in precisely defined variable relationships that permit the generation of estimates and quantitative measures (Goggin et. al. 1990, 11). An assessment of the evolution of this research provides an alternative model of categorization which focuses on "generations of research" (Lester et. al. 1987, 
201).

Indeed, the course of implementation research has proceeded not unlike the early study of physics, observing the consequences of a variety of behavioral interactions and then attempting to formulate "laws" having broad explanatory capacity. In retrospect, this evolution may be mapped by designating "generations" of research characterized by methodological approach and sophistication of the techniques employed. While there is no widespread consensus within the field on the exact number of generations of research that have transpired the following breakdown provided by Lester (et. al. 1987) is helpful in achieving perspective on the status of current research interests and their antecedents. Lester (et. al. 1987) designates four generations or stages of research: 1) case study research; 2) development of policy implementation frameworks; 3) application of the frameworks and analysis; 4) synthesis and revision. The first generation of case study research (Pressman and Wildavsky 1973; Derthick 1972; Bardach 1977) was generally a descriptive assessment of implementation processes with little emphasis on the identification of independent variables or model construction. The literature consisted largely of accounts of how a single policy was carried out within a given environment. Though criticized for their atheoretical research format, Goggin (et. al. 1990, 15) 
notes that the first generation literature provided useful information on: 1) the linkage between law and program; 2) the complexity and dynamic nature of implementation and diagnosed the common pathologies of the implementation process; 3 ) the significance of policy subsystems and the extent of required inter-system coordination.

Second generation (1975-1980) studies focused on the development of application models or frameworks which structured the analysis of the implementation process and which served to guide research. During this period of implementation research the "top down" models emerged, positing the existence of implementation variables, measurable linkages between policy intention and program outputs. Major models of this period include those developed by Van Meter and Van Horn (1975), Mazmanian and Sabatier (1981), and Edwards (1980). While the development of these refined models offered focus and moved the research forward, their over-broad specification of variables reflected the novelty of the area of research and, perhaps, the use of informational interview and intermittent site observation as data collection tools. Second generation models were the first to directly address the need to identify prescriptive methods that might apply across policies and focus on the derivation of implementation variables, those conditions and obstacles common to the implementation process that must be evaluated 
and addressed irrespective of scope of the implementation strategy or nature of the policy initiative. Van Horn and Van Meter (1975) recommended that the "disposition of the implementors" might be quantified and correlation estimates of implementation success drawn from that data.

Mazmanian and Sabatier first recommended study of the "attitudes and resources of constituency groups" (1980) before fully outlining their conceptual framework of the implementation process and establishing the six conditions of successful implementation (1983). Similar to the approach adopted by Mazmanian and Sabatier, Edwards suggested that there were four preconditions of successful implementation involving communication, resources, dispositions (of the implementors), and bureaucratic structure (1980). This research provided a rich source of descriptive information on inter-organizational and interpersonal dynamics but tended also to defy any form of measurement that had cross study relevance. There was also general criticism of the models for, while establishing a foundation for inquiry into the existence of implementation variables, a subsequent failure to then identify which variables were most important and under what circumstances (Lester 1987, 204). In response to the aforementioned criticisms and a general feeling that "top down" models simply did not portray the implementation process accurately, the "bottom 
up" school (discussed above) developed and specified during this period a family of models that focused on the network of actors and agents that delivered policy "on the ground."

The third stage (1980-1985), characterized by application of the frameworks, was a period of testing existing implementation models. Van Horn's assessment of this period suggests that four broad lessons may be inferred from the empirical testing of the models: 1) the frameworks were useful in explaining the scope of the implementation process; 2) implementation research tends to be time sensitive and findings on the same process may vary between studies that are cross-sectional and those which are longitudinal; 3 ) the rate of program "failure" may not be as high as was depicted in the early implementation literature; 4) even the most modest of programs can fail (Lester et. al. 1987,205$)$.

Among the significant achievements of this stage was the development of Mazmanian and Sabatier's multivariate implementation model (Mazmanian and Sabatier 1983), one of the first to provided a comprehensive list of what came to be called "factors" (Lester 1987, 203) associated with the implementation process. Whereas a number of implementation models emphasizing variable identification emerged from the "second generation" of implementation research (Van Meter and Horn 1975; Edwards 1980) the model specified by Mazmanian and Sabatier (1983) provided the most 
thorough treatment of independent variables whose presence or absence influenced the implementation process and determined the ultimate effectiveness of programs associated with that process. Additionally, the model contributed significantly to an appreciation of perspective, particularly when implementation involved several levels of government.

The model further noted that focus and concerns were differentiated by the level of the participant in the implementation hierarchy. Having identified the groups by hierarchical level (center, periphery, target), Mazmanian and sabatier went on to assert that successful implementation may be largely contingent upon the extent to which various groups understand the incentive structure of other groups in the hierarchy $(1983,13)$.

The model necessarily made certain assumptions about how implementation effectiveness should be measured by recommending that the proper unit of measure is the achievement of legal objectives. Mazmanian and Sabatier argue forcefully for evaluation that focuses on the attainment of the legal objectives of legislation, the intended outcomes and objectives of conscious policy choices made by the legislative branch of government. Where there exists clear and precise legal objectives there also exists evaluative criteria against which program outputs can be 
measured. A clear advantage of such an approach is the capacity of the model to specify, and perhaps quantify, legislative goals against which performance can be measured and to account for the role and influence of the dynamic intergovernmental and interorganizational relationships within the implementation environment.

This approach, characteristic of the "top down" approach, has been criticized for its emphasis on the primacy of legislative policy over policy initiatives generated by the bureaucracy or other policy sub-systems during the implementation process (Sabatier 1986; Lipsky 1980). The criticism is principally concerned with the actual character of the policy implementation environment. Is it a "seamless web" of policy iteration and reformulation as such diverse researchers as Bardach, Berman, Mclaughlin, Majone and Wildavsky have suggested or do definable boundaries exist between policy development and policy implementation? Do implementing officials determine the true nature of policy as a matter of course in attempting to interpret program directives (Lipsky, 1980)? While not dismissing the difficulties associated with the blurring of formulation-reformulation, Mazmanian and Sabatier assert that the need to maintain normative assumptions, particularly the theoretically important, if empirically tenuous, partitioning of legislative and administrative authority, remains a proper and compelling concern of 
implementation research.

Stage four (1985- ) research represents an attempt to synthesize the most fundamental and promising concepts of the various models with particular emphasis on resolving the "top down/bottom up" dichotomy. The challenge of this generation of research is the development of theories that offer both explanatory and predictive capacity (Goggin et. al. 1990,15$)$. The models proposed to date tend to focus on policy systems and sub-systems and acknowledge the recursive characteristics of intergovernmental/interorganizational policy implementation. Such an approach is consistent with the effort to reconcile the policy flow issue.

Major fourth generation models include efforts by Elmore (1985), Goggin (Goggin 1987, et. al. 1990), and Sabatier (1987). While each of these efforts aspires to identify and measure with ever greater accuracy the myriad constraints, influences, and inducements that drive the implementation process a major emerging distinction in the research is whether the emphasis should remain with developing "policy relevant" findings that may be employed by policy practitioners (Elmore 1985) or directed toward theory development (Sabatier 1986; Lester, et. al. 1987). Goggin (et. al. 1990) emphasizes the need for the theory development school to move forward from hypothesis building to employing research conventions which permit hypothesis 
testing with emphasis on application of the scientific method in implementation research. Characterizing their research as perhaps a "first step" toward a new generation of research, Goggin, Bowman, Lester, and O'Toole (1990) utilize communications theory to develop a set of testable propositions about implementation and establish a probable design for theory-testing research.

While there is no disagreement among researchers that utilitarian findings are of great value, the literature is clear that contributions that would move us toward some consensus on a general theory of implementation are the greater need. William Glazer, noting the importance of both perspectives, offered the following, "Fact-finding without theory produces a jumble ... Theorizing without fact is a dilettantish hobby rather than a useful contribution" (1955, 291). Implementation research, though once criticized as an atheoretically homogeneous exercise, can now legitimately claim to be on the edge of a diverse and dynamic research frontier.

While a number of engaging conceptual, theoretical, and practical issues present themselves in the literature, this research elected to focus on the related questions of the practicality of identifying and assigning levels of significance to theoretically derived implementation variables and the impact position within an implementation hierarchy played on one's perspective when evaluating 
variable significance.

The first issue, generating and establishing the relative criticality of implementation variables, was selected in response to the clear call for the need to identify not only the nature and composition of independent variables associated with the mechanics of implementation but the relative significance of the discrete variables. While the research literature has promulgated the existence of such variables (Sabatier and Mazmanian 1979, 1983) there is no evidence of quantified data on ranking variables in order of relative importance to the implementation process (Browne and Wildavsky 1984; Hargrove 1980; Wagner 1986). clearly, the nature of such relationships are theoretically significant as they impact profoundly on the level of contribution any one variable or combination makes toward the ultimate disposition of an implementation initiative. From a practical standpoint, such knowledge is invaluable when, faced with constrained resources, decisions must be made as to where and how effort and resources are to be directed.

The latter issue, the role hierarchical position plays in determining a participant's perception of what is important in the policy implementation environment, is fundamentally associated with the concerns of the "bottom up" school of thought. It is particularly relevant to those 
involved in researching the role of state/local government in the implementation of nationally directed programs. The theoretical perspective of the "bottom up" approach, as described above, suggests the significant impact ground level implementors have on policy implementation and the process of policy redesign. Indeed, some theorists suggest that, in practice, implementation analysts consciously factor in cooptation by the administering agency (Berman 1978.)

The literature of the "bottom up" perspective has provided substantial evidence that the dynamic and recursive nature of policy flow within a structural hierarchy is largely attributable to response and reaction to policy initiation across the hierarchy. Policy initiation does not occur only at the apex of the hierarchy nor is it a stable process. Does it not then follow that the relative significance of a discrete implementation variable is determined or influenced by one's position in the hierarchy; or are such relations well defined and theoretically static across levels of an intergovernmental hierarchy? These questions seemed particularly appropriate given the recent concerns of the literature for research that contributed to an understanding of implementation initiative involving interstate variations (Goggin et. al. 1990). 
COST SHARING: LITERATURE ON THE THEORETICAL FOUNDATIONS

It has been suggested that the intergovernmental cost sharing of water resource projects initiated by the WRDA 1986 was primarily a political response to: 1) enable increased executive branch involvement in project selection and water resource development policy; 2) reduce federal outlays for water resource development in a period of record budget deficits. There is undoubtedly some truth to both assertions, but these arguments fail to address an equally attractive alternative motive, the compelling economic logic of cost sharing. There exists a significant body of evidence that suggests cost sharing came to receive serious consideration largely on the merits of sound theory that, while at odds with the conventional political wisdom, argued strongly for the adoption of efficiency criteria to guide development. Though the political allocation model frequently fails to place a premium on efficiency, efficiency concerns present arguments that are not easily dismissed by decision makers facing increasingly scarce resources and a multitude of demands.

It had become increasingly clear prior to 1986 that the much criticized political distribution model of allocating developed water resource projects was simply no longer adequate (see discussion in the following section of this chapter) and that a replacement model would have to possess 
an appearance of rationality and equity if it was to receive broad acceptance within the water resource development community. This review seeks to set forth the rationale for cost sharing with a focus on basic economic principles and the application of those principles in the development of public policy.

The foundation of cost share principles is the belief that a rational development policy must address economic efficiency criteria if efficient decisions regarding development are to be made. Indeed, efficiency arguments should be considered even when the ultimate decision criteria is of a non-economic nature for that is how the true costs of forgone alternatives are determined. It is well understood that there are major non-efficiency criteria which are considered in the development of public policy, income redistribution being an example. However, so as to bring focus to the analysis at hand, this review restricts the discussion to an assessment of rational efficiency criteria as a basis for the development of policy. Specifically, the discussion focuses on the relatively straightforward and well understood body of principles associated with cost sharing and welfare economic theory.

Economic efficiency may be broadly defined as a condition wherein productive resources are so allocated among alternatives that any reallocation pattern would not improve any one person's position and still leave everyone 
else equally well off. This form of efficiency is determined by basic optimality criteria and is often referred to as "Pareto optimality." It may also be thought of as a condition which implies that output is maximized given a particular set of inputs (Krutilla and Eckstein $1958,17)$. Second order economic efficiency concerns itself more specifically with income maximization as the sole index of individual and social welfare. Here, the optimally developed resource project is that project which most effectively generates national income. As the basis for investment in resource projects is benefit generation, of some form, the generally applied criterion for resource allocation is economic efficiency (James and Lee 1971, 111). From the standpoint of the individual, economic efficiency is achieved when expenditures are allocated so as to maximize satisfaction. If one envisions the potential non-Federal sponsor in a water resource development project as representing an aggregate of individual preferences for the project, the demand for a particular project should be estimable and an efficient solution calculable. Why this is not so easily accomplished by conventional market mechanisms is discussed in detail later in this chapter. ${ }^{1}$

A related, and in the area of this research significant, issue involves the potential for conflict between the individual (the non-Federal interest) and 
society at large when the individual's preferences do not align with those of society. Selection of the locally preferred plan may, in such cases, result in a loss of efficiency to society with the tradeoff in efficiency losses offset by often equally critical non-efficiency criteria gains. A case in point might here be project acceptability to the interests who are responsible for the partial funding of the project effort.

A word on the national economic development (NED) plan alternative so frequently referenced in water resource development planning documents is here appropriate to identify what the plan consists of and what it represents. 2 The objective of Federal water resource development is the maximization of net economic development benefits consistent with protection of the environment and subject to such constraints as the safety, completeness, effectiveness, and acceptability of the project. The NED plan is the material reflection of this objective. The methodology for development and evaluation of the plan is set forth in the Economic and Environmental Principles and Guidelines for Water and Related Land Resources Implementation Studies issued March 10, 1983 by the United States Water Resources Council. Colloquially referred to as the "Principles and Guidelines P\&G," the document is the primary guide employed in the formulation and evaluation of major Federal water resource development agencies. The 
Principles and Guidelines replaced the Principles, Standards and Procedures (18 CFR, Parts 711, 713, 714 and 716) in March, 1983.

Addressing efficiency concerns, the Principles and Guidelines defines the NED plan as that plan which maximizes net national economic development benefits consistent with the Federal objective. As defined in the Principles and Guidelines, the Federal objective is " ... to contribute to environmental statutes, executive orders, and other Federal planning requirements" (EC 1105-2-115 1983, 1). Alternative plans which reduce net NED benefits in order to address other legitimate concerns (safety or environmental benefits) are formulated when it is determined these concerns are not fully addressed by the NED Plan. Notwithstanding the development of alternative plans, selection of other than the NED requires the approval of the Secretary of a Federal department or the head of an independent agency.

The water investment objective of the non-Federal interest involved in cost shared planning is best characterized as the accomplishment of a particular resource related goal subject to financial constraints: to "maximize the pace. and extent of water resource development subject to the sponsor's ability to obtain access funds at a reasonable cost ..." (Mugler 1984, 6). Arguably, this more focused 
(substantively and geographically) and "businesslike" approach may only infrequently (in the absence of Federal financial assistance) advance a development solution identical to that promulgated by the NED. A more detailed explication of why this is so is provided in the discussion of derivation of demand function for water resource development provided later in this chapter. Before proceeding further with a discussion of the relationship between cost sharing and the achievement of socially efficient investment it is necessary to distinguish between the efficiencies associated with private and public goods. Achieving a fundamental, if limited, understanding of the distinction is particularly critical when analyzing historical models of water resource development because . there is often debate as to the public/private nature of the benefits which accrue from such projects. Similarly, there is an accompanying argument as to who should pay for them. Private goods are goods that are consumed exclusively by an individual consumer and so confer a benefit to the consumer that is measurable by an expressed preference or "demand" for the good. Typically, such goods when consumed confer no benefit to others who are effectively excluded from the benefits which accrue to the consumer, e.g. food, drink, a pair of shoes, etc. Thus, consumer demand is a relatively straightforward measurement of an attempt by the individual to maximize personal utility (Singer 1976, 88). 
For the most part, market mechanisms deal effectively with the production, supply, and consumption of private goods.

Public goods may be defined as those goods not subject to exclusivity, that is goods whose benefits accrue beyond the individual consuming the good (e.g., education) or whose product may be shared by multiple consumers without diminishment of any one individual's benefit (e.g., street lighting). Benefits, in this instance, are said to "spillover." In the case of a pure public good, the benefits may be "all spillover" with many parties enjoying equal benefit from the good simultaneously and, more importantly, with no provision for exclusion and therefore subject to joint consumption (Haveman 1976, 25).

National defense is often proffered as an example of a pure public good. As a result of the inability to restrict access or assign rights to public goods the market may fail to produce such goods at a socially efficient level. Because individuals cannot be excluded from the benefits of such goods, and so need not pay for them, the private market will either fail to produce public goods or produce them in less than socially optimal quantities as a result of the non-exclusion principle. Figure 1 offers an example of this phenomena.

Water resource projects are infrequently either purely private or purely public in nature and so represent what is 
typically referred to as mixed goods. Navigation and recreation benefits are typically mixed goods. If one were

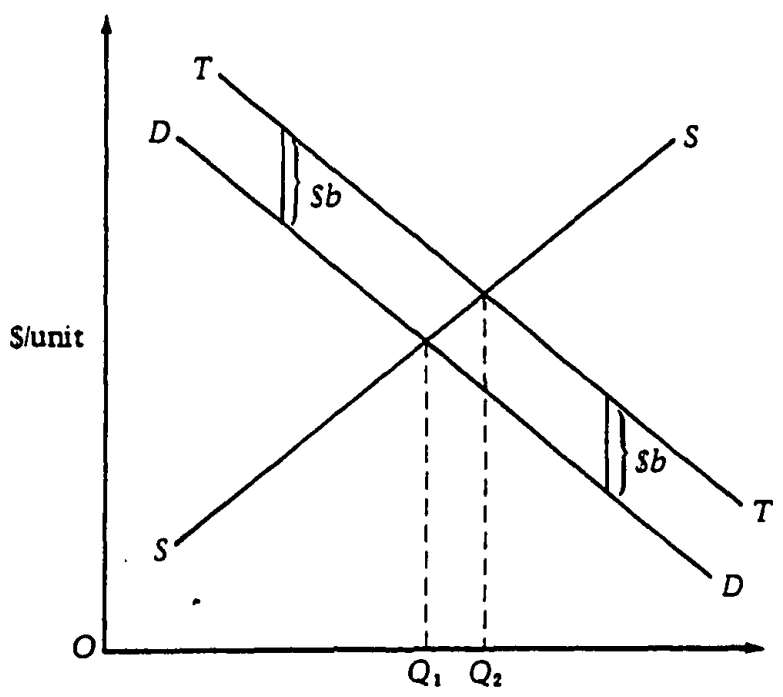

Figure 1. Output of public goods. Whereas an unregulated market would produce output $\Omega_{1}$, the socially optimal output would be $\Omega_{2}$ due to spillover benefits, e.g. individuals benefiting from provision of a social good who were not required to purchase units of the good. Welfare is not maximized in such a situation if the market is allowed to underproduce. Source: Robert $H$. Haveman, The Economicg of the Public sector, 1976.

to envision a private-public goods water resource project continuum with projects located along that continuum by type of project, the anchors would arguably be hydro projects at the private end and flood control at the public end.

Hydro-power projects generate essentially private goods in the sense that the product is vendible and potential consumers may be excluded from consumption by a market controlled distribution system. Not surprisingly, the 
private market is involved in the development of hydro-power projects and distribution systems, though such development is generally subject to some form of monopolistic regulation by the public.

Flood control projects present a quite different picture. Non-flood control benefits which obtain as a result of the project design (esthetic benefits, recreation) will typically be public in nature, though access to project lands can be controlled and fees assessed. Flood control benefits, on the other hand, while they clearly convey private benefit to those in the flood plain are essentially public goods as once they are provided, consumption of the protection within the plain can not be denied. Individuals who build in the protected area after construction of the project will enjoy the same level of benefit as those who occupied the area prior to project construction and who, ostensibly, "purchased" the protection.

Because the protection, once it has been provided, can not be denied (rationing of public goods is generally dismissed as an impractical solution) individual consumer strategy will be to wait for "someone else" to pay for the protection in hopes of receiving future unpurchased benefits. This behavior is typical of the "free rider phenomena." It should be readily apparent that in such an environment private firms would have no incentive to produce or market such commodities as consumers will be induced to 
deny that they wish to purchase such goods even though they are involved in their consumption. How then do we correct for such "failures" of the market to provide what societies generally have come to consider essential goods and services? The solution is collective action authorized by a body able to impose and enforce participation, or as it is more often referred to, the power to tax.

The critical question in the case of water resource development is not so much whether public investment is appropriate if we are to achieve socially efficient levels of development but where (at which level of government) the responsibility for such investment rests. Notwithstanding a good body of evidence which suggests a method of deriving economically efficient solutions, at least historically, the answer has been essentially political. A critical examination of who should pay for developed water resource projects is central to gaining an appreciation of the linkage between the level of government which initiates and supports investment and the development of economically efficient projects.

How then does cost sharing influence efficiency based decisions? Demand estimates for public as well as private goods may be thought of as approximations of anticipated returns on investment (refer back to Figure 1). When, however, the direct beneficiaries of a good or service do 
not pay the full cost of provision, a subsidy (or spillover benefit) condition exists. In addition to the subsidized transfer of resources to beneficiaries from the body of individuals providing the subsidy, general taxpayers in the case of a Federally subsidized project (a distributional issue), the relative underpricing of the resource to project beneficiaries will lead to an overstatement of demand for the good or service. ${ }^{3}$ Thus, beneficiaries will demand an inefficient quantity of the good based on the apparent (in this instance subsidized) price of the good rather than its actual cost, the full and true social cost of providing the good or service. Put more simply, the users will demand more of the good than they would if they had to pay the full cost of its provision.

It may here be helpful to here offer a somewhat more descriptive explanation of the demand function expressed by consumers of project benefits from the Federal and nonFederal interest perspective. 4 First, it is important to assume that Federal interests and non-Federal interests will each seek to maximize satisfaction (benefits) vithin a finite set of resource constraints. To simplify the analysis, we will also assume that the project under discussion is a single purpose project, that the interests agree on the value and distribution of benefits associated with the various alternatives, and that the production function for each project purpose is characterized by 
diminishing marginal returns for successive units of input.

For the Federal interest the demand function will result in the attempted maximization of net social benefits. Given a single purpose project under the assumptions provided, the Federal interest would select that project alternative which maximizes the difference between the present value of social benefits and social costs. Similarly, a rational non-Federal interest will argue for the project alternative that maximizes benefits which accrue within its jurisdiction at the least cost to the non-Federal interest. Marshall (1969) has demonstrated that the only cost sharing rule which will induce the non-Federal interest to select the socially efficient project alternative is that which imposes cost on the non-Federal interest in the same proportion as benefits are shared at the margin. The rule, which he refers to as the Association Rule, offers evidence of the linkage between cost sharing and efficiency criteria and demonstrates how that linkage may be employed to direct efficient project development.

stated most simply, the Association Rule posits that the project scale selected by the non-Federal interest will equal that picked by society only when costs are shared in the same proportion as benefits at the margin. If the proportion of benefits accruing to the non-Federal interest exceed costs at the margin the non-Federal interest will 
argue for greater project output (scale). Concomitantly, if costs to the non-Federal interest at the margin exceed benefits, they will be induced to prefer a project of reduced scope which produces less output than the socially optimal project (Marshall 1969, 31).

Figure 2 on the following page illustrates this concept and offers a graphic explanation of the efficiency loss associated with construction of a project larger or smaller than that which reflects the socially optimal scale.

Point $Q_{0}$ represent the level of output which maximizes benefits to society. Thus, it can be shown that to achieve non-Federal interest concurrence in selecting this level of output a cost share rate of $75 \%$ would be required. (This is determined by the intersection of $Q_{0} a$ and MNB.) Implementation of a $90 \%$ rate for the non-Federal interest would result in project output of $Q_{1}$ and a resulting loss of benefit represented by eda. Were a $50 \%$ rate to be applied the non-Federal interest would argue to increase output to $Q_{h}$ with an efficiency loss of abc.

In the general absence of cost shared construction on federally assisted water resource development projects and the tendency to adopt, when adopted at all, quite general cost sharing criteria, one would expect to see a pattern of development quite different from that which might have emerged under cost sharing. Broad criticism of the current pattern suggests as much (Eckstein 1961; Krutilla 1966; 


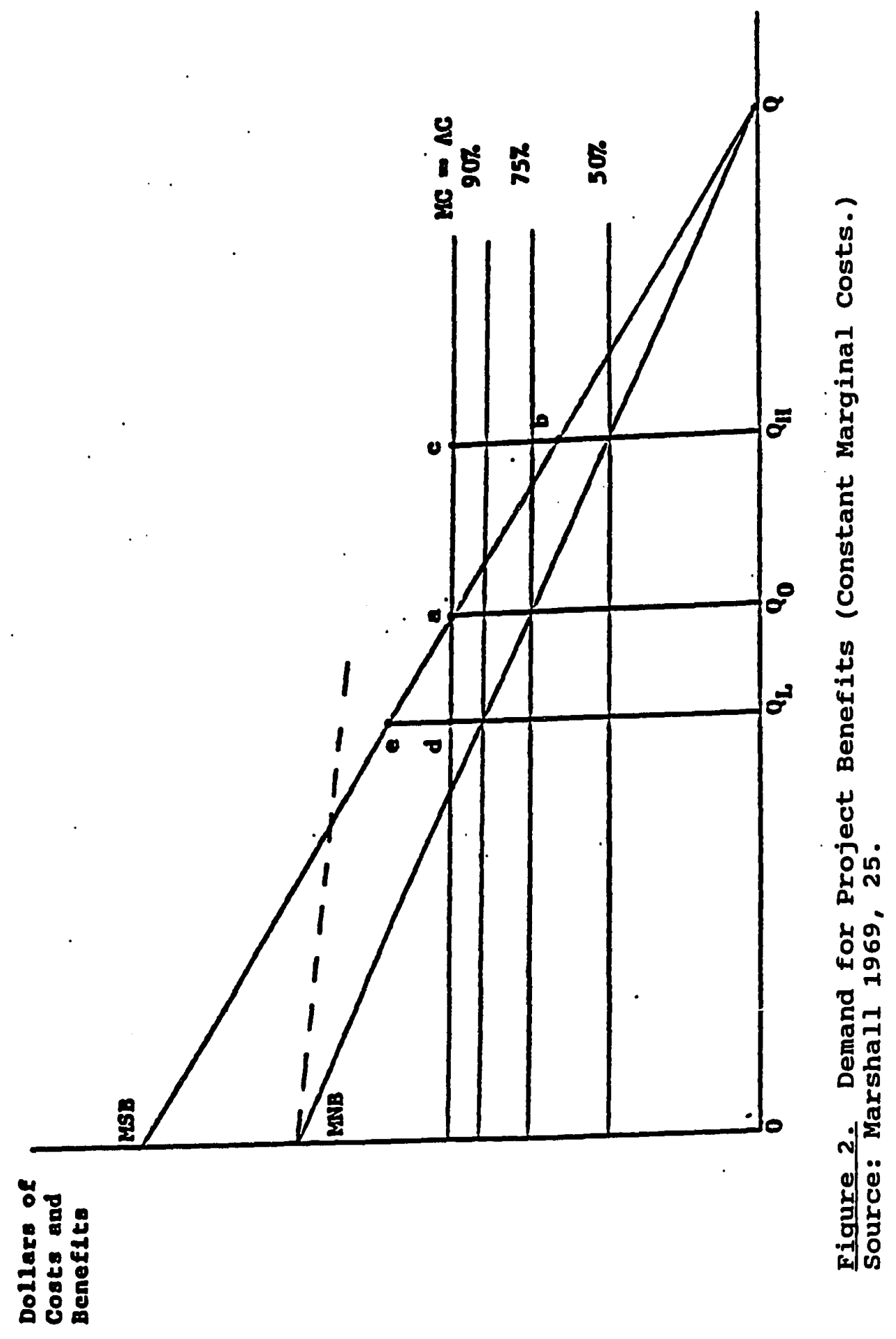


Marshall 1972; Reuss 1983).

Water resource development subsidies have typically represented transfers from the Federal level to state or local governments. A significant criticism of the availability of Federal funds transferred with low or no cost sharing requirements to state or local governments is that such an arrangement ultimately leads to the construction of Federal projects which yield primarily local benefits, thus displacing investments in other projects that may have a higher national interest (U.S. CBO August 1983, 33). John Bowman $(1986,4)$ in citing a Congressional Budget Office study on the Nations Public Works provided an excellent, concise summary of the problem Federal responsibility for development has created:

Undercharges to users. The direct beneficiaries of infrastructure services often pays fees that recover less than the cost of providing those services, thus leading to excessive demand for infrastructure services. This in turn can lead to overestimates of investment needs.

A graphic illustration of Bowman's caveat was provided in Figure 2 .

Bowman's observation is, of course, consistent with what would be expected under the theoretical framework outlined earlier in this chapter. Referring to the demand function delineated in Figure 2 , note that MSB represents marginal social benefits while MNB represents marginal net benefits to the non-Federal interest. 
As you may have noted, a curious irony permeates the arguments for achieving greater efficiency through the application of cost sharing criteria. On the one hand, a body of theory holds that cost sharing will lead to the construction of fewer and possibly smaller projects and that the sample of projects will represent an "efficient" mix of projects. This set of assumptions is discussed at length in Chapter $v$. Implicit in this argument, it should be noted, is the assumption that construction of large inefficient projects were the order prior to the advent of cost sharing, an assumption not wholly supported by fact. On the other hand, we know that cost sharing rules, improperly applied, will indeed induce local factions to negotiate for smaller projects but not necessarily projects that are socially efficient from a national standpoint.

From an efficiency perspective, it is essential that cost sharing principles be applied on a project by project basis if the non-Federal interest is to be induced to select the socially efficient project alternative. This is necessarily the case because the derivation of demand for a project purpose from the local perspective varies across projects. We know this to be true because for the nonFederal interest the marginal net benefits of a project are computed as a proportion of local benefits and costs compared with total benefits and cost of a specific project alternative. Thus, any across the board rate applied by 
project purpose would offer the correct inducement at best only coincidentally. Yet from a political perspective such allowances are seen as unacceptable as they are thought to encourage "bargaining" on the non-Federal interest share of individual projects and serve generally to undermine the equity of the process. The appearance of fairness is particularly important when development costs are imposed on interests that have historically enjoyed large scale social subsidies. The (inefficient) resolution of this paradox is further addressed in later chapters.

Ostensibly, the above mentioned problem could be readily overcome if each beneficiary or group paid a share of the development cost equal to the benefits they would receive from the project. (For the sake of simplicity we will assume that non-marketable benefits are assigned or shared to the mutual satisfaction of the parties involved.) Indeed, willingness to pay criteria, when employed as a project screening device, may provide a more accurate valuation of project benefits than application of benefitcost methodology by the Federal interest during the feasibility study phase (U.S. CBO August 1983, 41).

Were it that simple, however, general agreement on the application of efficiency criteria would have been reached some time ago. The problem, however, is resistant to such a solution due to the opportunity for a conflict of interest 
between the local position (non-Federal interest) and society. The conflict arises when the project, most desired from the local point of view, does not conform in significant ways with that proposed by the Federal interest, whose primary goal is to maximize national efficiency. Understandably, non-Federal interests may oppose contributing significantly to a project whose benefits will accrue largely outside the interest's jurisdiction and society may argue equally forcefully for a solution that is socially optimal from a national perspective. In this fashion, each interest will be induced to bargain for a project scale that maximizes its benefits (Marshall 1969, 12).

While the overview set forth above provides only the most superficial of perspectives on the relationship between efficiency considerations and cost sharing, it should be obvious that the set of incentives which move us toward the efficient solution in the selection and design of cost shared water resource development projects also lends to the conflict that may arise between interests. Moreover, it is well recognized that efficiency criteria are not the exclusive criteria applied in project selection. (A major non-efficiency consideration for Federal participation generally is income redistribution.) Thus; while theoretical solutions to such dilemmas have been skillfully proposed (Marshall 1969) the complexity of application in an 
environment with long standing traditions, expectations, and institutions serve to render cost sharing a potential solution--but not an easy one.

WRDA 1986: A HISTORY OF WATER RESOURCE DEVELOPMENT POLICY

The previous section contained a discussion of why cost sharing is advocated by those who seek to impose economic rationality on the Federal water resource development program and minimize the economic distortion associated with the Federal subsidy. Given the general consensus, at least within the economic and financial communities, one would expect that cost sharing would long ago have been incorporated into the water resource development calculus, and to some extent that has been the case. The Congressional Budget office ( $С B O$ ) noted in 1983 that emerging water development priorities were shifting away from large interstate projects toward local development, rehabilitation, and efficient management of existing projects and that the trend suggested a much stronger role for economic efficiency as a guiding principle in public investment (U. S. CBO 1983, 21).

Indeed, it is important to note that the WRDA 1986 is not the first piece of Federal cost share legislation nor are the cost sharing principles contained therein applied exclusively by the corps within its civil Works program 
(Holmes 1972). In some fashion cost share principles have been advocated and employed over time in project development, though neither to the extent required by the WRDA 1986 nor with great consistency. A review of the legal and administrative history of cost sharing reveals much about the intergovernmental dynamics of the water resource development process. That review is set forth here to provide a historical context for the ensuing discussion and to establish the political lineage of arguments for and against the application of cost sharing as Federal resource development policy.

In 1975 the U.S. Water Resources Council undertook a study to develop a set of cost sharing policy options for the implementation, operation, maintenance, and rehabilitation of federally assisted water and related land programs. In developing the analytical model, the research staff noted:

the mystery and obfuscation which these existing cost sharing ground rules bring to the planning and development of water resources, especially with respect to who benefits and who pays, brings to mind the art of veiled subterfuge which reached its zenith in the victorian period as demonstrated by formal garden mazes, superficial parlor games, formal costumes and genteel manners of the period, all of which were designed to contain the reality and the truth of a changing world (U.S. Water Resources Council 1975, 4).

The report went on to call for a "truth in cost sharing" policy and a reconciliation of the inconsistencies in both principles and numbers which existed among and between 
agencies producing the same output.

Specifically, the council's report decried the "plethora of laws, ad hoc decisions, and administrative procedures which authorize cost sharing arrangements under which Federal water resource agencies operate" (U.S. Water Resources Council 1975, 4). Thus, the WRDA 1986 did not, as is sometimes suggested, introduce cost shared water resource development planning so much as it brought a degree of consistency to its application. In so doing, the law called attention to the inevitability of greater local participation in the development of federally assisted water resource development.

Prior to examining the direct political and legislative history of the WRDA 1986, it is helpful to have an appreciation of the scope of the legal precedent for such policy and to offer some data on prior cost share arrangements and the impact they had on project funding. Table I set forth below establishes Federal cost sharing conventions that have been established by statute. It should be noted that the table addresses nominal cost share rates rather than effective rates, a distinction which will be addressed below, and does not include single purpose or project specific legislation that involved cost share principles. 
TABLE I

MAJOR FEDERAL LEGISLATION AUTHORIZING COST SHARING BY PROJECT PURPOSE

\begin{tabular}{|c|c|c|}
\hline $\begin{array}{l}\text { Water Resources Development } \\
\text { Purpose }\end{array}$ & Agency & $\begin{array}{l}\text { Authorizing } \\
\text { Legislation }\end{array}$ \\
\hline Urban Flood Damage & COE & $\begin{array}{l}\text { P.L. 74-738, } 1936 \\
\text { P.L. 75-761, } 1938\end{array}$ \\
\hline \multirow[t]{4}{*}{ Rural Flood Damage } & $\begin{array}{l}\text { COE } \\
\text { SCS }\end{array}$ & $\begin{array}{l}\text { Watershed Protect. } \\
\text { Act (P.L. 83-566) } \\
\text { Flood Cont. Act of } \\
1928 \text { (P.L. 70-391) }\end{array}$ \\
\hline & $\operatorname{COE}$ & $\begin{array}{l}\text { Flood Cont. Act } 1936 \\
\text { Flood Cont. Act } 1938 \\
\text { Rec. Projects Act } \\
1939 \text { (P.L. 76-260) }\end{array}$ \\
\hline & BLM & $\begin{array}{l}\text { Small Projects Act } \\
\text { (P.L. 84-984) }\end{array}$ \\
\hline & TVA & TVA Act (P.L. 73-017) \\
\hline \multirow[t]{2}{*}{ Drainage } & scs & $\begin{array}{l}\text { Soil Conserv. Act } \\
\text { (P.L. 40-460) }\end{array}$ \\
\hline & $\operatorname{COE}$ & $\begin{array}{l}\text { Flood Control Act } \\
1944 \text { (P.L. 78-534) }\end{array}$ \\
\hline \multirow[t]{3}{*}{ Irrigation } & $\operatorname{scs}$ & $\begin{array}{l}\text { Soil Conservation Act } \\
\text { Watershed Protect. Act }\end{array}$ \\
\hline & $\operatorname{COE}$ & $\begin{array}{l}\text { Flood Control Act } \\
1944 \text { (P.L. 78-534) } \\
\text { Reclamation Act } 1902 \\
\text { (P.L. 57-161) }\end{array}$ \\
\hline & Bureau & $\begin{array}{l}\text { Small Projects Act } \\
\text { Rec. Projects Act }\end{array}$ \\
\hline Municipal and Industrial & SCS & $\begin{array}{l}\text { Watershed Protection } \\
\text { Act }\end{array}$ \\
\hline
\end{tabular}


TABLE I

MAJOR FEDERAL LEGISLATION AUTHORIZING COST SHARING BY PROJECT PURPOSE

(continued)

Water Resources Development Purpose

Water Supply

Stream Flow Regulation

Fish and Wildlife

Ports/Harbors

Inland Water Waterways

Hydropower
Agency

$\operatorname{COE}$

Bureau

$\operatorname{COE}$

SCS

$\operatorname{COE}$

Bureau

COE

$\operatorname{COE}$

TVA

$\operatorname{COE}$

Bureau

TVA
Authorizing Legislation

Water Supp. Act 1958 (P.L. . 85-500)

Small Projects Act Rec. Projects Act

Federal Pollution Control Act 1972 (P.L. 92-500)

Watershed Prot. Act

Flood Cont. Act 1944 Water Resources Protection Act 1965 (P.L. 89-072) Water Res. Devel. Act 1974 (P.L. 93-251)

Water Resources Devel. Act 1974 (P.I. 93-251)

Rivers/Harbors Act 1920

Rivers/ Harbors Act 1920

TVA Act

Flood Cont. Act 1944 1937 BPA Act

(P.L. 75-329)

Recl Projects Act

TVA Act 
TABLE I

MAJOR FEDERAL LEGISLATION AUTHORIZING COST SHARING BY PROJECT PURPOSE (continued)

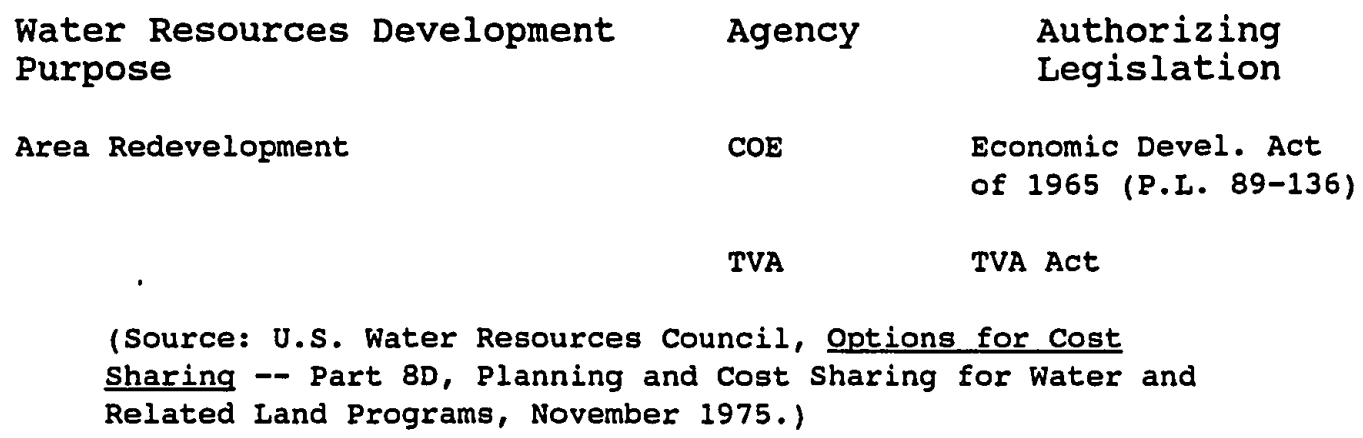

Table II set forth on the following page provides an overview of the status of cost sharing on a by-agency basis in 1975 for both implementation and O\&M costs. However, it is important to note that, notwithstanding the establishment of specific cost sharing language in the referenced legislation, no consolidated cost sharing policy was successfully incorporated into legislation prior to the passage of the WRDA 1986. Cost sharing arrangements were, as previously mentioned, authorized under a "plethora of laws, ad hoc decisions, letters, and administrative procedures" (U.S. Water Resources Council 1975).

In 1983 the U.S. Water Resources Council estimated that for all types of water resource projects involving Federal and non-Federal participants the mean non-Federal effective, composite cost share was $30 \%$ (U.S. CBO August, 1983). Table III sets out the effective pre-WRDA 1986 cost share ratios 
IMPLEMENTATION AND OM\&R COSTS FOR NON-FEDERAL COST SHARING FOR 20 AGENCIES

Non-Federal Cost Shares

$\begin{array}{ccl}\text { Implementation }^{1} & \text { OM\&R } & \\ \% & \% & \text { Effective } \\ & & \text { Composite } \%\end{array}$

Farmers Home Administration

Tennessee Valley Authority

$84 \quad 100 \quad 89$

Community Planning and Development

$79 \quad 46$

$70 \quad 100$

76

Economic Development Agency

$44 \quad 100$

Environmental Protection Agency

Soil Conservation Service

Small Business Administration

Bureau of Reclamation

Ag. Stab. and Conservation

NOOA

Corps of Engineers

Fish and Wildlife Service

Fed. Insurance Administration

Coast Guard

Forest Service

Bureau of Land Mgmt.

Bureau of Outdoor Rec.

National Park Service

federal Power Comm.

$26 \quad 98$

$43 \quad 100$

43

31

34

25

19

16

13

8

0

0

0

0

0

24

96

37

$50 \quad 34$

$29 \quad 33$

$73 \quad 20$

NA 13

NA $B$

$0 \quad 0$

NA 0

$0 \quad 0$

$0 \quad 0$

All Agencies

58

30

1. Implementation costs are the value of goods and services necessary to establish the project including construction, LERRD, mitigations, investigations, designs and plans.

2. OM\&R costs are the estimated annual cost of operations, maintenance and component replacement of capital water resource facilities required to insure that the project operates and produces as designed and constructed for the full expected life of the project.

3. The composite effective cost sharing rate which includes both implementation and OM\&R adjusted to present value.

(Source: U.S. Water Resources Council, Options for Cost sharing -Part 8D, Planning and Cost sharing for Water and Related Land Programs (November 1975). 
TABLE III

NONFEDERAL MEAN, EFFECTIVE, COMPOSITE COST SHARE BY PROJECT PURPOSE (IN PERCENTS)

\begin{tabular}{|c|c|c|c|c|}
\hline \multirow[b]{2}{*}{ Project Purpose } & \multicolumn{4}{|c|}{ AGENCIES } \\
\hline & CORPS & BUREAU & $\operatorname{scs}$ & OTHER \\
\hline \multicolumn{5}{|l|}{$\begin{array}{l}\text { Urban Flood } \\
\text { Damage Reduction }\end{array}$} \\
\hline Rural Flood Damage & 7 & 10 & 27 & 11 \\
\hline Drainage & 35 & $/ \mathrm{b}$ & 89 & 46 \\
\hline Irrigation & 19 & 18 & 54 & 19 \\
\hline Erosion Control & 5 & /b & 89 & 34 \\
\hline $\begin{array}{l}\text { Municipal/Industrial } \\
\text { Supply }\end{array}$ & 54 & 71 & 100 & 64 \\
\hline Water Quality Control & 3 & 82 & $/ \mathbf{b}$ & 60 \\
\hline $\begin{array}{l}\text { Fish/Wildlife } \\
\text { Preservation }\end{array}$ & 11 & 13 & 57 & 14 \\
\hline General Recreation & 17 & 18 & 63 & 19 \\
\hline Commercial Harbors & 16 & $/ b$ & 16 & 16 \\
\hline Inland Navigation/c & 6 & 7 & $/ \mathrm{b}$ & 6 \\
\hline Hydroelectric Power & 61 & 65 & $/ b$ & 64 \\
\hline Agency Mean & 20 & 37 & 49 & 30 \\
\hline \multicolumn{5}{|c|}{$\begin{array}{l}\text { /a. Agency reported a cost category for this purpose but did } \\
\text { not report cost sharing. } \\
\text { /b. No activity reported for this purpose. } \\
\text { /c. Estimates may understate percentage as fuel tax } \\
\text { receipts from Inland Waterways Revenue act of } 1978 \text { are not } \\
\text { included. }\end{array}$} \\
\hline \multicolumn{5}{|c|}{$\begin{array}{l}\text { (Source: U.S. Water Resources Council, Options for Cost } \\
\text { Sharing--Part } 5 \mathrm{~A} \text {, Planning and Cost Sharing Policy Options } \\
\text { for Water and Related Land Programs, November 1975.) }\end{array}$} \\
\hline
\end{tabular}


Soil Conservation Service, and Others, a composite of the remaining agencies listed from Table II.

As noted above, cost sharing, of a variety, has enjoyed a broad if irregular and inconsistent Federal application in the field of water resource development. Particularly alarming is the variation in rates between agencies whose functions (flood damage reduction) are comparable and the rate bias (from a sponsors viewpoint) in favor of structural alternatives. As noted earlier in the discussion on the theoretical literature of cost sharing, such inconsistency serves to undermine efficient development by inducing the non-Federal interest to negotiate for the least cost (from their perspective) solution rather than the most efficient solution from a national perspective (Marshall 1969).

\section{THE ARMY CORPS OF ENGINEERS AND THE HISTORY OF COST SHARED} WATER RESOURCE DEVELOPMENT

There have been a number of excellent histories on Federal water programs. 5 This research does not presume to offer the scope of a complete a history such as Holmes (1972) but does find it necessary to call upon a number of public history efforts, published and unpublished, in an attempt to provide adequate background on the involvement of the Corps in federally assisted/cost shared water resource development.

The earliest formal intergovernmental efforts of the 
Federal Government in water resource development were in the field of navigation with the Gallatin Report of 1808, Report on Roads and Canals, often cited as a landmark effort to provide federal assistance to the states and territories. The report data, provided largely by Army Engineers, offered evidence of the potential for navigation development in the new nation and called for a "cooperative effort" to develop that potential in the name of economic development and national defense (Elazar 1969, 87-94). Thereafter, cooperative development progressed slowly until 1824 and the passage of the General Survey Act. Though the Act provided little in the way of Federal funding $(\$ 30,000)$, it did empower the President to employ the "officers of the (Army) Corps of Engineers" to survey roads and canals that were thought to be of national importance. The legislation initiated, though on a very small scale, the first centralized national resource planning mission of a Federal agency (Holmes 1972, 4).

Shortly thereafter, the corps assumed planning responsibility for inland navigation. with passage of the first Omnibus Rivers and Harbors Act in 1826. This Act was to become the prototype for authorization of Federally assisted water resource development in navigation and later in the area of flood control culminating with passage of the 1936 Flood Control Act (President's Water Resources Policy $1950,92)$. 
As it had in many other areas, the Federal role in water resource development increased gradually as questions of the appropriateness of Federal financing required discussion and resolution. By 1865 the Federal appropriation for navigation improvements totaled approximately $\$ 17$ million. Additionally, large scale land grants had been provided the states for inland navigation development and enhancement. Still, the Federal contribution toward such development in the early 19th century was considered modest in view of the estimated one hundred and eighty-five million dollars that had been contributed to canal development by state and private interests (Pross 1938, 44).

Investment in canal infrastructure was so great during the period that the era between 1817 and 1838 is referred to by historians as the Canal Era, characterized by the efforts of state, municipal, and private interests to develop inland navigation. The failures of that era, due largely to the inadequate financial and technical resources of non-Federal developers and the growing influence of the Federal government in directing the economic development of the "western regions," signaled a shift in the assumption of responsibility for development of navigation resources toward the Federal government in general and the corps in particular (Caulfield 1984, 216).

Following the Civil war, the Federal contribution to 
development of harbors and inland navigation increased dramatically. This activity was consistent with a growing concern for the linkage between transportation infrastructure and national defense and recognized the significant deterioration of navigable waterways during the Civil War due to wartime budgetary constraints (Reuss 1990, 3). Thus, for the period 1866 to 1882 a total of 16 Federal rivers and harbors acts were signed into law. The Federal contribution had, by 1882 , reached $\$ 111$ million (Reuss 1983, 12).

The increase in Federal spending was not without its critics, particularly those who asserted that the project selection procedure lacked a coherent economic basis and frequently directed Federal expenditures at development that had little commercial potential. In 1872 Congress created a Select Committee on Transportation Routes composed of various Senators and headed by Minnesota's William Windom. The Committee established the funding priority of water over rail subsidy where waterways were "properly located" and, perhaps more importantly, established as policy the concept that river and harbor projects produced goods that reflected a national interest (Reuss 1990,6 ).

As a result of such efforts, Congress passed general navigation legislation in 1884 that instructed the District Engineer (COE) to review and approve the potential "worthiness" of projects prior to engaging in survey work 
(Holmes 1973,4 ). Though formal methodological cost benefit analysis was not required until passage of the Flood Control Act of 1936, it was clear that the political allocation model of water resource development was increasingly becoming the subject of critical scrutiny.

In an effort to exert additional control over the corps of Engineers, and impose greater rationality on the Federal water resource development program Ohio, Congressman Theodore Burton introduced legislation in 1902 which created the Board of Engineers of Rivers and Harbors. The Board was chartered to review and evaluate the feasibility of projects submitted by subordinate levels of the COE organization. Additionally, Burton, a staunch opponent of what had come to be known as "pork barrel legislation," advocated local cost sharing as a preferred method of determining the range of viable project that should enjoy Federal assistance.

As a result of such efforts, a number of early 20 th century projects were authorized with cost sharing provisions. No standard procedure for requiring local cost sharing was promulgated, however, until 1920 when the COE annual appropriations bill was passed with language requiring that the local and general benefits of a project be identified and a recommendation made as to whether cost sharing should be required (Reuss 1983, 15). It must also be noted that a good deal of the discussion on efficiency 
concerns dealt more specifically with the institutional arrangements within the Federal government (the competition between executive and legislative branches to control the direction of resource development policy) than whether the role of the Federal government in local and regional resource development was substantively correct.

The data on the subsequent development of federally assisted navigation projects suggests that cost sharing was only marginally effective in curtailing congressional support for projects of questionable efficiency. The political feasibility of project support was easily divorced from the economic feasibility of the locals mustering sufficient funds to meet their apportioned obligation (Reuss 1990, 5). Moreover, the issue of federally assisted water resource development, at least with respect to inland navigation, was largely dominated by ideological concerns: 1) the appropriate role of the Federal interest in furthering national economic development, particularly in the West; 2) the struggle of the Congress to reconcile rational economic development with the preservation of their authority as the primary allocators of Federal development dollars (Caulfield 1984, 217). Interestingly, the latter concern remains a potent influence in the derivation and development of Federal resource. development policy, particularly with respect to the promulgation of cost sharing initiatives. 
Flood control had traditionally been seen as a primarily local responsibility and federally assisted flood control projects were generally entertained only in conjunction with navigation improvement projects. The first significant Federal flood control legislation which authorized projects was the Flood Control Act of 1917 which authorized in excess of $\$ 50$ million for control efforts along the Mississippi and Sacramento Rivers (Reuss 1990, 13). Earlier efforts such as the Swamp Lands Acts of 1849 and 1850 were generally land grants to states who assumed and then sold flood plain lands with the proviso that the revenues from such sales would be dedicated to state sponsored flood control projects (Holmes 1973, 4).

The Flood Control Act of 1917 required local interests to cost share levee construction at a rate of $50 \%$ and required that they provide the necessary lands and rights of way to accomplish completion of the project (33 USC 701, 1917). The 1928 Flood Control Act reaffirmed the principle of cost shared flood protection projects but in deference to the poverty of the region being served, the lower Mississippi River valley, the local interests were, over time, relieved of cost obligations other than the provision of rights of way and operation and maintenance of the projects (Seeiy 1987).

Flood control was formally acknowledged as a "proper 
activity of the Federal government in cooperation with States, their political subdivisions, and localities thereof" with passage of the Flood Control Act of 1936, P.L. 74-738. The Act, which marked the beginning of comprehensive Federal flood control planning, greatly expanded the scope of the Corp's mission and reasserted Congressional control over federally assisted water resource development, a particularly compelling contrast to the general transfer of power to executive agencies which had been underway since 1902 .

Its passage, considered a response to both the devastating floods of 1935 and the growing acceptance of the necessity of federally assisted public works, was not without conflict. Specifically, numerous questions were directed at the local repayment provisions contained in or omitted from the Act.

Congress and the corps assumed the position that, unlike municipal water supply or hydro benefits, flood control benefits were "widespread and general" with specific beneficiaries unidentifiable. Thus, flood control benefits were treated as public goods of a national order and payment from a national account was deemed appropriate (Cook 1963, 427). This position was further strengthened, at least politically, by the poverty of the depression era communities that were the likely beneficiaries of a federally assisted flood control programs. When considering 
the development of local repayment provisions it must be remembered that the beneficiary regions along the Mississippi that suffered devastating floods in the first half of the 20th Century were also among the nation's poorest. Further, the Act was perceived by many to be as much a work relief measure as it was a Federal response to acts of nature. Critics also noted that the Act failed entirely to address the issues related to multipurpose, rational benefit based water resource development planning.

Importantly, the Act also failed to require construction repayment by local beneficiaries. Rather, it set forth the often referenced " $a-b-c$ " requirements which required local contribution of project lands, easements, rights of way, operation and maintenance responsibility, and hold and save harmless provisions which provided that the U.S. Government was free from all damages that may accrue as a result of the construction work. These requirements, though subsequently repealed for construction of flood control reservoirs by the Flood Control Act of 1938, became the benchmark "local interest share" for all future discussion of federally assisted water resource development for flood control.

Confusion surrounded the implementation of the requirements, particularly in the area of project lands ownership. The language in the Act was sufficiently 
ambiguous to suggest to some that title to project lands, and, thus, betterments within the project boundaries, were not transferred to Federal ownership (Leuchtenberg 1953, 96). This predicament was remedied by Federal largess in 1938 with passage of the Flood Control Act of 1938 which asserted full Federal responsibility for flood control; an assertion backed in no small measure by $100 \%$ Federal funding.

For the next two decades discussion (and legislation reflecting that discussion) continued on the appropriate Federal role in flood control, the conflict between the Congress and the Executive in determining which should serve as initiator of a Federal water policy, and the extent to which local interests should be involved in the planning, development, and funding of such a policy. While conservative administrations, such as that of Eisenhower, argued for a strengthened partnership with state interests and, ostensibly, greater contributions on behalf of the non-Federal interest, the Federal domination of water resource policy issues was generally supported judicially and legislatively. As a practical matter, the Federal government, when compared to state and local government, had overwhelming economic and technical dominance in planning as well as those administrative areas white (1953) had previously identified. 
The ongoing dialogue occasioned a number of commissions, committees, and study groups constituted to evaluate the various dimensions of a national water resources policy. These groups evaluated the contrasting architectures of centralized and decentralized planning systems and the viability of implementing multi-purpose regional water resource development planning in a political environment that had been dominated by Congressional control over project selection. As always, the bottom line of the discourse ultimately involved a move away from a purely ideological exchange to the more proximate concern of "who pays." Cost sharing emerged as the compelling issue that demanded the continued attention of all the players in the water resource development policy arena.

In 1973 the National Water Commission, a seven member commission authorized by Congress in 1968, published its final report in which it strongly urged an adoption of cost share principles. The commission urged that, "Insofar as is practicable and administratively feasible, the identifiable beneficiaries of project services should bear appropriate shares of development and operating costs through systems of pricing or user charges ..." (U.S. Cong. Senate, Committee on Public Works 1966, 10). Subsequently, a thorough evaluation of the existing cost share requirements for federally assisted water resource development programs and an alternative model was provided by the Water Resources 
Council (WRC), the details of this report having been discussed earlier in the chapter (U.S. Water Resources Council 1975).

Notwithstanding the apparent momentum of the movement to incorporate cost share principles into Federal development policy, at least within the executive branch, the WRC in response to requirements of the 1965 Water Resources Planning Act published the Principles and Standards for Planning Water and Related Land Resources in 1973. For the Corps, and other executive agencies involved in resource development, the Principles and Standards existed as the foundation of the planning and development effort and was the policy basis for implementing agency planning and engineering regulations. Other than to note that cost share principles were under policy review by the WRC, the Principles and standards was silent on the issue. This ensured that, barring intervening legislation, the status quo with respect to federal and federally assisted project planning and development for navigation and flood control would remain essentially unchanged; at least so it appeared.

Though the struggle to integrate cost share principles into federal water resource development policy may appear to have been primarily an Executive initiative, Congress was not without its cost sharing proponents. By the 1970 s the 
demands of debt financing the Federal budget were so great that "cost management" compelled a number of congressmen to reassess their position on Federal largess. Not surprisingly, the scope and character of the subsidy afforded the water resource development community became a target for reassessment. Significantly, the first major cost share legislation did not directly address cost sharing, as such, but focused on user charges for inland navigation.

While the concept of "free waterways" was regarded by many in the inland navigation industry as an immutable, if not constitutionally guaranteed, right, there had been mounting pressure from a number of sectors to temper the scope of the Federal subsidy afforded the industry. As might be expected, the rail industry was at the forefront of this effort to reduce what it perceived as a public subsidy to a market competitor. At the same time there was a growing awareness that neither the renovation nor maintenance of our inland waterway infrastructure was keeping pace with the demands put on the deteriorating system (Schilling et. al. 1987, iv-v). These forces, in conjunction with a Federal budget increasingly driven by debt financing led in 1977 to the first serious waterway user fee proposal introduced by Senator Pete Domenici of New Mexico.

Domenici's proposal would have implemented a fee system of tolls and licenses that recouped $100 \%$ of the operation 
and maintenance (O\&M) costs of a project and $50 \%$ of the initial construction costs. Initial estimates for the cost recovery mechanism suggested that some $\$ 200$ million a year would be recouped through the application of tolls and license fees (Wall street Journal June, 1977). The bill, though successful in the senate, was challenged by the House which employed the seldom used tactic of notifying the Senate that the measure (S.790) was a revenue generation measure that should appropriately have been introduced in the House (U.S. Cong. Senate, Committee on Environment and Civil Works 1978; Reid 1980, 69-71).

The House compromise solution resulted in a graduated rate fuel tax which required a levy of 4 cents a gallon for two years with a subsequent increase to 6 cents. Though precedent setting, the schedule recaptured far less than the anticipated revenues generated by Domenici's proposal and significantly less than the rate of 40 cents a gallon suggested by then Secretary of Transportation Brock Adams. Adams argued, unsuccessfully, that any flat rate tax should recover an amount similar to the amount that would have been recovered under the Senate plan (Reid 1980, 79).

There followed a series of efforts that either failed to meet the requirements of House/Senate conferees or faced the swift and certain fate of a Presidential veto. Carter strongly supported both recapture of O\&M costs and capital 
recovery and had been convinced to stand firm on his position that both components be reflected in any authorizing legislation. Ultimately, and strangely, the deadlock was resolved by the establishment of a "Inland Waterway Trust Fund" financed by a fuel tax. The legislation was skillfully attached to a bill that exempted bingo game profits earned by political organizations from taxation. Congress passed and Carter signed the bill into law on 21 October, 1978 thus establishing both the first user fee on the nation's waterways and further precedent for the implementation of cost share principles in the development of federally assisted water resource development policy (Reid 1980, 121-128).

The Reagan Administration in general, and OMB Director David stockman in particular, were strong advocates of cost sharing. This was consistent with Reagan's belief that the Federal government was larger (both in its budget and its assumption of responsibility) than it needed to be. stockman reasoned that, where benefits were assignable (as in navigation projects), full cost recovery from users for construction and O\&M was appropriate (Knickerbocker March 3 $1981,1)$. There was strong opposition to this position voiced by members of congress and the affected industries. stockman responded by intimating that without significant cost sharing there would be no authorization for "large scale new construction" for waterway or port improvements in 
the Administration's budget request (National Waterways Conference July 28, 1981, 1).

Waterway interests which had unsuccessfully fought to defeat waterway user charge legislation saw cost sharing as the next insidious step and were generally opposed to the concept. Some organizations, such as the Interstate Conference on Water Policy (ICWP), recognized the inevitability of cost sharing. The ICWP abandoned its outright opposition to cost sharing legislation and sought, rather, to ensure that cost sharing proposals effectively provided for full participation of the non-federal interest in project planning. The ICWP identified such critical study issues as the establishment of an equitable recovery mechanism that recognized the difference of state and federal budget cycles, the lack of uniform institutional arrangements for water resource development across states, and the financial constraints faced by many potential nonfederal interests.

While there existed a good deal of pessimism in the industry and Congress concerning the impact cost sharing would have on water programs it was tempered by the belief that, though things were not going well for those generally opposed to a modification of traditional funding formulas "things could hardly get worse ..." for federally assisted water resource development than they were during the Carter 
administration (Knickerbocker March 3, 1981, 14).

The rationale for cost sharing, at least from the perspective of the Reagan Administration was not purely economic, though the potential to transfer costs to nonFederal interests was certainly not lost on those whose job it was to find cost savings in "discretionary" Federal programs. While the water resource development portion of the Federal budget represented less than one-half of one percent $(.05 \%)$ of the total, it represented over three percent $(3 \%)$ of that portion which was subject to discretionary reductions.

There was also the issue of why it took so long for "bad" projects to be dismissed from consideration. The Assistant Secretary of the Army for Civil works (1982), William Gianelli, directed the corps to review the status of projects that had been considered for authorization in the period 1973 to 1981 . Of the 462 studies evaluated during that period 258 ultimately resulted in unfavorable reports, 38 of the remaining 204 were authorized, and only 13 constructed (U.S. House of Representatives 1982, 13-14). clearly, a good deal of time and money, virtually all of it Federal, was spent evaluating projects that had little chance of achieving fruition.

The traditional argument for the existence of this condition generally focused on the lack of risk associated with project advocacy by the non-Federal interest and their 
congressional representatives and the willingness of the Corps to engage in long range technical evaluation of such projects. Indeed, the corps frequently mentioned the twenty-plus year average it took for a major civil works project to move from conception to construction as a testament to the quality of the planning effort which supported Corps projects. Marginal projects (from a benefit-cost or environmental viewpoint) lingered at some level of project review within the corps hierarchy so long as there existed a congressional "champion" and sufficient study monies appropriated to fund the Corps' plan formulation and design effort. The local interests, who typically had no direct investment beyond the "a-b-c" requirements, generally sat patiently by and waited for the tortuous process to deliver on its promise.

Cost sharing, which included cost shared planning, would revise that incentive structure by allocating a portion of the planning costs to the non-Federal interest. Ostensibly this would result in the early termination of projects that did not enjoy enthusiastic (financial) local support and serve to redirect the technical resources of the Corps toward those projects that were more likely to move forward to authorization and construction. The data on "failed" projects hanging around in the planning process for years simply provided yet more ammunition for those who were 
impatient with the pace of the project planning and authorization process employed by the corps and was particularly useful to those cost sharing advocates who felt they had a solution.

Reagan, like Carter, was insistent that any long term solution to the water resource legislation impasse would include some component of cost sharing. Unlike Carter, he was elected to a second term and enjoyed enormous political popularity. Following a series of hardline initiatives, policy swings (in reaction to criticism from Western congressmen who felt cost sharing. was an anti-West proposal), and extensive negotiations with congress and the industry, the Administration achieved a compromise solution with the Senate in 1985 (McCool 1987, 203).

The Senate bill (1985 Supplemental Appropriations Act, P.I. 99-88 passed August 15, 1985) reflected a tentative agreement on cost sharing between the senate leadership and the Administration, an agreement that was to become the foundation of the WRDA 1986. Previous efforts of the Administration, including S. 809 (H.R. 2959), dealing with deep draft ports, and S. 810 (H.R. 2962), which addressed inland navigation, had attempted to recover $100 \%$ from the local interest who would then attempt to recover costs through fee assessment (U.S. CEQ 1981, 156). Though unsuccessful, these efforts were instrumental in forcing movement on the cost sharing issue. 
The movement was, predictably, not achieved without a great deal of political posturing. Shipping interests, both inland and port oriented, wanted assurance that the Federal sector, and the corps of Engineers in particular, would accelerate the development process if a compromise on cost sharing could be reached. The water borne transportation community emphasized their increasingly vocal position that the interminable delays associated with water resource project planning and approval were unacceptable even when the Federal share of financing was $100 \%$. A variety of formulas and plans were offered by members of Congress seeking to appease industry and constituent interests while, at the same time, accommodating the Administration's position on shifting a portion of the burden of water resource development to non-Federal interests. As previously noted, the congressional agenda also included an effort to reassert the primacy of the legislative branch as the force behind water resource development policy initiatives and project selection. Hearings; proposals, demands, and negotiations continued unabated; project authorization, on the other hand, was at a dead standstill. Passage of the 1985 Supplemental Appropriations Act on 15 August, 1985 broke the logjam. The bill was almost universally hailed as both landmark and imperfect, possibly because it represented a product of frustration and. 
exhaustion as much as one of creative compromise. The bill provided $\$ 63.1$ million dollars for 41 new start construction projects with the caveat that no Federal money was to be expended on the projects until such time as a cost sharing agreement on each was reached between the non-Federal interest and the Administration. The Act established a contingency date for resolution of cost sharing issues after which the release of funds for the authorized projects would be prohibited.

Reagan had made it clear that the supplemental bill would face a veto if it was sent to the Executive without cost sharing language. Execution of the agreements was required before June 30,1986 or the funding authorization was to be automatically revoked and there were assurances from the Senate leadership that cost share language, consistent with that set forth in the supplemental legislation, would be included in any future omnibus water bills referred to OMB (Congressional Quarterly June 22, $1985,1239)$.

On March 26, 1986 the Senate passed S. 1567, which was similar in most ways to HR 6, an omnibus water appropriation bill passed by the House on November 13, 1985. The Senate version of the legislation authorized fewer projects (180 vs. 360$)$, committed $\$ 8$ billion dollars less in Federal outlays, and demanded stricter cost share language than the House version. The resulting House-Senate conference was 
driven by a sense of inevitability as well as one of urgency. As Senator Moynihan stated, "Cost sharing is the absolute minimum. Absent that, there will be no legislation and we will lose another decade" (Congressional Quarterly March 29, 1986, 713).

Though HR 6 languished in conference for six months the House, now facing a certain veto if it failed to agree to stringent cost share language, capitulated to the senate's recommended language. The resulting legislation, the WRDA 1986, was the last piece of legislation passed by the 99 th Congress and the first omnibus water resource development legislation passed by congress and signed into law since 1970. Though it contained a large body of substantive water related policy, the Act was immediately identified as the most significant piece of cost sharing legislation in the water resource development field. As senator stafford remarked at passage, "The key to this bill - and possibly the single most important reform ever crafted onto the nation's water resource development policy - is cost sharing" (McCool 1987, 203).

For the Corps of Engineers which had seen new start construction steadily decline over the previous decade, the Act was similarly historic. While the administrative ramifications were complex and promised to fundamentally affect the relationship between the Army Corps of Engineers 
and its "clients", it also served notice that, as Congressman Robert Roe (NJ) stated following passage, "The Corps is back in business" (Stanfield 1986).

Pre-WRDA 1986 Cost Sharing For Corps-Projects

Frequently lost in the discussion on the status and impact of cost sharing is a recognition that the implementation of cost share principles represents, in many cases, an incremental adjustment rather than the introduction of an entirely new financing strategy. Former Chief of Engineers E.R. Heiberg noted following passage of the WRDA 1986 that:

The world hasn't flipped 180 degrees. We didn't go from no cost sharing to 5 out of every 15 dollars- the estimated average between Federal and non-Federal interest participation under the new arrangement (Engineering News Record April 23, $1987,24)$.

As Heiberg notes, it is the case that cost sharing, of a variety, has enjoyed a broad if irregular and inconsistent Federal application in the field of water resource development. Particularly alarming to those who have researched the implementation of cost share principles is the variation in rates between agencies whose functions (flood damage reduction) are comparable and the rate bias (from a sponsors viewpoint) in favor of a structural alternative. For corps projects, local interests have, since passage of the Flood Control Act of 1936, P.L. 74-738, been required to provide the necessary 
lands, easements, rights-of-way (the "a-b-c" requirements derived from section 3 of the Act) for project construction. Subsequent legislation resulted in relocations and dredge disposal area requirements being added to the list of local requirements, now referred to as the LERRD. Thus, the summed value of the local contribution was represented by the market or estimated value of the required LERRD. Additionally, specific cost share rates for Corps projects were required on a "by feature" basis. To appreciate the magnitude of the change the WRDA 1986 occasioned, a complete breakdown of feature and function cost share rates prior to and subsequent to the Act are set forth in the following tables IV, V, and VI. A review of the data set forth in the tables establishes a historical basis for comparison of the cost share provisions of the WRDA 1986 and its predecessors and should serve to emphasize the fact that the WRDA 1986 is precedent setting only in the scope and application of its cost share requirements.

Table $\mathrm{V}$ provides a by project function comparative breakdown of how the WRDA 1986 shifted the financial obligation in the direction of greater non-Federal participation with the implementation of statutory cost share formula. 
TABLE IV

ARMY CORPS OF ENGINEERS

COST SHARING ALLOCATION PRIOR TO WRDA 1986

PURPOSE

NON-FEDERAL SHARE CONSTRUCTION

HARBORS

$0 \%$ Cost of construction. Provision of lands easements, rights of way and disposal areas.

MAINTENANCE

$0 \%$

FLOOD CONTROL

Structural

$0 \%$ of total construction cost. Provision of lands, easements, and rights of way not to exceed 508 of project costs.

Non-structural

208

HYDRO-POWER

1008

MUNICIPAL \& INDUST.

1008

WATER SUPPLY

AGRICULTURAL

WATER SUPPLY

508 Lands, easements, rights away included as a portion of share.

RECREATION

$50 \%$ Lands, easements, and rights of way included as a portion of share.

HURRICANE AND STORM DAMAGE PROTECTION

$30 \%$ Land, easements, and rights of way included as a portion of share.

AQUATIC PLANT CONTROL

$30 \%$ Lands, easements, and rights of way included as a portion of share. 


\section{TABLE V}

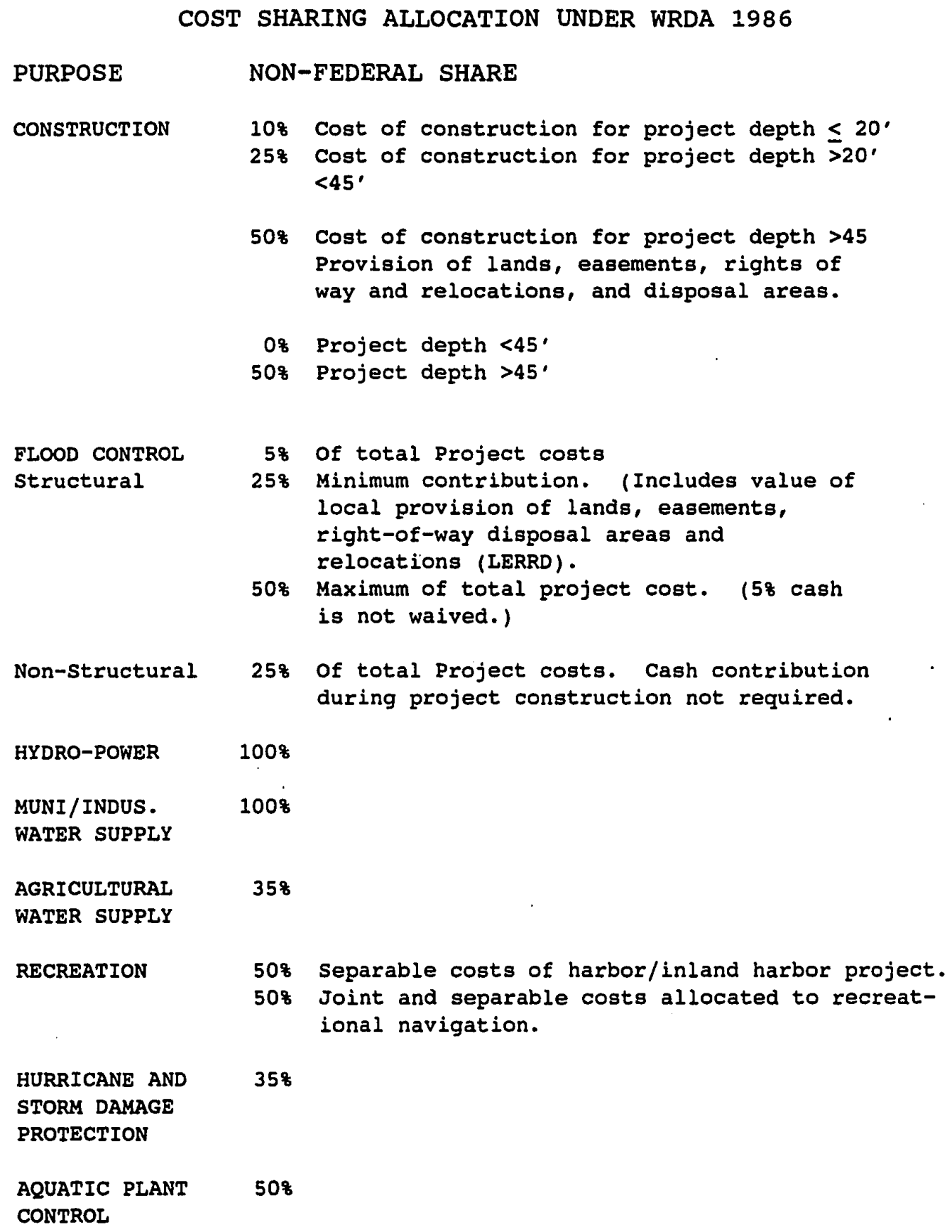

HURRICANE AND 


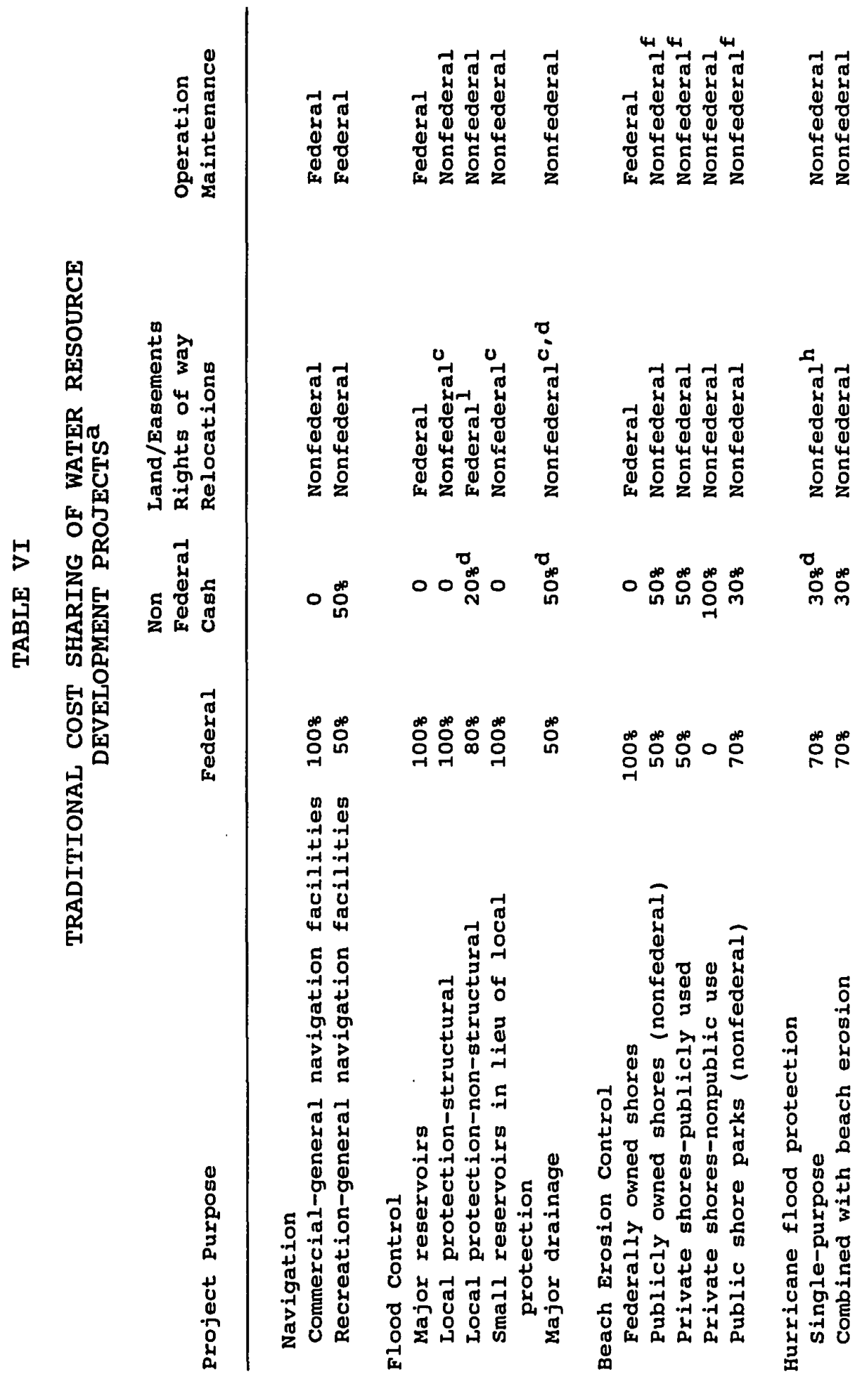




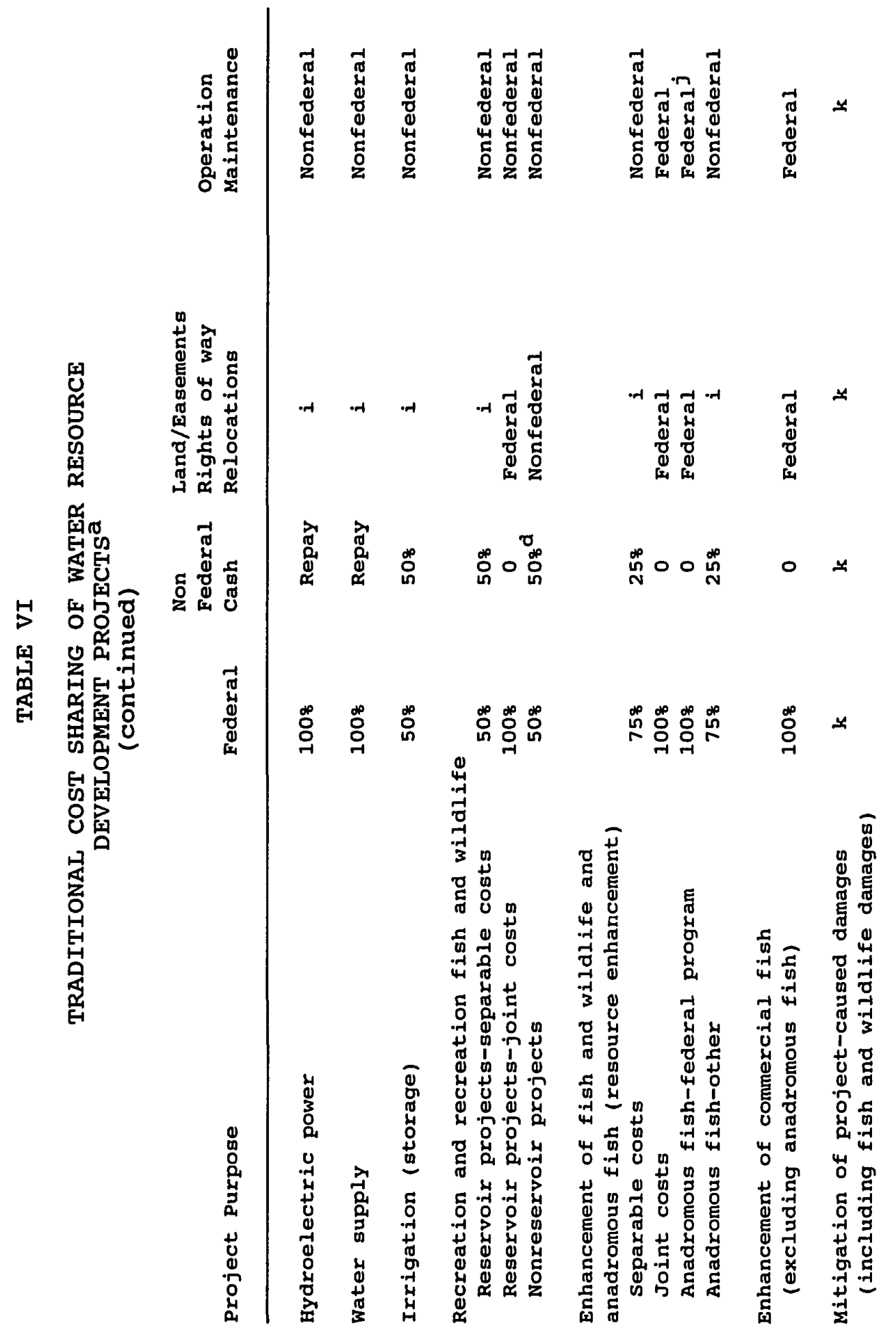




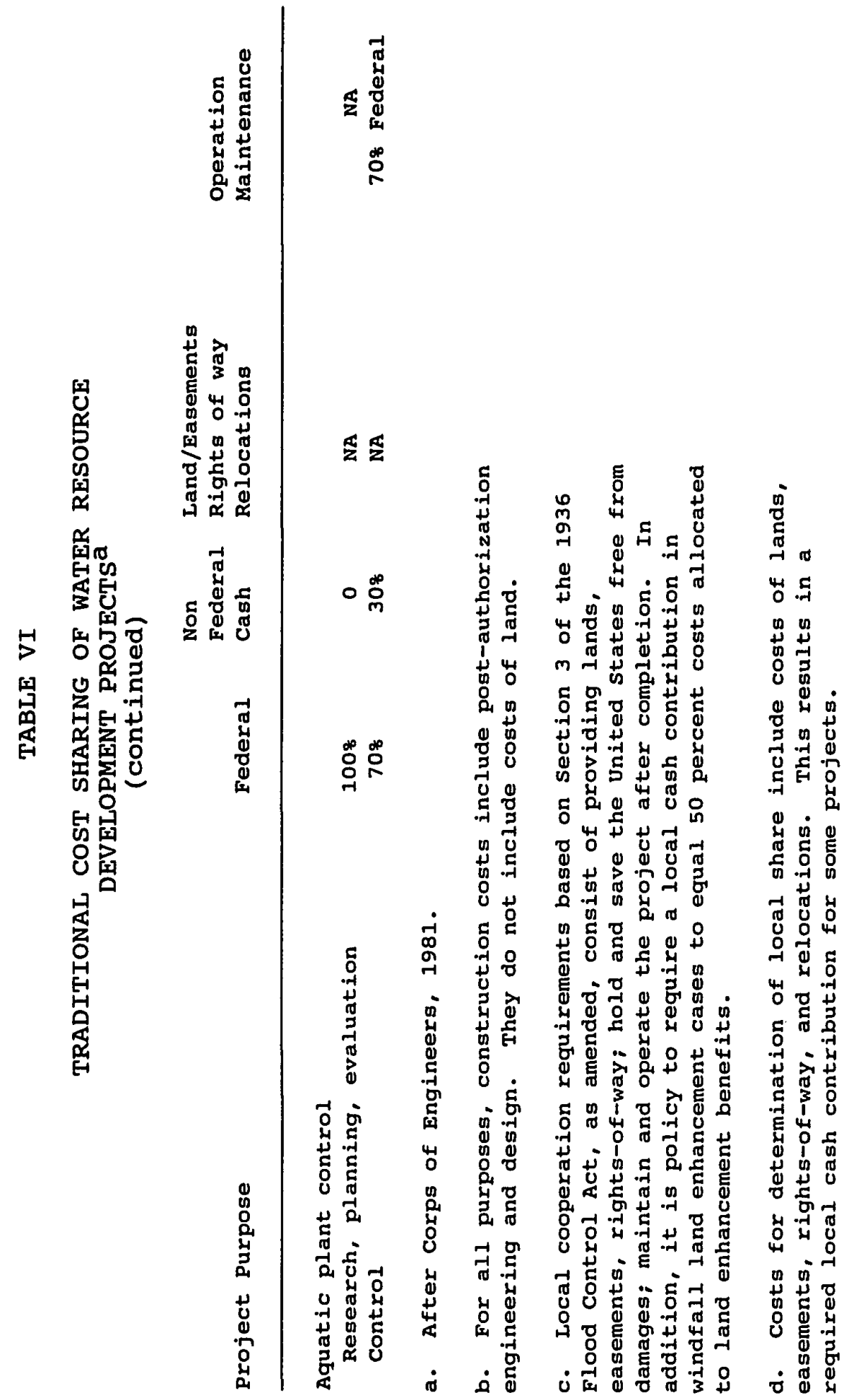


牙

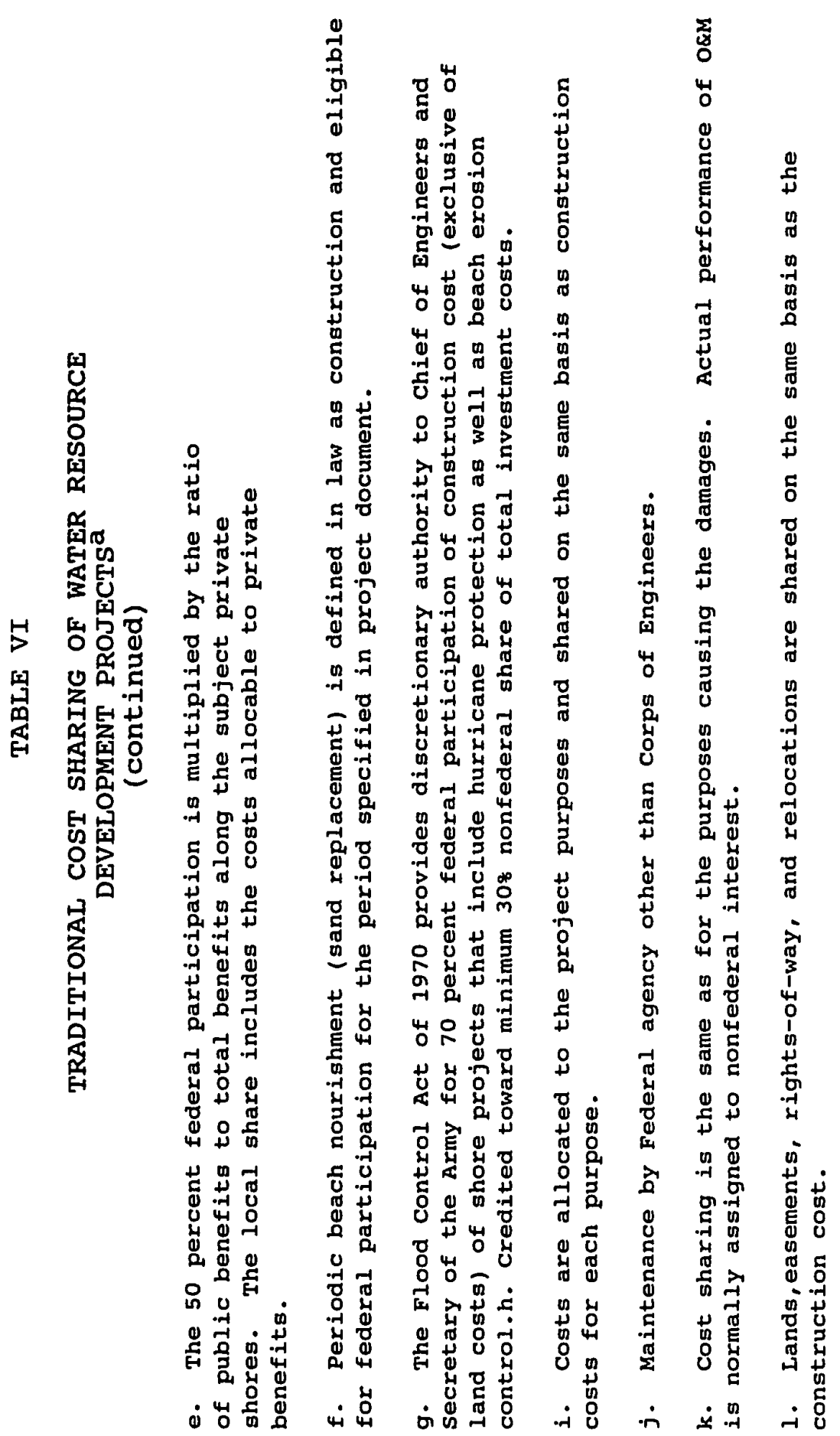

5 
As the tables reveal, the passage of the WRDA 1986 represented a substantial shift toward increased non-Federal financial participation in project construction and maintenance. Moreover, the percent-by-feature rates may understate the full impact of the shift as non-Federal sponsors are required to provide (for flood control projects) a five percent (5\%) of project cost cash contribution even when LERRD meets the twenty-five percent (25\%) minimum contribution. Table VII illustrates the financing options provided in the WRDA 1986 by project purpose.

How significant is the shift in financial terms? The impact of the shift is depicted in Table VIII which provides comparative data on a sample of early cost shared projects.

The mean non-Federal share (cash and LERRD) for the twenty-seven projects listed in Table VIII under traditional financing arrangements was an estimated $\$ 10,999,000$. The estimated mean non-Federal share for those projects with cost sharing was $\$ 23,463,000$, an increase of $113 \%$.

When discussing cost sharing and the impact of transferring a portion of the development and construction financial burden from the Federal interest, it is critical that an appreciation of the concepts of nominal, effective, and composite cost sharing be achieved. In the case of the WRDA 1986, such an understanding is most important due to the front-end or "pay-as-you-go" financing requirement 


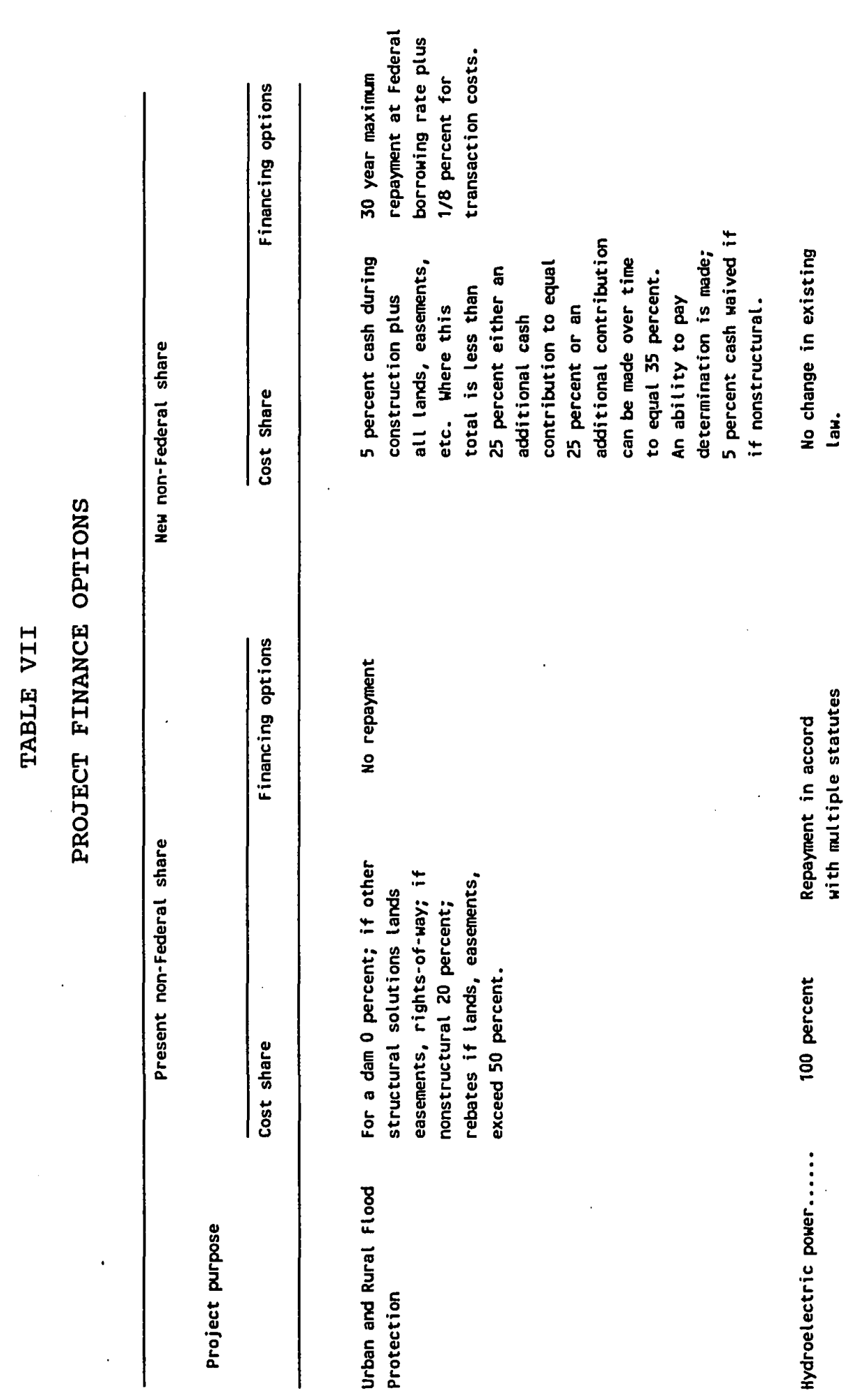




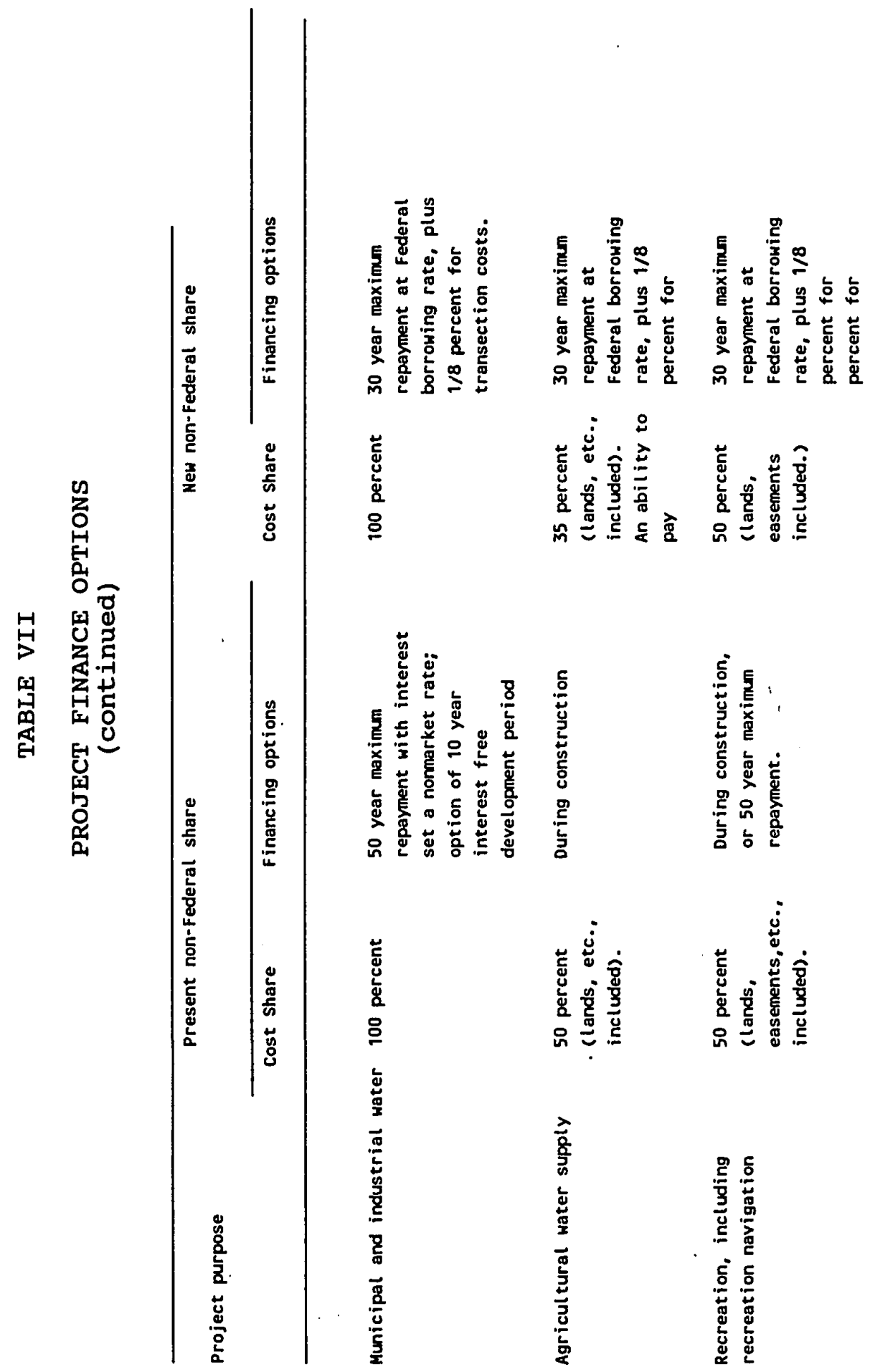




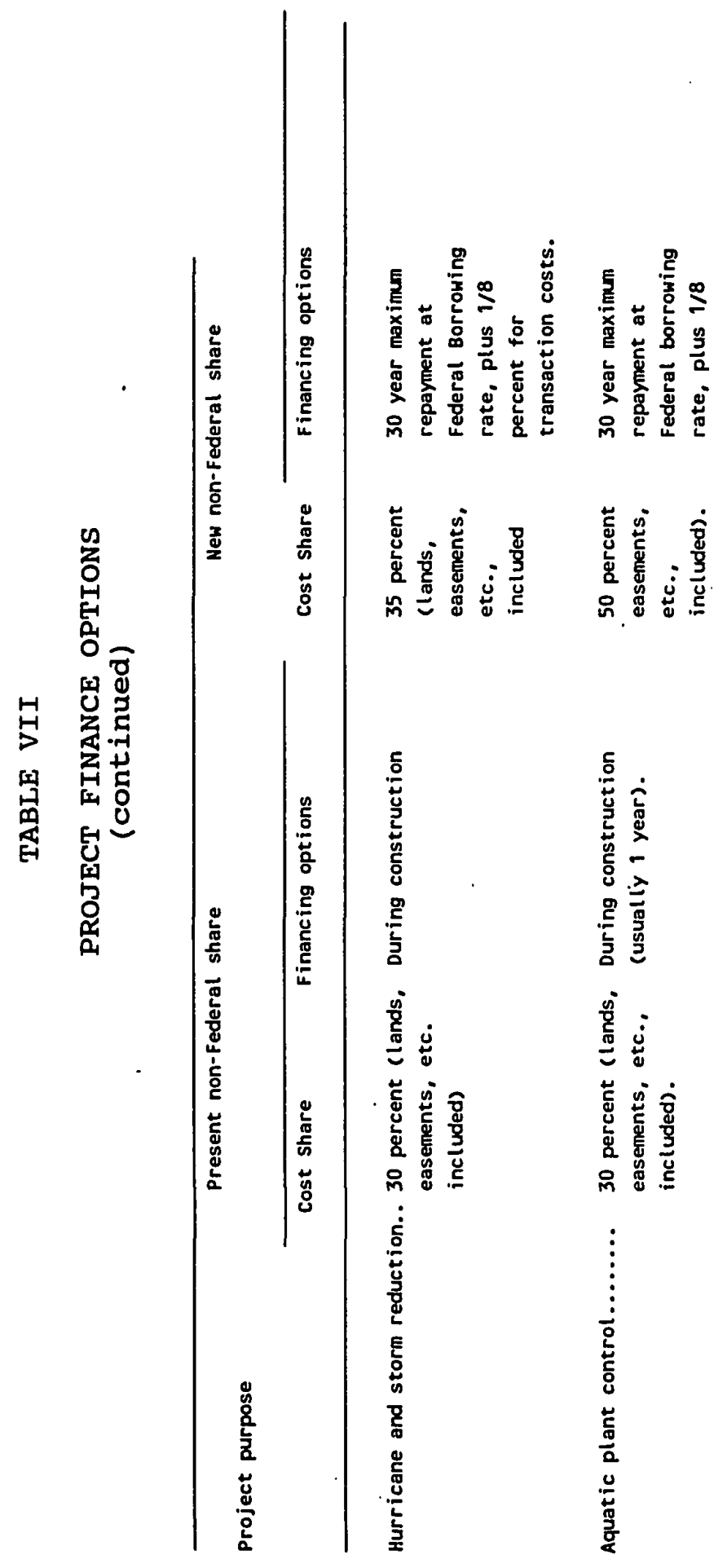




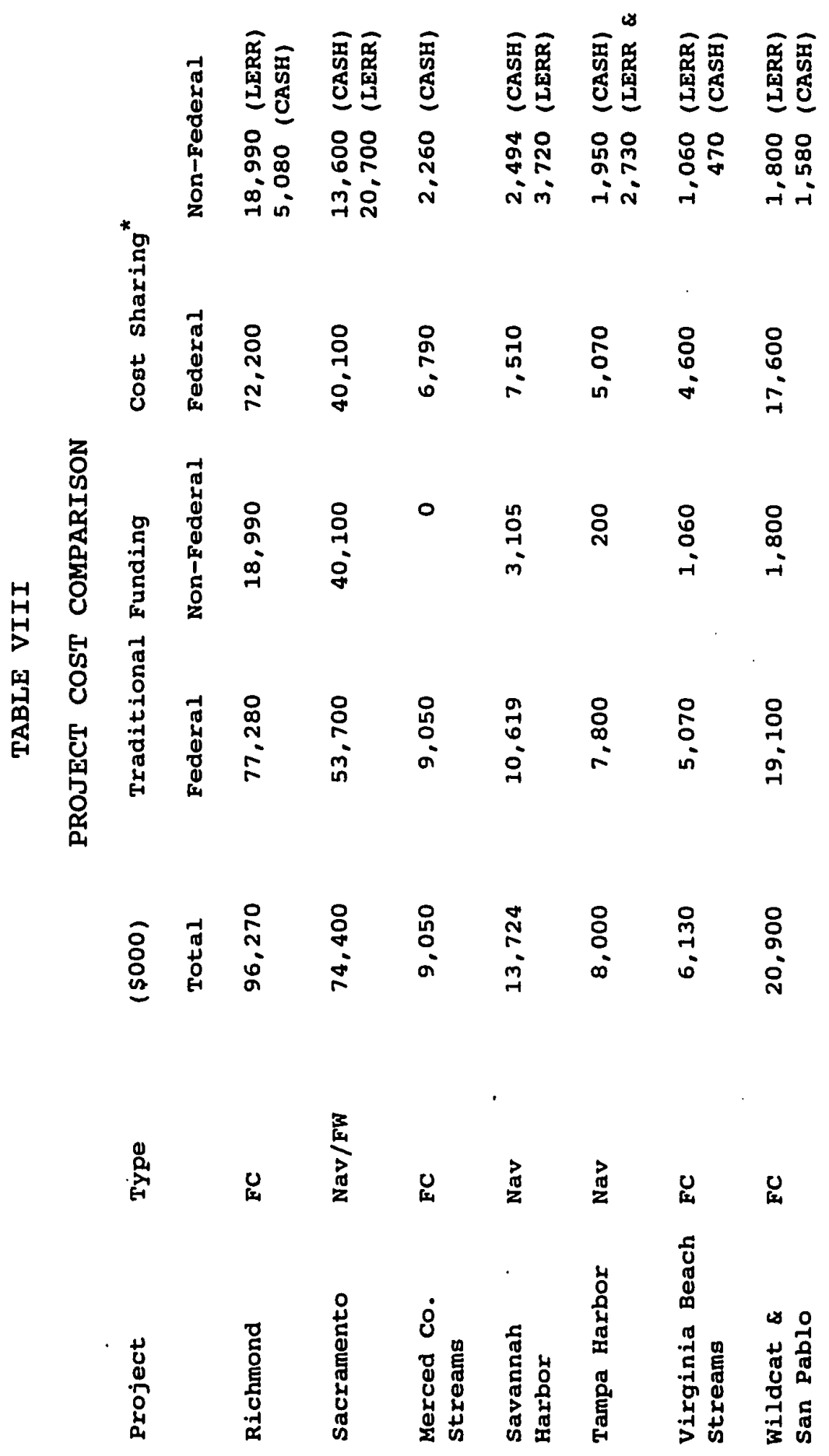




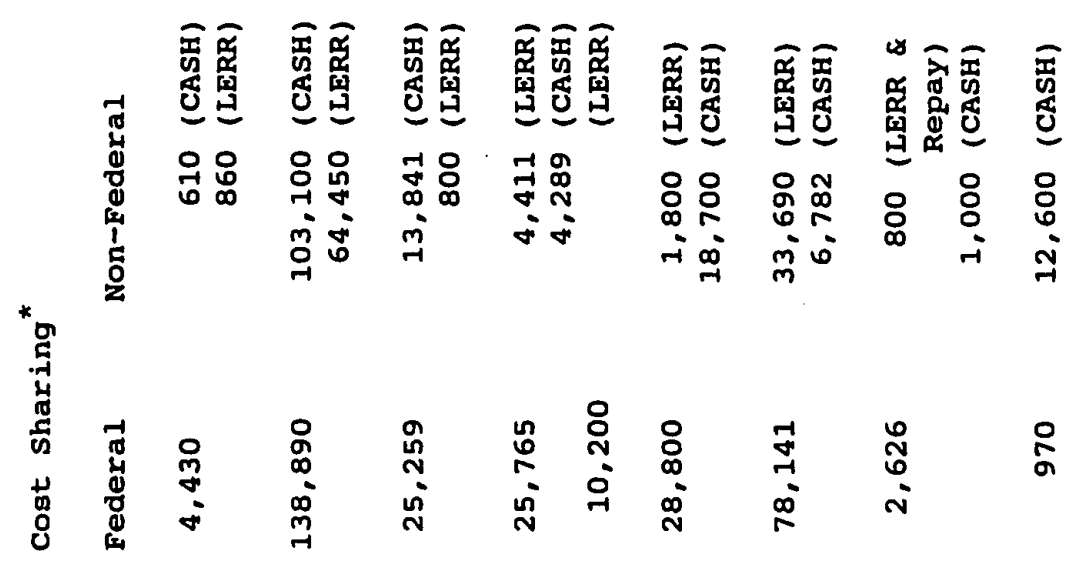

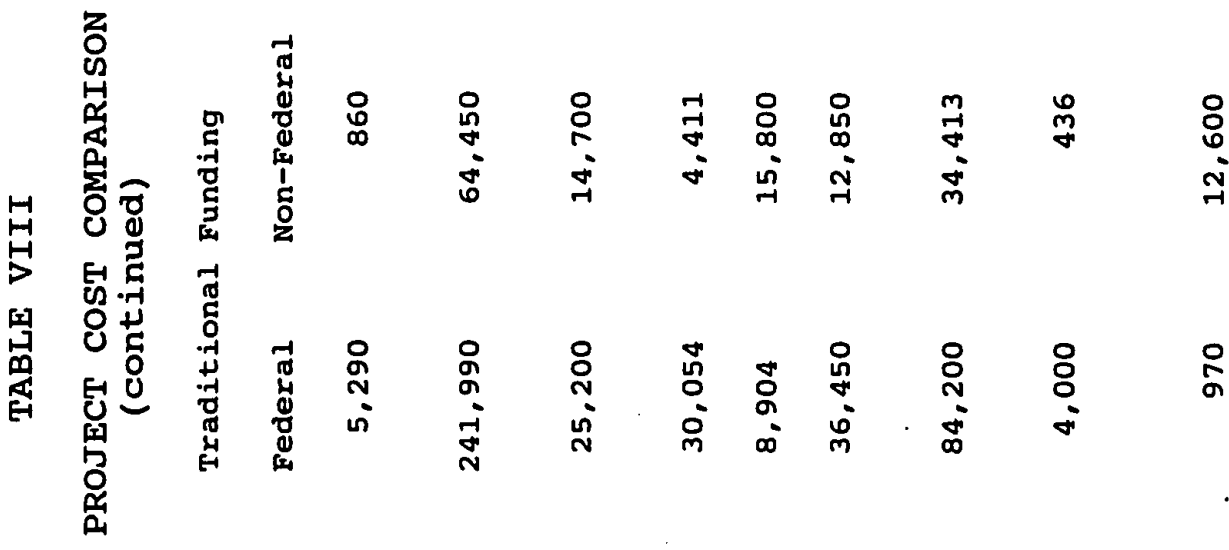

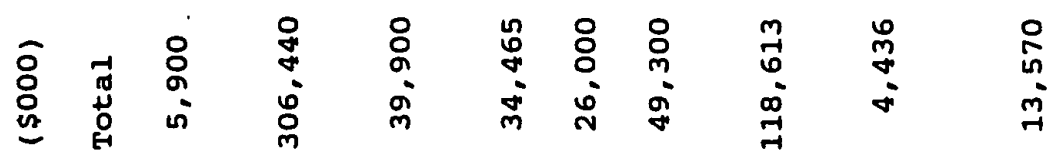

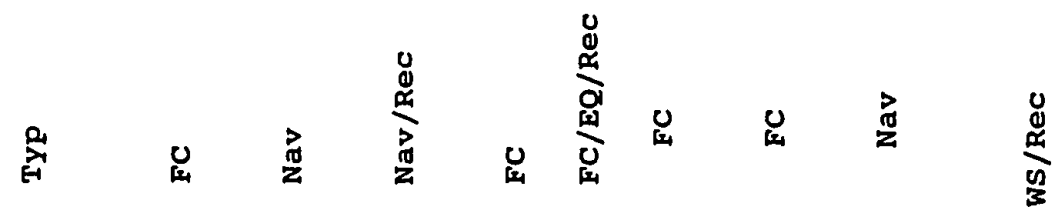

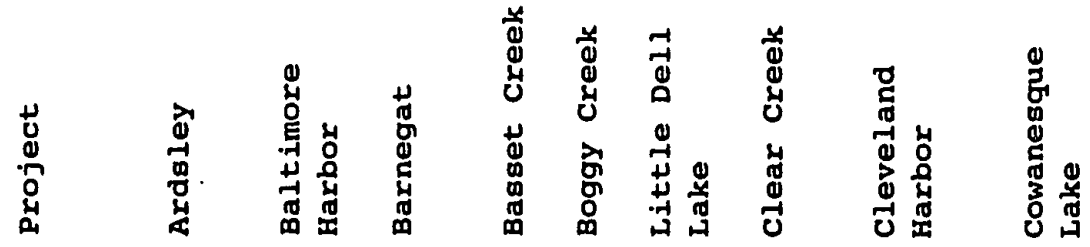




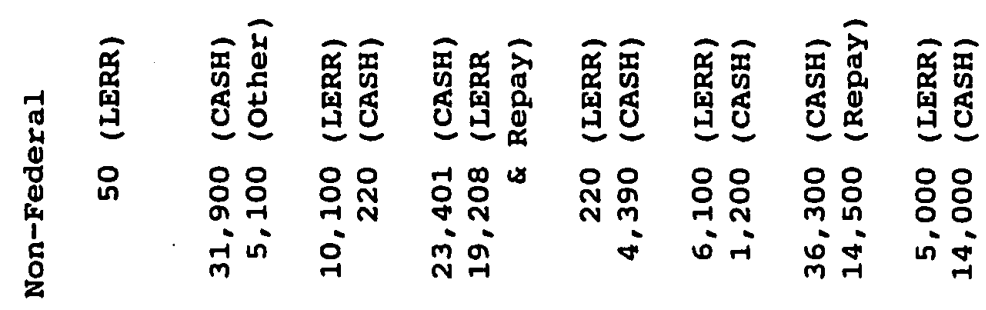

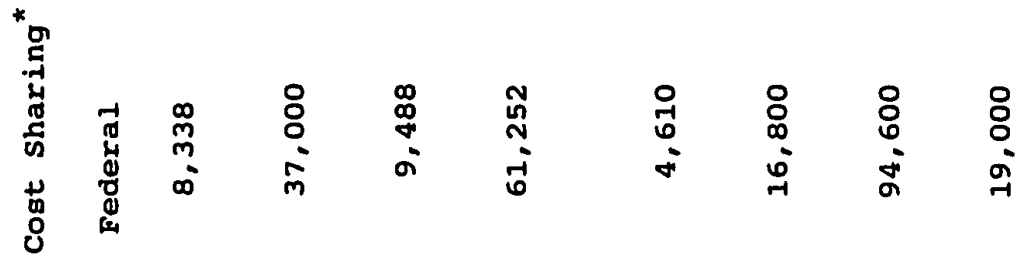

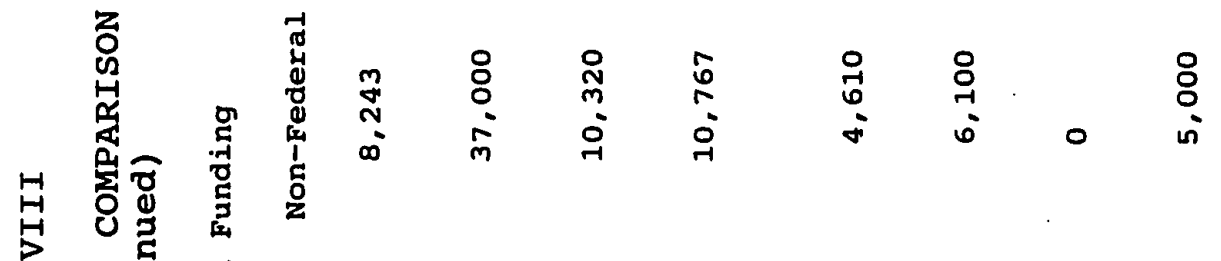

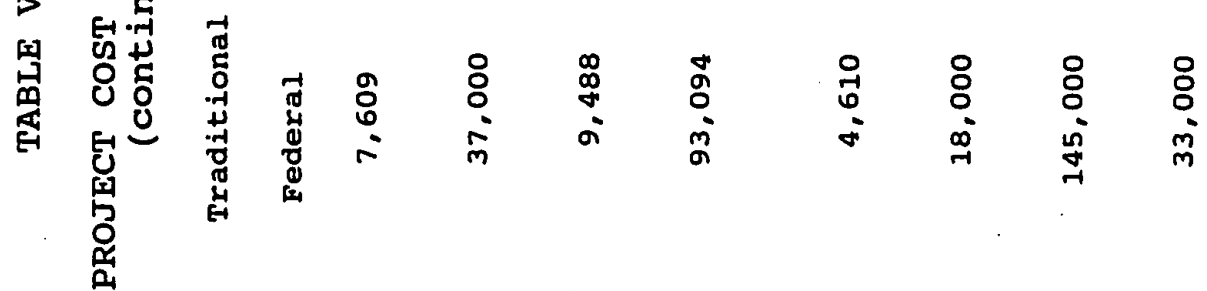

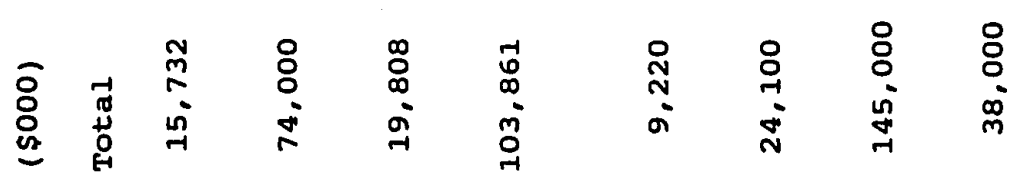

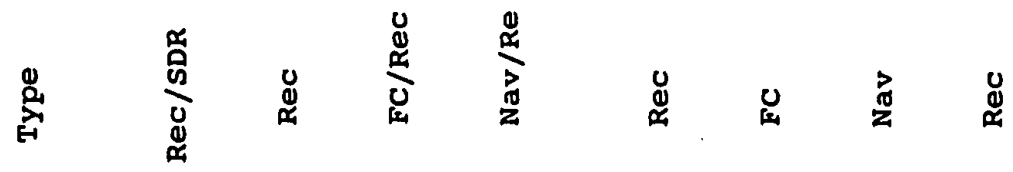

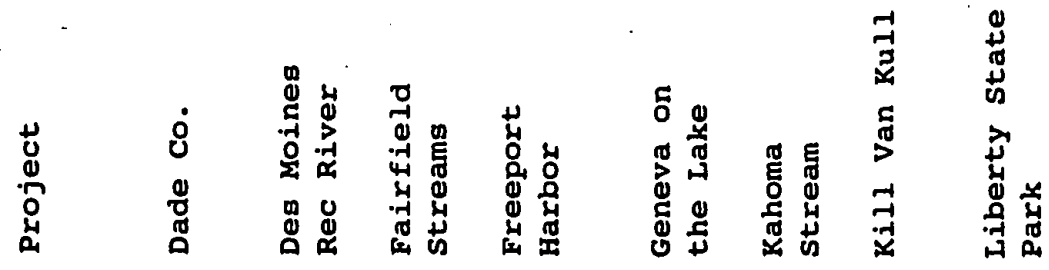




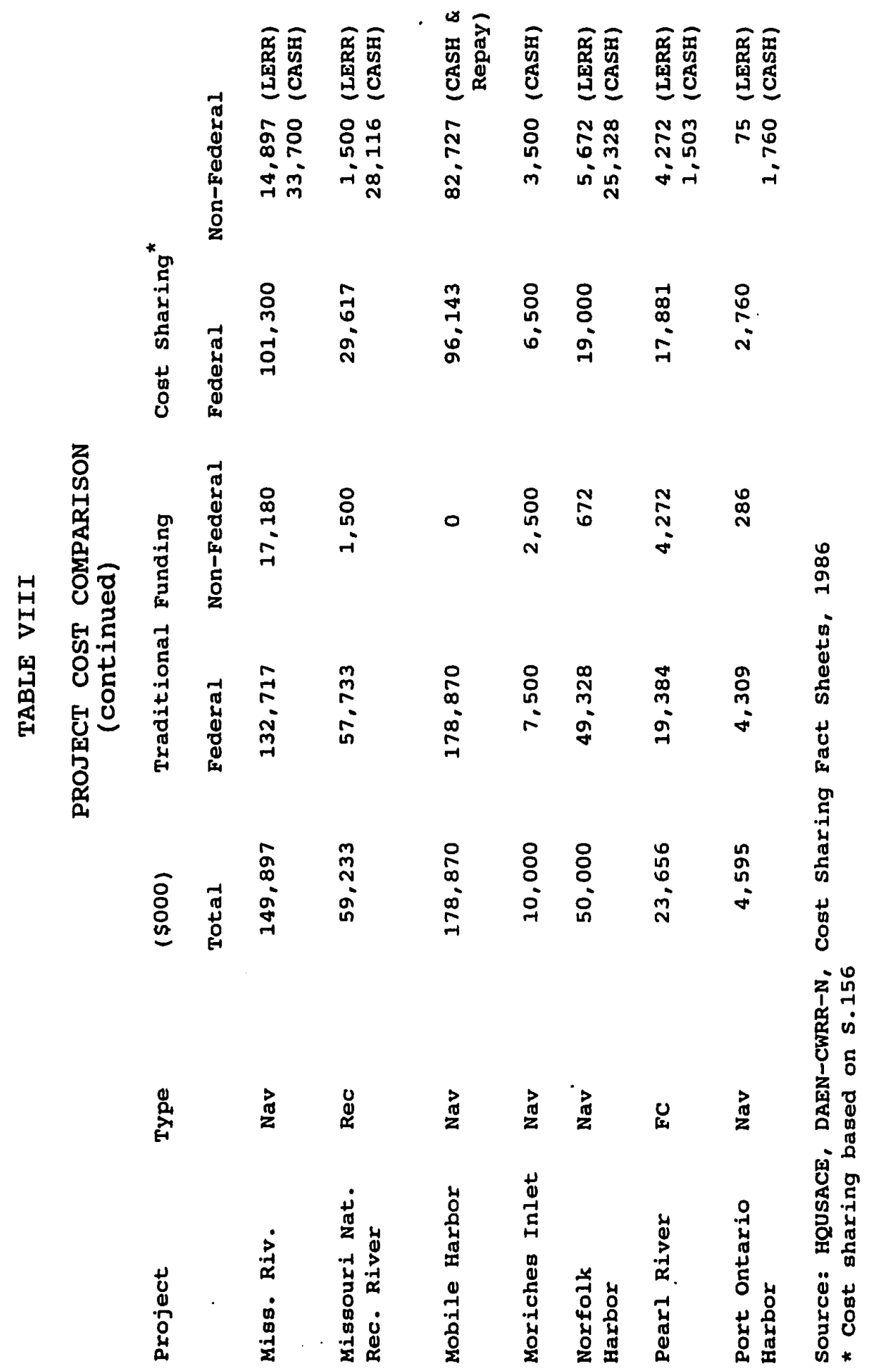


101(d) of the Act. In the estimation of some analysts, this represents a greater burden to non-Federal sponsors than does the overall requirement to cost share project construction. This requirement was ostensibly advocated by the administration to make difficult congressional grants of payment amnesty or to cancel debts incurred under the cost sharing arrangement, a scenario reminiscent of the Congressional exemptions granted for reclamation payback provisions (McCool 1987, 203).

The nominal cost share rate is the rate established by statute or regulation for a particular feature, function, etc. The nominal cost share rates for the WRDA 1986 were set out in Table $V$. The effective cost share rate is derived by calculating the Federal and non-Federal contribution of the capital cost of the project, their respective contributions to annual operating and maintenance costs, and an accounting for deferred non-Federal contributions to project cost. The effective composite rate includes all cash contributions, creditable contributions, O\&M costs, the repayment period interest rate, and any special transfers that accrue to the non-Federal interest.

For a single purpose flood control project with a nominal cost share of twenty-five percent $(25 \%)$, the nominal cost share rates for the Federal and non-Federal interests would be seventy-five (75\%) and twenty five (25\%) percent respectively. If, however, all O\&M costs over the 
life of the project accrued to the non-Federal interest, the effective cost share rate for the non-Federal interest would be greater than twenty five percent (25\%) of total project cost. Conversely, if the non-Federal interest were allowed to extend payment for construction cost interest free over the life of the project, the Federal subsidy would, be considerable and so reduce the effective rate for the non-Federal interest by some proportion.

Table II provided an overview of pre-WRDA 1986 effective, composite non-Federal cost share rates for the Corps of Engineers and twenty other Federal agencies involved in water resource development. 6

The WRDA 1986 established funding during construction as a principal requirement of the non-Federal interest for both navigation (Sec. 101(a)) and flood control (Sec. $103(a))$. Arguably, the impact of pay-as-you-go financing will be most acute for those projects (generally flood control) whose outputs are non-vendible and will require sponsors to engage in some form of bond financing for the local share. The Act provides that for projects authorized under Sec. 103, the Secretary of the Army may permit payments made by the non-Federal interest over the course of construction to be without interest, to defer initial payment for one year after construction has begun, or to provide for repayment with interest over a period of not more than 30 years from the date of completion of the 
project or separable element. As of 1992, the data revealed, somewhat surprisingly, that only two flood control projects had applied for such relief under the Act. Both projects were granted relief by the secretary. Though not explicitly referenced in the Act, the WRDA 1986 establishes de-facto a purpose-linked incentive structure which acknowledges the variability of features (variable cost share ratios for navigation, recreation, water supply, etc.) and the magnitude of proposed activities (variable cost share ratios for deep draft projects where final depth is the determinant). Analysis of this combination of intergovernmental cost reallocation and the existence of incentives embedded in the legislation suggests the possibility of a set of anticipated or induced behaviors that one might conclude non-Federal interests would engage in to offset the additional financial burden imposed by the increased cost share requirement.

The literature on cost shared water resource development, both the political and the economic, is largely concerned with the tractability of implementing large scale programs which involve significant policy redirection and the impact of policy change on program output. This research focuses on three aspects of the process addressed as significant issues by the literature:

1) The significance of issues raised by the literature regarding the criticality of a 
plausible "theory" underlying the implementation effort;

2) An examination of evidence of actual program outputs for purposes of comparison with what the literature suggests those outputs should be;

3) To provide a context for discussion of the findings on the implementation process analysis and to establish the linkage between the negotiated design outcomes of actual project and the implementation process.

Tractability concerns involve the extent and severity of the condition being considered for treatment. Is the problem solvable? Clearly, goal definition has a great deal to do with the issue of tractability. Eradicating poverty is a worthy goal, but so stated the goal is sufficiently imprecise as to be practically unachievable. The tractability issues associated with cost sharing are more circumscribed, and thus easier to measure and analyze.

Earlier sections of this chapter set forth both the theoretical foundations for establishing cost share legislation and the cost share formulas established by project function in the WRDA 1986. With this framework in place, the analysis of programmatic outputs proceeded.

The literature establishes a set of expectations as to how the non-Federal interest will react to cost sharing both as a rational economic actor and a political constituent. Marshall (1969, 1982) established the theoretical case for application of the Association Rule which calls for charging local beneficiaries a percentage of 
the project cost equal to their marginal benefit for that project which reflects the nationally efficient project design. Absent such a procedure, local interests will be induced to argue for a project that maximizes local benefits without regard to national benefits.

As the WRDA 1986 applies cost share ratios across the board by project function without regard to individual projects, it is reasonable to assume that non-Federal interests would exhibit some strategies to influence project design both with regard to maximization of local benefits and their ability to fund the preferred project. For ease of analysis it was presumed that no one project would be exempted from cost sharing and that, while the percentages may change due to subsequent legislation, the application of charges would be consistent across projects over time.

In broad terms, the available literature, including the pronouncements of the water resource development industry, suggested that local optimization strategies would likely focus on cost reduction to the non-Federal interest and would consist of: 1) shifting cost elements of a project to a Federal purpose, 2) staging or phasing construction so as to reduce the initial capital outlay requirement, 3) reducing the overall size or scope of the planned project, 4) eliminating project features that may be legally deleted from the plan. Having established these 
predicted behaviors, the research will proceed to evaluate the relationship between such incentives and the study assertions established above with the empirical data available on cost shared projects in an attempt to identify the impacts of cost sharing on projects designed and constructed under cost share criteria.

Strategic planning on the behalf of local interests has, of course, implications which extend well beyond the design of the approved project. Notwithstanding their inability to modify the legislated policy, policy opponents may attempt policy redesign through the negotiation of incremental compromise with their bureaucratic counterparts on project particulars; implementation as the "continuation of politics by other means" (Bardach 1977). Indeed, the impact of implementing cost sharing on the plan formulation and project development model employed by the corps of Engineers may well be as significant as the cumulative impact on project design.

The financial impact of cost sharing, at least in a macro sense, is relatively simple to appreciate. What is not so readily evident is the impact of that financial shift on project design and the development of a restructured partnership arrangement between the Federal government, the corps, and the non-Federal interest. Former Assistant Secretary of the Army for Civil Works 
(ASACW), Robert Dawson, optimistically noted that,

One of the great advantages of cost sharing is that there's going to be a renewed challenge of Corps criteria because those who will be paying a big share of the cost are going to demand that things be reasonable" (ENR April 23, 1987, 24).

Reasonableness, in this case, is a complex construct that will be reflected both in the evolution of the design and sçope of projects as a result of cost sharing and the interorganizational dynamics of the tiered partnership in project planning envisioned by the WRDA 1986. An empirical analysis of those "reflections" and the questions raised in this summary of the literature is the subject of the following chapters.

CONCLUSION

The literature set forth in this chapter on the implementation research, the theoretical framework of cost shared water resource development, and the historical antecedents of the WRDA 1986 encompass a broad and rich area of study. The literature reviews were established independently by subdivision so as to provide the framework within each to raise issues specific to that literature. It is, however, the relationships and interdependencies of those issues that are the focus of this research. With respect to the literature on the policy implementation process, this research will attempt to examine the explanatory capacity of a theoretical 
implementation model to the process of implementing the WRDA 1986. Specifically, the research will seek to identify and test implementation variables, independent conditions that contribute to the success or failure of policy implementation initiatives. It will then proceed to address issues raised in the literature regarding the impact of position in the intergovernmental implementation hierarchy on one's perspective of the identified variables. A detailed discussion of the approach the research proposes to provide data on these issues and the development of testable hypotheses is set forth in Chapter III.

The questions raised by the cost sharing literature deal more precisely with a body of theory that suggests how rational actors within the public sector will perform given limited resources to commit to water resource development and a specified set of incentives. A significant portion of that literature, previously discussed in this chapter, deals with the optimal sizing of projects and suggests how projects planned with and without cost sharing restraints may differ in important ways. Utilizing the passage of the WRDA 1986 as the catalyst event, this research proceeds to focus on issues related to the empirical impact cost sharing has on projects, and to develop and test assumptions established in the literature related to the sizing of projects under cost shared planning principles, construction 
scheduling of cost shared planning, and the influence of cost shared planning on project environmental features. Chapter III establishes the set of hypotheses and assumptions that will serve as the focus of this research and the basis of subsequent inferential findings and discussion. 
ENDNOTES

1. For a thorough accounting of market mechanisms and efficiency criteria with respect to water resources see John Krutilla and otto Ekstein's classic, Multiple purpose River Development, 1958.

2. The NED plan will be referenced and discussed throughout this research with particular attention paid to the effects of employing environmental quality protection as a planning constraint and the role of plan acceptability as a qualifying factor.

3. For the sake of simplicity let us assume that the majority of benefits from the project will accrue to an identifiable population within specified geographic and jurisdictional boundaries.

4. For a thorough treatment of how project demand functions are derived see Harold E. Marshall's discussion in The Relationship Between Local Cost Sharing and Efficient Water-Resource Development, and unpublished Doctoral dissertation submitted to the Graduate council of George Washington University in 1969.

5. For a particularly concise yet thorough treatment of the history see Beatrice Hort Holmes' History of Federal Water Resource Programs and Policies, a two volume publication of the U.S. Dept. of Agriculture. Volume 1 covers the period 1800-1960 and volume 2 the period 19611970 .

6. For a thorough discussion and treatment of the distinction between cost share rate and finance alternatives see the U.S. Water Resources Council's Section 80 (c) Study, Part 5A, options for options for cost sharing: Implementation and OM\&R Cost Sharing for Federal and Federally Assisted Water and Related Land Programs, 1975. 


\section{CHAPTER III}

\section{RESEARCH METHODOLOGY AND HYPOTHESIS DEVELOPMENT}

Implementation analysis may be process oriented (focusing on the inter-institutional dynamics of getting a program "on the ground"), impact oriented (assessing program achievements which occur as result of mediated conflict during implementation), or some combination of analyses that attempts to portray the broader picture. This research effort is of the latter variety insofar as it seeks to evaluate and measure the implementation of legislation within the parameters of a structured model as well as explore the empirical impacts cost shared project development has on the final product. Because this research attempts to explore dimensions of both process and empirical impact a variety of methodological tools and procedures, both qualitative and quantitative, were selected for application.

As the process analysis and impact analysis proposed by this research require different methodological approaches, the study is divided into logical subdivisions which address the specific process or phenomena under examination and provide a discussion of the research methodology employed. For purposes of clarity, the discussion of hypothesis 
derivation, research protocol, and data analysis shall

be handled independently for both the process and impact analysis.

HYPOTHESIS DEVELOPMENT: ANALYSIS OF IMPLEMENTATION VARIABLES

The literature on the application of methodology to implementation is, if possible, even less positive than that of the early implementation analysis literature. The criticism and qualifications appear legion. A sampling of the criticism in the literature, though by no means exhaustive, would include the following:

1. Application of a logical positivist paradigm has led to a narrow focus on goals achievement that may fail to account for intangible and long term policy effects (Rossi and Wright 1985) or lead researchers to confuse the consequence of implementation, the product (program outcomes), with the process (policy implementation) (Goggin 1986, 330).

2. Case studies, while they have been useful in constructing general explanations for policy implementation successes and failures have not been helpful in differentiating among type of implementation outcomes, the causal patterns associated with these outcomes, or the relative importance of the various independent variables (Lester 1987, 205).

3. Data gathered from the application of the various implementation models and analytical frameworks has not been integrated into a coherent systematic body of knowledge that would support theory development research (Palumbo 1987, 91).

4. The increasing complexity of the analytical frameworks employed has led to a loss of parsimony and intractable methodological problems as identified variable multiply in number and complexity (Ingram 1987). 
The foundation of the problem rests with the lack of agreement as to what factors generally contribute to the success or failure of implementation. As there is no general agreement on a predictive theory of implementation, particularly one that has application across program type, there is also no agreement on what variables are most important to consider (O'Toole and Montjoy 1984). This condition is further complicated by the case study method of analysis which suffers from a condition where the number of variables outstrips by orders of magnitude the number of cases. The complexity of the analysis, in addition to being methodologically intractable, makes it difficult to reduce the number of variables to the few that are "critical" or understand the relative importance and independent effects of each independent variable (Goggin 1987, 21).

This subdivision deals specifically with a discussion of a process oriented research design which seeks to address limited concerns of the literature involving the viability of developing and ranking selected implementation variables and the impact the perspective of the rater imposes on that ranking.

\section{Selection of Model}

As discussed in Chapter II, there exists a number of models that have been employed to explain the policy implementation process. Though there exists some scholarly 
disagreement on the number of generational sub-groupings the models may be divided into (O'Toole 1986, Lester et. al. 1987, Goggin et. al. 1990) it is generally conceded that there has been a progressive evolution of research both in terms of the overall complexity of the models advanced, the cumulative nature of the design, and its ability to integrate prior research.

For the purpose of this research, it was necessary to first identity those models which addressed the broader theoretical concerns of implementation rather than those which focused more narrowly on the descriptive framework of the process. This decision was not made to discount the richness and utility of the early case study research as a good deal of the insight and knowledge resulting from that. research is herein referenced. The case study approach is, however, inherently limited in that its findings do not easily lend themselves to generalization nor does that promote the systematic identification of theoretically critical variables. As this research focused on an appreciation of the nature and role of implementation variables in the policy implementation process, it was necessary to first eliminate models that did not offer a general theoretical framework and a developed position on implementation variables.

Following a survey of existing models in the literature, two were determined to meet the necessary 
evaluation criteria. Selected for comparison were Mazmanian and Sabatier's multivariate implementation model (1983) and Edwards critical factors model (1980). Each addressed theoretical concerns, was mindful of the need for parsimony in the variable identification process, focused on the explanatory capacity of their approach, and offered a set of conditions or variables which served as a basis for the evaluation of observed relationships in the implementation process.

Mazmanian and Sabatier's multivariate implementation model was selected as the preferred model for this research primarily due to it's adaptability to intergovernmental policy evaluation, the thoroughness of the model's formal structure, and because it provided the most comprehensive list of "factors" (Lester 1987, 203) associated with the implementation process. While Edward's model offered an excellent and insightful analytical framework it was rejected due to: 1) the breadth of its four "preconditions" to successful implementation made them difficult to operationalize for measurement; and 2) the model offered a less than fully realized systems diagram that might be used to explain the interaction of the preconditions with respect to other activities occurring in the implementation process. As previously discussed in the literature review, the model set forth by Mazmanian and sabatier (1983) provides 
perhaps the most thorough identification of independent variables whose presence or absence influence the implementation process and determine the ultimate effectiveness of programs associated with that process. In this instance, the choice of the model was made both because of its comprehensiveness and, when compared with competing models, its ability to lend itself to measurement of the dimensions under examination in this research. Most importantly, the model specified an intergovernmental implementation hierarchy that accurately reflected the actual implementation environment of the WRDA 1986.

The model necessarily makes certain assumptions about how implementation effectiveness should be measured. These assumptions have been challenged by competing researchers. It is thus helpful here to briefly discuss their usefulness in light of this research. Mazmanian and sabatier argue for evaluation that focuses on the attainment of the legal objectives of legislation, the intended outcomes and objectives of conscious policy choices made by the legislative branch of government. Where there exist clear and precise legal objectives there exist also evaluative criteria against which program outputs can be measured. A clear advantage of such an approach rests with the ability to specify, and perhaps quantify, legislative goals against which performance can be measured.

Given the range of opinion on implementing cost sharing 
as an integral component of water resource development, it was considered particularly crucial that the selected model be able to account for measurable differences in assessment of the implementation process in general and critical factors in particular. Mazmanian and Sabatier's model, mindful of the need to recognize the iterative nature of policy reformulation and the contributions sub-system personnel make to policy adjustment, acknowledges the significance of the role of perspective in the implementation process.

Three perspectives are identified in the model: the center, the nucleus of policy formulation, the periphery, field level officials in charge of program implementation, and the target, or group at whom the policy is directed. Mazmanian and sabatier note that each population is likely to perceive policy implementation and evaluate its success differently, though each would ostensibly share a common desire to see the intended legal objectives of the policy accomplished.

In certain cases outright conflict may exist between two or more of the group perspectives regarding the appropriateness of objectives. This is most likely to be the case when the target group is in basic disagreement with the selected policy or where the method, manner, or resourcing of implementation is contested by administrative 
personnel. (In bottom-up models, value judgments on these inevitable differences make measurement of successful implementation very difficult as the goal is constantly compromised by the ongoing analysis of the merit of the intended policy.) open intergroup conflict will, of course, demonstrably add to the difficulty of successfully achieving intended objectives. In fact, there is an equally good chance that under those conditions there will be not be agreement on the character or magnitude of outcomes. Subsequent adjustments and policy reformulation exercises in such cases lend credence to the theory that policy implementation is a good deal more recursive than linear.

A more normative assumption would be one that assumes general group agreement on broad intended objectives with differentiated views of process effectiveness. Under such conditions, all three groups will generally concur on the correctness of an intended policy (at least with regard to intended outcomes) though there may be disagreement on the regulatory interpretation by administrative agencies, the criteria by which success of the policy will be measured (quantity of service delivered versus measurable remediation), or, as Mazmanian and Sabatier so correctly note, a failure to appreciate the incentive structure required to promote change in the target population. Consistent with the model's formulation, there existed, within the implementation process for the WRDA 1986, three 
hierarchical groups are identified as follows for purposes of this research: 1

Center - staff personnel from the Headquarters, Army Corps of Engineers (HQUSACE) or HQ level policy personnel.

Periphery - Corps of Engineers implementing personnel at the District or Division level.

Target - Local sponsors (non-Federal interests) of cost shared water resource development projects.

A word here about the determination of groups is appropriate. Typically, according to Mazmanian and Sabatier's model, the center is composed of legislative policy makers. However, for the purpose of this research it was determined that headquarters level agency personnel would better represent the center. This determination was based on the fact that Headquarters, US Army Corps of Engineers (HQUSACE) staff personnel had lengthy and close professional involvement with and knowledge of the legislative process related to the development of cost sharing legislation. In fact, most of the data used by legislative proponents of the WRDA 1986 was prepared or provided by the COE. Moreover, the Assistant Secretary of the Army for Civil Works (ASACW) and Corps HQUSACE were responsible for promulgation of initial regulations implementing the legislation consistent with the intent of the legislative language and history. Lastly, these individuals were far easier to identity (as significantly 
involved in research related issues), and were relatively more accessible than congressmen. As it was also the intent of this research to quantify and compare intra-agency perceptions it appeared reasonable to so identify the groups.

The identification of the Periphery was a relatively straightforward procedure consistent with the theoretical framework of the model. Field level implementing officials within the COE are typically District level project management personnel. With the advent of life cycle project management (LCPM) in 1989 the task of identification was made even easier as COE project managers at the District level were designated at project inception (typically referred to as the reconnaissance study phase) and remained functionally responsible for project status throughout construction. Thus, it was possible to identify an accountable individual who was directly responsible for interpreting and implementing cost sharing regulations to Target group personnel. (Previously, managers were assigned responsibility for managing a scheduled portion of project, e.g., the planning phase.)

similarly, the Target group was easily identified for research purposes as either executive representatives of the non-Federal interests (all of whom represent public sector sub-Federal units of government or development agencies) involved in negotiations of Local Cooperation Agreements 
(LCAs) for water resource development projects between 1986 and 1991 or personnel from associations representing the interests of the non-Federal interest community in water resource development legislation. Understandably, the true Target population would include the full range of interests and institutions associated with water resource development. The views of this larger population are explored in the several chapters devoted to developing the historical and theoretical backgrounds of cost sharing. However, in specifying both project recipient interests and "institutional" interests from development associations the Target population comprised a reasonably broad sample whose views were thought to be highly consistent with those of the total population.

For ease of analysis, the terms non-Federal interest, local interest and sponsor are used interchangeably in the following chapters. Where the non-Federal interest position is represented by a formal association or professional group the association/group is identified.

Mazmanian and Sabatier's implementation framework provides a flow diagram of variables involved in the implementation process and a logical sequencing of events which they refer to as dependent variable stages (see Table IX). Seventeen independent variables are combined into three broad categories, each of which will be discussed in detail 
below. Prior to examining the composition of the independent variables it is important to first grasp an appreciation of the composition of the broad categories.

Tractability of The Problem. The first major category is identified as Tractability of the Problem, and as the name implies, is composed of variables which attempt to measure the "difficulty" of the problem behavior or condition. The model notes that some problems are simply much more difficult to ameliorate. The four variables which comprise the category involve:

1. Technical difficulties associated with the solution;

2. The diversity of the behavior subject to treatment;

3. The size of the Target population as a percentage of the total population;

4. The extent of change required.

Mazmanian and Sabatier note that though each variable may be considered separately, they also be combined to provide a summary index of tractability (See Table IX).

The task of implementing cost sharing is admittedly quite different from that of eradicating poverty or providing shelter for the homeless, and it is different in some important, if obvious, ways. There is ample evidence that a significant number of authorized projects have successfully negotiated Local Cooperation Agreements and there is no evidence that the policy is being considered 
TABLE IX

MODEL FLOW DIAGRAM

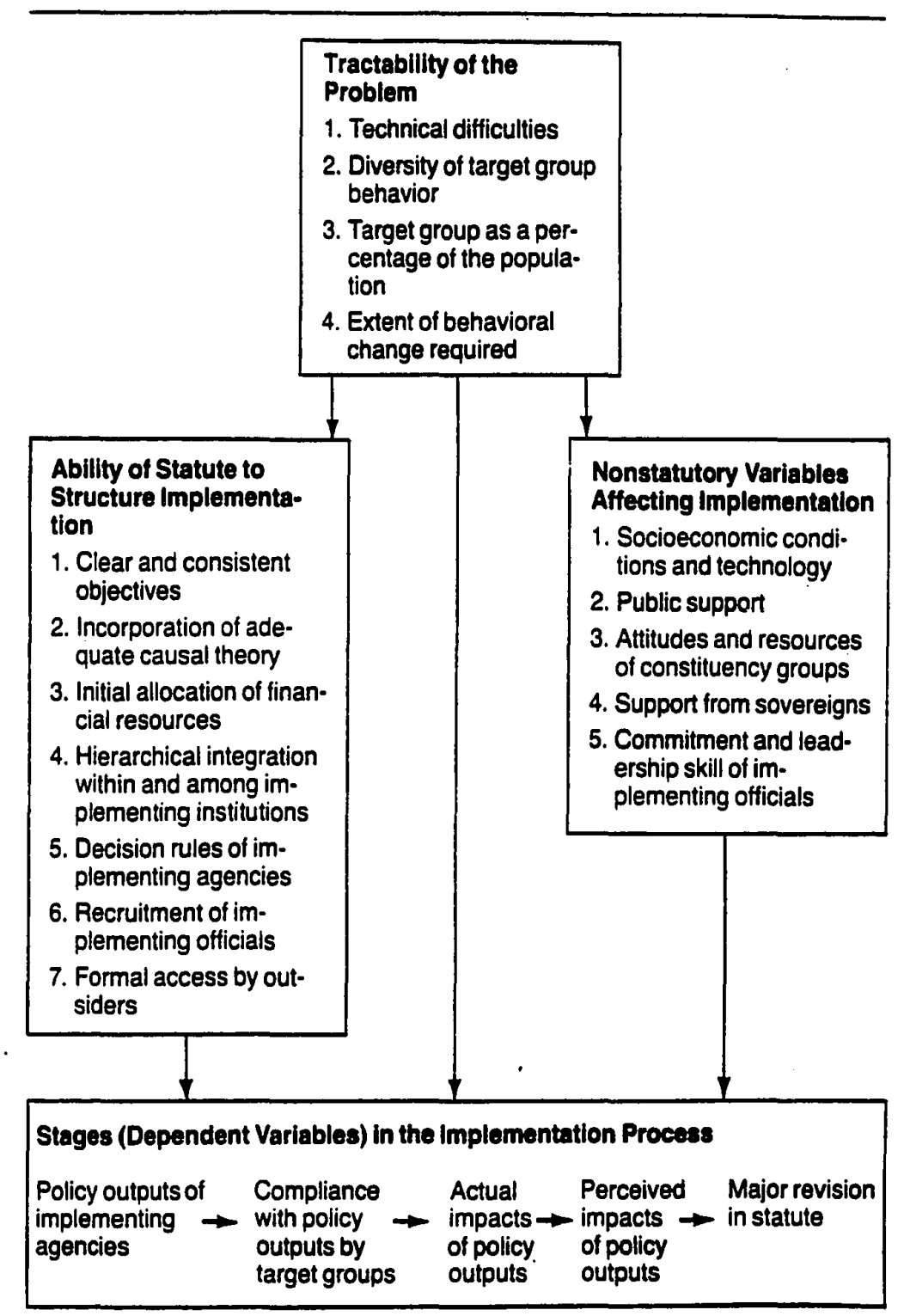

Source: Implementation and Public Policy. Daniel Mazmanian and Paul Sabatier (eds.). Scott, Foresman and co. 1983. 
for elimination. The cost sharing principles were reauthorized in the Water Resources Development Acts of 1988 and 1990. Indeed, in her testimony before the House Subcommittee on Public Works and Transportation ASACW Nancy Dorn noted that cost sharing remained a guiding principle of water resource development in times of fiscal austerity. "Cost sharing serves as a market test of a project's merits and insures active participation by project sponsors" (1992) •

Notwithstanding the previously discussed political difficulties associated with enactment of cost sharing legislation, the data of the past eight years indicates that successful implementation of the policy is a manageable if not always easy task. Thus, Tractability. of the Problem; and the associated sub-variables, are not included in the technique survey. This action is consistent with the caveats of the model wherein Mazmanian and Sabatier observe that attempting to measure tractability complicates the utility of estimating the potential for implementation effectiveness $(1983,42)$.

The sub-variables under Tractability are not theoretically trivial, however, and are not dismissed by this study. They will be addressed the discussions which follow on the theoretical foundations of cost sharing and referenced in Chapter $\mathrm{V}$ wherein the empirical impacts of cost-sharing on project development are evaluated. 
Ability of statute to structure Implementation. The seven independent variables which comprise the subcategory, Ability of Statute to structure Implementation, may be thought of as measures of the extent to which policy makers have attempted to structure a rational and coherent implementation strategy, a measure which Mazmanian and Sabatier assure us is a predictor of successful attainment of legal objectives $(1983,25)$. The variables within the sub-category include:

1. Precise and clear ranking of legal objectives. The precision with which objective can be unambiguously stated correlate positively with the likelihood that policy outputs will be the intent of the directive(s).

2. Validity of causal theory. Policy objectives and implementation plans, implicitly or explicitly, involve a theory which seeks to explain the linkage between the desired objectives and the implementation strategy; the reason for believing that a particular combination of actions, resources, etc. will result in a specific and predictable outcome. Inadequate causal theory, while seldom considered during "on the ground implementation" is frequently the underlying cause of failed implementation

3. Initial allocation of financial resources. Obviously, there is some positive correlation between the resourcing of an effort and the potential for desired outcomes. Inadequate funding may so impair a program's potential that failure by virtually any measure is inevitable and so suggests an initial lack of support or commitment from policy makers.

4. Hierarchical integration within and among implementing institutions. Hierarchical integration represents the extent to which groups within the implementation chain are integrated or committed to compliance with the program. 
Mazmanian and sabatier and note that such commitment may be measured by the willingness of individuals within the chain who represent veto/ clearance points to acquiesce to the larger goals and legal objectives of policy makers.

5. Decision rule of implementing agencies. Similar to the provision for precise and clear objectives, legislation can stipulate the parameters for decision rules promulgated by the implementing agency; thus further ensuring compliance with broad objectives and reducing the potential for interpretive deviancy by agency personnel.

6. Recruitment of implementing official's. The strong commitment of implementing agency officials to support the attainment of legal objects is imperative; conversely, a weak or restrained commitment by those officials may serve to defeat attainment or permit the substantial modification of implementation strategy from that intended. To the extent that it is practicable, policy makers through implementation legislation may choose or influence the choice of implementing officials that share a similar commitment to the objectives of the legislation:

7. Formal access by outsiders. Statutes which provide for formal access in the implementation process by affected outsiders (often Target group members) or other advocates of the intended legal objectives are more likely to have their

objectives met. This observation confirms the potential of institutionalized public support.

Nonstatutory variables. Subvariables under the third category, Nonstatutory Variables Affecting Implementation, acknowledge the impact politics and social change have on the implementation process. Mazmanian and sabatier note that while a carefully crafted statute may assist the attainment of legal objectives, a number of non-legal forces will serve to support or undermine the viability of programs to effect change. Among these forces which may be 
operationalized as variables are:

1. Socioeconomic conditions and technology. successful implementation may be adversely or favorably affected by economic swings and/or socioeconomic adjustments that markedly change the magnitude of the problem under treatment or result in shifting political preferences among Target groups. Technological advances may so radically modify the composition of the solution set that the problem being treated requires redefinition.

2. Public support. The ability of a policy issue and its associated program solution to maintain public support (funding) over time may have a significant effect on the success of implementation, particularly in those instances where long range solutions call for a constant application of resources.

3. Attitudes and resources of constituency groups. Changes in the potency of constituency groups, whether opposed or in favor of program objectives, will influence their ability to intervene and influence the implementation process.

4. Support from sovereigns. Mazmanian and Sabatier define sovereigns as the institutions which control the legal and financial resources of an implementing agency. These typically include legislative bodies, the executive branch, the courts. etc. When conflict exists between sovereigns with respect to legal objectives the implementing agency may align itself with the sovereign that will likely provide the greatest level of long term support.

5. Commitment and leadership skills of implementing officials. The model suggests that the variable which most directly affects the attainment of objectives is the commitment of implementing officials to the objectives and the skill with which they are able to marshal resources, including consistent internal support, to achieve those objectives. 
THE CONDITIONS OF EFFECTIVE IMPLEMENTATION

Having delineated a detailed subset of variables Mazmanian and sabatier admit that the list is somewhat "imposing" for a practitioner attempting to perform an implementation analysis $(1983,41)$. The same observation may be made with regards to methodological interpretation. Pretests were conducted which asked a limited sample population to rank order the full range of sub-variables. The findings indicated a general criticism that the coding scheme was ineffective due to both the large number of variables and the fact that, in the minds of the evaluators, a number of variables were so similar as to be indistinguishable for purposes of measurement.

Recognizing that parsimony is imperative in generating "on the ground estimates," the model performs what amounts to a factor analysis of the established sub-variables and defines a set of six sufficient conditions of effective implementation. The model goes on to assert that these conditions, if met to a high degree, virtually assure the accomplishment of implementation goals. The conditions, which are readily recognizable as a recombination of the sub-variables from the aforementioned subcategories are as follows:

1. The enabling legislation or other legal directive mandates policy objectives which are clear and consistent or at least provides substantive criteria for resolving goal conflicts. 
2. The enabling legislation incorporates a sound theory identifying the principal factors and causal linkages affecting policy objectives and gives implementing official sufficient jurisdiction over Target groups and other points of leverage to attain, at least potentially, the desired goals.

3. The enabling legislation structures the implementation process so as to maximize the probability that implementing officials and Target groups will perform as desired. This involves assignment to sympathetic agencies with adequate hierarchical integration, supportive decision rules, sufficient financial resources, and adequate access to supporters.

4. The leaders of the implementing agency possess substantial managerial and political skill and are committed to statutory goals.

5. The program is actively supported by organized constituency groups and by a few key legislators (or a chief executive) throughout the implementation process, with the courts being neutral or supportive.

6. The relative priority of statutory objectives . is not undermined over time by the emergence of conflicting public policies or by changes in relevant socioeconomic conditions which weaken the statute's causal theory or political support.

Mazmanian and Sabatier observe that while the first two conditions must always be met at least moderately well to achieve effective implementation, achievement of the latter four may be relaxed depending on the degree of change required. They do not, however, suggest any order of criticality beyond that.

As previously mentioned, a first question of this research considered whether to conduct a survey on the basis of the full set of independent variables or restrict the 
survey to the sufficiency conditions outlined in the model. A pretest utilizing a survey which called for a relational rating of all variables within the statutory and nonstatutory sub-categories was administered to a sample of management personnel from the Corps of Engineers, all of whom were familiar with the cost sharing program. The results were unpromising with many of the respondents reporting that the survey was unworkably complex and several noting that significant overlap between variables made it difficult to rate individual variables independently. Moreover, it was felt that project managers of the nonFederal interests would have even greater difficulty responding to the survey as they were less likely to have specific information on variables which dealt with intraagency organizational structure, the relationship between the $C O E$ and constituent institutions, etc. As the research was designed to compare ratings of variable criticality across groups and perspectives, this shortcoming represented a major impediment. Therefore, it was determined that the gain in specificity associated with surveying across the full set of independent variables was more than offset by the potential for confused, inaccurate, or incomplete responses.

For the reasons stated above, the decision was made to substitute Mazmanian and Sabatier's sufficient conditions 
for the full set of independent variables in conducting the analysis. This determination was made because: 1) the survey of combined variables was far simpler to complete and interpret and, thus, more likely to render accurate responses; 2) Mazmanian and Sabatier's work in interpreting program implementation utilizing the measurement of sufficiency conditions offers evidence that such analysis is both methodologically feasible and capable of providing information on implementation that is of sufficient quality to be useful in theory development.

It is assumed, then, for the purpose of this research that the sufficient conditions delineated by the model include the "true" set of significant factors. Moreover, the sufficient conditions will be hereafter referenced as implementation variables (VAR1 through VAR6) defined by the model unless specifically otherwise identified.

\section{Hypotheses}

Having established the choice of an implementation model and set forth its salient characteristics, the research then focused on specifying that set of critical issues raised by the literature which would serve as the basis for formulation of testable hypotheses. Acknowledging the criticisms in the literature with respect to the lack of data on variable significance and the need for such theory building information, the 
research focused on two aspects established by the model: 1) the perceived significance of variables established by the model; 2) the effect of position in the implementation hierarchy on rating the significance of the defined variables.

With regard to the first area, data on rankordering the variables were collected and statistically evaluated to establish an overall ranking of significance. The model does not suggest a theoretically normative ranking against which statistical tests could be applied, but does note that the first two variables must always be met moderately well whereas successful implementation may be achieved when fairly low ratings are recorded for variables 3 through 6 .

While Mazmanian and sabatier attempted to test for the extent to which a particular variable was "met" within a specific implementation environment they did not go on to test whether the assumptions of the model regarding variable criticality were shared by the participants of the process. Their findings rest on empirical observations which suggest that the legal objectives of a policy will most likely be met when all six variables are met, and that failure is most likely to occur when variables 1 and 2 are not met.

This assertion implies that individuals involved in a policy implementation exercise would, consistent with the theory, rank variables 1 and 2 higher on a significance 
scale than variables 3 through 6 . To address that

assumption the following null hypothesis was tested.

Hypothesis (1): The clarity of enabling

legislation and the soundness of its supporting

theory are not considered significantly more

important than other variables in the

implementation process by individuals involved in

the implementing of public policy.

Mazmanian and Sabatier and Sabatier note that the three perspectives identified by the model may view the implementation of any program quite differently. Likewise, it is reasonable to ask whether those differences would be reflected in rating the significance of the models implementation variables. The very existence of the "bottom up" school of implementation suggests that significant and meaningful differences on "what's important" may extend beyond simple disagreement with what and how a service is being delivered, and that the gap between Periphery and Target groups may be less than that between the Periphery and the Center (Lipsky 1980). It follows that it is then theoretically important to assess whether these observed differences extend to evaluations of what constitutes the necessary conditions of successful implementation.

To address these issues, the following two null hypotheses were tested to determine the effects of intergovernmental and intragovernmental perspective on the implementation process and the ordering of implementation 
variables.

Hypothesis (2): The hierarchical position of an implementing activity within a federalist framework has no significant effect on the determination of variable criticality.

Hypothesis (3): Within-agency orderings of variable criticality are consistent across the span of the organization.

\section{GENERAL DESIGN CONSIDERATIONS}

\section{Selection of Sample}

As previously discussed, the recombinant variables from the model were chosen to facilitate operationalization and measurement. It should be noted however, that the top-down emphasis of the model suggests an intergovernmental dichotomy that may prove misleading. For example, whereas the model is sensitive to the role of third parties in the implementation process and the difficulties associated with obtaining coordinated action among semi-autonomous agencies, it is less mindful of the potential for intra-agency conflict. The potential for such conflict is particularly great where the chain of command within the implementing agency is hierarchically and geographically extended.

In an effort to account for and attempt to measure the magnitude of this phenomenon, the survey was designed to sample opinion across the hierarchy of the implementing agency. In the case of this research, the District, Division, and Headquarter comprise the three levels of the 
COE organization. This approach permitted the data to be compiled on cohort samples at discrete levels of the organization and capture data that was acceptable for the analysis of intergroup comparisons.

The broad populations from which samples were taken were defined previously in this Chapter in the section on Model Selection. The sample survey groups were selected non-randomly on the basis of expertness. For the purposes of this research, expertness is linked to experience and is broadly defined as having had substantial participation in the implementation of cost sharing policy at some level of the implementation hierarchy. No restrictions were placed on the type of experience the individual had as it was understood that individual roles might vary greatly depending on which group they were associated with. Implicit in the selection is the notion that the opinions of the individuals selected are highly valued as a result of their being considered expert opinion. The utility of expert opinion is not generally agreed on by scholars and practitioners. Turoff argues that expertness is a secondary concern as there are no experts, only advocates and referees who contribute a quantifiable or analytical estimation about the issue $(1970,151)$. Sackman criticizes the use of experts for effectively neglecting the standard of documentation of the professional experience and qualifications of experts selected. Additionally, he 
asserts that choosing anonymous expert panels in unspecified ways increases the likelihood of an elitist sample (1976, 19-42.) A similar criticism is voiced by Quade $(1975,193)$ who notes that such sampling bias in the selection of experts along standard academic lines will likely be toward conservatism as the expert sample will tend to represent currently acceptable views.

A related and common selection problem in identifying experts is that the employment of "notoriety" criterion is often arbitrary and may lead to the selection of people who have little substantive knowledge of the area under research but who act as figureheads (Benarie 1988, 150). This caveat had particular import for this research as interviews revealed that organizational rank and direct experience with the implementation process were not always positively correlated.

Pill, on the other hand, argues that experts could really be defined as anyone who can contribute relevant inputs $(1971,52)$. Turoff implies that experts, particularly when compelled to evaluate policy issues, become promoters of efficiency and rational action and thus act in contradistinction to and compete with policy advocates $(1975,84)$.

Finally, in an argument that virtually renders the issue of sampling error moot, Sackman points out that a 
significant number of technological forecasting studies employing expert as well as non-expert samples have found no statistically significant demonstrable difference between groups in their ability to predict $(1976,42)$.

For the purpose of this study it was determined that expertness, when defined experientially, was a critical attribute in the rendering of opinion on the implementation process. Thus, the relevant criteria for participation in the survey were established as:

(1) Direct and substantial experience with the development of cost sharing policy or implementing regulations.

(2) A substantial understanding of the complexities of the implementation process of WRDA 1986 based on research or supervision of directed research of that topic.

(3) Direct and substantial experience in the negotiation of an LCA or management of that process.

Though all members of the sample were required to meet at least one of the standards it was not considered necessary for any member of the sample to meet more than one. Members of the target population, for example, would likely not have had experience in criteria (1) or (2) though they may have had direct input in providing testimony through industry channels on the original legislation. Likewise, members of the center may have little direct experience with criteria (3). Nevertheless, all candidates were selected on the basis of their having had direct, 
significant experience in some phase of the implementation process of the WRDA 1986 and held positions within the implementation hierarchy that were clearly identifiable with respect to the Center, Periphery, and Target populations.

\section{Survey and Instrument}

The survey instrument (see Appendix A) was administered to all participants selected for the sample. Respondents were asked for basic demographic data related to age, sex, level of education, occupation, years with current organization, etc. Respondents were then asked to rank the survey variables in order of importance employing the split-100 (s-100) technique. Points were to be assigned to variables in accordance with the respondent's opinion of the significance of the variable. Apart from the fact that the respondent was advised to distribute all 100 points no further restrictions on the distribution of points were offered.

Given the positive data on the correlation between group confidence and accuracy of the group estimate (Dalkey $1972,46)$ respondents were asked to self-rate their confidence in the accuracy of their responses. An ordinal level adjective scale from 1 to 5 was employed to derive group self confidence estimates for each variable response.

1. Very confident of accuracy of response.

2. Confident of accuracy of response.

3. Somewhat confident of accuracy of response.

4. Unsure of accuracy of response.

5. Just guessing 
Though confidence estimates were noted for purposes of discussion, the individual responses were not weighted on the basis of self reported certainty of response accuracy.

DATA ANALYSIS AND HYPOTHESIS TESTING

As a first step in the analysis, a ranking based on the sample mean for each variable was derived. This ranking included data from the entire sample population. The data, which represents a best estimate of the perceived criticality of the subject variables, was then evaluated in terms of how such information might be used to extend the predictive utility of the model and as a basis for a discussion of the potential use of the data in practical applications.

It is recognized that scaled responses to questions of value do not always constitute interval level data, a condition that greatly restricts the range of statistical applications if rigidly observed. What is not clear is the relative seriousness of the distortion produced by assuming interval scales (Blalock 1964, 34). Thus, interval level methods, where employed in the research to derive and compare group scores, are undertaken with full awareness that the resultant inferential assumptions are subject to challenge.

To test the null hypotheses it was necessary to first evaluate the data for within group and between group 
differentials on variable ranking. It was thus important to select a technique capable of evaluating the relationship between high or low scores registered on any one variable and the category (or group) of the respondent. Put differently, the necessary test was whether absolute differences recorded between group scores were greater than what might have been recorded had the groups been randomly selected. This approach was adopted as it allowed for inference as to the impact group association had on evaluating what is critical to successful implementation. Additionally, the approach allowed for a test of whether the model explained criticality equally well across hierarchical populations.

The statistical technique selected to perform this analysis was a oneway analysis of variance (ANOVA). ANOVA is related to a set of statistical techniques generally referred to as linear regression analysis. As ANOVA is a linear model technique, it assumes a linear relationship between a variable to be predicted and a potential determinant. It is generally a preferred technique when the independent variable is measurable only on a nominal scale and the dependent variable measurable on an interval level. (Iverson 1976, 5-8). More importantly, the technique permits the comparison of a variation of means (on a dependent interval level variable) within a group with the 
measured variation between groups. Thus, in the case of this research, the technique was employed to determine if mean ranking scores on the individual variables varied more between the identified groups than within groups; and if so, to what extent.

The analysis proceeded along the lines set forth in the formal ANOVA model for use with a single independent variable. A more formal and detailed of description of the selected technique will be set forth in Chapter IV, Data Analysis. With respect to the stated hypotheses:

Hypothesis (1) will be examined by comparing the aggregated and disaggregated rank ordered means of the variables.

Hypothesis (2) will be examined by testing for the significance of the difference in means with $F$ values and significance levels between the three groups.

Hypothesis (3) will be examined by testing for the significance of the difference in means with $F$ values and significance between the two COE samples (Center and Periphery samples.)

Use of Multiple Data Sources

A significant issue addressed in the research was the impact project specific inter-group conflict would have on the rating schema. It is reasonable to assume that, for any one grouping defined by the model, the quality of the costsharing experience with regard to administrative cooperation, receptivity of other hierarchical groups to input, etc. would influence their perception of the 
implementation process. For example, a target group which experienced a particularly rancorous LCA negotiation with Corps officials may have been inclined to rank the significance of (and need for) implementing agency managerial skill higher in relation to other variables than it might have had the negotiations proceeded more smoothly. In such an instance, the issue is whether the respondent is providing data on the implementation process generally or ascribing attributes to a unique experience associated with that process.

To some extent, the concern is not significant as a degree of random conflict will be present in all implementation efforts and the need to reduce or constructively address such conflict is well understood. A sufficiently large sample will likely reflect examples of individual conflict but will mediate the extremes. Moreover, it would be methodologically awkward to attempt to separate "expert" opinion from "emotional" opinion; or to suggest the theoretical implications of such a division. The model accounts for the significance of the incentive structure of groups, particularly Target groups, when it asserts the criticality of the linkage between incentive to change and the desired behavioral change. It is asserted that clarity of purpose will not be enough to ensure successful implementation if substantial behavioral change is required of the Target population. 
Nevertheless, it became apparent that for the purpose of this research, analysis of the raw data gathered on implementation required an understanding of the "background noise" in the implementation environment and an appreciation of the fundamental geography of the "partnership" proposed by cost sharing. This observation is generally reinforced by Yin's observation (1982) that structured interviews and survey formats tend not to provide the quality of data necessary to fully appreciate the dynamics of the implementation process. Yin's assessment of the methodological strengths of exemplary implementation studies revealed that such studies exhibit a bias toward multiple sources of evidence $(1982,51)$. Multiple sources were generally employed to address concerns roughly analogous to internal and external validity. Emphasis here is placed on the explanatory power of the unstructured response which offers insight into complexities of the process under examination that are not easily quantified or captured by use of a constrained survey or interview format. Thus, to gain an appreciation of the status of that partnership and to establish a richer, more complete framework from within which to analyze the survey findings, a variety of data sources were either generated or consulted. Multiple sources were employed to confirm the reliability of trends or patterns evidenced by the survey 
data (external validity) in an effort to expand the generalizability of the findings. It should be noted that while the "type" of data from the sources is similar to that elicited by the survey instrument (App. A), no attempt was made to construct an experimental design. The data, though often presented in a statistical format, was sought to provide supplemental longitudinal, descriptive information on the process and the findings of the research.

A first effort at soliciting secondary data sources involved focused interviews conducted by this researcher during the summer of 1987 with thirty-one (31) corps project managers (from Districts and Divisions) and twenty (20) local sponsor representatives. Because the sample represented personnel from projects that had been authorized under traditional cost arrangements and reauthorized under cost sharing criteria, it was skewed slightly toward individuals associated with projects which had undergone changes or experienced difficulties associated with implementing the requirements of cost-sharing.

It is recognized that, as a measurement device, the open-ended interview format is faulty owing to the noncomparibilty of one interview with another (Kidder 1981, 198). The intent of the interview process here, however, was not to derive data for statistical analysis of intergroup differences but to explore the range of opinion and attitude on the implementation of cost sharing policy. 
Moreover, the purpose of the interview process was not to derive quantitative data on direct questions but information on the nuances and complexities of the implementation process and the underlying sentiments of the respondents. The structured interview is considered an excellent tool for that type of inquiry (Kidder 1981, 153).

During the course of this research additional data sets on related research were made available. In December of 1989, a joint workshop sponsored by the National Association of Flood and Stormwater Management Agencies (NAFSMA) and the COE was convened to explore the evolving relationship between the $\operatorname{COE}$ and non-Federal interests in the development of cost shared projects. Of particular interest was an evaluation of the partnering model of project development. The goal of the workshop was the development of " ... a common understanding of the changes envisioned in the 1986 and 1988 (WRDA 1986 and WRDA 1988) laws" (NAFSMA 1990, 7). The product of that meeting was a report that presented a detailed analysis, including survey data, of the implementation process from the perspective of the COE participants and the non-Federal interests. The survey results are set forth in Appendix B.

A second data set which was made available during the course of the research was the report from the General Accounting office (GAO), Water Resources: Local 
Sponsor's Views on Corps' Implementation of cost

Sharing (U. S. General Accounting office, 1991). The GAO survey identified 605 projects that were subject to cost sharing provisions of the law and subsequently met screening criteria established by the GAO. The screening criteria generally dealt with issues of project viability and so eliminated projects from the sample that would clearly not qualify for authorized future construction. Questionnaires were sent to 448 local sponsors of the 605 projects included in the sample. Following analysis of the returned surveys, the universe of projects was further reduced to 563 represented by 448 local sponsors. While the GAO noted that random selection was not employed, the survey sample population was sufficiently large to make a strong case for the utility of the data as a validity check (U.S. GAO 1991, 5-7) .

The supplemental data sets were used primarily to "flesh out" and lend credence to the findings of this research. They provided both additional information directly related to the topics under examination and supported efforts to more fully develop a dimension of the larger issue at hand, an appreciation of the complex network of influences which shape water resource development policy implementation. The data contained in these supplemental studies is discussed in depth in Chapter IV, Data Analysis. 
The Impact of cost Sharing on Projects

The analysis of empirical project impacts, which receives narrative and analytical treatment in Chapter $V$, was conducted with reference to a set of assumptions established in the formal literature on cost sharing set forth in chapter II and in the section which discussed the legislative history of the WRDA 1986. This section of the analysis focused on assessing impacts in three areas where it was asserted by the literature and cost share advocates that change was likely to occur as a result of the implementation of cost shared project development and where empirical data was available to compare outputs of the implementation process with anticipated outcomes. The areas evaluated in this portion of the research involve the impact of cost sharing on the magnitude of the project (project size), the construction schedules of large civil works projects, and the environmental component of project planning.

While a variety of questions are raised in the literature, both political and economic, the assumptions cited on the next page emerged as the likely outcomes of cost-sharing legislation by opponents and advocates alike. Moreover, they were selected for directed study by the ASACW in 1987 to provide data on the effects of cost shared legislation. It is not intended to be an exhaustive list of impacts but one that indicates how the implementation of 
cost shared water resource development might materially and measurably alter the end product. These assumptions were selected for analysis because they are recognized to be substantively important in both a theoretical and applied sense. If true, they will potentially shape the future of federally assisted water resource development in rather profound ways. They are as follows:

Assumption (1): Cost shared project development will lead to the formulation and authorization of smaller water resource development projects.

Assumption (2): Cost shared project development will lead to the formulation and authorization of projects that involve phased or staged construction schedules.

Assumption (3): Cost shared project development will lead to a reduction in environmental impacts associated with Federal water resource development projects.

\section{Selection of Sample}

The basis of the analysis for each assumption involved a comparison between non cost shared projects and projects developed under cost-sharing. Thus, to perform the analysis it was necessary to identify to data from two distinct project samples. Data on the samples could then be compared to determine if significant differences existed in areas related to project scope, construction schedules, project mitigation levels, etc. clearly, this method posed some thorny methodological problems. Chief among these was equating and evaluating the observed differences in pre and 
post-WRDA 1986 projects.

It is generally recognized that projects planned under cost sharing constraints may exhibit significant differences from those planned under previous funding guidelines, but it is not possible to infer that all the differences are attributable to cost sharing. Moreover, in this research the treatment, the imposition of cost shared planning, is imposed on legislative and agency implementation processes, not a strictly defined sample population. Thus, a seemingly straightforward approach such as comparing a pre-WRDA 1986 sample population of projects and one selected post-WRDA 1986 in fact may offer comparisons that are substantively different in ways which would influence the analysis but were not related to the imposition of cost shared planning. A solution to this challenge presented itself in the form of a unique project sample that provided an attractive alternative. Projects authorized by the WRDA 1986 including projects originally authorized in the 1985 supplemental legislation (P.I. 88) were initially developed under preWRDA 1986 planning parameters. Thus, reconnaissance estimates, feasibility studies, and general design memoranda were initially developed without cost sharing constraints. Subsequent to passage of P.L. 88 and the WRDA 1986, the projects were reformulated to accommodate cost-sharing requirements. Ostensibly, the resulting project 
modifications in size, schedule, mitigation plans, etc. were then attributable to the imposition of a single significant reformulation constraint, cost sharing.

As the sample was discrete, the basis for project modification in the areas under study was attainable either by evaluating data on reformulation submittals or phone interview with project managers. Thus, it was determined that a single sample was capable of providing both pre and post cost shared planning data. Furthermore, it was determined that the accuracy of the data on the impact of cost sharing for this single sample would likely be better than that achieved from merely selecting a random sample of projects from the pre and post-WRDA 1986 eras.

This approach assumed that the initial sample of projects defined by Public Law 88 and the WRDA 1986 were essentially similar to projects planned and authorized prior to the implementation of cost-sharing legislation. Initially, it was thought that such a cross sample comparison could be verified by identifying and evaluating salient project features such as constant dollar cost, weighted benefit-cost ratio, percentage of LERRD to total project cost, etc. Analysis, however, revealed that, owing to the extreme variation of project design and type over time, and shifting regulatory requirements; such an analysis was both infeasible and unlikely to provide data of sufficient quality to either confirm or dismiss the 
assumption. This finding was validated in conversations with staff of the Board of Engineers of Rivers and Harbors (BERH). ${ }^{2}$ Thus, absent evidence to the contrary, the assumption was allowed to stand.

The selected sample consisted of that set of projects authorized (or reauthorized) by the WRDA 1986 which required negotiation of an LCA. Unlike the goals associated with sweeping social programs (eliminate poverty in the inner city, reduce unemployment, etc.), the empirical goal of cost sharing would appear to be quite straightforward. Projects are either successfully accomplished under a cost sharing format or they are abandoned. Execution of an LCA represents successful implementation of the program insofar as the sub-objectives of cost sharing are thus met and reflected in the terms of the LCA.

This analysis, of course, to some extent oversimplifies the process as it does not account for differences (physical and schedule related) between the contemplated project as originally designed and the constructed project. This research attempts to define the substantive changes to projects attributable to cost shared planning and to compare those findings with the development patterns anticipated by the literature.

Sixteen flood control projects were identified as having incorporated sponsor initiated changes into the final 
project design. Nine (56\%) of those projects so identified reported modifications to the authorized project design involving a reduction or deletion of design elements, reduced recreation or staging of construction. As previously mentioned, such changes are considered design changes for both flood control and navigation projects when the unconstructed separable element(s) will require the negotiation of an independent LCA.

It should be noted that some projects represented in the selected sample were downsized on the initiative of Federal interests prior to the initiation of cost shared development. This may have been in response to local dissatisfaction with proposed features of the project that did not enjoy public support, even when non-Federal financial obligations would have been quite minimal. Thus, limiting the scope of the analysis to only those project features that were revised during negotiation of the LCA may reflect a conservative bias in the estimation of negotiated changes and understate the responsiveness of the Federal interest to accommodate local concerns.

Furthermore, it is crucial to note the potential for project size and scope reduction where a new LCA must be negotiated prior to the initiation and construction of subsequent project phases. Absent an executed LCA there is no guarantee that separable project elements, though Congressionally authorized, will ever be constructed. For 
that reason, staged projects for the purpose of this research, are considered de facto short range size reductions when deriving estimates of the impact of the legislation on project design. This approach, which was selected after a series of interviews with non-Federal interest project/program managers errs on the conservative side and may tend to overstate the impact of cost sharing. As the data collected for this portion of the research was independent of the data on the implementation process analysis it was deemed necessary to also set forth the analysis separately to preclude confusion of technique or findings. Individual subsections of chapter $V$ complete with supplemental background information are reserved for an indepth discussion of the assumptions and an analysis of sample research data on collected on projects. 


\section{ENDNOTES}

1. To distinguish between physical groups identified in by research and theoretical concepts, the terms center, Periphery, and Target shall hereafter be capitalized when they refer to the cohort of individuals selected as samples for this research.

2. The BERH provides an executive level review of all civil works water resource development projects submitted by the Army Corps of Engineers for Congressional authorization. In 1989 it was reconstituted as the Washington Level Review Center and charged with expediting the project process. 


\section{CHAPTER IV}

\section{SURVEY DATA ANALYSIS}

This chapter examines the survey and supplemental data collected for the process analysis portion of this research. As previously established in the preceding Chapter, the data employed for this component of the research was limited to survey data collected on the WRDA 1986 implementation process, either by the researcher or an independent source. ${ }^{1}$ This first subdivision of the Chapter deals specifically with the statistical analysis of the data collected on the survey instrument (Appendix A) for purposes of testing the established hypotheses.

Data from the survey was coded for use with the Statistical Package for the Social Sciences (SPSS). A variety of statistical procedures were utilized to analyze the data. Explanations of the techniques and basic findings are set forth below. The raw data tabulations and derived computations from the survey are also incorporated in tabular format.

RESPONDENT ASSESSMENT OF VARIABLE IMPORTANCE

The first statistical analysis was a straightforward derivation of the mean score for each group on each 
variable. The findings are set out in Table $x$. Variables were then ranked for each group in accordance with the mean (Table XI). Because it was logistically difficult to develop a shorthand acronym for each variable, variables are simply described in the analysis as VAR1 through VAR6. The legend provided in Table $X$ below may be used as a referẹce.

TABLE X

MEAN DISTRIBUTION SCORES FOR IMPLEMENTATION VARIABLES

VAR1: The enabling legislation or other legal directive mandates policy objectives which are clear and consistent or at least provides substantive criteria for resolving goal conflicts.

$\begin{array}{lrrrr}\text { GROUP } & \text { COUNT } & \text { MEAN } & \begin{array}{r}\text { STANDARD } \\ \text { DEVIATION }\end{array} & \begin{array}{r}\text { STANDARD } \\ \text { ERROR }\end{array} \\ \text { TARGET } & 10 & 16.0000 & 11.8739 & 3.7548 \\ \text { PERIPHERY } & 16 & 15.6250 & 11.0868 & 2.7717 \\ \text { CENTER } & 11 & 20.9000 & 14.967 & 4.5135 \\ \text { TOTAL } & 37 & 17.3243 & 12.4232 & 2.0424\end{array}$

VAR2: The enabling legislation incorporates a sound theory identifying the principal factors and causal linkages affecting policy objectives and gives implementing official sufficient jurisdiction over target groups and other points of leverage to attain, at least potentially, the desired goals.

$\begin{array}{lrrrr}\text { GROUP } & \text { COUNT } & \text { MEAN } & \begin{array}{r}\text { STANDARD } \\ \text { DEVIATION }\end{array} & \begin{array}{r}\text { STANDARD } \\ \text { ERROR }\end{array} \\ \text { TARGET } & 10 & 17.8002 & 11.7644 & 3.7202 \\ \text { PERIPHERY } & 16 & 15.6250 & 17.7834 & 4.4459 \\ \text { CENTER } & 11 & 15.0000 & 12.0414 & 3.6307 \\ \text { TOTAL } & 37 & 16.0270 & 14.4193 & 2.3705\end{array}$


TABLE X

MEAN DISTRIBUTION SCORES FOR IMPLEMENTATION VARIABLES (continued)

VAR3: The enabling legislation structures the implementation process so as to maximize the probability that implementing officials and target groups will perform as desired. This involves assignment to sympathetic agencies with adequate hierarchical integration, supportive decision rules, sufficient financial resources, and adequate access to supporters.

$\begin{array}{lrrrr}\text { GROUP } & \text { COUNT } & \text { MEAN } & \begin{array}{r}\text { STANDARD } \\ \text { DEVIATION }\end{array} & \begin{array}{r}\text { STANDARD } \\ \text { ERROR }\end{array} \\ \text { TARGET } & 10 & 21.1111 & 8.9938 & 2.8441 \\ \text { PERIPHERY } & 16 & 20.6250 & 12.3659 & 3.0915 \\ \text { CENTER } & 11 & 13.6364 & 10.9752 & 3.3091 \\ \text { TOTAL } & 37 & 18.6436 & 11.3290 & 1.8625\end{array}$

VAR4: The leaders of the implementing agency possess substantial managerial and political skill and are committed to statutory goals.

$\begin{array}{lrrrr}\text { GROUP } & \text { COUNT } & \text { MEAN } & \begin{array}{r}\text { STANDARD } \\ \text { DEVIATION }\end{array} & \begin{array}{r}\text { STANDARD } \\ \text { ERROR }\end{array} \\ \text { TARGET } & 10 & 18.9000 & 10.4291 & 3.2980 \\ \text { PERIPHERY } & 16 & 25.0000 & 13.7840 & 3.4460 \\ \text { CENTER } & 11 & 15.7273 & 9.8396 & 2.9686 \\ \text { TOTAL } & 37 & 20.5946 & 12.2440 & 2.0191\end{array}$

VAR5: The program is actively supported by organized constituency groups and by a few key legislators (or a chief executive) throughout the implementation process, with the courts being neutral or supportive.

$\begin{array}{lrrrr}\text { GROUP } & \text { COUNT } & \text { MEAN } & \begin{array}{r}\text { STANDARD } \\ \text { DEVIATION }\end{array} & \begin{array}{r}\text { STANDARD } \\ \text { ERROR }\end{array} \\ \text { TARGET } & 10 & 16.0000 & 8.4327 & 2.6667 \\ \text { PERIPHERY } & 16 & 15.6250 & 9.8107 & 2.4527 \\ \text { CENTER } & 11 & 20.1727 & 15.5505 & 4.6887 \\ \text { TOTAL } & 37 & 17.1081 & 11.3786 & 1.8703\end{array}$


TABLE X

\section{MEAN DISTRIBUTION SCORES FOR IMPLEMENTATION VARIABLES}

(continued)

VAR6: The relative priority of statutory objectives is not undermined over time by the emergence of conflicting public policies or by changes in relevant socioeconomic conditions which weaken the statute's causal theory or political support.

$\begin{array}{lrrrr}\text { GROUP } & \text { COUNT } & \text { MEAN } & \begin{array}{r}\text { STANDARD } \\ \text { DEVIATION }\end{array} & \begin{array}{r}\text { STANDARD } \\ \text { ERROR }\end{array} \\ \text { TARGET } & 10 & 10.2000 & 5.8080 & 1.8367 \\ \text { PERIPHERY } & 16 & 7.5000 & 4.4721 & 1.1180 \\ \text { CENTER } & 11 & 14.0000 & 10.1622 & 3.3039 \\ \text { TOTAL } & 37 & 10.1622 & 7.5994 & 1.2493\end{array}$

TABLE XI

RELATIVE VARIABLE RANKINGS BASED ON MEAN BY GROUP

$\begin{array}{rllllll} & \text { VARI } & \text { VAR2 } & \text { VAR3 } & \text { VAR4 } & \text { VAR5 } & \text { VAR6 } \\ \text { TARGET } & 4 & 3 & 1 & 2 & 5 & 6 \\ \text { (Mean) } & 16.10 & 17.80 & 21.00 & 18.90 & 16.00 & 10.20 \\ \text { CENTER } & 1 & 4 & 6 & 3 & 2 & 5 \\ \quad \text { (Mean) } & 20.90 & 15.00 & 13.63 & 15.72 & 20.27 & 14.00 \\ \text { PERIPHERY } & 4 & 3 & 2 & 1 & 5 & 6 \\ \quad \text { (Mean) } & 15.62 & 15.62 & 20.62 & 25.00 & 15.62 & 7.50 \\ \begin{array}{c}\text { Composite } \\ \text { Total }\end{array} & 3 & 5 & 2 & 1 & 4 & 6 \\ \text { (Mean) } & 17.32 & 16.02 & 18.64 & 20.59 & 17.12 & 10.16\end{array}$

Table XII provides a frequency distribution of scores across the variables. 
TABLE XII

FREQUENCY DISTRIBUTION TABLE OF VARIABLE RANKINGS

\section{Variable 1}

Value Label
Value Frequency Percent Percent Percent

$\begin{array}{rrrrr}0 & 3 & 8.1 & 8.1 & 8.1 \\ 5 & 2 & 5.4 & 5.4 & 13.5 \\ 6 & 1 & 2.7 & 2.7 & 16.2 \\ 10 & 10 & 27.0 & 27.0 & 43.2 \\ 15 & 6 & 16.2 & 16.2 & 59.5 \\ 20 & 5 & 13.5 & 13.5 & 73.0 \\ 25 & 5 & 13.5 & 13.5 & 86.5 \\ 30 & 1 & 2.7 & 2.7 & 89.2 \\ 40 & 2 & 5.4 & 5.4 & 94.6 \\ 50 & 2 & 5.4 & 5.4 & 100.0 \\ & ---- & ----- & ----- & \end{array}$

$\begin{array}{lr}\text { Mean } & 17.324 \\ \text { Mode } & 10.000 \\ \text { Kurtosis } & 1.161 \\ \text { S E Skew } & .388 \\ \text { Maximum } & 50.000\end{array}$

Variable 2

Value Label

std err
Std dev
S E Kurt
Range
Sum

2.042

12.423

.759

50.000

641.000

$$
\begin{aligned}
& \text { Median } \\
& \text { Variance } \\
& \text { Skewness } \\
& \text { Minimum }
\end{aligned}
$$

15.000

154.336

\begin{tabular}{|c|c|c|c|c|}
\hline 0 & 6 & 16.2 & 16.2 & 16.2 \\
\hline 5 & 5 & 13.5 & 13.5 & 29.7 \\
\hline 10 & 8 & 21.6 & 21.6 & 51.4 \\
\hline 15 & 4 & 10.8 & 10.8 & 62.2 \\
\hline 20 & 3 & 8.1 & 8.1 & 70.3 \\
\hline 25 & 4 & 10.8 & 10.8 & 81.1 \\
\hline 30 & 2 & 5.4 & 5.4 & 86.5 \\
\hline 33 & 1 & 2.7 & 2.7 & 89.2 \\
\hline 35 & 3 & 8.1 & 8.1 & 97.3 \\
\hline 70 & 1 & 2.7 & 2.7 & 100.0 \\
\hline al & 37 & 100.0 & 100.0 & \\
\hline
\end{tabular}

1.113

.000

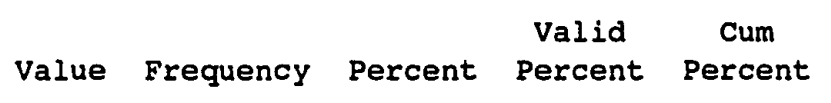

Std err

Std dev

s $\mathbf{E}$ Kurt Range

Sum
2.371

14.419

.759

70.000

593.000

$\begin{array}{lr}\text { Median } & 10.000 \\ \text { Variance } & 207.916 \\ \text { Skewness } & 1.547 \\ \text { Minimum } & .000\end{array}$


TABLE XII

FREQUENCY DISTRIBUTION TABLE OF VARIABLE RANKINGS (continued)

Variable 3

Value Label

Value Frequency Percent Percent Percent

\begin{tabular}{|c|c|c|c|c|c|c|}
\hline & & 0 & 3 & 8.1 & 8.1 & 8.1 \\
\hline & & 10 & 11 & 29.7 & 29.7 & 37.8 \\
\hline & & 15 & 4 & 10.8 & 10.8 & 48.6 \\
\hline & & 17 & 1 & 2.7 & 2.7 & 51.4 \\
\hline & & 18 & 1 & 2.7 & 2.7 & 54.1 \\
\hline & & 20 & 6 & 16.2 & 16.2 & 70.3 \\
\hline & & 25 & 2 & 5.4 & 5.4 & 75.7 \\
\hline & & 30 & 4 & 10.8 & 10.8 & 86.5 \\
\hline & & 35 & 1 & 2.7 & 2.7 & 89.2 \\
\hline & & 40 & 4 & 10.8 & 10.8 & 100.0 \\
\hline & & Total & 37 & 100.0 & 100.0 & \\
\hline Mean & 18.649 & Std err & 1.862 & Med: & & 17.000 \\
\hline Mode & 10.000 & Std dev & 11.329 & $\operatorname{Var}$ & ance & 128.345 \\
\hline Kurtosis & -.483 & S E Kurt & .759 & Skev & ness & .463 \\
\hline S E skew & .388 & Range & 40.000 & Min & mum & .000 \\
\hline Maximum & 40.000 & Sum & 690.000 & & & \\
\hline Variable 4 & & & & & & \\
\hline Value Label & & Value & Frequency & Percent & $\begin{array}{l}\text { Valid } \\
\text { Percent }\end{array}$ & $\begin{array}{c}\text { Cum } \\
\text { Percent }\end{array}$ \\
\hline & & 0 & 3 & 8.1 & 8.1 & 8.1 \\
\hline & & 5 & 2 & 5.4 & 5.4 & 13.5 \\
\hline & & 10 & 6 & 16.2 & 16.2 & 29.7 \\
\hline & & 15 & 3 & 8.1 & 8.1 & 37.8 \\
\hline & & 20 & 6 & 16.2 & 16.2 & 54.1 \\
\hline & & 24 & 1 & 2.7 & 2.7 & 56.8 \\
\hline & & 25 & 6. & 16.2 & 16.2 & 73.0 \\
\hline & & 30 & 5 & 13.5 & 13.5 & 86.5 \\
\hline & & 33 & 1 & 2.7 & 2.7 & 89.2 \\
\hline & & 35 & 2 & 5.4 & 5.4 & 94.6 \\
\hline & & 50 & 2 & 5.4 & 5.4 & 100.0 \\
\hline & & Total & 37 & 100.0 & 100.0 & \\
\hline Mean & 20.595 & Std err & 2.013 & Med: & & 20.000 \\
\hline Mode & 10.000 & Std dev & 12.244 & Var: & ance & 149.914 \\
\hline Kurtosis & .213 & $S E$ Kurt & .759 & Skev & ness & .352 \\
\hline S E Skew & .388 & Range & 50.000 & Min: & & .000 \\
\hline Maximum & 50.000 & Sum & 762.000 & & & \\
\hline
\end{tabular}


TABLE XII

\section{FREQUENCY DISTRIBUTION TABLE OF VARIABLE RANKINGS} (continued)

Variable 5

Value Label

\begin{tabular}{|c|c|c|c|c|}
\hline Value & Frequency & Percent & $\begin{array}{l}\text { Valid } \\
\text { Percent }\end{array}$ & $\begin{array}{c}\text { Cum } \\
\text { Percent }\end{array}$ \\
\hline 0 & 5 & 13.5 & 13.5 & 13.5 \\
\hline 5 & 2 & 5.4 & 5.4 & 18.9 \\
\hline 10 & 5 & 13.5 & 13.5 & 32.4 \\
\hline 15 & 7 & 18.9 & 18.9 & 51.4 \\
\hline 20 & 9 & 24.3 & 24.3 & 75.7 \\
\hline 25 & 3 & 8.1 & 8.1 & 83.8 \\
\hline 30 & 3 & 8.1 & 8.1 & 91.9 \\
\hline 33 & 1 & 2.7 & 2.7 & 94.6 \\
\hline 40 & 1 & 2.7 & 2.7 & 97.3 \\
\hline 50 & 1 & 2.7 & 2.7 & 100.0 \\
\hline & ----ー-- & -- - - - & $----n-$ & \\
\hline Total & - 37 & 100.0 & 100.0 & \\
\hline err & 1.870 & \multicolumn{2}{|c|}{ Median } & 15.000 \\
\hline dev & 11.377 & \multicolumn{2}{|c|}{ Variance } & 129.432 \\
\hline Kurt & .759 & \multicolumn{2}{|c|}{ Skewness } & .584 \\
\hline gee & 50.000 & \multirow{2}{*}{\multicolumn{2}{|c|}{ Minimum }} & .000 \\
\hline & 633.000 & & & \\
\hline
\end{tabular}

Variable 6

Value Label

\begin{abstract}
Std err
Std dev

S E Kurt

Sum
\end{abstract}

633.000

$$
\begin{array}{ccc}
\text { Valid } & \text { Cum } \\
\text { Percent } & \text { Percent } & \text { Percent }
\end{array}
$$

\begin{tabular}{rrr}
16.2 & 16.2 & 16.2 \\
16.2 & 16.2 & 32.4 \\
43.2 & 43.2 & 75.7 \\
2.7 & 2.7 & 78.4 \\
2.7 & 2.7 & 81.1 \\
13.5 & 13.5 & 94.6 \\
2.7 & 2.7 & 97.3 \\
.2 .7 & 2.7 & 100.0 \\
\hline 100.0 & 100.0 &
\end{tabular}

Total

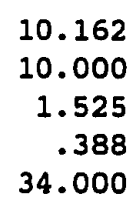

std err

Std dev

s $\mathrm{E}$ Kurt

Range

Sum

Median
Variance
Skewness
Minimum

10.000

57.751

.975

.000 
Hypothesis (1): The clarity of enabling legislation and the soundness of the its supporting theory are not considered significantly more important than other variables in the implementation process by individuals involved in the implementing of public policy.

Hypothesis 1 is confirmed. The data confirms that Variables 1 and 2 are not considered more important/significant than other identified implementation variables.

Analysis: Hypothesis 1

The survey data does not confirm the assumption of the model that the clarity of enabling legislation and the soundness of the its supporting theory are considered significantly more important than other variables in the implementation process by individuals involved in implementing public policy. Indeed, only variable 1 was ranked first or second in order of significance by any. cohort in the sample. It should be noted that because of the small sample sizes of the individual groups and the range of scores registered, it may have been impracticable to use arguments regarding rejection in the $5 \%$ region even had variables 1 and 2 been rated as more significant. Virtually all scores for the individual variables exhibit overlapping confidence intervals at $95 \%$. Nevertheless, the survey data clearly exhibits that only one group (Center) rated VAR1 (clarity of legal mandates) as 
most significant. No group rated VAR2 (sound theory) higher than third in order of importance. The composite ratings offer substantial evidence in support of the null hypothesis.

A possible explanation of this finding rests on the observation that if the conditions of VAR1 and VAR2 are met, participants in the implementation process will tend to discount their true significance and focus attention on more proximate issues involving available resources, management skills of the implementing agency, etc. However, it is not possible to determine statistically from the survey data if this was the case as there is no evidence that respondents felt the conditions of VAR1 and VAR2 were materially met. Confirmation of the null hypothesis, however, adds little to our understanding of alternative interpretations of the data. The findings suggest that VAR3 and VAR4 which focus on the skills, attitudes, and resources of the implementing agency may be viewed as more significant than the conditions represented by VAR1 and VAR2. A review of the score distribution in Table XII supports this alternative and suggests that this view may be more strongly held by Target and Periphery groups than by the center. Indeed, the Center's ranking of VAR1 as most significant is highly consistent with the model's assumption regarding the proper concerns of top down analysis.

While VAR3 was rated most highly by the Target 
population and VAR4 most highly by the Periphery, the center rated neither variable higher than third. This finding is not wholly inconsistent with the model insofar as it suggests that Target and Periphery groups may tend to focus on the enabling aspects of the implementing agency more so than does the agency itself. The agency, acting as the Center, is arguably more concerned with the substantive policy and legal issues they are assigned.

It also may be asserted that variables 3 and 4 are somewhat more "hands on" than are 1 and 2 , which is to say they are more closely related to the proximate issues of program administration. As the survey was conducted while the participants were actively engaged in the implementation process, there may have been a tendency to over-rate the significance of variables directly related to the day to day problems and frustrations of the respondents. There was, however, no direct evidence offered by respondents in support of such bias.

While the survey data does not provide a solid statistical basis for other than rejection of the model's assumption with regard to VAR1 and VAR2, the existence of group score variance provides clear evidence that estimates of significance may vary across populations and may be linked closely to one's position in the implementation environment. The significance of the group score variance 
is addressed in detail in the discussion which follows on ANOVA.

Because the data collected on variable criticality were of an opinion nature, a simple difference of means on any one variable would not indicate the absolute magnitude of difference between groups. Though the scaling instructions suggested that respondents submit observations on an interval scale (a variable receiving 30 points would be considered three times as important as one receiving 10 points), the scaling technique could be fairly criticized for rendering results that were, in fact, ordinal. For that reason, the data analysis associated with hypotheses 2 and 3 proceeded along the lines of formal oneway ANOVA but with particular interpretive attention paid to the ordering of the variables.

ANOVA involves an evaluation of variance in mean scores. Clearly, as can be observed in Table XII, there is a quantifiable variation in means for the dependent variable of each group. The issue, however, is whether the observed variation is large enough to constitute a statistically significant difference. 2 The data from one-way ANOVA on the six implementation variables and survey groups is set forth below followed by an independent analysis of the technique for each variable. 
TABLE XIII

ONE WAY ANOVA

IMPLEMENTATION VARIABLE BY GROUP

VARI

By Group

\begin{tabular}{|c|c|c|c|c|c|c|c|}
\hline & SOURCE & D.F. & $\begin{array}{l}\text { SUM OF } \\
\text { SQUARES }\end{array}$ & $\begin{array}{l}\text { MEAN } \\
\text { SQUARES }\end{array}$ & $\begin{array}{l}\text { F } \\
\text { RATIO }\end{array}$ & \multicolumn{2}{|c|}{$\begin{array}{c}\mathbf{F} \\
\text { PROB. }\end{array}$} \\
\hline BETWEEN & GROUPS & 2 & 202.54 & 101.27 & .6432 & \multicolumn{2}{|l|}{.5319} \\
\hline WITHIN & GROUPS & 34 & 5353.5591 & 157.45 & REGION & \multicolumn{2}{|c|}{$\begin{array}{l}\text { OF REJECT. } \\
(5 \%)\end{array}$} \\
\hline TOTAL & & 36 & 5456.1081 & & 3.28 & \multicolumn{2}{|c|}{ Rejected } \\
\hline & $\begin{array}{c}\text { VAR2 } \\
\text { By Group }\end{array}$ & & & & & & \\
\hline & SOURCE & D.F. & $\begin{array}{l}\text { SUM OF } \\
\text { SQUARES }\end{array}$ & $\begin{array}{l}\text { MEAN } \\
\text { SQUARES }\end{array}$ & \multicolumn{3}{|c|}{$\begin{array}{cc}F & F \\
\text { RATIO } & \text { PROB. }\end{array}$} \\
\hline BETWEEN & GROUPS & 2 & 45.62 & 22.81 & \multicolumn{3}{|c|}{$.1043 \quad .9013$} \\
\hline WITHIN & GROUPS & 34 & 7439.3500 & 218.80 & \multicolumn{3}{|c|}{$\begin{array}{c}\text { REGION OF REJECT. } \\
(5 q)\end{array}$} \\
\hline TOTAL & & 36 & 7484.9730 & & & & \\
\hline
\end{tabular}

VAR3

By Group

$\begin{array}{lccccc}\text { SOURCE } & \text { D.F. } & \text { SUM OF } & \text { MEAN } & \text { F } & \text { F } \\ \text { SQURES } & \text { SQUARES } & \text { RATIO } & \text { PROB. } \\ \text { BETWEEN GROUPS } & 2 & 394.13 & 197.06 & 1.5854 & .2196 \\ \text { WITHIN GROUPS } & 34 & 4226.2955 & 124.30 & \text { REGION OF REJECT. } \\ \text { TOTAL } & 36 & 4620.4324 & & & \text { (58) }\end{array}$


TABLE XIII

ONE WAY ANOVA

IMPLEMENTATION VARIABLE BY GROUP

(continued)

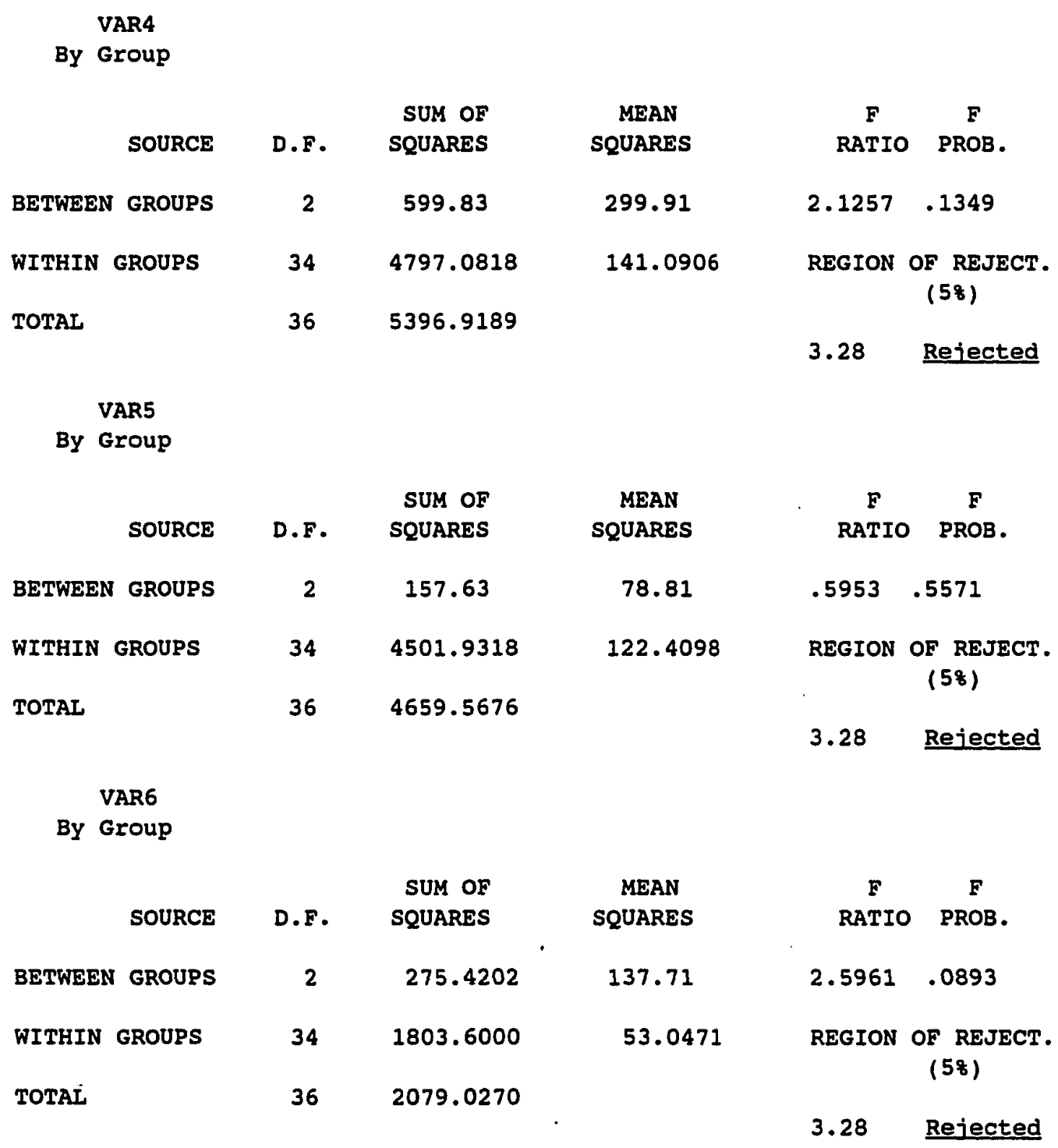

The data on hypotheses 2 and 3 are evaluated below. A review of Table XIII reveals that no variable registered a significant $F$ ratio at the $95 \%$ confidence interval. 
Analysis of the score spread for each group (see Table XIII) reveals that the spread was sufficiently large to suppress $F$ values below a point which would allow dismissal of the null hypothesis. Thus, while important betweengroup variations were present, the recorded differences were not large enough to be statistically significant. The examination and discussion of hypotheses 2 and 3 with respect to the study variables is, therefore, conducted with this caveat in mind. Supplemental data, when available, is presented to suggest possible findings and conclusions in the absence of statistical support.

Hypothesis (2): The hierarchical position of an implementing activity within a federalist framework has no significant effect on the determination of variable criticality.

Variable 1. The enabling legislation (Congressional authorization of the project and cost sharing program) or other legal directive mandates policy objectives which are clear and consistent or at least provides clear criteria for resolving goal conflicts.

The variation of means on VAR 1 were statistically insignificant $(F=.643)$. It is not surprising, however, that the center would rate VARI as high or higher than Periphery and Target groups. The Center, in this case the executive staff of the implementing agency, is directly involved with the promulgation of implementing regulations, provision of procedural guidance, and other activities specifically associated the policy objectives of the subject legislation. 
The task is made considerably more difficult when legislation fails to provide substantive criteria upon which to develop regulatory guidelines.

Vague or poorly crafted legislation may have an impact on Target and Periphery groups. The effect, however, may not be as readily attributable to "lack of clear legal mandates" by such interests simply because those groups are not forced to deal with the legislation so much as they are exposed to resulting programs and regulatory guidelines. Target and Periphery groups frustrated with program administration or support are more likely to target administrative and resourcing agencies for criticism than identify defective legislation as the problem.

Moreover, the model suggests that while clarity and consistency of the legal mandates are critical in the short term, they are probably less critical in the long term in relation to changing socioeconomic conditions and the support of various constituency groups (Mazmanian 1983, 277). Arguably, over time, Target and Periphery groups become more concerned with "on the ground" problem solving, and less concerned with the linkages between operating policy and congressional intent expressed through legislation. The center, on the other hand, will be more regularly concerned with revisiting the legislation and its authors. Thus, the substantive context of legislation and its associated policy is a realtime concern of the center. ${ }^{3}$ 
Variable 2. The enabling legislation

(Congressional authorization of the project and cost sharing program) incorporates a sound theory identifying the principal factors and causal linkages affecting policy objectives and gives implementing officials sufficient jurisdiction over non-Federal interests, members of the water resource development community, and other points of leverage to attain, at least potentially, the desired goals.

The variation of means on VAR 2 were statistically insignificant $(F=.1043)$. Interestingly, the center ranked the variable relatively lower (fourth) than either the Target or Periphery (third). This is somewhat surprising given the fact that one of the principal components of the variable deals with the awarding of sufficient authority to the implementing agency. An interpretation of this finding will be offered in the discussion of hypothesis 2.

Variable 3 . The enabling legislation (Congressional authorization of the project and cost sharing program) structures the implementation process so as to maximize the probability that implementing officials (representative of the Corps of Engineers) will perform as desired. This involves assignment to a sympathetic agency with clear, hierarchical organizational structure, supportive decision rules, sufficient financial resources, and adequate access to supporters.

The variation of means on VAR 3 were statistically insignificant $(F=1.5854)$. However the rankings were consistent with the observation that the Target, which ranked VAR3 as most significant, places great emphasis on the ability of the bureaucracy to respond to the partnership. VAR3 is directly related to the capacity of 
the implementing agency to "follow through" on decisions and determinations which must be made and executed during the implementation process. A more detailed analysis of this concern is offered in the following subdivision on analysis.

Variable 4. The leaders of the implementing agency (Corps of Engineers) possess substantial managerial and political skill and are committed to the success of the program.

The variation of means on VAR 4 were statistically insignificant $(F=2.1257)$. Though the means rankings fell outside the region of rejection, it is interesting that VAR4 was rated most significant by the Periphery. In this instance, the rating assumes a dimension of self reflection as the Periphery is, to some extent, evaluating the importance of their personal commitment and abilities to effect change as well as that of their superiors at the HQUSACE level. It is, then, not surprising that this population would view their role in the process as vital and significant to the success of the policy initiative and the implementation effort.

Somewhat surprising is the fact that the center, by contrast, rated VAR4 only third in order of significance, though the composite rating for all groups identified VAR4 as the most significant. Notwithstanding the relative ranking of the Center, it appears that, based on mean scores, VAR4 is considered by all three groups to be a most significant variable in the implementation process. 
Variable 5. The cost shared water resource development program is actively supported by organized constituency groups and by a few key legislators (or a chief executive) throughout the implementation process, with the courts being neutral or supportive.

The variation of means on VAR 5 were statistically insignificant $(F=.5953)$. Though the mean scores for Target and Periphery groups were not significantly different the Center ranked this variable as second most critical. This is not surprising given the political difficulties the COE has had with Target group interests and with pressure from some legislative concerns to "go back" to the old way of doing business. Indeed, it begs the question of whether the constituency for cost shared water resource development extends beyond the Executive branch of government.

Whereas the Target and Periphery groups find this variable to be moderately important they view it as significantly less so that does the center. This dichotomy is likely the result of the Center's agenda for overall program success being perceived as far more politically "sensitive."

The data supports the conclusion that the center is sensitive to and solicitous of the support of organized constituencies. A detailed discussion of this effort in included in the following subdivision on analysis.

Variable 6. The relative priority of statutory objectives is not undermined over time by the emergence of conflicting public policies or by 
changes in relevant socioeconomic conditions which weaken the legislation's causal theory or political support.

The variation of means on VAR 6 were statistically insignificant (F=2.5961). VAR6 was generally considered of lesser importance by all groups.

\section{Analysis: Hypothesis 2}

Clearly, one's position within the hierarchical framework established by the model exerts influence on the rating of implementation variables though the direction and magnitude of that influence is not consistent across variables. Because the null hypothesis is concerned with data on all six variables, rejection is predicated on the observed differences of means for all variables. As $F$ ratios for all variables were found to be statistically insignificant, the null hypothesis cannot be rejected. This does not rule out, however, a discussion of findings that, while statistically fragile, contribute to an understanding of the model and the implementation process.

Two broad trends which emerged upon examination were 1) the tendency of the Target to rate variables related to clarity and consistency of program administration high and 2) those at the apex of the intergovernmental hierarchy tended to rate highly variables which addressed issues of constituency and interest group support for the policy. Though difficult to defend methodologically, there is an 
intuitive logic to this finding.

Target groups, now resigned to operating in a costsharing environment, have decided to focus on the administrative processes in an effort to reduce operational friction, streamline approval processes, and generally negotiate a more equal "partnership." The center, aware that criticism of the administrative process may translate into an attack on the policy itself, is properly concerned with broad support from the water resource development "industry" as well as its own internal administrative machinery.

The concern of the Target population for effective administration by the center and the Periphery represents, in this instance, a straightforward acknowledgement that Target resources are committed to that administrative process. Supplemental data collected in 1987 involving thirty-one COE project managers and twenty (20) local sponsor representatives (see discussion in Chapter III, Use of Multiple Data Sources) asked the following questions regarding the implementation of cost shared planning:

1. Did cost sharing increase the amount of time spent engaged in negotiating project design, schedules, etc. with local sponsors over what would have been spent prior to the implementation of cost sharing?

2. If additional time was spent what was the effect/impact of this additional effort? Positive or negative?

Twenty-eight of the thirty-one respondents $(90 \%)$ 
indicated that project planning under cost sharing required additional time. The requirement of additional effort was most often attributed to:

(1) Increased technical design coordination and review. (2) Increased general coordination of correspondence and communications.

(3) Resolution of crediting for prior work performed by sponsor.

(4) Coordination of sponsor's financial plan. Notwithstanding the perception that the partnership in planning model requires additional time and staff resources, a surprisingly large number of project managers indicated that implementation of cost shared planning had a positive impact on the project formulation process. Table XIV presents the data. Interestingly, the data collected on process impacts in 1987 is consistent with that collected in the 1990-1991 time frame. (See survey data contained in NAFSMA Survey, Appendix B.)

TABLE XIV

PROJECT MANAGER SURVEY FOR COST SHARED PLANNING

(N) Increased Time Cost Shared Planning Model

17 Yes Positive (55\%)

9 Yes Neutral (no change) (29\%)

2 Yes Adverse (6\%)

$\frac{3}{31}$ No No change (10\%) 
The two most frequently cited positive impacts associated with cost shared planning were:

(1) Plan support as result of improved cooperation with local sponsor and interest groups.

(2) Development of a better plan as a result of sponsor input.

Adverse impacts identified most often consisted of the following:

(1) Delays in project formulation associated with sponsor inability to arrange financing.

(2) Disputes over issues of appropriate crediting for non-Federal interest LERRD or reimbursable work.

(3) Delays and confusion associated with direct negotiation between sponsors and HQUSACE/ASA(CW) staff.

The Project Manager sample represented projects that, generally, were authorized by P.L. 99-88, the supplemental Appropriations Act of 1985 or the WRDA 1986 and involved some negotiated change to the authorized project. Thus, it would be expected that these individuals were attempting to implement cost sharing in an environment that was at best volatile and characterized by change and relative policy instability. Given that, the data on Project Managers is encouragingly positive.

Interestingly, the development of a close, positive working relationship between the sponsor and COE District personnel acts to illustrate the point that intergovernmental alliances and positions of advocacy are shaped more by a commonality of interests than 
organizational affiliation. In most instances the direct communication link between the non-Federal sponsor and the Corps will be at the District level. This linkage is critical both in terms of establishing a consistent chain of command for the processing of information and decisions and because of the potential for relationships to develop between local sponsors and District Corps personnel that are significantly more complex than those defined by the LCA. similar intergovernmental relationships have been addressed at length in the literature most notably by Bernstein, whose early work on regulated industries led to the development of the "capture" thesis (Bernstein 1955).4

Corps Project Managers reported that they were frequently subject to competing pressures when negotiating an LCA. Pressure was exerted by the sponsor (their partner) to adapt the terms of the agreement to meet local concerns and constraints. Management at the Periphery exerted pressure to keep the project "on track." Pressure from the Center generally focused on the submission of standardized submittals and the need to adhere to the formal policy guidance and models set forth in ER 1165-2-131.

The decision environment was further complicated when local sponsors sought to engage in direct, non-coordinated negotiations with HQUSACE or ASA(CW) personnel to appeal a District position or seek final judgment on apparent 
deviations from the model LCA format. Such behavior from a sponsor's perspective represented a perfectly rational attempt to expedite the LCA process. Unfortunately, it also raised serious organizational questions with regard to the ability of Districts to negotiate with authority and contributed to further policy instability. This observation is supported by the survey data on VAR3 for the Target group.

Hypothesis (3): Within-agency orderings of variable criticality are consistent across the span of the organization.

The statistical test for hypothesis 3 involved use of oneway ANOVA with a means comparison on VAR1 through VAR6 between only the center and Periphery. The findings are set out in Table XV.

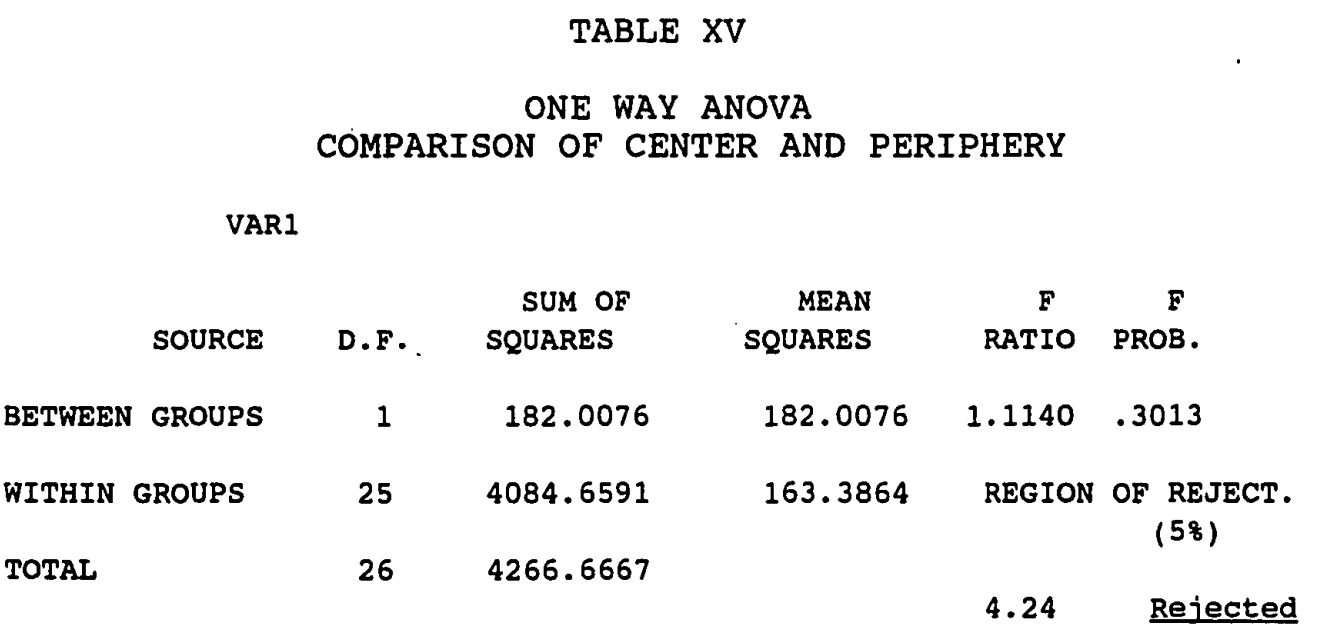




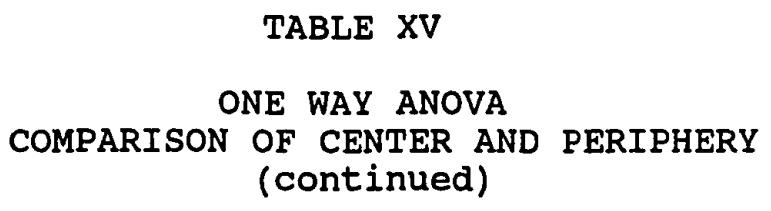

\begin{tabular}{lcrrrr}
\multicolumn{1}{c}{ SOURCE } & D.F. & \multicolumn{1}{c}{$\begin{array}{l}\text { SUM OF } \\
\text { SQUARES }\end{array}$} & $\begin{array}{c}\text { MEAN } \\
\text { SQUARES }\end{array}$ & $\begin{array}{c}\text { F } \\
\text { RATIO }\end{array}$ & $\begin{array}{c}\text { F } \\
\text { PROB. }\end{array}$ \\
BETWEEN GROUPS & 1 & 2.5463 & 2.5463 & .0103 & .9201 \\
WITHIN GROUPS & 25 & 6193.7500 & 247.7500 & REGION OF REJECT. \\
TOTAL & 26 & 6196.2963 & & & (58) \\
& & & & 4.24 & Rejected
\end{tabular}

VAR3

$\begin{array}{lccccc}\text { SOURCE } & \text { D.F. } & \begin{array}{c}\text { SUM OF } \\ \text { SQUARES }\end{array} & \begin{array}{c}\text { MEAN } \\ \text { SQUARES }\end{array} & \begin{array}{c}F \\ \text { RATIO }\end{array} & \begin{array}{c}F \\ \text { PROB. }\end{array} \\ \text { BETWEEN GROUPS } & 1 & 318.3712 & 318.3712 & 2.2752 & .1440 \\ \text { WITHIN GROUPS } & 25 & 3498.2955 & 139.9318 & \text { REGION OF REJECT. } \\ \text { TOTAL } & 26 & 3816.6667 & & & \text { (58) }\end{array}$

VAR4

\begin{tabular}{|c|c|c|c|c|c|c|}
\hline & SOURCE & D.F. & $\begin{array}{r}\text { SUM OF } \\
\text { SQUARES }\end{array}$ & $\begin{array}{c}\text { MEAN } \\
\text { SQUARES }\end{array}$ & $\begin{array}{c}F \\
\text { RATIO }\end{array}$ & $\begin{array}{c}F \\
\text { PROB. }\end{array}$ \\
\hline BETWEEI & S GROUPS & 1 & 560.4848 & 560.4848 & 3.6698 & .0669 \\
\hline WITHIN & GROUPS & 25 & 3818.1818 & 152.7273 & REGION & $\begin{array}{c}\text { OF REJECT. } \\
(58)\end{array}$ \\
\hline TOTAL & & 26 & 4378.6667 & & & \\
\hline
\end{tabular}

4.24 Rejected 
TABLE XV

ONE WAY ANOVA

COMPARISON OF CENTER AND PERIPHERY

(continued)

\begin{tabular}{|c|c|c|c|c|c|c|}
\hline \multicolumn{7}{|c|}{ VAR5 } \\
\hline & SOURCE & D.F. & $\begin{array}{r}\text { SUM OF } \\
\text { SQUARES }\end{array}$ & $\begin{array}{c}\text { MEAN } \\
\text { SQUARES }\end{array}$ & $\begin{array}{c}\mathbf{F} \\
\text { RATIO }\end{array}$ & $\begin{array}{c}F \\
\text { PROB. }\end{array}$ \\
\hline BETWEEN & N GROUPS & 1 & 140.8089 & 140.8089 & .9115 & .3489 \\
\hline WITHIN & GROUPS & 25 & 3861.9318 & 154.4773 & REGION & $\begin{array}{c}\text { N OF REJECT } \\
(5 \%)\end{array}$ \\
\hline \multirow[t]{3}{*}{ TOTAL } & & 26 & 4002.7407 & & 4.24 & Rejected \\
\hline & VAR6 & & & & & \\
\hline & SOURCE & D.F. & $\begin{array}{r}\text { SUM OF } \\
\text { SQUARES }\end{array}$ & $\begin{array}{c}\text { MEAN } \\
\text { SQUARES }\end{array}$ & $\begin{array}{c}F \\
\text { RATIO }\end{array}$ & $\begin{array}{c}F \\
\text { PROB. }\end{array}$ \\
\hline BETWEEN & N GROUPS & 1 & 275.4074 & 275.4074 & 4.5901 & .0421 \\
\hline WITHIN & GROUPS & 25 & 1500.0000 & 60.0000 & REGION O & $\begin{array}{l}\text { OF REJECT. } \\
(5 \%)\end{array}$ \\
\hline TOTAL & & 26 & 1775.4074 & & & \\
\hline
\end{tabular}

4.24 Accepted

The data on hypothesis 3 presents an interesting picture. Rejection of statistically significant differences for five of the six variables supports the hypothesis that scoring across the organization is comparable. However, the magnitude of the relative ranking differences between center and Periphery merit attention. For that reason it was important to assess the differences measured on individual variables and evaluate the basis for such variation.

Variable 1. The enabling legislation (Congressional authorization of the project and cost sharing program) or other legal directive mandates policy objectives which are clear and 
consistent or at least provides clear criteria for resolving goal conflicts.

The variation of means on VAR1 were statistically

insignificant $(F=1.114)$.

Variable 2. The enabling legislation (Congressional authorization of the project and cost sharing program) incorporates a sound theory identifying the principal factors and causal linkages affecting policy objectives and gives implementing officials sufficient jurisdiction over non-Federal interests, members of the water resource development community, and other points of leverage to attain, at least potentially, the desired goals.

The variation of means on VAR 2 were statistically

insignificant $(F=.0103)$.

Variable 3. The enabling legislation

(Congressional authorization of the project and cost sharing program) structures the implementation process so as to maximize the probability that implementing officials (representative of the Corps of Engineers) will perform as desired. This involves assignment to a sympathetic agency with clear, hierarchical organizational structure, supportive decision rules, sufficient financial resources, and adequate access to supporters.

The variation of means on VAR 3 were statistically insignificant $(F=2.2752)$.

of note, however, is the large relative rank order spread with the center determining this the least important variable while the Periphery considers it second most important. While not supported by a statistically sufficient $F$ ratio, the positional differences here suggest that the "resourcing and mechanics" of implementation are of greater importance to the Periphery than the center. As the 
Periphery is the direct recipient of such resources and guidance, the finding is of intuitive (if not statistical) significance.

Variable 4. The leaders of the implementing agency (Corps of Engineers) possess substantial managerial and political skill and are committed to the success of the program.

The variation of means on VAR 4 were statistically insignificant $(\mathrm{F}=3.6698)$.

The high rating (first) for VAR4 supplied by Periphery respondents may in some ways be linked to frustration experienced with the vertical flow of communication and approvals and so reflect an appreciation of how critical managerial and leadership skills are within the organizational hierarchy. The Center, however, also rated VAR4 as significant (third). There appears to be shared appreciation for the criticality of capable implementing personnel. Given the statistical insignificance of the observed differences it is impractical to speculate further on the relative differences of the rankings.

Variable 5. The cost shared water resource development program is actively supported by organized constituency groups and by a few key legislators (or a chief executive) throughout the implementation process, with the courts being neutral or supportive.

The variation of means on VAR 5 were statistically insignificant $(\mathrm{F}=.9115)$.

The basis for the observed within-agency variance 
likely rests in the focus of the center (broad programmatic perspective) vice that of the Periphery (individual project or single non-Federal interest.) While the Periphery group may appreciate the necessity of organized constituency support it is clear that matters of "political support" is better understood by the center which must routinely deal with organized constituency pressure on a national scale. Whereas members of the Periphery would likely deal with local components of organized constituencies they would be less likely than the center to depend on direct organized constituency support of policy initiatives.

Variable 6 . The relative priority of statutory objectives is not undermined over time by the emergence of conflicting public policies or by changes in relevant socioeconomic conditions which weaken the legislation's causal theory or political support.

The variation of means on VAR 6 were statistically significant $(F=4.5901)$. However, as both center and Periphery groups rated this variable as least or near-least in significance the confirmation of statistical differences is not analytically relevant.

\section{Analysis: Hypothesis 3}

As was the case with hypothesis 2 , observable but statistically insignificant differences were recorded between within-agency elements, e.g. Center and Periphery groups. While the subject groups did not offer comparable rankings on the variables the recorded differences in scores 
between groups were not large enough to affirm statistically significant differences between the center and the Periphery. Rejection of the null hypothesis is not supported by the data. The most significant differences between groups was registered on VAR3 which involved the resourcing of the implementation initiative and VAR5 involving the support of constituency for the policy/legislation.

With regard to VAR3, the higher ranking registered by the Periphery was likely influenced by the difficulty corps field personnel had with non-Federal interests on matters of interpretation and out-of-chain communication efforts. The perceived need for a supportive structure is reflected in this ranking and confirmed by supplemental data sources (primarily Corps project managers) cited throughout this study. In this instance, the statistical insignificance of the data may be a result of the variable being perceived as important by both groups, though not equally so. The recorded differences provide limited evidence of an important difference in perspective.

The findings on VAR5 are consistent with the model in that the Center is more directly involved with constituency group."negotiation" than are components of the Periphery who are typically engaged in implementing policy "on the ground" for individual projects. Whereas constituency and special 
interest groups may attempt to exert influence over individual projects (particularly when such projects are large scale or represent an opportunity to set policy precedent), they more typically focus their energies on effecting substantive legislative policy change. That was clearly the case in the development of the WRDA 1986 as was reflected by the legislative history set out in chapter II. The data on VAR5 suggests that the perceived significance of constituency group support may vary across the organization by a meaningful, if statistically insignificant amount. This observation is an important one and will be discussed in greater detail in Chapter VI where the evolution and status of the planning "partnership" is evaluated.

\section{CONCLUSION}

Data on the process analysis portion of this research provides a mixed picture with regard to Mazmanian and Sabatier's conceptual framework of implementation and its theoretical foundations. The survey data, though generally supportive of the model, is inconclusive as a result of statistically insignificant findings and the fact that the sample groups tended to reject the models contention that clear legal mandates and sound theory would be perceived by individuals involved in the implementation process as the most critical of effective implementation conditions. Whereas the findings of the ANOVA do not in most cases allow 
for the inference that the recorded scores of the Target, Center, and Periphery are significantly different, the differences are not meaningless. The recorded differences on variables one through six indicate patterns that are consistent with both the conceptual framework of the model and much of the general theory of organization (Mazmanian $1983,20)$. The discussion of inter-group differences set forth in this chapter will be continued in chapter VI wherein the findings of the process analysis will be evaluated in conjunction with the data on empirical project impacts (Chapter $V$ ) and the independent supplemental data sources referenced in Chapter II to provide an overview and summary analysis of the implementation research. 


\section{ENDNOTES}

1. See Chapter III, subdivision, Use of Multiple Data Sources, for a full explication.

2. Anova allows for an analysis of the difference of means relative to the spread of the scores within and between groups. Significance levels, determined by $F$ ratios, are then computed. For purposes of this research, the $95 \%$ confidence interval is used to establish significance.

3. Because Federal water resource development legislation is typically authorized via biannual appropriation this condition is particularly relevant.

4. The "capture" model, and criticism of its impact on democratic decision making has been authoritatively treated in general administration theory by a number of scholars including McConnell (1966) and Lowi (1969), who provide excellent critiques of the application of the theory in the administration of natural resources. Counter-theorists include James Q. Wilson (1980) who argue that "capture" theory fails to appreciate the political basis of regulatory policy. 


\section{CHAPTER V}

\section{THE IMPACT OF COST SHARING ON PROJECT DEVELOPMENT}

The analysis in this Chapter proceeds somewhat differently from that of the previous Chapter in that, rather than deal directly with theoretical aspects of implementation theory, the discussion focuses on an assessment of the design impact cost shared water resource development has had on projects. The WRDA 1986 did not set forth specific goals in the legislation with regard to the type of projects which would emerge. Indeed, the introductory narrative of the Act was remarkably brief:

To provide for the conservation and development of . water and related resources and the improvement and rehabilitation of the Nation's water resources infrastructure. (P.L. 99-662 1986)

The brevity of the formal comment in the legislation was, however, compensated for by the swirl of argument and posturing which preceded passage of the WRDA 1986. For the purpose of this analysis a set of three assumptions were established in Chapter III to serve as a framework from within which the impact of cost-sharing on physical project development could be evaluated. This Chapter addresses the background and substance of each of those assumptions in greater detail and evaluates each in light of data collected on cost shared water resource development projects 
authorized since the inception WRDA 1986.

\section{IMPACT ON PROJECT SIZE}

During the next few years we expect the make up of our construction program to shift to smaller scaled projects, made up mostly of flood control and commercial navigation projects... The ability to fully fund a project, or to do it in stages, stems from such institutional constraints on the sponsor such as debt ceilings and the willingness of the beneficiaries to assume additional costs.

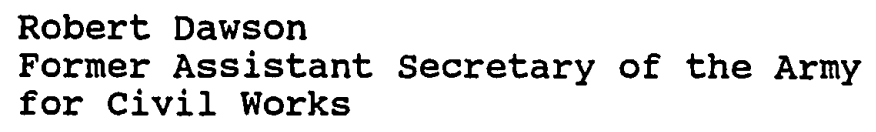

We believe that increased non-Federal cost sharing has benefits which go beyond reducing Federal expenditures. For instance, I believe the planned projects will more closely reflect the need of the specific sponsor. The change also will cause a shift to smaller more easily financed projects and the phased construction of larger projects...cost sharing of the feasibility phase study will assure a more effective participatory role by the sponsors, focus the evaluation of alternatives on those that are tailored to the sponsor's financial and institutional capabilities and produce authorized plans that can be implemented with the full support and participation of the sponsor.

$$
\begin{aligned}
& \text { L.T. General E.R. Heiberg III } \\
& \text { Chief of Engineers, USACE (Ret.) }
\end{aligned}
$$

(Source: Testimony before Congressional subcommittee on Energy and Water Development.)

The first assumption established in chapter III dealt specifically with the impact of cost-sharing on the project size: 1) Cost shared project development will lead to the formulation and authorization of smaller water resource development projects. The second assumption regarding the 
trend toward staged or phased cost shared projects is similar in so far as staging and/or phasing the construction of separable elements (elements of a total project that could function independently as a separately identified project) may be considered an interim reduction. As each element of a phased project requires negotiation of a separate LCA, the interim solution may never be realized if the Federal or non-Federal interest decides to forego further development. In those instances, the total project as originally conceived is never constructed.

These assumptions, and their common logic, are central to the argument that smaller, fewer, and better projects will result from a cost shared planning model. Why is this so? Because, the requirement for additional non-Federal interest financial commitment to project construction, in conjunction with the increased planning role of the nonFederal interest, will reduce the incentive of non-Federal interests to negotiate for large scale/large capacity structural solutions and induce them to negotiate for reduced capacity solutions that more directly address the problem from the perspective of the local interest. Alternatively, the non-Federal interest may agree to the full project size in principle but fund construction in phases of increments thus reducing the initial financial burden while providing an opportunity to evaluate the benefit stream of the completed portion. 
In either case, cost sharing dramatically altered the calculus as it shifted the burden of project proponency from the Corps of Engineers to the non-Federal interest now responsible for building and maintaining public and political support for the life of the project (Kelly 1989).

The assertion that cost sharing will lead to reductions in project size presupposes a number of conditions and responses to economic incentives and financial inducements established by the legislation. (See Chapter II on the theoretical foundations of cost sharing.) principal among them are the following: 1) Corps project design (and the associated planning processes) has traditionally reflected a conservative approach to risk and uncertainty assessment; 2) Sponsors, constrained by limited financial resources and competing demands for public goods production will award preference to the lowest cost "acceptable" alternative; 3 ) Sponsor participation in the planning process will lead to projects that vary in design as well as magnitude and so will better reflect local preferences as well as financial capabilities.

Arguments supporting this assumption are also frequently offered as evidence of why Federal projects in general, and corps projects in particular, have historically been criticized for being "overbuilt." Arguably, overbuilding or designed-in overcapacity is far less 
frequently a criticism expressed by project beneficiaries of Federally funded projects than an observation on behalf of individuals who are dissatisfied with the political allocation of Federal development dollars. Critics are also frequently disinclined to support water resource development which impose structural solutions. Nevertheless, based on the economic inducements which have been historically available to the non-Federal interest and the long standing criticism (and literature) of "pork barrel" resource development, charges of project over-design and the authorization of marginal projects can neither be easily nor summarily dismissed. Indeed, no less an authority than former Assistant secretary of the Army for Civil Works (ASACW), Robert Dawson in defending the Administration's cost sharing proposals admitted that, "The old epithet of pork barrel, which was justifiably, at times, hung around our neck, just won't be available to a critic anymore" (National Journal 22 November 1986, 2824).

While it is not the case that projects are planned without regard to returns on investment, and has not been since the implementation of benefit-cost analysis was required by the Flood Control Act of 1936, the institutionalization of preferences (e.g., selection of the National Economic Development (NED) Plan as the preferred alternative) clearly suggests a selection criteria with a bias is quite different from one that would reflect a purely 
local bias. The critical dimension with regards to formulation of the NED Plan is the explicit goal of maximizing net national economic development consistent with the Federal objective(s) (Principles and Guidelines 1983, Part $V$, iv). Indeed, with implementation of the Principles and Guidelines, multi-objective planning was superseded by a model which featured single objective planning (maximization of economic benefits) with constraints (environmental preservation). 1

The net benefits decision rule established in the Principles and Guidelines optimizes economic efficiency without regard to the first cost of the selected alternative. Application of these criteria would not necessarily lead to selection of the same project alternative as would be chosen by local sponsors (project beneficiaries) whose assessment of risk and return on capital are far less likely, in the absence of legal inducement or financial incentive, to consider the advancement of national economic goals a desirable planning objective. Indeed, it has been asserted that the central problem of implementing cost sharing rests with design of a cost sharing system that induces non-Federal interests to select the same project as prescribed by the NED (Marshall 1969).

Thus, Federal projects may be perceived to be overbuilt 
by critics who compare the magnitude of the authorized project with a conception of what would have been constructed to remedy the instant and local situation (be it flood control, navigation, etc.) had the project funding been wholly non-Federal.

The Influence of Risk Assessment on Project Design

An alternative explanation for perceived overbuilding by the Federal interest involves risk assessment. All developed water resource projects, irrespective of authorized purpose(s), involve an assessment of risk and uncertainty. The Principles and Guidelines identifies the planner's primary role in dealing with risk and uncertainty as describing the areas of sensitivity clearly so that decisions can be made with knowledge of the degree of reliability of available information (U. S. Water Resources Council 1983, 5). The process, however, is far from straightforward as the planning process is characterized by the uncertainty associated with stochastic meteorological and hydrologic processes and systems.

The traditional solution has been to increase the quality and quantity of information available and to then assess how much confidence can be placed in the available data (Manual for Risk and Uncertainty Analysis in Corp's Civil Works Planning 1989, 2.2). The remaining uncertainty is a critical and unstable variable that must be factored 
into the planning and decision making process.

That process in not dissimilar to what a sponsor would engage in when assessing the risks of alternative project designs, sizes, etc. Nevertheless, risk assessment, notwithstanding the rigor of the formal analysis, remains an exercise that is largely subjective, albeit expert, judgment designed to arrive at a "sufficient reduction" solution (Fischoff, et. al. 1981, 105). That solution will be largely dependent on the decision analyst's criterion for buying down risk which, in the case of cost shared projects, is complex because it is not a unilateral determination. one can, with little difficulty, imagine the increase in difficulty associated with arriving at a negotiated multiparty consensus on mutually acceptable risk.

It is this potential difference in willingness to accept risk (in the case of choosing flood protection levels) or avoid risk (in estimating return on investment for vendible projects) that may contribute to sponsor selection of project alternatives which are smaller (or larger) than what is proposed by the Federal interest. In either case, the NED Plan may be challenged by the local alternative thus leading to negotiation on project scope and, ultimately, dialogue about the primacy of Federal regulations in a relationship characterized as a partnership in planning.

Federal estimates of risk assessment may tend to err on 
the conservative side for a variety of reasons. Risk allotment from Federal flood control projects is assigned risk. Assigned risk is risk that is determined by regulation, statute, etc., and so is appreciably different from acquired risk which may bought down by local beneficiaries who express a risk preference by "purchasing" a level of risk. In the case of flood control, risk preference may be reflected in the level of protection local beneficiaries would "purchase" if they were constructing the project.

There has been an understandable reluctance on behalf of Federal interests to underestimate such risks; partly owing to concerns for the welfare of project beneficiaries and partly because of a desire to ensure the long term integrity of the project and the associated agency. Indeed, from a Federal perspective the opportunity costs associated with project failure may be far greater than that increment of actual project cost which would accrue from overassessment. Failure of Federal projects, as was demonstrated by the collapse of the Bureau of Reclamation's Teton Dam in 1976, has serious implications for an agency dependent on public support and trust or who must compete for public works with other agencies. For an agency such as the Corps, whose principle strength rests with the perception that it is the Federal government's center of 
technical expertise for engineering design and construction, there exists great incentive to err on the conservative side of risk assignment. Decisions which lead to overly conservative design will almost invariably produce effects far less acute than those associated with a policy that can be linked to a disaster condition.

Interestingly, such a conservative bias in the selection of a project design is theoretically supported by observations made by the those engaged in decision research. Selection of a preferred design for a flood control project constitutes what decision analysts refer to as "unique choice" risk which means simply that once a project design (or a particular construction requirement procedure is selected, there are relatively few opportunities to make a second or third real time choice as there would be in a repetitive choice scenario (e.g., taking a "hit" while holding 17 during a Blackjack session). The data on unique versus repetitive choice behavior suggest that people tend to be more risk averse when faced with a unique choice decision (von winterfeldt 1986, 215). Thus, there may exist a human tendency when selecting a risk related project design to choose conservatively.

Moreover, Federal projects do not compete, in a strict market sense, with other capital project demands as is the case with capital projects funded at the local level. This latter point is critical and worthy of closer examination. 
While it is true that Federal agencies compete for dollars within a political allocation model, the Corps of Engineers has not traditionally designed projects to meet budget constraints nor is the corps directly concerned with the competing capital or social needs of project beneficiaries.

The corps is authorized by law to engage in water resource development projects, i.e. projects that improve, increase, or support the primary factors of economic production, not curb and gutter maintenance, road improvements, public housing, etc. ${ }^{2}$ That is clearly not the case for local governments. Capital expenditure at the local level represents a resource investment for which there is a competing demand that may represent an equal or higher rate of return on investment or invite consideration on the basis of distributional equity. Overassessment of risk for any one probable event, and the resultant overinvestment of constrained resources, may lead to neglect of other areas that warrant attention (Fischoff 1981, 36).

Thus, local governments, or project sponsors, are more likely to perceive risk reduction as having certain and quantifiable opportunity costs and to choose a level of risk that is acceptable from the standpoints of fiscal efficacy, efficiency, and political acceptability as well as one that satisfies minimal safety concerns. It must also be noted that the ongoing public and political support for such 
projects is now largely the responsibility of the nonFederal interest. Thus, from the perspective of the local, long term capital project tradeoffs must be factored into the decision.

Deep draft navigation projects also present risk assessment issues that may be evaluated differently by Federal and non-Federal interests. Channel width, size of turning basins, underkeel clearance, and traffic projections represent project design issues for which there exist standard Federal design and assessment guides which the Corps employs to derive project feature size estimates. ${ }^{3}$ Here too, in the case of a Federally funded project, there exist incentives to engage in a conservative assessment of risk and design accordingly. Wider and deeper channels, bends, and turning basins are certain to meet with the approval of shipping and harbor interests as will promoting a design that will accommodate long range projected growth. Nevertheless, in the absence of full Federal funding, navigation requirements are subject to assessment by sponsor interests who must share both first costs (construction and interest costs) and, in some cases, operation and maintenance costs associated with the project. Risk assessment in this instance is further complicated by the cost share ratios set out in WRDA 1986 which are "progressive" with respect to dredging activity. The nonFederal construction share doubles beyond a forty-five foot 
depth (25\% to 50\%) and non-Federal interests are required to pay $50 \%$ of operation and maintenance dredging beyond the forty-five foot depth.

A revealed preference of local risk assessment may differ both in the level of acceptable risk for a given feature and the selected method of risk reduction. For example, the use of tug assisted turns in turning basins may be substituted for the development of expanded basins. The choice of alternatives in this example may represent a rather straightforward preference for tug assisted turns over the provision of adequate space to permit unassisted ship maneuvers. It should be noted, however, that whereas turning basin construction is a cost shared feature, tug fees may be charged directly to the using vessel and so generate a revenue stream for the sponsor while requiring neither first costs for construction nor the development of additional cost recovery mechanisms. The point is simply that revealed risk preference is frequently not a decision made in isolation or on the basis of risk alone. It is a decision made in conjunction with a host of other project considerations and financing strategies.

The Principles and Guidelines acknowledges that, in principle, the government should be neutral toward risk and uncertainty in evaluating alternatives. It is clearly the case that de facto "risk standards," particularly with 
respect to design safety, may be identified throughout the Corps of Engineers Engineering Regulations series which specify design standards for a wide variety of functional project types. 4 while such standards are thought to reflect good "engineering judgment" based on engineering theory and a broad history of application, they also reflect institutional preferences regarding risk assignment. Sponsors who opt to choose riskier or less risky solutions are confronted with the necessity of negotiating not only with the engineering expertise of the local Federal interest but also challenging a large body of existing Federal regulation and law that frequently appears to leave little discretion with respect to prescribed design standards, a position sponsors are likely to feel violates the commitment to true "partnership in planning." The situation begs the question of whether the non-Federal interest contribution extends beyond a financial commitment to include serious consideration of alternative engineering solutions.

A critical challenge for the planning partnership will be the review of Federal regulatory guidance to determine that which is necessitated by law and that which is the product of convention, and so represents policy subject to negotiation with sponsor interests. Sickles, in his assessment of the future of intergovernmental relations for the Corps of Engineers, calls for a determination of new 
allowable standards to supplement risk assessment procedures and argues that these standards should be the product of a broad consensus of state and Federal engineers (Sickles $1986,153)$.

The Influence of Budget Constraint on Project Design

A third, and by no means less significant, force driving project size reduction is the sponsor's funding constraint. The planning process acknowledges that the financial limitations of sponsors may lead to economic suboptimization in selection of project design. Each plan formulated for a particular project is evaluated in consideration of four criteria: completeness, effectiveness, efficiency, and acceptability (EC 1105-2-115 1983, iv). Acceptability has been interpreted to mean financially. acceptable to the non-Federal interest though the distinction is somewhat muddied as when a "constrained NED" is put forth as the NED plan rather than classified as an alternative which might otherwise require Agency Secretary level approval. Interestingly, it argued that this same constraint (beneficiary payment) acts positively to put pressure on local interests to be more attentive to cost effectiveness in project design and scale (Shabman and Dickey 1986, 361).

There are a number of ways in which a project may be reevaluated to meet financial constraint requirements and 
not all of them actually involve anticipated reductions in the size or scope of the project. Phasing and staging are two construction strategies which have enjoyed some popularity, particularly in the navigation project arena. Assertions regarding phased or staged construction of separable elements differ in important ways from those associated with scope reduction, though both are linked to local budget constraints.

The concept of the separable element is fundamental to appreciating the application of staging and phasing, and, indeed, to understanding key economic criticisms of the statute's implementation which shall be discussed later in this chapter. A separable element is defined by the WRDA 1986 (Sec. $103(f)$ ) as a portion of a project which is physically separate from other portions of the project and which has benefits separately identifiable. Though the statute does not specifically identify separable elements for navigation projects, conceptually, components of a navigation project can be staged or phased in a manner similar to that employed for flood control projects. 5

The staging or phasing of construction does not necessarily imply that the NED Plan is rejected in favor of a smaller alternative plan. Moreover, if full project construction is completed over an extended schedule due to staging, the overall project costs will likely be increased 
as a result of inflation and price escalation.

Adoption of a phased construction schedule by the nonFederal interest may generally be considered a strategy to reduce the first costs of construction and is occasioned by either: 1) insufficient available financing to go forward with the full NED plan or; 2) a desire to examine the project benefit stream by stages before proceeding with financing of the fully authorized project. The latter case is a particularly important influence where project outputs (e.g., revenues from induced shipping traffic) are vendible and actual benefit accrual may be compared with planning estimates.

With regard to planning estimates, it should be noted that the potential for error in projected cargo estimates constitutes risk of another variety, investment risk, which the sponsor must assess in determining an appropriate level of capital obligation. Whereas there is evidence that there exist considerable barriers to the use of formal risk assessment methods, sponsors conducting a financial analysis will look carefully at the projected benefit stream and may choose to select an alternative that allows for the realization of initial benefits before expanding to meet future needs.

While it would be incorrect to suggest that project staging represents the selection of a reduced scope alternative it would be equally misleading to assume that 
staging will not in some cases lead to "partial" construction. Chapter III offered a discussion of this condition and how it would be treated methodologically in this research. Only observation over time of the subject projects will offer evidence of the extent to which phased construction actually represents project downsizing.

The focus of the preceding discussion has largely concerned what individuals would purchase given a choice of alternatives. It is also necessary to discuss the absolute constraints that are factored into that decision. Affordability has become a salient issue in the implementation of WRDA 1986 owing primarily to discussion (and possibly some confusion) about whether plan affordability should be linked directly to the financial capacity of the sponsor to generate share revenues (ability to pay) or determined by the sponsors willingness to transfer moneys from competing demands to purchase some level of project output (willingness to pay). The distinction is a crucial one and merits at least summary discussion.

Ability to pay is a measure of the capacity of an individual or public body to raise and commit resources to meet measured needs, in this case the financial capability of the non-Federal interest. For flood control projects under cost share principles this capability is established 
by formula, the calculation of which was published as an interim rule in the Federal Register, Wednesday, September 23,1987 . Section 241.4 (b) of the interim rule states that the test shall not be used to affect project scope or to change budgeting priorities among projects competing for scarce funds. Notwithstanding such regulatory admonitions, it would seem less than prudent or pragmatic for the Federal interest to push for a cost effective design that is clearly beyond the capacity of the sponsor to fund or maintain.

Likewise, modifications that result in significant project cost growth are a concern to sponsors who view the Federal interest as having no true cost ceiling on a project budget. There is a body of evidence that suggest the corps has become increasingly sensitive to the expressed concerns of the non-Federal interest on these subjects.

Ability to pay is, then, a relatively straightforward index of the capacity of a jurisdiction or multijurisdictional combine to generate revenues derived primarily from calculation of an eligibility factor (EF), a component of state and county per capita income as a percentage of the national average (PCI Index). The test is applied not only to jurisdiction(s) which encompass the project area but also the financial condition of the state. The state, though not itself a direct sponsor, is deemed a potential and likely source of financial assistance. Jurisdictions which qualify for relief may be eligible for a 
reduction in the non-Federal share though in no case will the non-Federal share drop below five percent (Federal Register 23 September 1987, 242.4(f)).

The test does not attempt to measure or otherwise account for sponsor expenditure preferences, current indebtedness, or level of tax effort. Indeed, the guidelines specifically assert that "... the borrowing capability of the local sponsor should not be a factor in the ability to pay determination." As of March, 1992 only one project formulated under cost share principles had qualified for a reduction in share and a second project's application was under review.

Notwithstanding formal admonitions that the sponsor's ability to pay and credit rating shall not impact on the overall approach to project planning and plan formulation or matter, the data suggests that non-Federal interest budget constraints do and will continue to have a profound influence on project formulation. A GAO survey conducted in 1991 indicated that in approximately twenty-five percent (25\%) of the surveyed projects that had progressed to preconstruction engineering and design (PED) the non-Federal interest indicated "moderate" to very great "difficulty" in meeting the requirements for local share of construction costs (GAO 1991, 41).

Ability to pay should not be confused (though it seems 
frequently to be in discussions regarding sponsor choice) with willingness to pay (WTP). This function is better represented by construction of the consumer's indifference curve rather than calculation of actual financial capability of the non-Federal interest to incur additional debt. Willingness to pay (WTP) is a "market-like" index of what an individual would pay for a particular good or service or, what they would pay to sustain a level of benefit or avoid the threat of loss. WTP is generally considered an appropriate measure of benefits because it leads to an accurate valuation of outputs by consumers/beneficiaries. As such, WTP is the P\&G prescribed standard by which benefits are derived in benefit-cost analysis. In the case of flood control projects, the good may be generally considered flood damage reduction and the WTP an aggregated sum of individual WTPs across the range of project beneficiaries.

WTP for either individuals or groups should theoretically reflect the stated preference for a combination of the ability of the beneficiaries to pay and recognition of the competing demands for resources, i.e., a budget constraint. Thus WTP does not operate in any practical sense independent of the financial capacity of beneficiaries to exercise a preference and, notwithstanding a determination by formula that project beneficiaries are 
financially capable of paying, the estimate will likely reflect mediated preferences.

Benefit Capture and Jurisdictional Externalities

WTP is closely linked, at least theoretically, to the existence of public goods and extra-market transactions. The principal concern to project sponsors, and potential financial institutions, is the ability of the sponsor to translate benefits, as projected in plan formulation, into revenues in the case of projects which produce vendible outcomes or to reduce the threat of damage (avoided damage benefits) as is the case for flood control projects. The problem of benefit capture may become particularly acute for those projects where benefits are largely non-vendible, as is frequently the case for local flood control projects, or where jurisdictional boundaries do not coincide with patterns of benefit distribution. Each of these conditions acts to constrain the ability of the sponsor to recover invested capital and may thus potentially result in overinvestment (from a local perspective) or diminished future financial capability due to unbalanced debt service for the project. 6

Political and geographic correspondence between the boundaries of the jurisdiction and area of project related benefits is considered crucial for maximum efficiency in the production and delivery of public goods. In a perfect 
correspondence model the population of the jurisdiction that determines the level of a public good includes precisely the set of individuals who will consume and benefit from production of that good.

Moreover, it is argued, that, provided costs of provision are similar for service producers at any level, it is always more efficient for local government to provide a level of public goods for local consumption than for a centralized government to provide a uniform level of service across all jurisdictions (U.S. ACIR Perspective Summer/Fall $1987,36)$. This is so for a variety of reasons involving collective preferences and the existence of interjurisdictional externalities. Indeed, the conventional research on local government organization affirms that a multiplicity of governments linked interactively may serve a number of useful purposes including increased sensitivity to citizen preference, closer match of benefit distribution to the economic demand of the community, and increased elected official accountability to a specific community of interest (U.S. ACIR December 1987).

In cases where it appears that public goods outputs will not achieve efficient levels of production due to the existence of interjurisdictional externalities or other efficiency constraints on recovery, and in the absence of potential for jurisdictional cooperation, centralized (Federal) funding provides an interim solution by assigning 
costs over the universe of beneficiaries and nonbeneficiaries alike. The solution, however, forgoes the efficiencies associated with correspondence. Local interests who pay for only a negligible portion of a project are less inclined to express concern with non-contributing beneficiaries and are subsequently induced to request higher levels of output than what would have been purchased had a pure user pay or collective decision model been employed to derive demand. The result is demand driven overproduction of a good or level of service.

Benefit Capture: Flood Control. Flood protection projects present a difficult combination of cost recovery constraints for local interests who may be the principal but not exclusive beneficiary because: 1) flood damage prevention is largely a non-vendible benefit with an indefinite pay-back and, 2) there exist competing demands for constrained capital budgets. Flood protection is a nonvendible output in so far as it is difficult to exclude contingent properties from protection once the protection has been provided. 7

In that fashion, flood protection acts like a public good and so must typically be paid for by extraction of tax revenues. Raising taxes or assessments against property is never a popular activity and is made less so when the linkage between tax increase and total benefit is uncertain 
as is so frequently the case with flood protection benefits. Moreover, flood protection benefits have an indefinite time horizon. Property values and development in the protected zone may increase but the magnitude of the benefit stream, absent a recurring flood of record, is decidedly uncertain when compared with investment alternatives. Absent actual flood damages, it is difficult to sustain the political coalitions necessary to support development of a (Federal) project that may take in excess of 20 years to move from conception to construction.

Cost sharing for local flood protection may be thought of as functionally comparable to an intergovernmental matching grant designed to generate public goods production within a specified area. Figure 3 illustrates how such

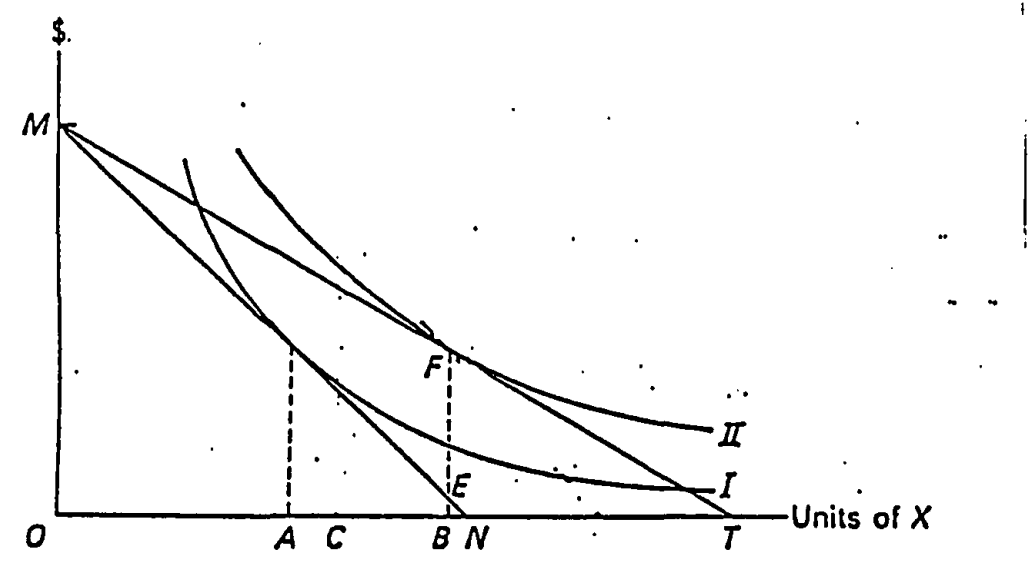

Fiqure 3 Indifference curve for public goods. Source: Oates, Wallace E., Fiscal Federalism, Harcourt, Brace, Jovanovich, Inc., 1972. 
transfers reduce the unit price of goods production to project benefit recipients. Assume that curves I and III represent community indifference curves between a public good (X) and all other goods. In the absence of subsidy and with a budget constraint of MN, the consumption of $X$ would be $O A$. If a unit subsidy were provided that generated budget constraint MT, the consumption of $X$ would increase to OB. Cost sharing, where the non-Federal interest share is less than $100 \%$, may be thought of a unit subsidy as it decreases the price of a good (project) across a range of project sizes.

Still it must remembered that while the unit price of flood protection is being subsidized, the sponsor's budget constraint for capital projects is not otherwise adjusted, as might be the case were the transfer unconditional. Thus, pressure to meet competing capital demands within the jurisdiction will continue to act as a constraint.

Benefit Capture: Deep Draft Navigation. For deep draft navigation projects the problem of interjurisdictional externalities is somewhat less consequential than for flood control projects owing to characteristics of the benefit stream that increase the likelihood of full recovery of invested capital. Deep draft navigation and harbor improvement generate vendible benefits but non-Federal sponsors generally must recover project share outlays through conventional cost recovery mechanisms such as 
dockage fees, wharfage fees, facility leasing, etc. The WRDA 1986 Section 208, Port or Harbor Dues, provides that the non-Federal interest may levy port or harbor dues to recapture project outlays but are restricted from levying such dues on vessels that could have used the port or harbor prior to project improvements. Thus the recovery mechanism is limited by law to induced traffic whose draft exceeded the handling capacity of the port prior to navigation improvements associated with the project.

Ports have understandably shown extreme reluctance to initiate new fees on such traffic as it is that very traffic which must be induced to realize the benefit stream associated with the project. The imposition of a "new traffic" fee would serve as a disincentive in a highly competitive market and has been largely dismissed by ports as a viable cost recovery alternative. Presumably, cost recovery will be achieved through the collection of normal fees, rents, etc. or transfers from state or local legislative bodies in support of economic development.

It is also the case that implementation of section 208 levies represents an administratively complex procedure requiring review and comment in the Federal Register, filing of proposed dues schedules with the Federal Maritime Commission, and periodic audits by the Comptroller General to ensure legal compliance with provisions of the Act. In 
practice, no ports have attempted to implement direct Section 208 fee recovery for project outlays owing primarily to an unwillingness to weaken their competitive position in the market. Like flood control project sponsors, port project sponsor's WTP will be time sensitive and linked closely to benefits that are materially tangible and recoverable.

\section{DATA ON PHYSICAL IMPACTS}

Project data on projects reported to have known cost share impacts were separated by project purpose, flood control or navigation, so that differential impacts by project type might be identified.

\section{Cost Trend for cost Shared Flood Control Projects}

A rough measure of trend in cost shared projects is an annualized comparison, adjusted for inflation, of the current working estimate of the project. This computation is at best an indirect measure of design elasticity as it does not account directly for changes in project cost estimates unrelated to cost sharing. Such changes are, of course, not insignificant and may represent cost increments or decrements as well as cost reallocations either toward or away from the non-Federal interest. 8 Nevertheless, if project downsizing represented a broad trend among cost shared flood control projects then one would expect to see a 
decrease in the current working project estimate (adjusted to constant dollars) from that originally authorized.

Multiyear cost estimate data was available for fourteen of the sixteen flood control projects identified as having design changes attributable to cost sharing. For each of these projects the FY-89 total project cost estimates, adjusted for inflation utilizing the Engineering News Record Construction cost Index, were computed as a percentage of the original authorized project estimate. The formula is provided below.

$$
\begin{aligned}
Q= & \frac{x_{i}}{x_{a}} . \\
& X_{a}=\text { Initial Project estimate } \\
& X_{i=\text { Project adjusted for annualized inflation }}=\text { Adjusted index }(\%) \text { price comparison }
\end{aligned}
$$

only scheduled construction estimates were employed so as to account for the impact of phasing and the uncertainty of future construction.

Subsequently, a sample mean was computed where:

$$
\begin{aligned}
& x=\sum_{\frac{i=1}{N}}^{n} x_{i} \\
& \begin{array}{l}
x=\text { arithmetic mean } \\
N
\end{array}=\text { number of observations }
\end{aligned}
$$

When computed in this fashion, the means of the samples are merely suggestive of cost growth or decrease over a range of projects. The authorized estimate for the 
project(s) is used as a base $(1.00)$ against which the FY-89 cost estimates may be compared.

The mean FY-89 cost estimate of the sample was .929 (92.9\%) of the mean authorized project estimate. The average authorized total cost estimate for the sample was $\$ 58,854,000$.

For purposes of comparison, a sample $(n=20)$ of flood control projects which required LCAs but did not appear to have changes directly attributable to cost sharing were evaluated employing the same methodology. The resultant mean FY-89 cost estimate for the sample was 1.06 or $106 \%$ of the mean of the initial authorized cost estimate for the projects.

The average authorized estimate for the no change sample was $\$ 19,274,000$. The average for all flood control project new starts (requiring LCAs) from the 1985 Supplemental Appropriations Act through FY-87 was $\$ 47,812,680$. See Table XVI.

The data on flood control projects, at best, presents a mixed picture and computations or findings based on gross project estimates should be viewed with caution as, for each project, there exist potential cost shifts that are not directly attributable to either Federal or non-Federal initiatives. Also, the variance among individual projects is extreme enough to call into question what may be inferred from an application of the mean as a measure of central 
tendency .

Whereas the post-LCA Little Dell, Utah project is approximately half of the originally authorized project size, some cost shared flood control projects have experienced growth in real dollar terms. It should be noted that considerable cost estimate variance over time was also found among those flood control projects where cost sharing was not considered a factor in the ultimate project design and schedule.

TABLE XVI

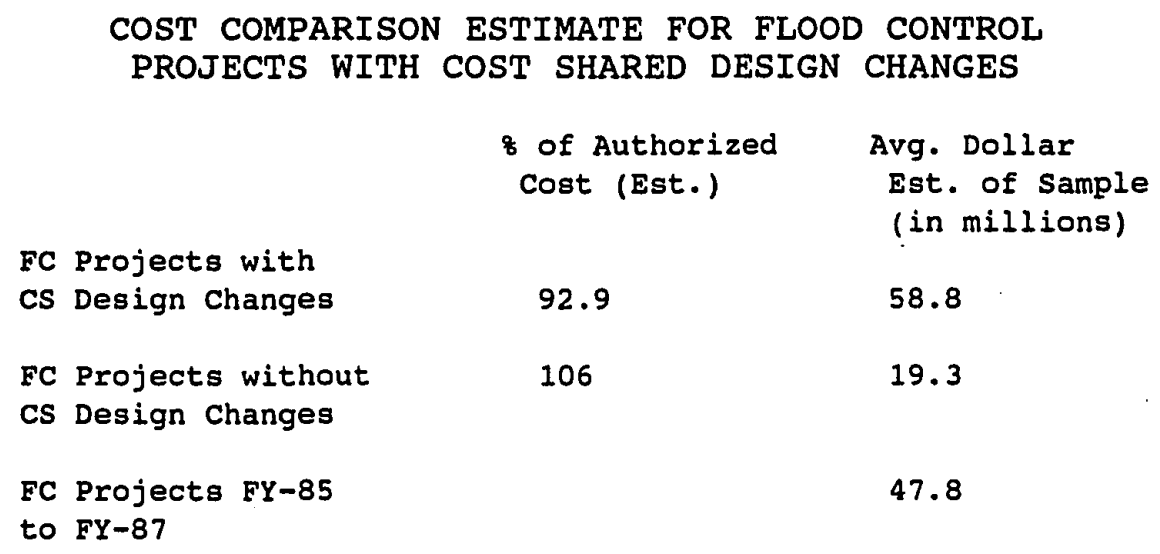

There would then appear to be statistical evidence that, on balance, the net impact of cost sharing on flood control projects will lead to a reduction in project size, particularly for large projects. There is no evidence, however, that projects will trend toward uniform size reduction. Cost shared modifications associated with flood control projects tend to be far less uniform than for 
navigation projects and frequently involve the adoption of alternative engineering solutions rather than the addition or deletion of a project feature. Such changes are frequently agreed upon during the feasibility study stage and so become difficult to separate and identify as products of cost sharing.

Based on a comparison of the average total dollar of projects which experienced changes as a result of cost sharing and those which did not, it may be inferred that large dollar projects may be more "sensitive" to cost sharing than small dollar projects. This finding is consistent with the view that pay-as-you-go financing represents a serious constraint for projects whose outputs are non-vendible and/or where the local interest must rely on bond financing for the generation of revenues to fund the non-Federal share.

Cost Trend for Cost Shared Navigation Projects The analysis of cost shared impacts for commercial navigation projects is somewhat more straightforward than that for flood control owing largely to the fact that the rates of return on individual project investment are more easily calculated and the fact that navigation project design features are comparable across projects. Table XVII provides a list of the 39 channel and harbor improvement projects authorized by the WRDA 1986. As of July, 1989, the 
Water Resource Support Center reported that 15 ports had signed LCAs (Skaggs 1989). The magnitude of the impact of cost sharing is particularly profound if one accepts the premise that phasing and staging of construction in fact represents a proxy condition for project size reduction.

TABLE XVII

WATER RESOURCES DEVELOPMENT ACT OF 1986 AUTHORIZED CHANNEL IMPROVEMENT PROJECTS

PORT

AUTHORIZED DEPTH

Mobile Harbor, AL $55^{\prime}$

Missj.ssippi R. Ship Ch., Baton Rouge, LA to Gulf $55^{\prime}$ Texas City Channel, TX

Norfolk Harbor \& Channels, VA

Los Angeles \& Long Beach Harbors, CA

New York Harbor \& Adjacent Channels, NY \& NJ

Kodiak Harbor, AK

St. Paul Island Harbor, AK

Oakland Harbor, CA

Richmond Harbor, CA

Sacramento Deep Water Ship Channel, CA

New Haven Harbor, CT

Palm Beach Harbor, FL (maintenance only)

Manatee Harbor, FL

Tampa Harbor, East Bay Channel, FL

Savannah Harbor, GA (widening only)

$50^{\prime}$

$60 / 55^{\prime}$

$65 / 76^{\prime}$

$55 / 45^{\prime}$

$20^{\prime}$

$18^{\prime}$

$42^{\prime}$

$41^{\prime}$

$35^{\prime}$

$40 "$

$33^{\prime}$

$40^{\prime}$

34 '

$38^{\prime}$

Hilo Harbor, HI

Grand Haven Harbor, MI

$39^{\prime}$

$27^{\prime}$

271

271

$38^{\prime}$

Duluth-Superior, MN \& WI

Pascagoula Harbor, MS

$38^{\prime}$

Gulfport Harbor, MS

$35^{\prime}$

$40^{\prime}$

$45^{\prime}$

Kill Van Kull, NY \& NJ

$35^{\prime}$

Wilmington Harbor \& Cape Fear River, NC

271

Cleveland Harbor, OH (bulkheading \& repairs only)

$27^{\prime}$

Charleston Harbor, SC

Brazos Island Harbor \& Brownsville Channel, TX

Blair \& Sitcum Waterways, Tacoma Harbor, WA 
TABLE XVII

WATER RESOURCES DEVELOPMENT ACT OF 1986 AUTHORIZED CHANNEL IMPROVEMENT PROJECTS (continued)

PORT AUTHORIZED DEPTH

East, West, \& Duwamish Waterways, Seattle Hbr, WA $39^{\prime}$ Saipan Harbor, Northern Mariana Islands 12' San Juan Harbor, PR

St. Thomas Harbor, VI Fresh Kills in Carteret, NJ Arthur Kill, NY \& NJ Lake Charles, LA

Source: Report of the Committee on Public Works and Transportation to Accompany H.R. 6. 1985.

Seventeen navigation projects requiring LCAs were evaluated. An abstract of design changes to on-going cost shared navigation projects is provided below in Table XVIII. Table XIX provides pre and post-LCA data on project costs and their distribution.

The data on deep draft and harbor construction projects tends to confirm assertions that anticipate potential reductions in project size and phased construction, particularly with regard to large projects with indefinite benefit streams. This trend was tested and confirmed through selected interviews with sponsors of navigation projects that had elected to phase construction or otherwise reduce project features depth, width, etc.

Nine navigation project sponsors were interviewed. The sample can not be considered representative of all 
navigation project sponsors as the nine projects were selected on the basis of sponsor initiated design changes or phased construction. Thus, while the "findings" do not lend themselves to statistical generalization, they do offer further insight as to why a navigation project sponsor may be induced to press for design or scope modifications. A composite summary of interview responses as to why they chose to proceed with smaller than authorized projects suggests the following:

(1) Port sponsors are uncertain as to the magnitude and timing of induced traffic benefits projected in Corps planning models.

(2) Sponsor initiated financial analysis focuses on the instant benefit increments that will be realized with implementation of the project and tends to discount benefits associated with induced traffic for new commodity markets and benefits for which there exist no in-place recovery mechanisms.

(3) Sponsor behavior with respect to development is competition driven. Projects whose features would provide or help maintain a competitive market position are supported. However, expansion of port capacity beyond what may be thought of as the competitive margin and which requires large front end capitalization costs and increased operation and maintenance costs is considered a high risk investment. Sponsor investment behavior is "incremental" with minor adjustments made to achieve or maintain a market share.

(4) Sponsors are willing to assume greater design risk than would be typically afforded by Corps design standards. Where appropriate, nonstructural alternatives may be preferred, particularly if the cost of the alternative solution is more readily recoverable or transferable to shipping interests (e.g., the use of tug assisted tows rather than construction of turning basins). 


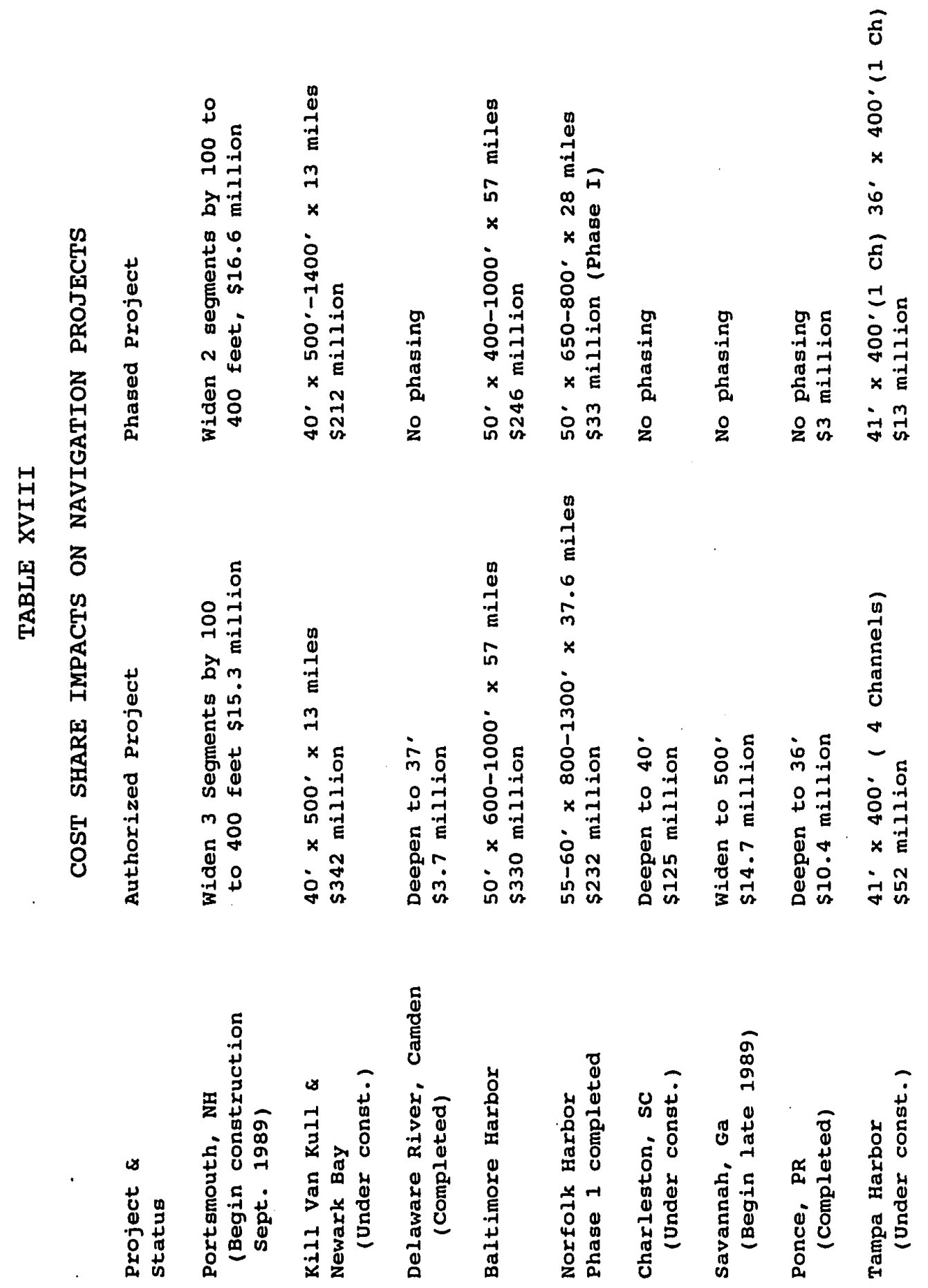




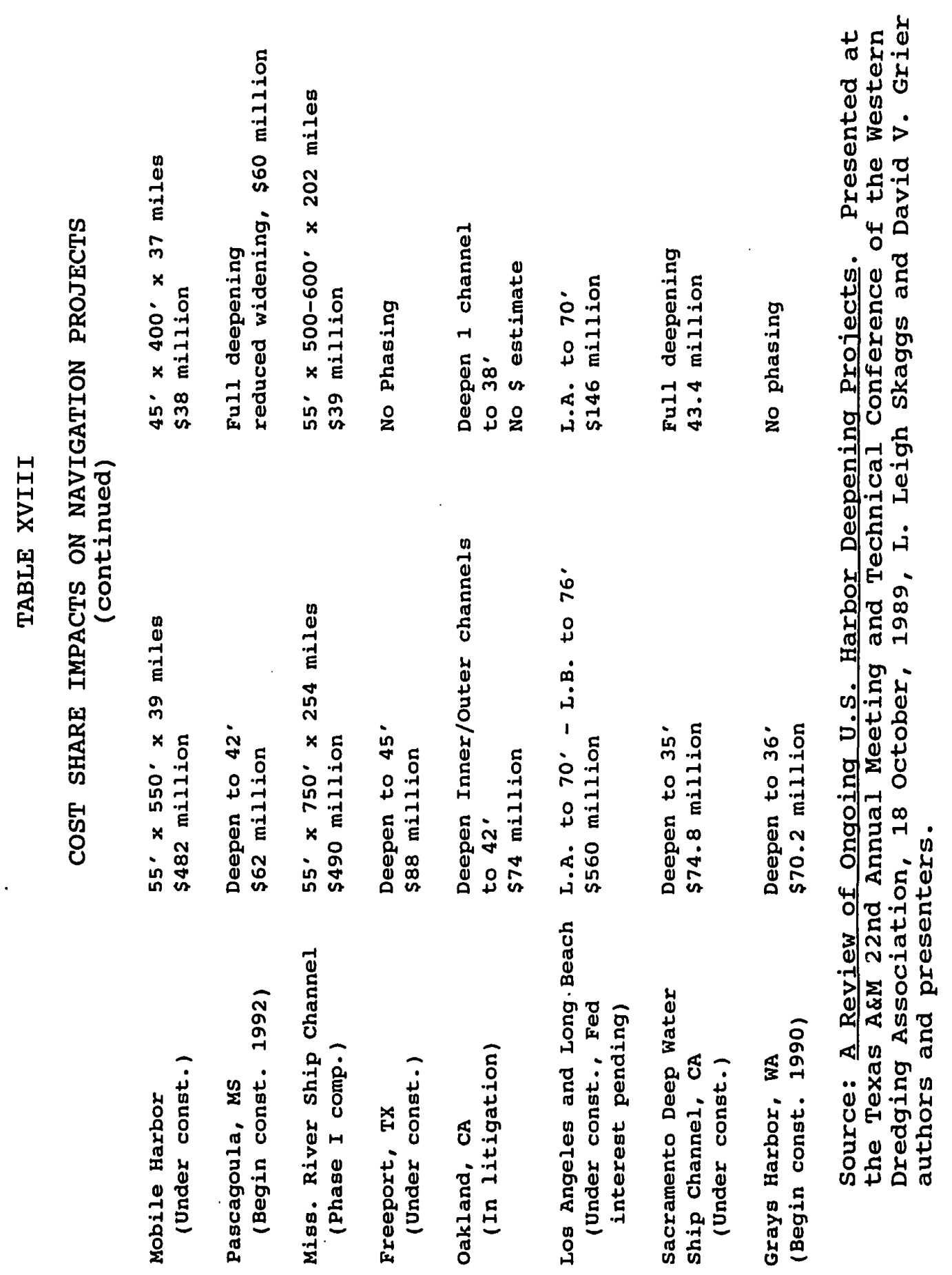




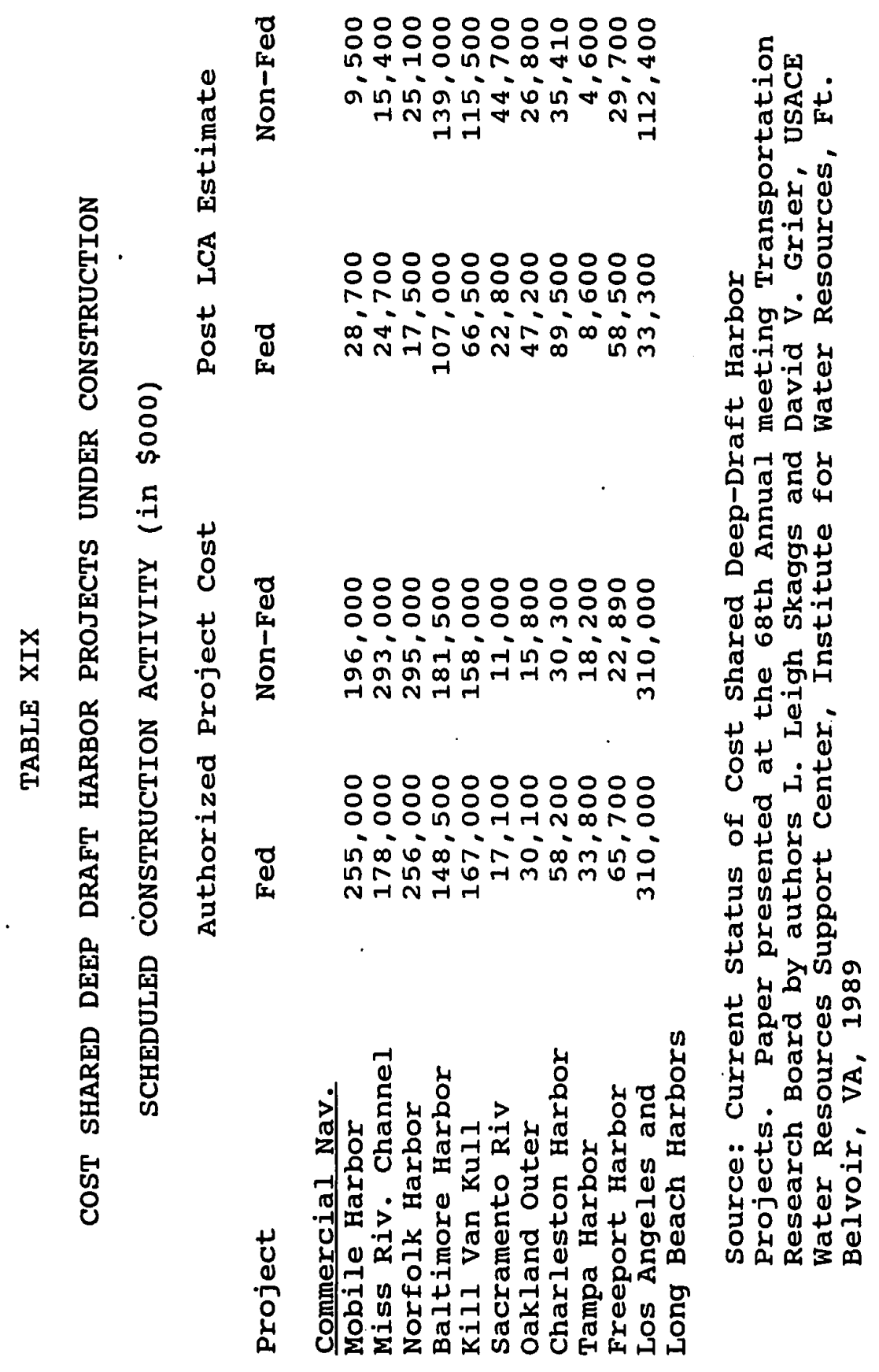


General Project cost Trends

Whereas an assumption of discernible trends in

declining project size, and potentially declining numbers of new starts is consistent with the available data on cost shared projects it would be precipitous to suggest that implementation of cost share principles initiated the trend. Were that the case, one would expect to see, subsequent to the implementation of WRDA 1986, an identifiable downward trend in authorized project size, number of new starts, number of authorized studies, etc. Longitudinal data on such indicators, as provided in Table XX, does not support such a conclusion.

TABLE XX

CORPS OF ENGINEERS CONSTRUCTION GENERAL EXPENDITURES

(In constant 1965 dollars $\times 1000$ )

FY Actual Appropriation Value 1965 \$

$\begin{array}{rrr}1967 & 965,955 & 965,955 \\ 1968 & 967,599 & 920,253 \\ 1969 & 862,714 & 778,849 \\ 1970 & 711,992 & 586,126 \\ 1973 & 851,178 & 649,916 \\ 1972 & 1,025,084 & 703,666 \\ 1973 & 1,203,943 & 726,796 \\ 1974 & 873,589 & 502,346 \\ 1975 & 966,338 & 501,177 \\ 1976 & 1,237,151 & 600,374 \\ 1977 & 1,430,195 & 618,289 \\ 1978 & 1,537,820 & 618,674 \\ 1979 . & 1,343,711 & 506,440 \\ 1980 & 1,659,752 & 580,661 \\ 1981 & 1,593,892 & 514,327 \\ 1980 & 1,429,992 & 431,768 \\ 1983 & 1,508,405 & 415,873 \\ 1984 & 926,804 & 241,009\end{array}$


TABLE XX

CORPS OF ENGINEERS CONSTRUCTION GENERAL EXPENDITURES (continued)

(In constant 1965 dollars $\times 1000$ )

FY Actual Appropriation Value 1965 \$

$\begin{array}{rrr}1985 & 947,500 & 234,326 \\ 1986 & 879,830 & 216,062 \\ 1987 & 1,148,918 & 269,129 \\ 1988 & 1,200,175 & 266,987 \\ 1989 & 1,184,735 & 252,391 \\ 1990 & 1,199,790 & 249,085 *\end{array}$

*Estimate of appropriation

Source: United State Army Corps of Engineers, HQ USACE Civil Works - Western Branch (1989).

Gross data on Federal aid to state and substate levels of government confirms that the pattern of reduced Federal assistance for water resource development. is consistent with the larger trend of reduction in Federal transfers to subnational jurisdictions for all programs. According to data compiled by the U. S. Advisory Council on Intergovernmental Relations (ACIR) the trend is partially attributable to a philosophy of decentralized Federalism and partially to Federal deficits that work to constrain policy choice to those programs that are essentially national in character (U.S. ACIR Summer/Fall 1987, 36). See Figure 4. for a graphical analysis of this phenomenon.

The data shows that, whereas, federal aid to state and local government rose in both real and nominal terms from 1950 through 1970 it ceased to do so in 1978. The most 
The Rise and Decline of Federal Aid, 1958.88 (as a Percentage of State-Local Outlays)

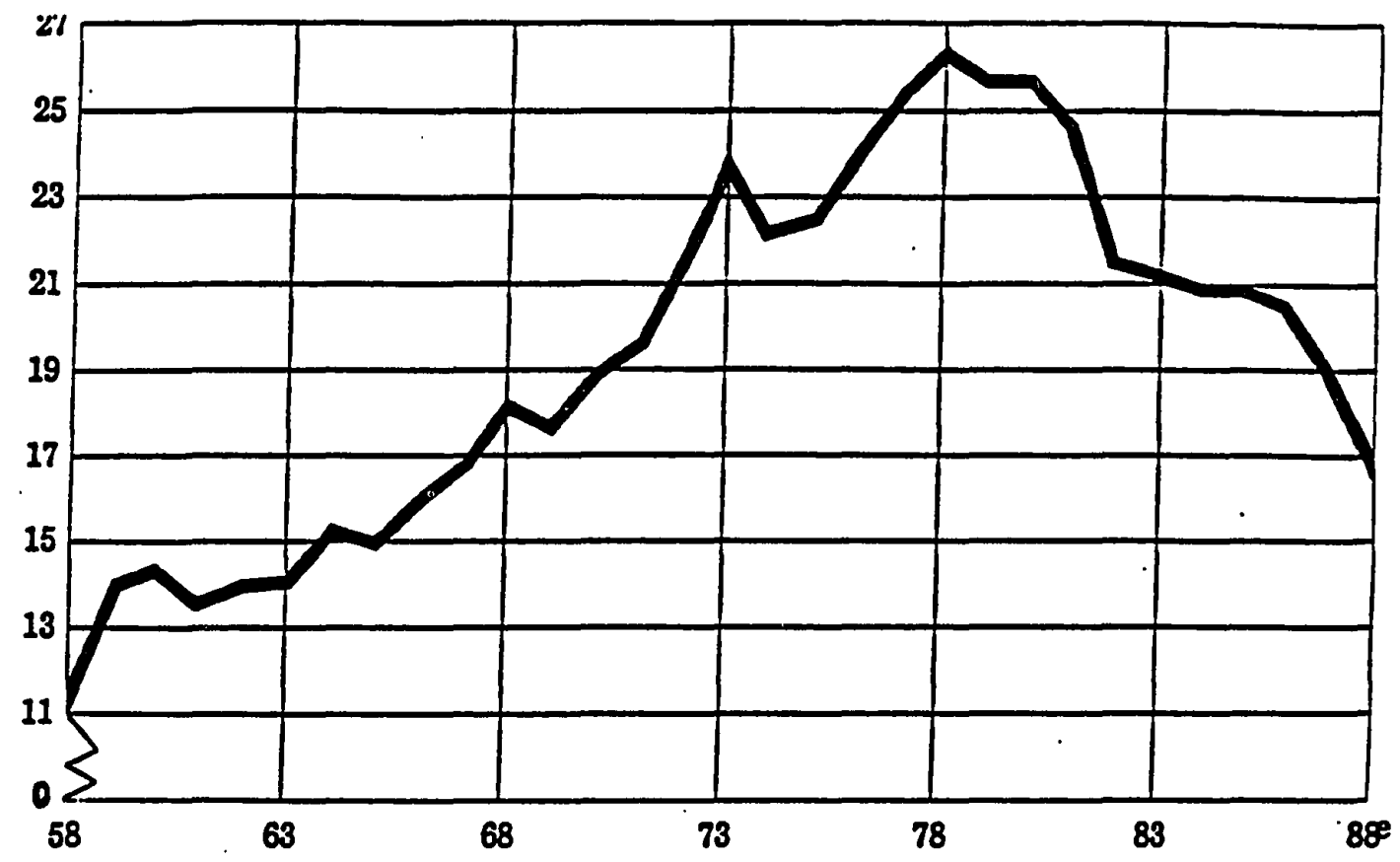

Fiqure 4. The Rise and Decline of Federal Aid 1958-1988. Source: U.S. ACIR, Summer/Fall 1987.

pronounced drop was in aid to local units of government. Federal aid to local governments was 8.6 times as great in 1981 as 1970 whereas aid to states over that period increased only $350 \%$. However, while aid to states continued to grow, direct Federal assistance to local governments suffered a reverse. By 1987 aid to states had increased by $40 \%$ over 1981 while aid to locals had decreased 13\%. (See Figure 5). This disparity is due largely to the fact that 
aid to states is more directly tied to means-tested entitlements (Swartz 1990, 100).

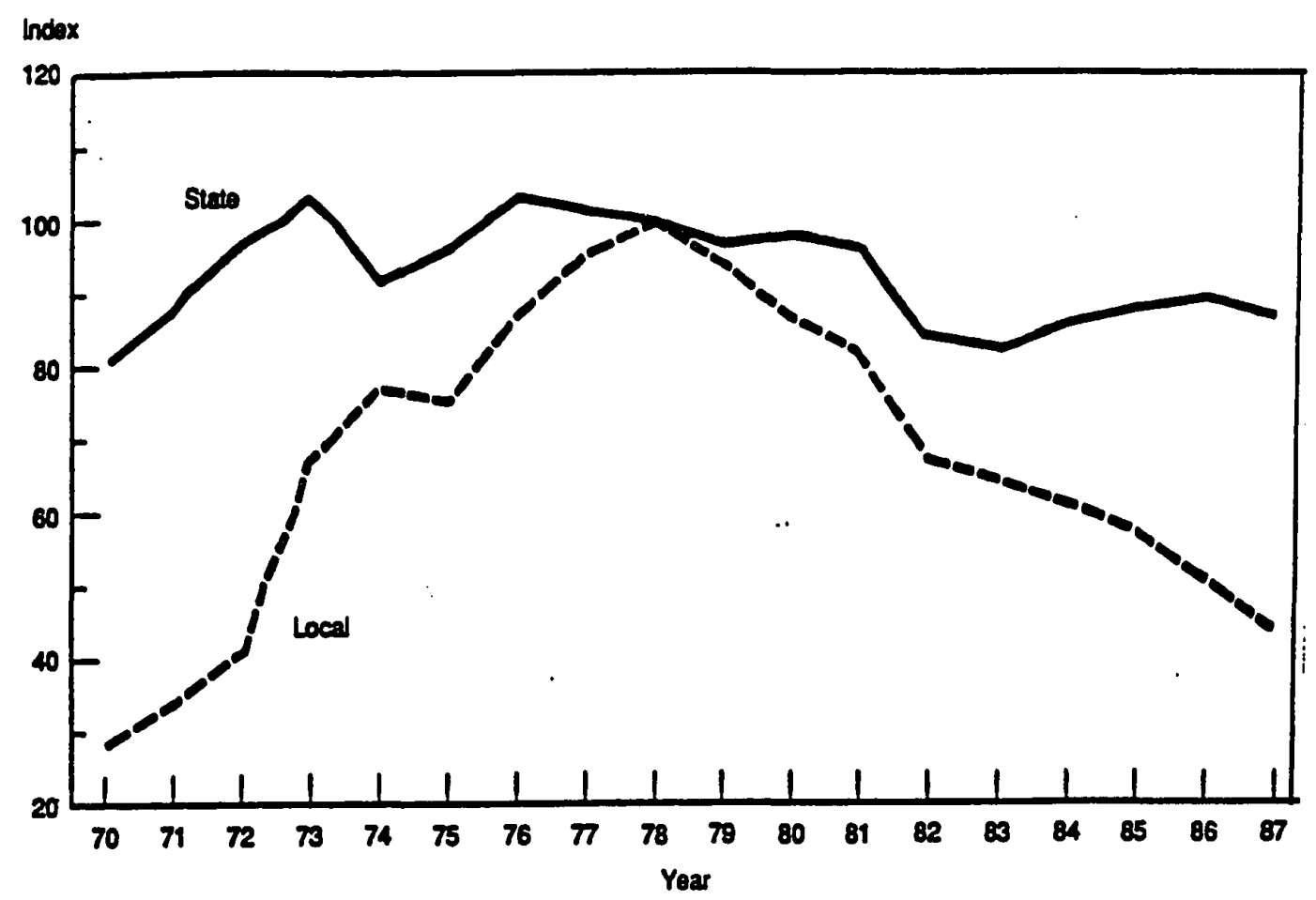

Fiqure 5. Federal Aid to State and Local Government per $\$ 100$ of Personal Income, 1970-1987 $(1987=100)$.

Figure 6. presents a graphic representation of federal aid to state and local government as a proportion of their general revenue. Tax effort data presented in Figure 7. reveals that tax effort, particularly for local governments, declined dramatically after 1979. State tax effort, which had declined from 1979 through 1983, showed increases after 1983 though not in excess of the highs registered in 1979 . Similarly, aggregate local tax efforts, through the late 
1980s failed to return 1978 levels. (Stonecash 1990, 756757.

Interestingly, the expenditure patterns reveal that the trend toward state centralization of direct service provision continued to increase throughout the 1980s, though the trend was slowed by the absolute decrease in Federal transfers subsequent to 1987. This observation is, of course, consistent with the policy shift toward cost shared water resource development planning with its emphasis on state and local involvement in both planning and funding. of direct significance to this analysis is the observation that public support for all levels of public investment activity exhibited a reduced rate of growth subsequent to 1978 .

The assertion that cost sharing will lead to fewer projects acknowledges the potential influence of the "market like" requirements of cost share principles which, by design, inhibit continued activity on projects that lack local support as determined by WTP. It also accounts for the impact of Federal budget constraints. on funding for water resource development specifically and Federal assistance to subnational units of government generally. There is no question but what cost is a primary, if not the principal concern of sponsors. When project sponsors were asked which aspect of cost-sharing they had the greatest 


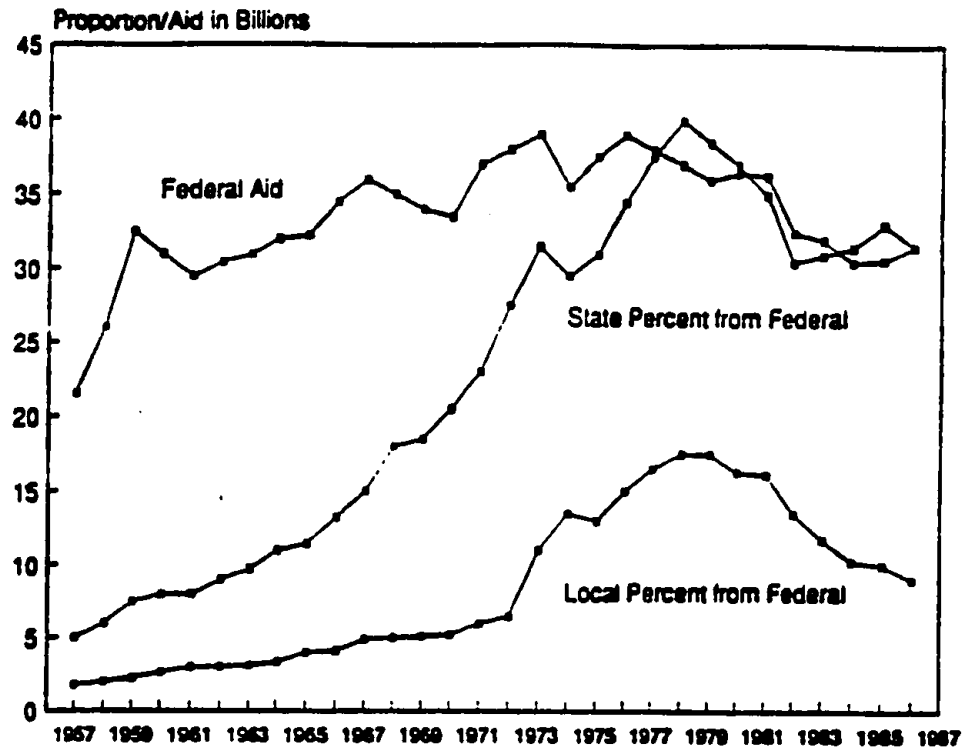

Figure 6. Changes in Federal Aid to state and Local Government (1957-1986). Stonecash 1990.

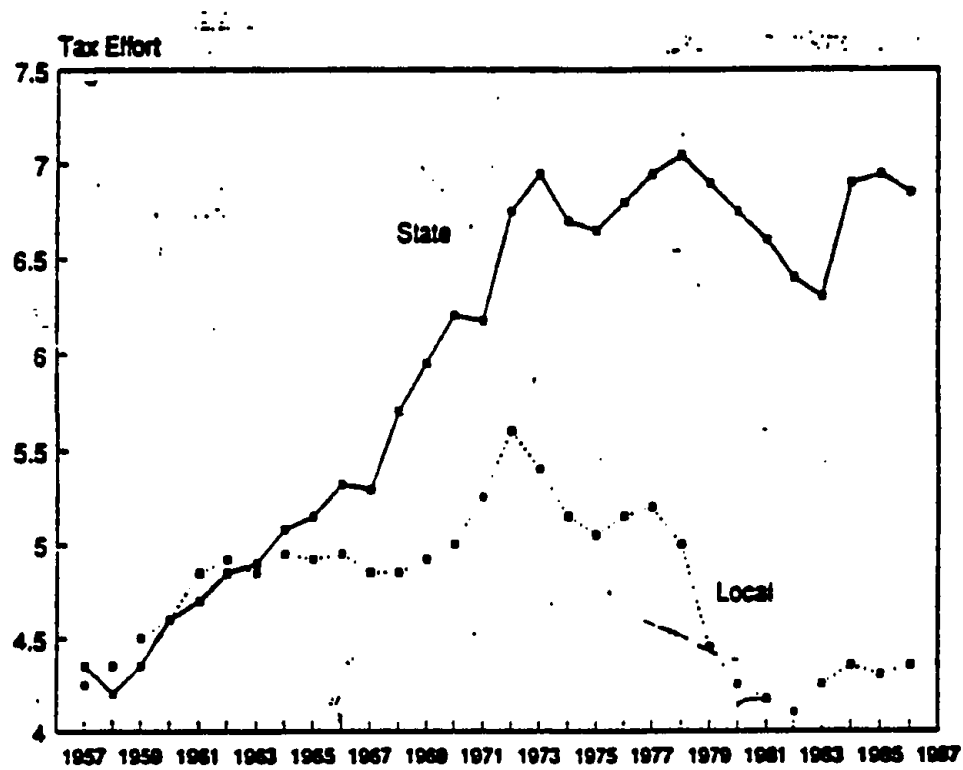

Figure 7. State and Local Tax Effort by Level of Government (1957-1986). Stonecash 1990. 
concern with, total study/project cost led the list of issues by a large margin (U.S. GAO 1991, 19).

Because the focus of the discussion has largely been restricted to the financial capacity of the non-Federal interest it is here important to note that the research found evidence of significant restraining influences on the "growth" of the water resources industry unrelated to sponsor resources or preferences. Since the inception of the WRDA 1986, the office of Management and Budget (OMB) has routinely recommended fewer projects for inclusion in the executive budget than are submitted for consideration by Congress. The Executive branch in this way argues both for influence over the mix of projects authorized and the size of the total Federal budget dedicated to water resource. development. Thus, while cost sharing may result in fewer projects competing for budget consideration, the relative decline in appropriations for new start construction appears to be associated as closely with budget constraints (at all levels of government) as with the implementation of cost sharing.

It is, of course, far easier to establish a funding trend based on historical data than to predict the probability of that trend being sustained over time by future authorizations. In an to effort evaluate the long range impacts of cost sharing the research sought to identify a set of indicators which were known to influence 
the project selection process. A direct indicator of future project activity is the volume of reports submitted to the Washington Level Review Center WLRC (formerly the Corps of Engineers of Board of Rivers and Harbors (CEBRH). If cost sharing will indeed lead to fewer projects as a result of lack of sponsor commitment, that phenomena should be reflected in the report traffic submitted to the Board whose review authority includes, but is not limited to, all feasibility studies for $\operatorname{COE}$ cost shared projects.

A review of WLRC activity in May of 1992 revealed that the volume of reports subject to WLRC review had indeed declined since 1986. Subsequently, the WLRC has reduced the average review time for a project from $5 \frac{1}{2}$ years to 11 months.

Concomitantly, if "better" projects emerge from cost sharing one would expect to see the ratio of projects reported out of the WLRC with a favorable recommendation to increase. Data show that from 1975 to 1986 the WLRC reported out 266 (49.7\%) favorable reports and 269 (50.3\%) unfavorable reports. During the post-WRDA 86 era, from 1987 to 1992 , the WLRC reported out 42 (36\%) favorable reports and 72 (63\%) unfavorable. Assuming no major shifts in review criteria or application, the data does not confirm that the overall quality of projects submitted for review since inception of cost sharing is substantially greater. 
A companion argument to the "fewer new starts" assumption involves the use of cost shared planning as a market test of project feasibility. This effort attempts to identify early on local support and screen marginal projects before large time and dollar study commitments are made (Stakhiv and Wright 1984, Huddleston 1987). Reconnaissance studies, while they are funded $100 \%$ by the Federal interest are, ostensibly, not engaged in unless potential sponsors of sufficient capacity to support the project have been identified. Once the reconnaissance study is completed, favorable projects may not transition to the feasibility study phase unless the sponsor is willing to engage in cost sharing $(50 \% / 50 \%)$ the feasibility study with the Federal interest.

Has cost sharing effectively filtered "weak" projects prior to implementation of the cost shared feasibility study? Again, the available data is limited and inconclusive. It would appear, however, that as only one non-Federal interest during the FY 86-87 period (see Table XXI) chose not to participate in a recommended feasibility study the sample of favorably reported reconnaissance studies enjoyed strong local support.

Still, it is important to note that sponsor support of cost shared feasibility planning, and the project that emerges from that process, may differ significantly from sponsor support of an authorized project formulated under 
TABLE XXI

RECONNAISSANCE STUDIES

STARTED IN FY 1986-87

Total Studies started

62

Studies Still Underway 12

Studies Terminated 8*

Studies Completed $\quad 42$

Unfavorable Reports $\quad 7$

Favorable Reports 36**

To be Accomplished Under Other
Program

Sponsor Refused to Continue With
Feasibility

Awaiting FCSA $\quad 16$

FCSA Signed

* No information on reason for termination. ** Two reports generated from one study.

the prior doctrine of mandated Federal design. Sponsors would be expected to express a preference for projects that were designed cooperatively and for which they felt "ownership." For these projects, the previously discussed Federal interest positions regarding risk, capital intensive solutions, etc. will have been mediated by non-Federal interest input during the feasibility planning process.

\section{Conclusion}

The argument that smaller projects or projects which 
employ phased construction will result from the application of cost sharing is relatively widely shared and, at least theoretically, appears firmly grounded on the presumption that market-like incentives will act to reduce the size and number of projects ultimately emerge from the process. The existing data is confirming, particularly for commercial navigation projects. While the correlation between cost sharing and size reduction is significant the data may be misleading to the extent that it overstates the case for cost sharing as being a first order initiator of a trend that the data indicates was observable nearly a decade prior to the widespread implementation of cost share principles in the field of water resource development.

In addition to general trends of reduced Federal aid to state and local government for all purposes, one must also consider the role of capitalization in "a maturing industry." (See Figure 8 below). The private sector analogy is here appropriate when one considers the history of water resource development.

The transitional preference from hydropower projects to navigation and flood control is indicative of an "industry" that, at least in one sector, has matured. Dollar expenditures for the water resource systems would not necessarily be reduced but shifted to operation, maintenance and renewal of existing infrastructure (Cortner 1987, 6).

The argument for maturity of the industry as a whole is 
further supported by the fact that in 1984, for the first time since the inception of the Corps' Civil Works mission,

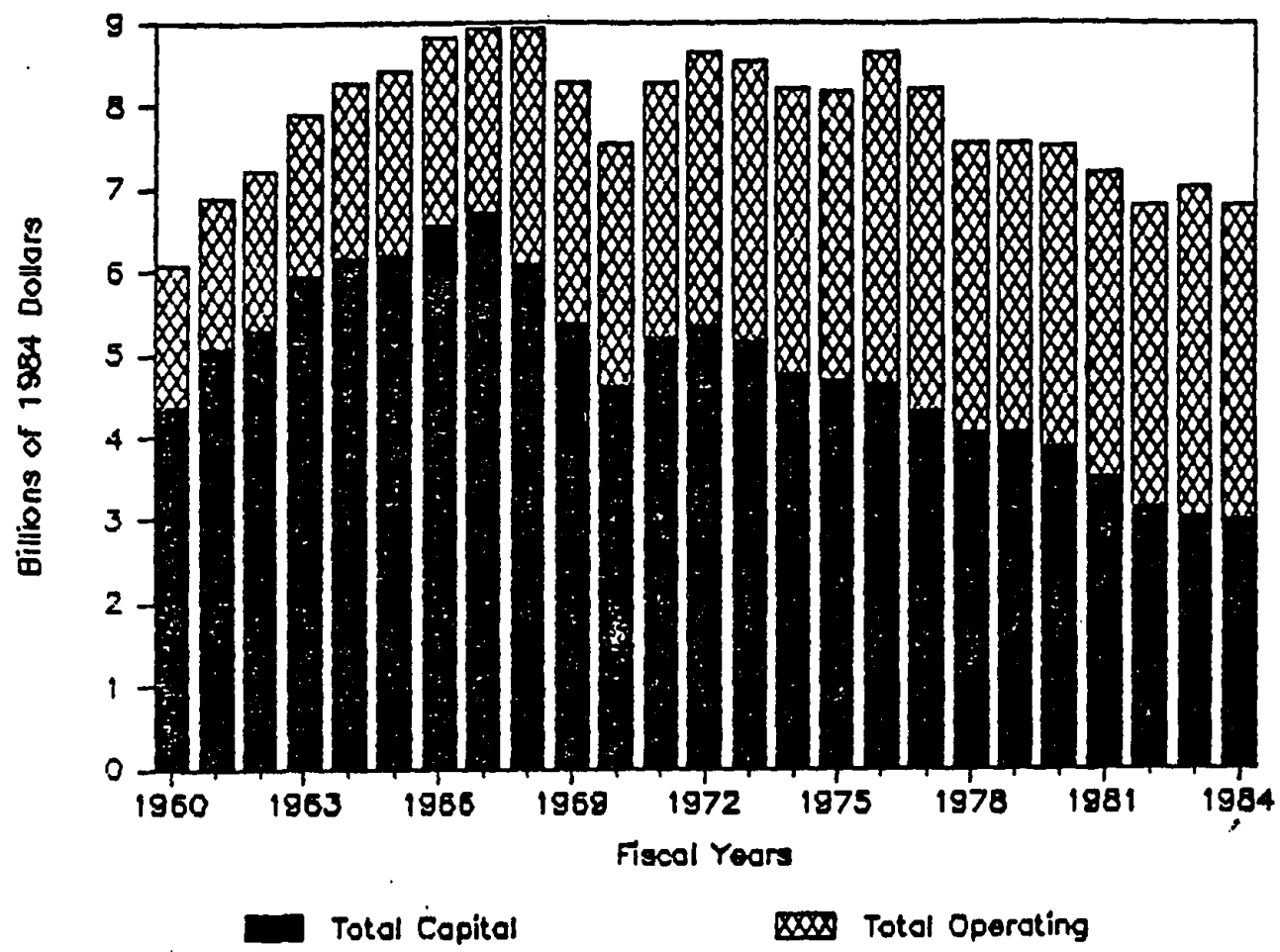

Fiqure 8. Capital and operating outlays for Water Resource by All Level of Government. Source:

Apogee Research from Congressional Budget office.

the operation and maintenance budget exceeded the construction budget while the civil works workforce declined from 33,000 in 1978 to 26,000 in 1987 (Bowman 1986). In the case of a public goods industry, maturation does not suggest that opportunities for new development have been exhausted. An argument may be made for private sector development of 
the remaining potential (as appears to be the case for hydropower) or a call for a "slowdown," an incrementally reduced public development effort.

While cost sharing clearly contributes in a significant way to the observed trend, questions remain as to the extent of change that can be directly linked to the impact of cost sharing. Future research is required on cost shared projects, including projects that were planned and constructed under cost sharing, and application of a sophisticated multiple regression model able to account for the discrete explanatory impact of cost sharing as a single variable. Absent such findings, it can only be said with certainty that the implementation of cost share principles have acted in concert with a larger body of constraints to lead to a "downsizing" of cost shared developed water resource projects. Among those constraints herein identified would be the implementation of Federal deficit - reduction criteria, local funding constraints, the uncertainty of cost recovery for non-vendible project outputs, reduced state aid to local governments for resource development, the requirement for front end financing of cost shared projects, and the cost of money. 
COST SHARED PROJECT DEVELOPMENT AND ENVIRONMENTAL IMPACTS

To that end, the pragmatic consequence of these financial adjustments (cost sharing) may be much smaller scale projects which reduce the absolute level of social and environmental impacts, even without emphasizing the attainment of social and environmental objectives.

Eugene Z. Stakhiv (Stakhiv 1986, 112)

The third assumption under consideration, that cost sharing will lead to reduced environmental impacts, may be evaluated positively (sponsor initiatives will lead to the adoption of more environmentally sensitive plans) or measured as a by-product of project size reduction. Whereas the outcomes are similar, there is merit in attempting to distinguish between influences when measurable reductions in impact are observed.

Early proponents of cost sharing and a number of environmental groups find in the implementation of cost share principles the promise of reduced environmental impacts associated with water resource development projects. Their optimism is attributed to the potential reduction in impacts as a result of 1) smaller projects, 2) fewer projects, and 3) projects that more fully account for the environmental sensitivities of local (non-Federal) interests. Groups such as the National Wildlife Federation saw in cost sharing an opportunity for the Corps to "... identify ways to cope with a problem without building an 
enormous project." Other analysts, such as Kenneth Rubin, a former budget analyst for the Congressional Budget office, were less sanguine noting that, "If you don't want a structural solution don't call the Corps" (National Journal November 1986,2824 ).

Nevertheless, the assumptions associated with cost sharing led to general environmental support for the legislation, though that support was largely attributable to the Act's requirements for submission of mitigation plans with proposed project plans (Sec. 908) and implementation of the mitigation plan prior to or concurrent with construction (Sec. 906).

To assess the foundations of this line of reasoning, and to test for continuing support of cost share principles among organized groups associated. with environmental issues, four environmental interest groups were selected to elicit their views on the probable impacts of cost sharing: the Izaack. Walton League, Friends of the Earth, Wildlife Management Institute and the National Audubon Society. Phone interviews were held with national headquarters representatives of the selected groups. The representatives registered uniform support for cost share principles, largely for the aforementioned reasons. The sentiment of the environmental community was that smaller cost shared projects more accurately reflected the "true needs" of the sponsor/region and that pure "pork barrel" projects were 
less likely to be supported when cost share constraints were applicable. Concomitantly, the groups were unanimous in their belief that cost sharing would lead to project size reduction.

Though support for cost share principles was broad it was not without reservation. There was acknowledgment that local sponsors, faced with cost sharing mitigation, may attempt to trade off environmental quality (EQ) for additional authorized benefits or attempt to defer implementation of the mitigation plan. It was the consensus of the environmental organizations that, should such patterns emerge, a Federal response was appropriate. Among the recommended solutions was the targeting of Federal assistance to support mitigation efforts.

The assertion that a direct correlation exists between constructed project size and the magnitude of associated environmental impacts has normative implications to the - extent that it advances the position that water resource projects specifically, and development generally, have a negative impact on the natural environment. That may or may not be true in the short run, depending on the nature of the disruption and the capacity for compensating mitigation. It may be even less true in the long run as it is unreasonable to assume that, absent a project, lands will forever remain undeveloped, particularly if they are near urban 
development. Indeed, large multi-purpose projects that obligate considerable land holdings, thus ensuring open space over the life of the project, may represent increasing environmental quality (EQ) value as contingent lands are developed. This phenomena is readily apparent where Corps' projects abut suburban developments providing both a growth boundary and an environmental buffer.

Secondly, it is generally acknowledged that water resource projects have an impact on site-specific ecology often resulting in habitat substitution as a result of mitigation efforts. The environment is, in a sense, reorganized with the goal of achieving a balance between the degradation or elimination of existing habitat and the introduction of new or enhanced habitat. In the case of . mitigation, habitat substitution results when non-equivalent environments are substituted for lost habitat, an exchange most wildlife ecologists consider ecologically adverse. Opposition to such tradeoffs is frequently based on the net loss in ecological diversity. on the other hand, the net environmental change may be positive where features are added that enhance or stabilize the watershed and the aquatic environment (Stakhiv, et. al. 1989, 82).

The concept of "without plan" development is addressed in the P\&G, Chapter 5 of ER 1105-2-100. The guidance provides that "likely future conditions without a plan," should be used in evaluating the impacts of alternative 
plans. However, assessments of without plan environmental degradation due to likely development are necessarily conservative in the absence of knowledge about planned activities and foreseeable land use changes. Moreover, it is highly unlikely that the public perception of, and attraction to, existing resources is properly discounted for futurè non-plan encroachments.

Whereas a case can be made for a positive correlation between project size reduction and a reduction in associated impacts, it should not be presumed that reductions in impact are proportional to reductions in project size, even when the project feature experiencing reduction has direct, observable environmental consequences. The basis and significance of this argument is presented below.

Critical habitat destruction in the case of an impoundment occurs with the subsuming of the stream and riparian area as the reservoir is allowed to fill. The impact registers irrespective of the projected reservoir capacity. Studies reveal that lands that are subsumed at the project periphery, and which may be reserved if the project is scaled down, typically do not provide habitat as rich as that found along the riparian borders. Thus, while reductions in net impact may be achieved by reductions in project size (represented by a downsizing of reservoir capacity) the added increments of $\mathrm{EQ}$ will not be 
proportional to the reduction in project acreage and may, in instances where border lands are ecologically marginal, be negligible.

Though environmental quality is often one of the designed outputs of constructed projects the degree to which that output is factored in as an objective of the planning process will largely determine the extent to which a preferred development alternative is allowed to impact existing natural resources. It has been argued that multiobjective water resource planning, as exemplified by application of the criteria set forth in the Principles and Standards (U.S. WRC 1973), is substantively different from planning within the framework of a single purpose economic efficiency model (Principles and Guidelines 1983). The principal distinction between the two approaches rests with the treatment of $\mathrm{EQ}$. While the Principles and Standards treated $E Q$ as a project objective, the P\&G approach treats the protection of environmental quality as a planning constraint. Planning objectives are to be achieved with minimal impact on the environment. While the products of the two models are theoretically comparable, one would not anticipate similar environmental outcomes to emerge from these distinct planning regimes (Stakhiv 1976).

For the purpose of this analysis it is important that the distinction between "multi-purpose" and "multiobjective" planning be clearly identified. Multi-purpose 
projects are designed to provide for specific (multiple) outputs such as flood control, water supply, recreation, etc. Objectives may best be thought of as goals which are advanced by the production of project outputs; e.g. economic development, social equity, environmental quality. Multiobjective planning explicitly considers the achievement of broad social goals in conjunction with the more constrained assessment of monetary benefits associated with the individual purposes for which the project is authorized (Loucks 1986).

The production of environmental quality, whether it be evaluated as a constraining influence or as a desired objective has assumed public commodity status. As such, EQ embodies many of the attributes of a pure public good where a level of quality is consumed by all within the "benefit" area because no one individual can purchase a different level of $\mathrm{EQ}$. Thus, no true demand curve can be generated, only an estimate of the value individuals place on EQ based on the amount their elected representatives purchase (Freeman 1979, 4).

In this model, individuals purchase $E Q$, or more specifically a level of $\mathrm{EQ}$. In Figure 9., $A A^{\prime}$ represents the budget constraint of a set of poor individuals and BB' that of wealthier individuals. I and II represent the relative indifference curves for $\mathrm{EQ}$ and other goods. 


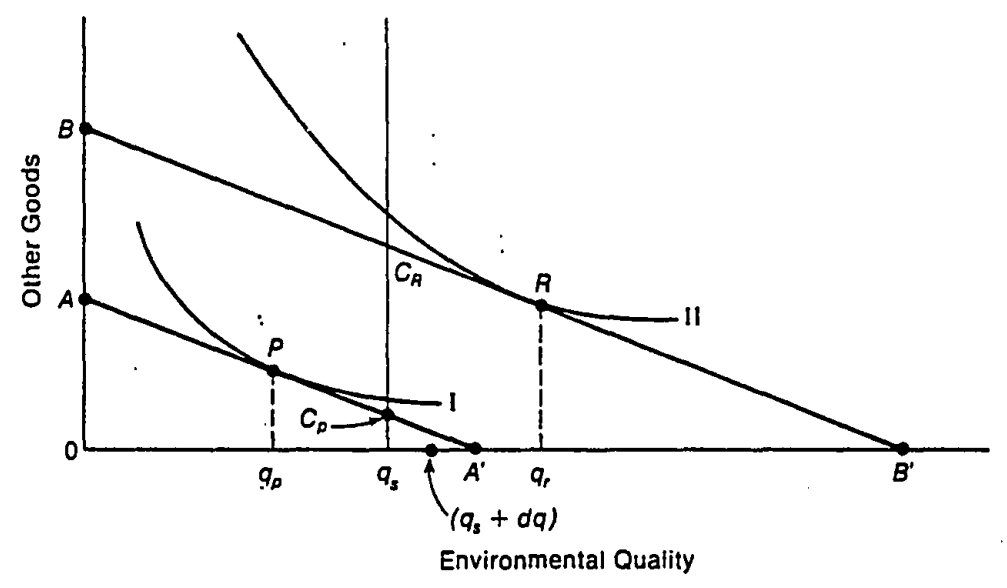

Figure 9. Output of Environmental Quality. Source: Baumol 1988, 198.

Because the provision of $\mathrm{EQ}$ is a social decision, the actual level of output will likely be a compromise represented by point qs. We would then expect for the more affluent to argue for more $E Q$ and the less affluent to argue for less given their stated preferences. (Note that this does not imply that the less affluent would prefer less EQ if the acquisition of $E Q$ did not involve tradeoff decisions between $E Q$ and alternative goods or services.) An appreciation of collective choice models and the potential for selection of sub-optimal levels of public goods is an important first step in understanding the implications of cost sharing with respect to distributional equity issues 
and the impact of market forces on sponsor demand for EQ benefits.

If the authorized $\mathrm{EQ}$ output is at qY it is unlikely that the sponsor would argue for greater $\mathrm{EQ}$ though he may wish to have greater participation in EQ planning. Indeed, there would appear to be incentive to argue for less EQ as qy represents more EQ than any one individual would voluntarily purchase. Similarly, an authorized EQ output at qz would represent less $\mathrm{EQ}$ than any set of individuals would purchase and pressure would be exerted for greater expenditure for EQ (Oates 1972, 76).

The model, particularly with respect to local flood control projects, has significant implications. Other goods may be here thought of not as representing items of personal consumption but competing local capital improvements for which there exists a demand. EQ output is "purchased" in the sense that sponsors participate in the development or approval of mitigation/enhancement plans and so are afforded an opportunity to negotiate for increases or decreases in the amount of $\mathrm{EQ}$. The choice of $\mathrm{EQ}$, however, is neither derived nor constrained solely by the sponsor's ability or willingness to pay. Guidelines for minimum EQ may be established by application of Federal interest planning guidelines and by the input of state and Federal environmental/natural resource agencies. output qY may be the preferred level of $\mathrm{EQ}$ by those 
agencies whose mission is directly related to preserving or enhancing EQ and who individually bear no direct costs related to the purchase of a specified level. The directed output of project EQ by agency interpretation of regulation is similar in concept, and probably impact, to the phenomena of state mandated services to county or local jurisdictions where fund transfers do not accompany the mandated service guidelines.

The argument that local sponsors may seek additional environmental features or larger $E Q$ outlays than would have been provided without formal sponsor participation in plan formulation cannot be made in the absence of data on the EQ output independently recommended by commenting resource oriented agencies. Because these comments must be considered and addressed in plan formulation (ER 1105-2-50) they have the effect of establishing a "baseline minimum" of EQ. It is important to note that the baseline is derived wholly without regard to the sponsors willingness or ability to pay for $E Q$ at the recommended level. The sponsor may purchase higher EQ, though the purchase will be at a premium as EQ that exceeds the amount required for mitigation is considered enhancement and is cost shared $100 \%$ non-Federal. Reduced $\mathrm{EQ}$ outlays are often infeasible as they are met with stiff resistance by resource agencies and environmental interest groups who are prepared to litigate. 


\section{Data collection on Cost Shared Projects}

To collect data on cost shared project impacts, 24

project managers and environmental resource specialists (all Corps personnel) involved with cost shared projects were interviewed by phone (June-September 1988). Five environmental interest groups were contacted and interviewed by phone for their perception of how the application of cost shared planning principles would impact project related environmental planning. A discussion of the issues and findings are discussed below.

As is too frequently the case, data on environmental impacts and compensating mitigation is difficult to track even on a within-project basis. This problem is particularly acute where different methods of identifying environmental dimensions and ecological values had been employed across the life of the project. One indirect measure of environmental impact is mitigation in so far as mitigation represents the "replacement" cost of the environmental values that were, displaced by the project.

When output units of lost values (e.g. dollar values or standardized habitat units) are non-comparable over time due to variations in the methodology that was applied, point-intime comparisons of mitigation as a measure of environmental impact are invalid. Why are project impacts so difficult to assign and assess? While the reasons are many and varied, 
three emerged from the interviews as being broadly recognized impediments to accurate impact measurement.

A potential measure of the standard unit reduction of impact in reduced scope projects would be a comparison of mitigation required at the time of original authorization with that required subsequent to negotiation of the LCA. Unfortunately, such comparisons are for the most part untenable as: 1) mitigation is not tracked as a line item cost element in project budgets; 2) many cost shared projects had mitigation plans that were developed under planning criteria that are substantially different from those which would now be applied. The potential for meaningful cross-plan comparisons is thus greatly reduced.

This condition is further complicated when attempting. to compare mitigation plans which do not require $100 \%$. mitigation of identified impacts as might be the case where there exists insufficient acquirable replacement habitat or where incremental analysis finds full replacement not to be justified on efficiency grounds, a determination for which there is currently no firm decision rule. in those instances, plans may be non-comparable on the basis of differentiated outputs as well as estimated costs.

Design alterations, which may have a larger impact on project related EQ than reductions in project size, may or may not be attributable to cost sharing. Such modification may be the result of a cost shared initiative or they may 
have emerged as a result of further "internal" engineering and design study. Thus, treating all design modifications on cost shared projects as "outputs" of cost shared planning will tend to overstate the impact of the process. Moreover, interviews with project managers and sponsor representatives confirm that proposed changes are frequently derived coincidentally or emerge from an indeterminable source. It is, of course, difficult to assess the impact of cost sharing where it cannot be determined which project features are properly attributable to cost shared planning or how the ultimate project would have looked in the absence of sponsor participation in the planning process.

The identification and measurement of environmental impacts (or avoided impacts) requires data generation and, in that respect, is not dissimilar to other forms of research requiring data collection in that there are associated costs. Interviews with project environmental specialists revealed that small measures may be taken which, based on knowledge of the project environment and professional judgment, increase EQ; but the increment of increase is not measured because the cost of assessment would likely outweigh the benefit achieved. Cost shared projects may be particularly susceptible to the incorporation of such "minor adjustments" which are consistent with sound environmental planning as well as 
sponsor preferences but which go largely unreported and unaccounted for.

Moreover, the "state of the art" in environmental

assessment has improved dramatically. This fact is reflected in the sophistication and level of detail reflected in $\mathrm{EQ}$ valuation reports. Valuations conducted today on a proposed project would likely not yield comparable findings to one conducted 10 or fifteen years ago. Project impacts, which may be empirically equivalent over time, may appear to vary significantly as a result of the methodology employed. Thus, a project reauthorized under cost sharing legislation may incorporate a mitigation plan which calls for a significantly larger mitigation effort than that of the originally authorized project when, in fact, project impacts have changed little if at all.

\section{Case Study Analysis of Cost Shared Projects}

To test for the impact of cost sharing on environmental impacts a sample of projects from the 1985 supplemental Appropriation and WRDA 1986 were selected for survey. The data collection focused on whether mitigation plans had been revised as a result of sponsor initiated changes to cost shared projects and whether the implementation of the mitigation was concurrent with construction. Bear in mind that a finding of "no change" in the mitigation plan cannot be directly interpreted as a finding of no change in project 
environmental impact. The findings are depicted in Table XXII. The data on post authorization revision of mitigation plans, at least for the selected sample, suggest that relatively few changes in mitigation plans can be attributed to cost shared changes except in those cases where large scale dredging projects are scaled back dramatically.

In the case of flood control projects, the data shows that environmental impact reduction was typically associated with reduced elimination of wildlife habitat on project lands. In those cases where dams or levee reaches were eliminated, reductions in effected lands were significant. Generally, however, reported reductions in impact were less substantial and only infrequently were such reductions quantified in land or habitat units. Notwithstanding the lack of quantified data on reduction units, environmental specialists involved with the sample projects reported that, where projects were reduced in size or scope, identifiable if not always clearly measurable reductions in environmental impacts were realized.

Deleterious effects linked to dredging include removal of habitat, resuspension of pollutants adsorbed to sediments, physical damage to organisms, the creation of a barrier to marine life, burial of habitat, change of flow patterns, and turbidity (Herbich 1975, 529). Impacts associated with reduced scope navigation projects are primarily associated with reduced turbidity, reduced 


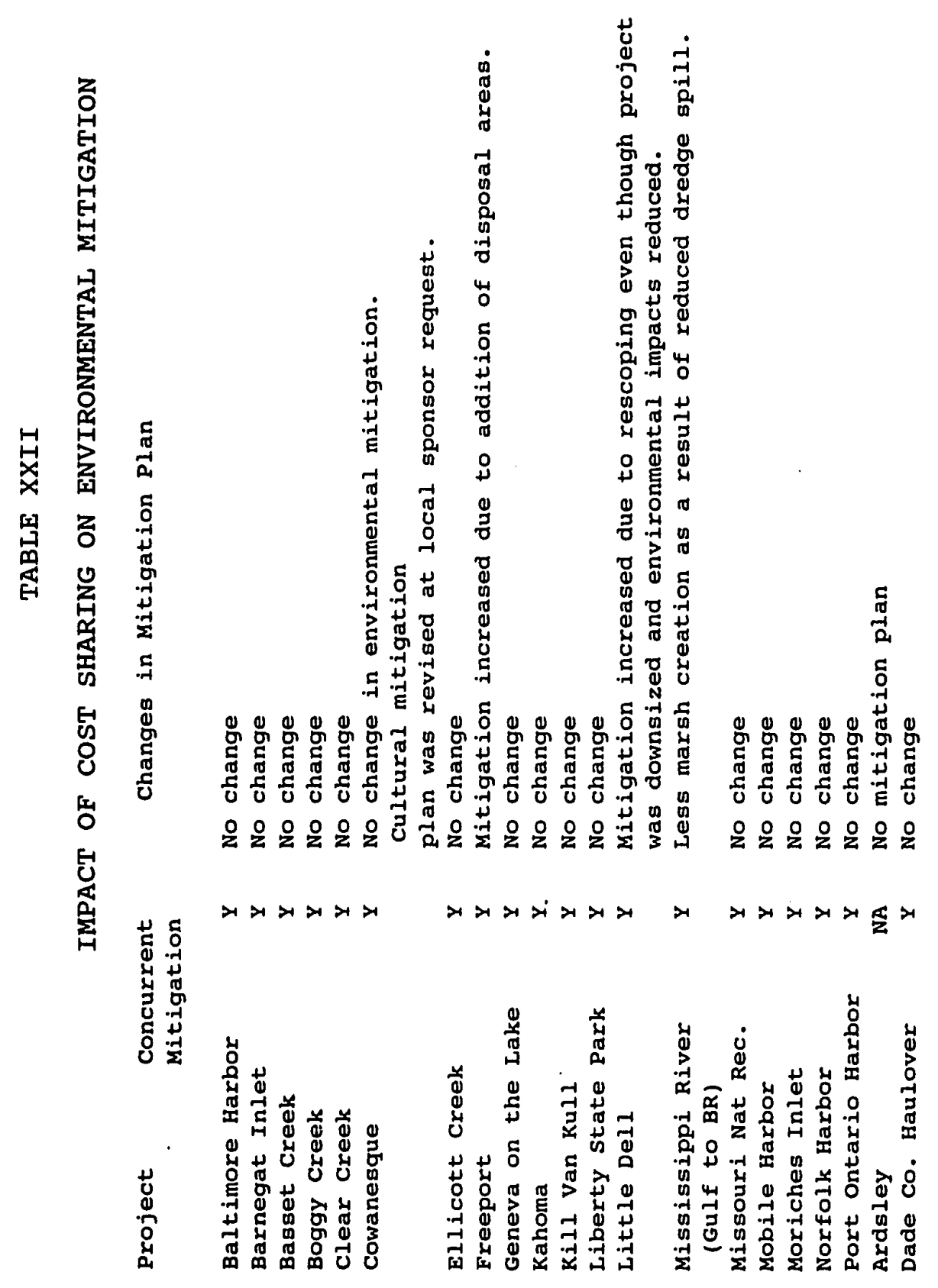




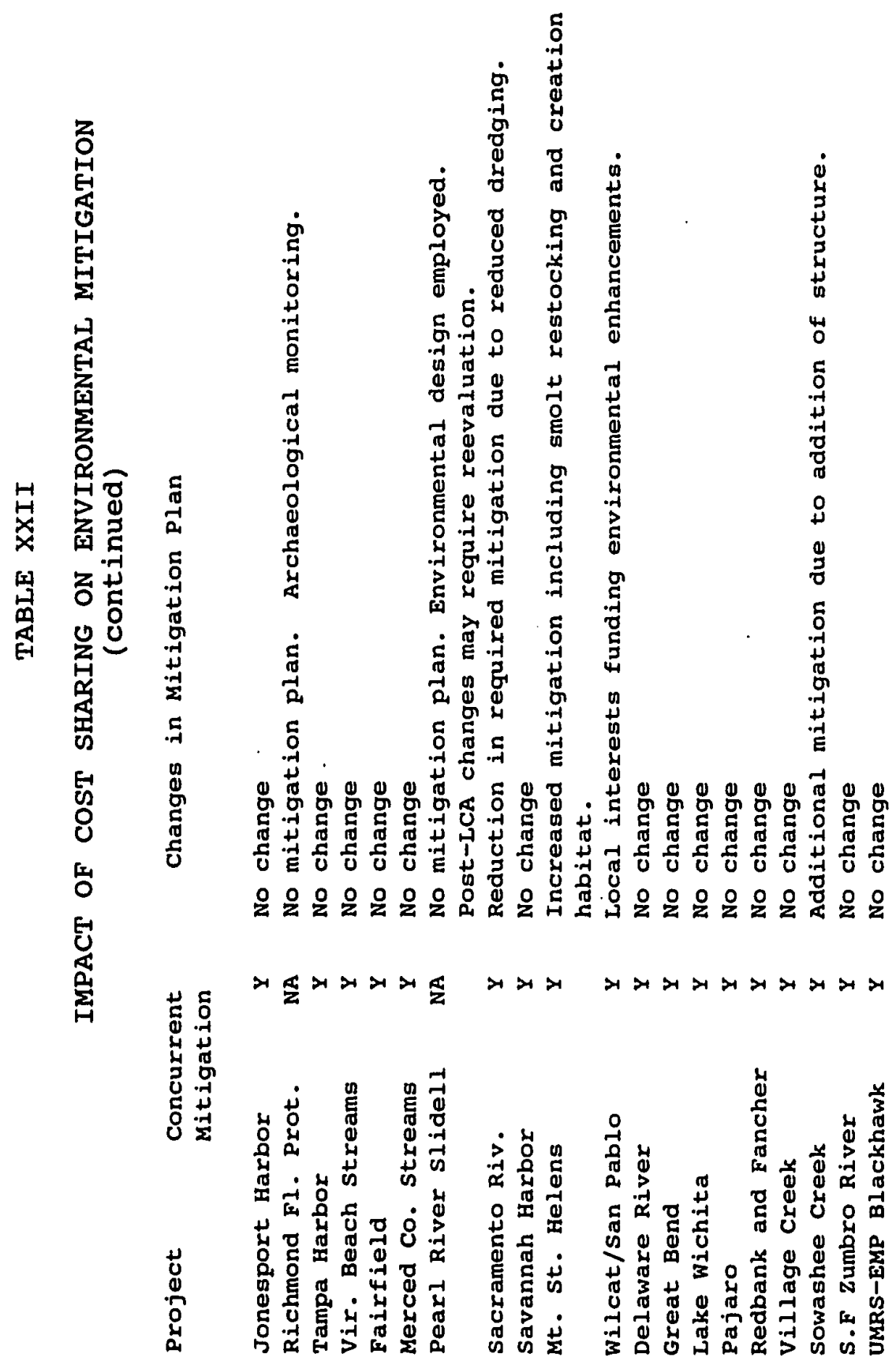


requirement for dredge material deposit, and less "deadwater" in channels. Of the nine navigation projects surveyed six reported reduced environmental impacts associated with reduced dredging requirements with the largest impact reductions linked to decreases in dredge fill. Where beneficial use of dredged material is not an option, disposal becomes a costly and sometimes environmentally critical issue. Indeed, such issues may determine the feasibility of navigation projects where the environmental sensitivity of the area call for the long haul transfer of spoil materials. Two projects, Oakland Harbor and Richmond (CA) Harbor, were forced to delay construction pending the resolution of litigation on dredge disposal sites.

Where contained sites are required, reduced fill has the effect of conserving capacity and thus deferring or eliminating the necessity and cost of developing new sites. Interestingly, reduction in the volume of dredge material and costs appear to increase geometrically rather than in a linear manner as dredge depths are decreased. A proposed ten foot reduction in the channel depth of the Mobile Harbor Deepening project reduced the estimated quantity of dredged material from one hundred forty one million cubic yards to eighteen million cubic yards. The relationship, which is not readily apparent when visually comparing alternative depth dredge prisms, depends largely on changes in the 
density of the material being dredged, the extent of sloughing on side slopes, and the rate of infill associated with the deeper channels. Exponential cost growth with increased depth is linked to depth dependent productivity loss, dredge disposal costs (particularly for upland or ocean off-shelf sites), and maintenance of the deeper channel.

Where upland disposal sites are used, reduced dredging requirements may lead to reductions in land obligations for mitigation. Land obligations typically involve siteadjacent lands being acquired to substitute for project lands lost as habitat. In the case of the Sacramento River Deep Water Ship Channel a reduction of proposed channel widening (400' to $350^{\prime}$ ) resulted in a twenty seven percent (27\%) decrease in the acreage (sixty-three to forty-six) required to mitigate project impacts.

Whereas the collected data on the linkage between project size and associated environmental impact is confirming, counter instances for both flood control and navigation suggest that the correlation is more complex than might at first be assumed. In fact, design modifications initiated by the non-Federal interest may lead to increased impact. Corps Environmental Resource specialists for two flood control projects reported design changes that either directly or indirectly resulted in increased impacts. 
In the case of Mingo Creek the sponsor's (City of Tulsa, Oklahoma) proposal which accommodated design plans for an unrelated airport project subsumed the original habitat-rich mitigation land thus requiring the acquisition of additional lands. Whereas the mitigation plan for the originally authorized project called for a thirty five acre set-aside the plan now calls for one hundred twenty five acres. Mitigation for the project is planned at $100 \%$. The sponsor of the Lock Haven Flood Control Project (City of Lock Haven, PA) requested that the airport runway alignment be reconfigured (extended) rather than tilted, in accordance with the originally authorized plan. This alternative allowed for new levee construction. The proposed realignment impacted two additional acres of wetlands, impinged upon a site having archaeological value, and required the purchase of a number of existing homes and relocation of the residents. In this instance, a broad range of impacts on the human environment, some quite difficult to measure, were associated with plan modification.

Whereas reducing the amount of dredge material associated with a navigation or harbor improvement project may lead to decreases in environmental impact there exists the potential for quite an opposite effect when beneficial uses for dredge material are proposed. Channel depth reduction for the Mississippi River Ship Channel project 
should result in less turbidity and reduced salt water intrusion from the Gulf of Mexico. However, as fill from the project would have been used to replace marshlands lost to subsidence the reduction in available fill may result in a net negative impact on the regional environment. As previously discussed, such tradeoffs, though conceptually straightforward, are almost impossible to accurately quantify.

\section{Conclusions}

While the body of evidence tends to support the assertion that environmental impact reduction is to some degree positively correlated to reductions in project size precise measurement is difficult. For that reason, the findings discussed below are offered with caution, the specific concerns being established in the discussion of each finding.

Based on specific projects where there were measurable decrements in environmental impact associated with project size reduction the assertion that project size reduction has a positive impact on environmental impact is confirmed. Their is no confirming evidence, however, that project downsizing will lead to impact reductions in all cases, or result in downward adjustments in impact proportional to size reduction. In specific instances, size reduction may result in projects that, over time, actually increase rather 
than decrease regional impacts.

Cost sharing will lead to projects that more accurately reflect local environmental interests but not projects that are dramatically different from what would have been authorized under pre-cost shared planning. Among the sample of projects surveyed, several reported sponsor initiated (and adopted) EQ features. Examples included avoidance of disturbing cultural sites by realignment of floodwalls (Richmond, VA - Flood Control), community participation and contribution to mitigation of an urban flood control project (Papillion Creek, Omaha, NB), and sponsor initiated enhancement that will have impacts similar to those which would have resulted had the $\mathrm{EQ}$ Plan alternative been adopted (Wildcat and San Pablo Creeks, Contra costa County, CA).

The intent here is not to suggest that these cases represent an exhaustive listing of cost shared projects that have incorporated sponsor initiated $E Q$ features but to offer examples of ways in which sponsor EQ preferences manifest themselves via cost shared planning. What is perhaps most notable is that sponsor initiated $E Q$ recommendations tend not to conflict with the general EQ positions advanced by the Federal interest so much as they make the case for "fine tuning" of the EQ plan.

The baseline for $\mathrm{EQ}$ is, for the most part, established not by sponsor preference but by public law, regulation, and the review process required by ER 1105-2-100, Principles and 
Guidelines. This finding is not surprising when one considers the technical complexity, thoroughness, and intergovernmental character of the formal review and coordination process. The sponsor, while acutely aware of environmental values and the political pressure that may be brought to bear by environmental groups, is necessarily committed to a solution set that places high priority on achievement of the authorized purpose of the project, be that flood control, navigation, etc. Natural resource agencies, on the other hand, have a statutory and institutional obligation to exercise stewardship over public resources and remain unconflicted in their role as advisor with respect to development. Irrespective of the tremendous weight their comments convey in the review and coordination process, resource agencies are perceived to be only tangentially involved in the partnership in planning that cost sharing seeks to engender.

While coordination and review comments or permitting actions may be negotiated, appealed, etc., there is little evidence on cost shared projects to suggest that sponsors routinely attempt to negotiate or purchase more EQ than would be produced as a result of agency request during the review and coordination process. 


\section{SUMMARY}

This chapter has attempted to provide data on the empirical impacts of cost-sharing on project planning and construction. This portion of the research was undertaken primarily to test whether the initial and expected effects of cost-sharing, consistent with microeconomic theory, were in fact observed in the implementation process of the WRDA 1986. Assumptions were generated and tests conducted for the expected effects in three areas, project size, construction scheduling, and project related environmental impacts.

The results of the analysis were generally confirming though the findings on project sizing and scheduling suggest that the intergovernmental behavior of Federal and nonFederal interests is far too complex and strategic to be dominated exclusively by "market incentives." The data suggest that future cost shared projects will tend to be smaller, but for a myriad of reasons, only some of which bear a relationship to the additional financial burden cost-sharing imposes on the non-Federal interest. Further study in this area is called for to better characterize the underlying dimension of the phenomenon; perhaps employing factor analytic techniques to reduce the set of identified independent variables to a smaller set of hypothetical variables with explanatory power. 
The data on environmental impacts is illustrative of the manner in which the standards of a regulated bureaucracy acts as a proxy for estimating what individuals would otherwise demand as a preferred level of EQ. EQ is regulated because it is essentially a public good subject to market failure, thus eliminating the possibility of establishing a demand curve based on market price and quantity (Freeman 1979, 5). The research finds that the "baseline EQ" (one might think of this as a demand curve) is generally established not through negotiation between Federal and non-Federal interests. but by state and Federal regulation expressed via the agency comment process. Overall EQ measurement is complicated by the absence of a straightforward correlation between project size and EQ. Notwithstanding, the non-Federal interest, as a result of cost shared planning, does have more input on how the $E Q$ minimums will be achieved and whether enhancements will be incorporated into the project. Thus, while absolute EQ may not increase as a result of cost shared planning, the benefit estimation of resulting $E Q$ by the non-Federal interest may be higher as a result of their ability to influence the final plan.

A second research consideration in the analysis of data on empirical impacts relates back to a fundamental issue of the model, tractability. The research set forth in this chapter provides further evidence that Target groups will not 
only sign LCAs, thus acceding to cost shared development of projects, but will generally execute their responsibilities during the planning process in accordance with accepted theory. Thus it can be shown that the "problem" (implementing cost shared water resource development) is tractable across a range of populations (non-Federal interests) with some degree of predictability as to the outputs of the process. This finding confirms the correctness of the assumption established in Chapter II to treat tractability as a given rather than include it as a survey variable.

Lastly, this Chapter, along with the historical and legislative data provided in Chapter II, provides a larger and, hopefully, richer framework from within which to evaluate the survey findings. One can question individuals as to their expert opinion on process absent data on the outcome or output of that process; but to truly appreciate their responses there should necessarily be some understanding of results and the implications of those results. This chapter sought to focus on the resultant projects of the implementation process and to measure the extent to which those projects conformed to theoretical expectations. That same data also contributes to the rational analysis of the larger policy issues associated with this research by establishing of measurable outputs 
which provide a context for discussion of the implementation journey from law to constructed project. 
ENDNOTES

1. For a detailed analysis of this distinction see Stakhiv, Eugene Z., Achieving Social and Environmental objectives In Water Resources Planning: Theory and Practice, in Social and Environmental objectives in Water Resources Planning and Management, Warren Viessman, Jr. and Kyle E. Schilling Eds., American Society of Civil Engineers, New York, 1986.

2. It is the case that there now exist OMB funding caps which impose constraints on the mix of projects funded for construction within a given fiscal cycle.

3. See EM 1110-2-1613 for a complete discussion of standard Federal design procedures.

4. Principles \& Guidelines guidance on risk and uncertainty analysis is further supplemented by EC 1105-2179 .

5. A significant example of phased navigation project construction under cost sharing is the four phase deepening of Norfolk Harbor and Channels. Delayed deepening of the outbound channel at Norfolk reduced the non-Federal interest obligated share from $\$ 130$ million to $\$ 17.5$ million.

6. For a complete treatment of this topic see U.S. Army COE, Institute for Water Resources Policy study $84-6240$.

7. For an excellent treatment of the identification and estimation of flood control benefits see otto Eckstein's Water Resource Development, 1961, Cambridge, MA: Harvard University Press.

8. Special project legislation and clarification of sponsor reimbursement policy are ready examples of variables that may generate rather dramatic mid-project cost reallocations. 
CHAPTER VI

SUMMARY FINDINGS

As discussed in previous chapters, implementation research, is properly concerned with the derivation of strategies that maximize the possibility of achieving the desired ends of policy initiatives. With that purpose in mind, data from this study was examined with an eye toward extending the prescriptive component of the model being evaluated and to suggest new research perspectives which may be generally applied to the field of implementation research. It is recognized that the research presented here, from a theory expanding perspective, is constrained. The use of a single policy sector and the non-random selection of survey participants raises legitimate questions about validity and reliability shortcomings of the nonexperimental study design.

While the hypotheses advanced in the research are generally supported, the survey portion of the research involving the criticality of implementation variables reveals a spread of recorded scores about the mean within identified groups which suggests that expert opinion on the foundation variables of successful implementation varies widely. This finding is not inconsistent with previous 
research efforts which have concluded that policy

observations are typically specific to the policy at hand and difficult to generalize across policy types. Moreover, the dominant thinking in the research field at this time notes that data analysis for implementation research must combine multiple data sources and techniques that are longitudinal and comparative as well as intensive and extensive (Goggin 1990, 194).

While it is unlikely that any one study will soon provide a definitive solution, implementation research, and studies such as this, continue to provide a research platform where models are combined, tested, and refined; and thus provide a foundation for the next generation of research.

The data herein collected reveals much about the implementation process and offers evidence on implementation behavior that, it is hoped, will be of both theoretical and practical significance. A review of the empirical findings established in previous chapters and supplemental observations are set forth below in what is intended to serve as integrated summary of the research and its contribution to our understanding of implementation mechanics in an intergovernmental environment.

It is, perhaps, important to note that by virtually any measure, the implementation of the WRDA 1986 and cost shared water resource development was a success. Though the 
implementation process has occasioned extensive negotiation, policy clarification, and organizational adjustment, the end product, a biennial Federally authorized water resources program appears to be on track following 16 years of stalemate prior to the passage of the WRDA 1986. This assessment acknowledges the distinction between estimating the success of the process and that of the output (product) (Goggin et. al. 1990, 174). In this instance, both process and product were measured to identify the extent to which a broad goal or objective was met; and the resulting data was convincingly, if not overwhelmingly, positive.

Figure 10. reveals the manner in which typical effective implementations proceed. The level of achievement and compliance associated with the implementation of the WRDA 1986 suggest that the success of such an effort falls

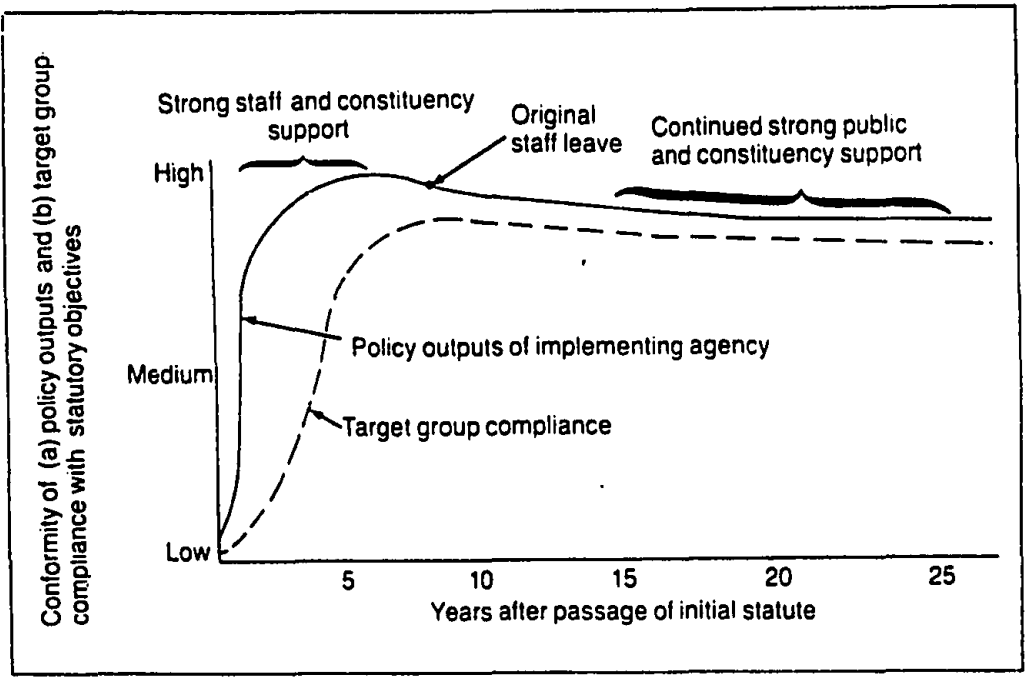

Figure 10. Pattern of Effective Implementation. Source: Mazmanian 1980, 278. 
well outside reasonable expectations (Bardach 1977). Most importantly, contrary to assertions that mutual adjustment during the implementation process will vitiate program objectives (Berman 1980) or that adaptive strategies will inevitably lead to a retreat from original objectives (Wildavsky 1979), the implementation of cost shared water resource development has held the line on the application of beneficiary pay principles.

From the enactment of the WRDA 1986 through 1992, 177 LCAs had been signed obligating Federal and non-Federal interests to over seven billion dollars of development. In that period, an additional 85 feasibility cost-sharing agreements have been negotiated committing in excess of $\$ 132,000,000$ to planning for future projects. The GAO determined in 1991 . that a total of 563 projects nationwide were involved in cost shared planning or construction. The Bush Administration's position, set forth by Assistant Secretary of the Army for Civil Works (ASACW), Nancy Dorn, in her testimony on before the House on the WRDA 1992 unequivocally declared that the future of water resource development involves an adherence to cost-sharing and beneficiary-pay principles by both the legislative bodies and the water resource development community (Dorn 1992).

It would appear then that, absent a new administration with a markedly different development philosophy and a far smaller Federal deficit to contend with, the cost share 
principles established in the WRDA 1986 will continue to direct Federally assisted water resource development into the next century. What will that future look like? The data on the assumptions related to the empirical impact cost shared water resource development, though mixed, offers some evidence as some definite patterns have emerged.

With respect to the assumption that cost shared projects would tend to be smaller on average there is confirming evidence. The data as to causality, however, is not conclusive in that the marginal downsizing of Federally assisted water resource development projects may have occurred even in the absence of cost shared planning constraints. While there remains a tremendous "backlog" of projects to be considered, it is generally accepted within the Corps of Engineers and the water resource development community that the days of the massive water impoundment projects are over. The compelling economic arguments that are mere topics for parlor discussion in an era of plenty come to dictate policy during periods of scarcity.

Measured in constant dollars, the civil works program of the Corps has been reduced $25 \%$ since 1965 . Fewer available sites, restricted funding, and environmental constraints all act in concert to reduce the probability the nation will return to the "Public Works" era. Indeed, it is 
far more likely that available funds will be redirected to provide maintenance for the $\$ 125$ billion capital project inventory that the corps now possesses.

It is theoretically consistent, that future cost shared projects will reflect a somewhat smaller scale than that which would have been planned and built had the funding source remained $100 \%$ Federal. That is so simply because the non-Federal interests either can not or will not accede to funding projects whose benefits far exceed their needs. Concrete evidence of that trend is provided in Chapter $v$. There is now ample evidence that: 1) cost shared projects will not exceed the capacity of the non-Federal interest to fund their portion of the design; 2) non-Federal interests will argue to limit initial costs by eliminating separable elements or staging/phasing construction; 3) the corps, while adhering to beneficiary-pay principles, is increasingly willing to listen and accommodate the needs of non-Federal interests.

The data on project size and project scheduling assumptions set forth in Chapter $V$ suggest that cost shared projects will likely result in designs that are negotiated "at the margin" to produce projects that are both revenue sensitive and reflect the engineering judgment of the nonFederal interest. The likely result of that negotiation, based on available data, suggests a modest downsizing of projects, particularly in the flood control arena. This 
observation is both consistent with the data available and with the applicable theory established in Chapter II which posits that non-Federal interests will tend to support projects that have a direct and identifiable benefit stream over those where benefits are more long range or less tangible.

As previously noted, operation and maintenance of the existing water resource infrastructure will continue to compete with new start projects and likely dominate budgets to a larger degree than ever before. 1 . Twelve percent of all Corps projects are now in excess of fifty years old and 172 of the 370 existing flood control reservoirs are in excess of thirty years old. By the year 2000, a significant portion of the inventory will have reached its design life (Dorn 1992). There can be no question that O\&M budgets will outpace investment in new structures. Given the limited and probably diminishing resource base, new investments will likely reflect a conservative design bias that favors "limited" projects and ease of maintenance. ${ }^{2}$

The data on the impact of cost-sharing on environmental planning reveals that while the cost shared planning model induces greater input by the non-Federal interest in environmental planning there was little evidence of resulting large scale changes in remediation or mitigation plans. The collected data supports a finding that the 
review and coordination process required by Federal and state law and associated environmental regulations effectively establishes a "baseline" for environmental quality as an "output" that is typically equal to or in excess of that which either the non-Federal interest or the Corps advocates. The planning partnership occasioned by cost sharing has led to increased non-Federal interest involvement in environmental plan formulation and that input will likely be reflected in final design. Thus, while the data does not support a finding that project generated environmental impacts will be greatly reduced as a result of cost shared planning, there is evidence that final plans will more accurately reflect local preferences. Notwithstanding this limited finding, the long range impact of the WRDA 1986 environmental planning principles may be of significance. The Act provides in Section 1135 that the corps may modify the structures and operations of projects it constructs for the purpose of improving environmental quality. Since the inception of the WRDA 1986, thirty-eight studies have been funded under this authority. One project is under construction and two are in the final review process. Importantly, both the Bush and Clinton Administration (based on campaign positions) have established $\mathrm{fish}$ and wildlife habitat restoration as a high priority project purpose to be considered equally with navigation and flood control. As you will recall from the 
discussion in Chapter $V$, stakhiv argues persuasively that elevating environmental outputs to planning objectives necessarily results in projects that are qualitatively different from those planned under the environmental "constraint" model. (Water supply and recreation have been deemed of lesser significance and are now considered primarily a responsibility of the local beneficiary.) The FY-92 COE budget request included studies for nine environmental projects for fish and wildlife habitat. The FY-93 request will include four additional studies (Dorn 1992) .

With respect to environmental impacts, the Act is not deterministic. The WRDA 1986 does not mandate new environmental standards. Rather, it provides non-Federal interests an avenue to leverage local monies for project related environmental enhancement if they so choose. The Administration has offered signs of support for such initiatives provided cost share criteria are met. Thus, the ultimate impact of the Act on environmental planning will be largely determined by the extent to which non-Federal interests choose to exercise the section 1135 authorities and their active involvement in mitigation planning. As is frequently the case in assessing broad scale implementation efforts, it will be several more years before sufficient data to reach a conclusion on the impact of the 
implementation effort is available.

The findings generated by the process analysis on implementation variables are suggestive but inconclusive, and so are consistent with much of the research in the field. The excellent recent research done by Goggin, Bowman, Lester, and O'Toole lends further support to the rather gloomy notion that no scientific principles of implementation apply under all circumstances (Goggin et. al. 1992). Importantly, the data suggests that research on policy redesign should not focus exclusively on the modification of subsequent authorizing legislation, as previous research has recommended, but more appropriately focus on an analysis of the functional and organizational responses of the implementing agency to legislative initiatives.

Though the implementation analysis model established by Mazmanian and sabatier provided and excellent vehicle to assess how implementation "elites" view the process, the data showed little support for the model's assertion that clear legal mandates and sound theory were the most significant of the six conditions of effective implementation. Indeed, the composite survey sample ranked those conditions third and fifth respectively in order of importance. This finding may be misleading in so far as the conditions, while not ranked highly in the survey, appear, in fact, to have been met. Much of the prior research on 
the model (Mazmanian and Sabatier 1983, Lester and Bowman 1986) has attempted, using various methodologies, to ascertain the extent to which the conditions were met rather than assess their criticality to the process. It should be noted that WRDA 1986 did not specify why cost sharing was being implemented but how. Thus, from the perspective of the target and periphery, soundness of theory is a relatively moot point, that discussion having been settled once the Reagan administration determined that no water resource development bill would be passed without cost sharing language. As a member of the ASACW staff noted in 1992, "it (the theory) may not have a constituency outside the administration."

Nevertheless, the economic theory supporting costsharing is well established and the legal objectives of the legislation (with regard to the implementation of cost share criteria) are clearly delineated in the Act and subordinate implementing regulations. It is frequently the case that the significance of any one component/condition of an implementation effort may not be accurately assessed until its supply or quality is reduced. There is ample evidence in previous research to suggest that population samples associated with implementation efforts involving unsound theory and/or unclear legal mandates and goals may have ranked conditions one and two much higher. 
clearly there is a need for additional cross policy research which develops "functionally equivalent" measures of variable significance to provide further insight on the identification and ordering of implementation variables. Notwithstanding the complexity of the implementation environment and the apparent non-comparability of policy types, this research confirms the call for parsimony in the identification of causal and explanatory variables. Expanding the range and scope of variables to accomodate unexplained variance quickly leads to an unpromising situation for both the theorist in pursuit of hypothesis development and the practitioner seeking useful guidelines. It is not surprising that so much of implementation research has found that "actual results tend to depend on the nature of the policy task," thus reaffirming the suspicion that scientific principles and implementation variables likely covary with the task at hand (Goggin et. al. 1990, 201).

An interesting finding of the survey research revealed that the conditions ranked highest were substantially focused on the capacity, will, and resources of the implementing agency to support the "program" and "make things happen." One would expect participants in an intergovernmental implementation to be acutely aware of the necessity of a competent, sympathetic, and committed lead agency.

The finding is consistent with those of the General 
Accounting office (GAO) survey on cost shared water resource development which determined that principal among the complaints from non-Federal interests was the perceived inequity of the Federal/non-Federal interest partnership, cost growth over the life of the project (and over which they felt they had little control), and reimbursement schedules (U.S. GAO 1991, 2). Though participants may not be able to effect policy redesign through direct negotiation with Congress, they soon learn that the policy learning process provides a vehicle by which Target groups and other organized constituencies can exert influence over policy implementation. The implementation of cost shared planning principles offers an excellent example of this "second-tier" policy learning phenomenon.

Kaufman (1981) observed that the degree of responsiveness exhibited by a Federal agency to "client" input is positively related to the influence and reputation of the agency. Thus, one would expect the corps to be directly involved and actively responsive to concerns expressed by Target groups related to programs the Corps administers, and that has been the case. Indeed, the LifeCycle Project Management (LCPM) initiative implemented in 1989, largely as a result of demands of managing the LCA process associated with the WRDA 1986, resulted in a major functional realignment of Corps personnel and the way in 
which the Corps does business.

Responding to criticism that the LCA process was overly complex and lines of authority were either not clear or erratically dynamic, the corps has engaged in a series of activities designed to foment an appreciation and understanding of the partnership model. To assure that sponsors understand the mechanics of the ICA process and to provide additional avenues of input from "partners and potential partners," the sponsors Information Kit was issued as an Engineering Pamphlet. The kit forthrightly acknowledges the bewilderment that non-Federal interests may encounter in its dealings with the Federal bureaucracy generally and the Corps specifically (Kelly 1990).3

structurally, the corps implemented LCPM to provide a . direct single Project Manager (PM) linkage with non-Federal partners for all aspects of project development. The single point of contact manages the project from feasibility study through construction. The objectives of this initiative have been established as: 1) improving overall performance by maintaining accountability and commitment to project schedules, cost estimates; 2) integration of sponsors, partners, and customers into the implementation process; ensure consistent application of administration policy; and 3) vest project accountability in a single individual/function (EC 5-1-48 1992).

A variety of procedural and organizational measures 
have been implemented in support of this initiative including the development of automated reporting and tracking systems designed to reduce the review time for project submittals, a corps wide commitment to adopt a cost/Schedule control system Criteria planning model for all projects, and extensive training for corps personnel authorized to implement the initiative. Cognizant of internal criticism from District PMs regarding sluggish review systems at the Division level and beyond, confusing or conflicting guidance from multiple sources, and the propensity for sponsors to "leapfrog" over Districts on important issues, the corps has sought to provide sufficient "resources" to its "street level" managers to avoid the phenomenon of resistance to policy compliance (Lipsky 1980, 23).

Though the implementation of ICPM appears a seemingly practical and reasonable response to the problems associated with the partnering model, the initiative has proved difficult to fully implement as it involved the creation of a new major functional "stovepipe" and a perceived realignment of organizational authority. While the corps has moved incrementally forward on the initiative, the implementing regulation has only recently (24 April 1992) been approved and issued by the HQ USACE. A unique aspect of the policy learning environment 
associated with the WRDA 1986 was the scale of the groups involved in the implementation. As the Federal and nonFederal interests communities were easily identified and relatively small, they were able to engage in what amounted to "town hall" sessions that provided face to face discussions of impediments to implementation. The products of such sessions are referenced throughout this research and provide a rich source of information on the discourse between Center, Periphery, and Target constituencies. Viewed as a whole, the documents provide graphic evidence of the powerful dynamic of the policy learning process. While the corps, attending to the admonitions of the Administration, has adhered to the cost share criteria and beneficiary pay principles set forth in the Act, there is ample evidence that the implementation process itself has been subject to an iterative modification process. Such evidence supports the "bottom up" perspective and suggests that whereas the "critical elements" of implementation policy may be imposed through legal mandates, the interface environment of Periphery and Target groups will be largely defined by the give and take of field personnel.

The supplemental data sample referenced in Chapter III provides some insight on the nature and substance of the dialogue associated with policy learning. A sample of early program (1986) local sponsors $(\mathrm{N}=20)$ consisting of ten flood control or flood control/recreation projects and ten 
harbor/navigation projects were surveyed for their opinions on the implementation process. To each, the following questions were posed:

1. Did the Corps provide adequate guidance (if requested) on financing issues associated with water resource development issues (generally) and cost sharing specifically?

2. Was there a problem with crediting for prior work performed on the project by the sponsor?

3. Did you feel that the Corps' planning process was more accessible under cost sharing guidelines?

4. Did your input into the mitigation plan (and lor other environmental features) lead to a change in the environmental outputs of the project?

The findings for questions 1 . through 4 . are contained in Table XXIII.

\section{TABLE XXIII}

NON-FEDERAL INTEREST DATA ON COST SHARED PLANNING

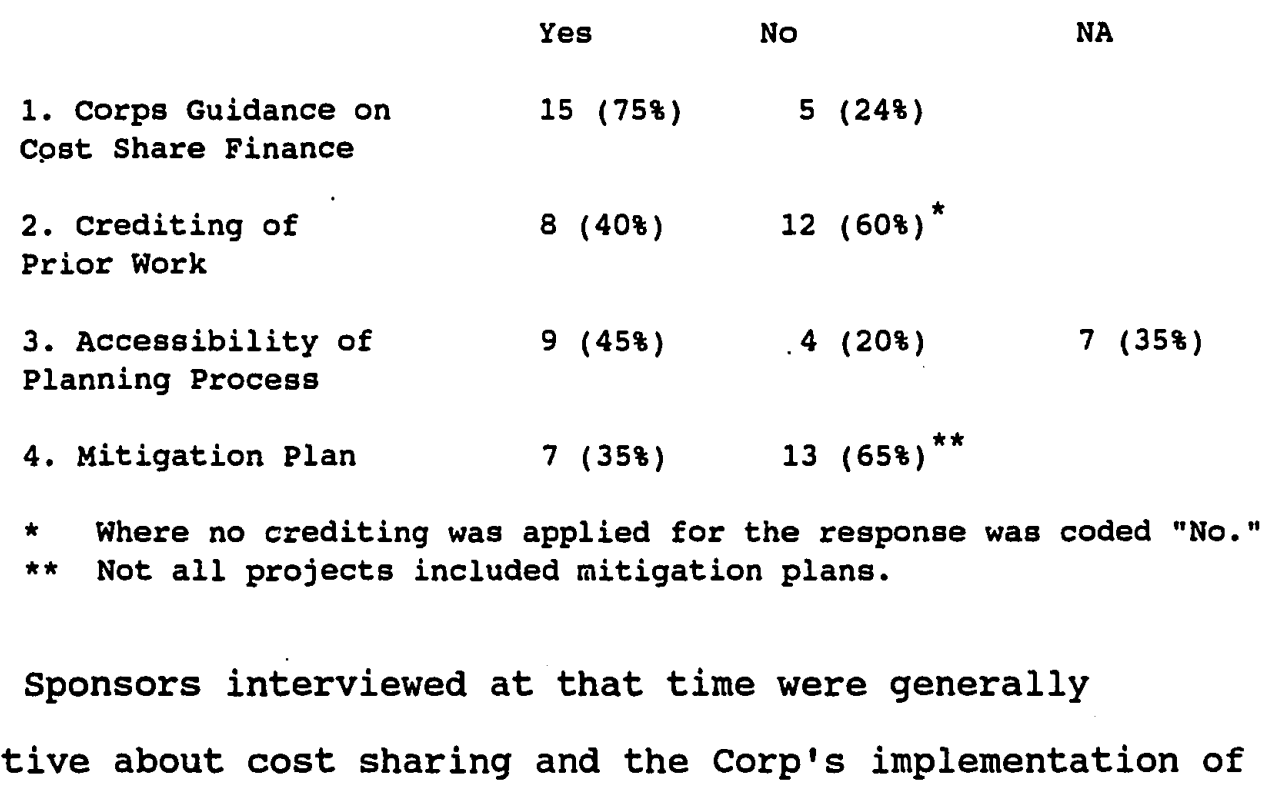

positive about cost sharing and the Corp's implementation of 
the program. Notwithstanding the difficulty some sponsors experienced in the negotiation of the LCA virtually all indicated that corps personnel had executed their duties in a professional and cooperative fashion. As might be expected, District personnel were typically perceived to be more flexible and understanding of local concerns than were higher level Federal interest personnel. This is not to suggest that concerns were not raised. Sponsors, while satisfied with the overall corps effort in implementing the process, indicated a number of areas that they felt required additional attention. An abbreviated sample of observations are offered below:

a. The (non-Federal) benefit analysis is more business oriented (for navigation projects) than is the Corps project (NED plan) benefit-cost analysis. Local sponsors are leery of constructing for "anticipated" benefits that may not develop for years.

b. The corps is very conservative as regards risk assessment. Projects should be designed to risk levels acceptable to those facing exposure.

c. Pay-as-you-go financing places a tremendous burden on sponsor jurisdictions who must trade off water resource projects with other infrastructure demands. Sponsors have to take an incremental approach.

d. Corps cost estimates are not as accurate as sponsors would like. This is a particularly acute problem when sponsor must engage in bond elections to fund projects.

e. The review time at District, Division, HQUSACE, and ASA(CW) level is inordinately slow.

f. Policy advice is not always consistent. This 
is particularly acute when policy is issued at different levels of the Corps organization.

g. The Corps needs to be more flexible in negotiating design standards.

h. It is hard to be a partner because the corps has so much tradition that sponsors are not familiar with.

i. It is not a 50/50 partnership when one partner has all the regulations and final say.

What is most striking, is the similarity of these observations and those recorded in the NAFSMA (see Appendix B) and GAO surveys conducted 5 years later. This finding tends to confirm that the initial observations by participants have held true over time and across a range of projects. A review of Corps functional standard operating procedures and policies and organizational restructuring over that same period of time would reveal that efforts to address virtually all of these concerns have been made. similar to the conclusion reached by many of the bottom-up theorists, the data on the implementation of the WRDA 1986 suggests that state and local governments do exert influence over Federally mandated policy, though in this instance that influence is more directly reflected in the organization and internal policies of the implementing agency than in the WRDA 1986 and subsequent water resource development legislation. This observation is consistent with the findings of the research which suggests that the focus of the policy learning process may be redirected from 
efforts to effect legislative policy design to shaping the operating relationship with the principal implementing agency. This may or may not represent a sub-optimal approach from the perspective of the Target group and its constituency depending on the extent to which basic policy differences can be resolved in their favor.

In the case of cost shared water resource development, it became clear to the development community that fighting the continued application of cost shared development criteria at the legislative level would likely result in little more than Executive veto of pending water legislation and a return to the "no growth" era which characterized the 1970s and early 1980s.

Consistent with bottom-up implementation theory, negotiations of this type at this stage of the process represent the continuing effort of "implementation elites" to influence the goals, objectives, and procedures of the process. Thus, the marshaling of resources in an effort to persuade the corps to use its discretion to interpret the legislation "liberally" with respect to the status and rights of the non-Federal interest appears to be a rational strategy with a reasonable chance of success. 4

It must be noted that the future of the Corps' civil works program as well as the development plans of the nonFederal water resource development community are linked to the success of the partnership model. The substance of this 
interdependency is lost on neither party. As Mazmanian and Sabatier have noted in tests on their model, while strength of the original statute and clear policy objectives are initially most significant, in the long term, the existence of a supportive constituency is probably more important (Mazmanian 1983, 277). 


\section{ENDNOTES}

1. The clinton administration economic stimulus package submitted to Congress in FY-93 proposed $\$ 79,053,000$ in expenditures for Corps O\&M civil works and $\$ 3,900,000$ for construction general expenditures with the CG portion dedicated to accelerating authorized hurricane protection projects. clearly, the thrust of the stimulus package confirms the assumption that O\&M will dominate an increasingly larger share of the Corps' civil works budget. For additional data on the stimulus package and a complete listing of projects see the CEDB 22 March 1993 letter from the Director, Small and Disadvantaged Business Utilization Program to Commanders, Major Subordinate Commands, subject, Economic stimulus Package for FY-93.

2. Cortner (1987) maintains that failure to control the Federal deficit, which resulted in the Gramm-RudmanHollings, Balanced Budget and Emergency Deficit Reduction Act, effectively signaled the end of large scale civil works programs by identifying water resource development projects as subject to discretionary cuts. Coupled with increased Executive control of the agenda and non-Federal interest budget constraints, new-start civil works construction will not likely rise to pre-1970 levels in the foreseeable future.

3. Following the December 1.990 Corps/NAFSMA Conference, the corps (CECW-LP) issued a report of findings on the conference that substantially echoed and reaffirmed the findings of this research on the status of interorganizational relations. High praise was given the Corps for its project management initiatives and the focus on a single point of contact during project planning and construction. Sponsors still felt uneasy with their level of participation in project management planning and with the erratic nature of District decision making on cost shared planning. A call was also made for more flexible financing arrangements. A report of findings is available in CECW-LP (February 1991) letter to Major subordinate Commands, subject: NAFSMA Conference, 10-12 December 1990, New Orleans LA.

4. In response to sponsor concerns, a specific if partial listing of what is and is not negotiable in the development and execution of LCAs was published in the 1992 edition of the Sponsors Information Kit published by the COE. 
33 USC 701. 1917. 39 stat. $948,950$.

Allison, Graham T. 1971. Essence of Decision. Boston: Little Brown.

Anderson, J.E. 1975. Public Policy Making. New York: Praeger

Alexander, E.R. 1985. "From Ideas to Action, Notes for a Contingency Theory of the Policy Implementation Process." Administration and Society 16.4 .

Andrus, Cecil D. 1980. Report on Phase 1 of Water Policy Implementation, Submitted to the President of the United States by the Secretary of the Interior. Washington, D.C.: U.S Department of Interior (June 6) .

Bardach, E. 1977. The Implementation Game. Cambridge: MIT Press.

Barret, Susan and Michael Hill. 1984. "Policy, Bargaining and Structure in Implementation Theory: Towards an Integrated Perspective." Policy and Politics 12.3. Baumol, William J. and Wallace E. Oates. 1988. The Theory of Environmental Policy. Unpublished draft paper prepared for the National Council on Public Works Improvements.

Benarie, Michel. 1988. "Delphi- and Delphilike Approaches with Special Regard to Environmental Standard Setting." Technological Forecasting and Social Change 33.2.

Berman, P. 1978. "The Study of Macro and Micro Implementation." Public Policy 26(2).

- 1980. "Thinking About Programmed and Adaptive Implementation: Matching strategies to situations." In why Policies succeed or Fail, eds. H. Ingram and D. Mann. Beverly Hills: Sage.

- 1978. "The Study of Macro and Micro

Implementation." Public Policy 26(2). 
Berman, Paul and Milbrey McGlaughlin. 1975. Federal Programs Supporting Educational Change, Vol. IV: The Findings in Review. Santa Monica: Rand Corporation.

Bernstein, Marver. 1955. Regulating Business by Independent Commission. Princeton, N.J.: Princeton University Press.

Blalock, Hubert M. Jr. 1964. Causal Inferences in Nonexperimental Research. Chapel Hill: The University of North Carolina Press.

Bowman, John H. 1986. Cost Sharing in the Provision of Public Works: Conceptual and Policy Issues. Draft Paper Prepared for N.C.P.W.I (August).

Browne, A. and A. Wildavsky. 1984. "Implementation as Mutual Adaptation." In Implementation, eds. J.L. Pressman and A. Wildavsky. Berkley, CA: University of California Press.

Bunker, Douglas R. 1972. "Policy Sciences Perspectives on Implementation Processes." Policy Sciences. Amsterdam the Netherlands: Elsevier Publishing Company 3.

Caulfield, Henry P., Jr. 1984. "U.S. Water Resources Development, Policy and Intergovernmental Relations " In The Management of Natural Resources in a Time of Declining Federalism, eds. John G. Francis and Richard Ganzel. Rothman and Allenheld.

Congressional Quarterly. 1985. Washington DC: Congressional Quarterly Inc. (June 22).

1986. Washington DC: Congressional Quarterly Inc. (March 29).

Cook, Howard L. 1963. Principles underlying legislative policies governing Federal assumption of responsibilities in the field of water resource development. Notes from Seminar on River Basin Planning. Ft. Belvoir, VA. U.S. Department of Army, COE, May.

Cortner, Hannah J. 1987. The Water Resource Development Act of 1986: A Non-Federal Perspective. Unpublished paper prepared for the Corps of Engineers, Institute for Water Resources. Ft. Belvoir, VA. 
Dalkey, Norman C. 1969. The Delphi Method: An Experimental study of Group opinion. Santa Monica, CA: The Rand Corporation, RM-5888-PR, (June).

Dajani, Jarir S. and Michail Z. Sincoff. 1986. "Stability and Agreement Criteria for the Termination of Delphi Studies." Technological Forecasting and Social Change 29.

Dalkey, Norman C., Daniel L. Rourke, Ralph Lewis, and David Snyder. 1972. Studies in the Quality of Life. Lexington, MA: Lexington Books, D.C. Heath and Co.

Derthick, Martha. 1972. New Towns in Town. Washington, D.C: The Urban Institute.

Dickey, G. Edward and Leonard Shabman. 1984. Benefits Revenues and Cost Recovery. Paper presented at COE/ICWP Conference on Water Problems Workshops on Water Project Financing.

Dickey, G. Edward. 1982. "Overview of Federal and Nonfederal Water Resources Programs and Project Cost Sharing." In Financing Water Resources: Cost Allocation, cost sharing, eds. Ronald $M$. North and Steven H. Hanke. The Institute of Natural Resources: University of Georgia.

Dietz, Thomas. 1987. "Methods for Analyzing Data from Delphi Panels: Some Evidence from a Forecasting study." Technological Forecasting and Social Change 31(1) (March).

Dorn, Nancy P. 1992. Statement of the ASACW before the Subcommittee on water Resources, Committee on Public Works and Transportation, U.S. House of Representatives (March 11).

Eckstein, Otto. 1961. Water Resource Development. Cambridge, MA: Harvard University Press.

Edwards, George III. 1980. Implementing Public Policy. Washington, DC: Congressional Quarterly Press.

Elazar, Daniel J. 1969. "Federal state collaboration in the Nineteenth Century United States." In Cooperation and Conflict: Readings in American Federalism, eds. Daniel J. Elazar, R. Bruce Carroll, E. LEster Levine, and Douglas St. Angelo. Itasca, Ill: F. E. Peacock Publishers, Inc. 
Elmore, Richard. 1978. "Organizational Models of Social Program Implementation." Public Policy 26(2) (Spring).

1979. "Backward mapping: Using Implementation Analysis to structure Political Decisions." Political Science Quarterly $94(4)$.

1985. "Forward and Backward Mapping: Reversible Logic in the Analysis of Public Policy." In Policy Implementation in Federal and Unitary Systems, eds. K. Hanf and T.A.J. Toonen. Dordrecht: Martinus Nijhof.

1987. "Instruments and Strategy in Public Policy." Policy studies Review 7(1).

EC 5-1-48. 1992. Implementation of Project Management. Engineering Circular issued by the U.S. Army Corps of Engineers (April 1992).

EC 1105-2-115. 1983. Economic and Environmental Principles and Guidelines for Water and Land Related Implementation Studies. Engineering Circular issued by the U.S. Army Corps of Engineers (March 10).

EM 1110-2-1613. 1983. Hydraulic Design of Deep Draft Navigation Projects. Engineering Manual issued by the Department of the Army, Office of the Chief of Engineers, DAEN- CCWE-HD (8 April).

Engineering News Record. 1987. (April 23).

EP 1165-2-1. 1975. Water Resource Policies and Authorities, Digest of Water Resource Policies. Engineering Pamphlet issued by Department of the Army, office of the Chief of Engineers (January).

ER 1105-2-50. 1990. Policy and Planning Guidance. Engineering Regulation issued by Department of the Army, Office of the Chief of Engineers, CECW-P (December 28)

ER 1165-2-29. 1987. General credit for Flood control. Engineering Regulation issued by Department of the Army, Office of the Chief of Engineers, CECW-RR (November). 
ER 1165-2-120. 1988. Reimbursement for Advance Non-Federal Construction of Authorized Federal Harbor and Inland Harbor Improvements. Engineering Regulation issued by Department of the Army, office of the Chief of Engineers, CECW-RP (June).

ER 1165-2-131. 1988. Water Resources Policies and Authorities, Local Cooperation Agreements for New Start Construction Projects. Engineering Regulation issued by Department of the Army, Office of the Chief of Engineers, CECW-R (June).

Erffmeyer, Robert C. with Elizabeth S. Erffmeyer and Irving Lane. 1986. "The Delphi Technique: An Empirical Evaluation of the optimal Number of Rounds." Group \& Organizational Studies. Beverly Hills: Sage Publications 11(1-2) (March-June).

Federal Register. 1987.23 September, $241.4(f)$.

Fischoff, Baruch, Sarah Lichtenstein, Paul Slovic, Stephen I. Derby, and Ralph Keeney. 1981. Acceptable Risk. Cambridge: Cambridge University Press.

Fox, Charles J. 1987. "Biases in Public Policy Implementation Evaluation." Policy Studies Review 7 (1) (Autumn).

Freeman III, A. Myrick. 1979. The Benefits of Environmental Improvement. Baltimore: John Hopkins Press.

Glazer, William A. 1955. "The Type and Uses of Political Theory." Social Research 22 .

Goggin, Malcolm L. 1986. "The 'Too Few Cases/Too Many Variables' Problem in Implementation Research." Western Political Quarterly 38.

- 1987. Policy Design and the Politics of Implementation. Knoxville: The University of Tennessee Press.

Goggin, Malcolm L., L. O'Toole Jr., A. O. Bowman, J. P. Lester. 1990. Implementation Theory and Practice: Toward a Third Generation. Harper Collins Publisher.

Hargrove, E. 1980. The Search for Implementation Theory. Nashville TN: Vanderbilt University Institute for Policy studies. 
Haveman, Robert H. 1976. The Economics of the Public sector. New York: John Wiley Sons.

Herbich, John B. 1975. Coastal and Deep Ocean Dredging. Houston: Gulf Publishing Co.

Hjern, B., K. Hanf and D. Porter. 1978. "Local Networks of Manpower Training in the FRG and Sweden." Interorganizational policymaking. London: Sage

Hirsch, Werner Z. 1984. Urban Economics. New York: Mcmillan Publishing.

Hogwood, B. and G. Peters. 1983. Policy Dynamics. New York: St. Martins Press.

Holmes, Beatrice Hort. 1972. A History of Federal Water Resources 1800-1960. Washington D.C: U.S Department of Agriculture Economic Research Service, Miscellaneous Publication No. 1233 (June).

Holmes, Beatrice Hort. 1979. A History of Federal Water Resources Programs and Policies, 1961-1970. Washington D.C: U.S Department of Agriculture Economic Research Service, Miscellaneous Publication No. 1379.

Hrezo, Margaret S. and William E. 1985. "From Antagonistic to Cooperative Federalism on water Resources Development." American Journal of Economics and Sociology 44 (2) (April): 199-214.

Huddleston, G. Wayne. 1987. Cost-Shared Feasibility studies - A Year in Review. Unpublished paper prepared for the Corps of Engineers, Water Resources Support Center, Planning Associates Program.

Ingram, Helen. 1987. "Implementation, A Review and Suggested Framework." In Public Administration, The state of the Field, eds. A. Wildavsky and N. B. Lyons. Chatham, New Jersey: Chatham House Publishers Inc.

Iversen, Gudmund R., and Helmut Norpoth. 1976. Analysis of Variance. Sage University Paper Series on Quantitative Applications in the Social Sciences. Berverly Hills: Sage Publications.

James, L. Douglas, and Robert R. Lee. 1971. Economics of Water Resource Planning. McGraw-Hill Book Company.

Jones, C. 1977. An Introduction to study of Public Policy. Belmont, CA: Wadsworth 
Kaufman, Herbert. 1981. The Administrative Behavior of Federal Bureau Chiefs. Washington, D.C.: The Brookings Institution.

Kelly, Major General Patrick J. 1989. Letter of 6 April from the Director of Corp of Engineers, Civil Works to the water resource development community.

Kelly, Major General Patrick J. 1990. Sponsors Partnership Kit. Publication prepared by U.S. Army Corps of Engineers, HQUSACE, CECW-PW.

Kidder, Louise H. 1981. Research Methods in Social Relations. Holt, Rinehart and Winston.

Knickerbocker, Brad. 1981. "Water Projects Under Reagan: Down then Up." Christian Science Monitor. Boston, Ma., 3 March.

Krutilla, John V. and Otto Eckstein. 1958. Multiple Purpose River Development. Baltimore: The John Hopkins Press.

Krutilla, John V. 1966. "Is Public Intervention in Water Resource Development Conducive to Economic Efficiency." Natural Resources Journal (January): 60-75

Lester, James. P., et. al. 1987. "Future Directions for Research in Implementation." Policy Studies Review 7 (1) (Autumn) : 201-216.

Lester, J.P. and A. Bowman. 1986. "Subnational Hazardous Waste Policy Implementation: A Test of the SabatierMazmanian Model." Paper presented at annual meeting of the American Political science Association, Washington, DC.

Leuchtenberg, William Edward. 1953. Flood Control Politics: The connecticut River Valley Problem, 19271950. Cambridge: Harvard University Press.

Linder, S. H. \& B.G. Peters. 1987. "A Design Perspective on Policy Implementation: The Fallacies of Misplaced Prescription." Policy Studies Review 6(3) (February): 459-476.

Lipsky, M. 1978. "Standing the Study of Public Policy Implementation on Its Head." In W.D. Burnham and M.W. Weinberg (eds.) American Politics and Public Policy. Cambridge: MIT Press. 
Lipsky, M. 1980. Street Level Bureaucracy. New York: Russell Sage Foundation.

Loucks, Daniel P. 1986. Analytical Methods for Multiobjective Planning, in water Resources planning and Management, eds. Warren Viessman, Jr. and Kyle E. Schilling Eds. American Society of Civil Engineers, New York.

Lowi, Theodore. 1969. The End of Liberalism. New York: Norton.

McConnel, Grant. 1966. Private Power and American Democracy. New York: Knopf.

Majone, Giandomenico. 1975. "The Feasibility of Social Policies." Policy sciences. 6.

Manual for Risk and Uncertainty Analysis in Corp's Civil Works Planning. 1989. Draft report prepared for the U.S. Army Corps of Engineers Humphreys Engineer Center Support Activity, Fort Belvoir, VA. (April 24).

Marshall, Harold E. 1969. The Relationship Between Local Cost Sharing and Efficient Water Resource Development. Ph.D. dissertation, the George Washington University.

Marshall, Harold E, and V. L. Brousallian. 1982. "Federal Cost-Sharing Policies for Water Resources." National Bureau of Standards Report \# NWC- SBS-72-039 (April).

Mazmanian, Daniel A. and Paul A. Sabatier 1979. "The Conditions of Effective Implementation: A Guide to Accomplishing Policy Objectives." Policy Analysis 5(4).

- eds. 1980. Successful Policy Implementation. Policy studies organization

- 1981. Effective Policy Implementation. Lexington, MA: Lexington Books.

- 1983. Implementation and Public Policy.

Dallas: Scott, Foresman and Company.

McCool, Daniel. 1987. Command of the Waters: Iron Triangles, Federal Water Development, and Indian Water. Berkeley: University of California Press. 
Moreau, David. 1987. Financing Urban Water Resources. Unpublished paper presented to the Engineering Foundation Conference.

Moreel, Ben. 1957. Our Nation's Water Resources: Policies and Politics. Chicago: University of Chicago Law School.

Mugler, Mark. 1984. Non-Federal Cost Recovery and Financing for Water Projects. Research Report 84-R-1, U.S. Army Corps of Engineers Engineer Institute for Water Resources, Ft. Belvoir, VA (March).

- 1986. "The Initial and Expected Effects of Increased cost Sharing." Unpublished Discussion Paper prepared for the U.S. Army Corps of Engineers Engineer Institute for Water Resources, Ft. Belvoir, VA.

- 1984. NED Versus Affordability Considerations in Plan Selection. Draft report prepared for the U.S. Corps of Engineers, Institute for Water Resources Policy Study 84-6240, U.S. Army Corps of Engineers Engineer Institute for Water Resources, Ft. Belvoir, VA.

Nakamura, Robert T. 1987. "The Textbook Policy Process and Implementation Research." Policy Studies Review 7(1) (Autumn).

National Journal. 1986. Washington D.C.: National Journal Inc. (November 22).

National Waterways Conference, Inc. 1981. Newsletter (July 28).

National Association of Flood and stormwater Management Agencies (NAFSMA) and the U.S. Army Corps of Engineers. 1989. Making the Water Resources Development Act of 1986 and 1988 Work: Strengthening the Local Partnership. Conference report. NAFSMA: Washington D.C.

Nelson, William Bradley. 1977. The Statistical Manipulation of Delphi statements. Ph.D. dissertation, Portland State University.

Oates, Wallace E. 1972. Fiscal Federalism. Harcourt, Brace, Jovanovich, Inc. 
O'Toole, Laurence J. and R. S. Montjoy. 1984. "Interorganizational Policy Implementation: A Theoretical Perspective." Public Administration Review (November/December): 491-503.

O'Toole, Laurence J. 1986. "Policy recommendations for Multi-Actor Implementation: An Assessment of the Field." Journal of Public Policy 6 .

Palumbo, Dennis J. 1987. "Implementation: What We Have Learned and Still Need to Know." Policy Studies Review 7(1) (Autumn): 91-102.

Pill, Jury. 1971. "The Delphi Method: Substance, Context, A Critique and an Annotated Bibliography." SocioEconomic Planning Sciences 5 .

President's Water Resources Policy Commission, Report of the Commission. 1950. Water Resources Law 3.

Pressman, Jeffrey L. and Aaron B. Wildavsky. 1973. Implementation. Berkeley: University of California Press.

Pross, Edward Lawrence. 1938. A History of Rivers and Harbors Appropriations Bills, 1866-1933. Unpublished Ph.D. dissertation, The Ohio state University.

Public Law 99-662. 1986. Water Resource Development Act of November 1986.

Quade E.S. 1975. Analysis for Public Decisions. New York: American Elsevier Publishing Company, Inc.

Reid, T. R. 1980. Congressional Odyssey: The Saga of a Senate Bill. New York: W. H. Freeman and Co.

Rein, Martin and Francine F. Rabinovitz. 1978. Implementation: A Theoretical Perspective, "American Politics and Public Policy. Edited by Walter D. Burnham and Martha W. Weinberg. Cambridge: MIT Press.

Reuss, Martin. 1990. Working papers on the legislative history of the Water Resource Development Act of 1986, in preparation for the United States Corps of Engineers, History Division, located at the Humphreys Engineering Center, Ft. Belvoir, Va. 
Reuss, Martin and Paul K. Walker. 1983. Financing Water Resources Development: A Brief History. U.S. Army Corps of Engineers, Engineering Pamphlet 870-1-13 (July).

Rieger, wilfred G. 1986. "Directions in Delphi Developments: Dissertations and Their Quality." Technological Forecasting and Social change. New York, NY: Elsevier Science Publishing 29.

Rossi, Peter H. \& James D. Wright. 1985. "Social Science Research and the Politics of Gun Control." In Social Science and Social Policy, ed. R. L. Shotland and M.M. Mark. Beverly Hills, CA: Sage Publications.

Report of the Corps of Engineers Panel on Project Development in Partnership. 1988. Directorate of Civil Works, Headquarters, U.S. Army Corps of Engineers, Washington, D.C.

Sabatier, Paul A. 1986. "Top Down and Bottom Up Approaches to Implementation Research: A Critical Analysis and Suggested Synthesis." Journal of Public Policy 6: 2148 .

1987. "Knowledge, Policy-oriented Learning, and Policy Change: An Advocacy Coalition Framework." Knowledge: Creation, Diffusion, Utilization 8: 649-92.

Sackman, Harold. 1976. Delphi Critique. Lexington: D.C. Heath and Company.

Salamon, L. 1981. "Rethinking Public Management: Third Party Government and the Changing Forms of Government Action." Public Policy 29(3):255-275.

Schilling, Kyle, Claudia Copeland, Joseph Dixon, James Smythe, Mary Vincent, and Jan Peterson. 1987. The Nation's Public Works: Report on Water Resources. Washington D.C: National Council on Fublic Works Improvement.

Seely, Bruce E. 1987. Building the American Highway System: Engineers as Policy Makers. Philadelphia: Temple University Press.

Setty, K. P. Srinivasa with S. Padmanabhan and R. Natarajan. 1987. "A National Energy-Conservation Policy Delphi: Report of the Findings." Technological Forecasting and Social Change. New York: Elsevier Science Publishing 31 (3) (May). 
Shabman, Leonard and G. Edward Dickey. 1986. "Federal Financial Responsibility for Coastal Port Development: A study of the Process of Policy Redefinition." Policy Studies Review $6(2)$ (November).

Sickles, Mark. 1986. The Future of Intergovernmental Relations and the United States Army Corps of Engineers. Working Paper 86-WP-1 prepared for the U.S. Army Corps of Engineers Engineer Institute for Water Resources, Ft. Belvoir, VA.

Singer, Neil M. 1976. Public Microeconomics, An Introduction to Government Finance. Boston: Little Brown and Company.

Skaggs, L. Leigh and David V. Grier. 1986. Current Status of Cost Shared Deep-Draft Harbor Projects. Paper presented at the 68th Annual meeting Transportation Research Board. USACE Water Resources Support Center, Institute for Water Resources, Ft. Belvoir, VA.

Skaggs, L. Leigh and David V. Grier. 1989. A Review of ongoing $U$. S. Harbor Deepening Projects. Paper presented at Texas A\&M 22nd Annual Meeting and Technical Conference of the Western Dredging Association.

Stakhiv, Eugene z. 1986. "Achieving Social and Environmental objectives In Water Resources Planning: Theory and Practice, in Social and Environmental objectives." In Water Resources Planning and Management, eds. Warren Viessman, Jr. and Kyle E. Schilling. New York: American Society of Civil Engineers.

Stakhiv, Eugene Z. and Janet Wright. 1984. An Evaluation of the Efficacy of Cost-Shared Planning studies. Unpublished paper prepared for the U.S. Army Corps of Engineers Engineer Institute for Water Resources, Ft. Belvoir, VA.

Stakhiv, E.Z., M. Reuss, L. Skaggs, and W. Warick. 1989. Developed Water Resources and the Environment. Draft paper prepared for the U.S. Army Corps of Engineers Engineer Institute for Water Resources, Ft. Belvoir, VA.

Stanfield, Rochelle L. 1986. "A New Era." National Journal 47 (November). 
Steinberg, Bory. 1987. Memorandum dated 3 November from Bory Steinberg, Army Corps of Engineers, CECW-R, Subject: Ability to Pay for Flood Control Projects.

Stone, Clarence N. 1980. "The Implementation of Social Programs." Journal of Social Issues $36(4)$.

Stonecash, Jeffrey M. 1990. "State Responses to Declining Federal Support: Behavior in The Post-1978 Era." Policy Studies Journal 18 (3) (Spring).

Swartz, Thomas R., John E. Peck, eds. 1990. The Changing Face of Fiscal Federalism. Armonk, NY: M.E. Sharpe, Inc.

Turoff, Murray. 1970. "The Design of a Policy Delphi." Technological Forecasting and Social Change $2(2)$.

Turoff, Murray. 1975. "The Policy Delphi." In The Delphi Method: Techniques and Applications, eds. Harold A. Linstone and Murray Turoff. Addison-Wesley Publishing Company.

U.S. Advisory Council on Intergovernmental Relations. 1987. Perspective. (Summer/Fall).

- 1987. The Organization of Local Public Economies, A-109. December 1987 .

U.S. Army Audit Agency, 1989. Report of Audit, Civil Works Projects. Report issued in draft 19 July. Washington D.C.: U.S. Audit Agency.

U.S. Congressional Budget office. 1983. Current costSharing and Financing Policies for Federal and state Water Resources Development. Washington, D.C.: Congressional Budget office.

- 1983. Efficient Investment in Water Resources: Issues and Options. CBO study. Washington, D.C.: Congressional Budget office.

U.S. General Accounting office. 1991. Water Resources: Local Sponsors' Views of Corps' Implementation of Project Cost Sharing. Fact Sheet for Congressional Requesters. Washington D.C.: GAO.

U.S. Congress. House. 1982. Proposed Water Resources Development Projects. Hearings held June 8 . 
U.S. Congress. Senate. 1978. A Perspective on the Waterway User Charges Legislation During the 95th Congress. Before the Committee on the Environment and Civil Works. 95th Congress., 2nd Session. Washington D.C: U.S. Government Printing office.

U.S. Congress. Senate. 1966. Committee on Public Works, A Report to the Secretary of the Army by the Civil Works Study Board. 89th Congress. 2nd. Session. Washington, D.C.: U.S. Government Printing office.

U.S. Council on Environmental Quality. 1981. Environmental Quality 1981: 12th Annual Report. Washington D.C.: Council on Environmental Quality.

U.S. Water Resources Council. 1975. Section 80 (c) Study, Part 5A, options for cost Sharing: Implementation and OM\&R cost Sharing for Federal and Federally Assisted Water and Related Land Programs. Washington D.C.: U.S. Government Printing office.

- 1983. Economic and Environmental Principles and Guidelines for Water and Related Land Resources Implementation Studies. Washington D.C.: U.S. Water Resources Council (March 10).

Van Horn, Carl E. 1979. Policy Implementation in the Federal system. Lexington: D.C. Heath and Company.

Van Meter, D.S. and C. E. Van Horn. 1975. "The Policy Implementation Process: A Conceptual Framework." Administration and Society, 6 .

Wagner, K.D. 1986. Implementation Gap: Congress, EPA, and the Development of Environmental Policies. Paper presented at American Political Science Association. Washington, D.C.

Wall, General John F. and Kyle E. Schilling. 1985. "The Corps of Engineers: "Planning to Meet the Financing Challenge." In Water Management in Transition 1985. Navarre MN: Freshwater Foundation.

Wall Street Journal. 1977. June 23.

White, Leonard D. 1953. The state and the Nation. Baton Rouge: Louisiana State Press.

Wildavsky, Aaron. 1979. Speaking Truth to Power: The Art and Craft of Policy Analysis. Boston: Little Brown and Co. 
Williams, Walter and Richard F. Elmore. 1976. Social Program Implementation. New York: Academic Press.

Williams, Walter. 1982. Studying Implementation, Methodological and Administrative Issues. Chatam, New Jersey: Chatham House Publishers.

Wilson, James Q. ed. 1980. The Politics of Regulation. New York: Basic Books.

Winter, S. 1983. Studying Implementation of Top-Down Policy From the Bottom Up: Implementation of Danish Youth Employment Policy. Denmark: Institute of Political Science.

Wittrock, B. 1984. "Beyond organizational Design: Contextuality and the Political Theory of Public Policy." In Policy Implementation in Federal and Unitary Systems, eds. K. Hanf and T.A. J. Toonen. Dordrecht: Martinus Nijhoff.

wittrock, B., and P. De Leon. 1986. "Policy as a Moving Target: A Call for Conceptual Realism." Policy Studies Review, 6 .

Wolf, c. Jr. 1988. Markets or Governments: Choosing Between Imperfect Alternatives. Boston: MIT Press.

Wright, Deil S. 1982. Understanding Intergovernmental Relations. Monterey: Brooks Cole Publishing.

Yin, R.K. 1982. "Studying the Implementation of Public Programs." In Studying Implementation: Methodological and Administrative Issues. Chatham, NJ: Chatham House Publishers. 
APPENDIX A

SURVEY INSTRUMENT 
SURVEY FORMAT

IMPLEMENTATION OF COST SHARING FOR WATER RESOURCE DEVELOPMENT Please provide the following information:

1. Name 2. $\operatorname{sex}$

3. Age 4. Occupation

5. Position Title (Employer)

6. Years in current occupation

7. Years in current position

8. Years of Education (Circle one)

Highschool graduate / Some College / College Graduate / Graduate Studies

Masters Degree / Doctoral Degree

9. Number of cost shared projects you have worked with.

1. The variables included in this survey are variables thought to be important in achieving the successful implementation of legislated policy. You will find that they are stated quite generally. Thus, you are asked to rank these variable in order of relative importance based on your experience in the implementation of cost sharing as promulgated by WRDA 1986 and subsequent legislaton. The order in which the variables appear in the survey is completely arbitrary and so should not affect your evaluation of their significance. All questions should be answered from YOUR PROFESSIONAL PERSPECTIVE.

2. Distribute 100 points among the variables in their relative (according to your best estimate) order of significance with the most important variable being assigned the greatest number of points. You may distribute the points in any manner you feel appropriate. Variables which you feel are insignificant do not need to be ranked. 
3. Please write, if you care to explain your ranking or feel that it would be informative, a brief (1-3 sentence) reason for your ranking of the three (3) variables you consider most significant. Space on the questionnaire is provided beneath the description of each variable.

4. Self-rate the confidence of your estimates by assigning yourself a score in the categories listed below. Please place a check beside the choice that best describes how you would rate the accuracy of your estimates.

1. Very confident of accuracy of response.

2. Confident of accuracy of response.

3. Somewhat confident of accuracy of response.

4. Unsure of accuracy of response.

5. Just guessing 


\section{VARIABLES TO BE RANKED}

SCORE (Total points assigned should equal 100)

1. The enabling legislation (Congressinal authorization of the project and cost sharing program) or other legal directive mandates policy objectives which are clear and consistent or at least provides clear criteria for resolving goal conflicts.

2. The enabling legislation (Congressinal authorization of the project and cost sharing program) incorporates a sound theory identifying the principal factors and causal linkages affecting policy objectives and gives implementing officials sufficient jurisdiction over non-Federal interests, members of the water resource development community, and other points of leverage to attain, at least potentially, the desired goals.

3. The enabling legislation (Congressinal authorization of the project and cost sharing program) structures the implementation process so as to maximize the probability that implementing officials (representative of the Corps of Engineers) will perform as desired. This involves assignment to a sympathetic agency with clear, hierarchical organizational structure, supportive decision rules, sufficient financial resources, and adequate access to supporters.

4. The leaders of the implementing agency (Corps of Engineers) possess substantial managerial and political skill and are committed to the succes of the program.

5. The cost shared water resource development program is actively supported by organized constituency groups and by a few key legislators (or a chief executive) throughout the implementation process, with the courts being neutral or supportive.

6. The relative priority of statutory objectives is not undermined over time by the emergence of conflicting public policies or by changes in relelvant socioeconomic conditions which weaken the legislation's causal theory or political support. 
APPENDIX B

NATIONAL ASSOCIATION OF FLOOD AND STORMWATER

MANAGEMENT AGENCIES (NAFSMA) SURVEY 


\section{NAFSMA SURVEY ON CORPS OF ENGINEERS-PARTNERED} WATER RESOURCE PROJECTS (Percentages)

\section{(Final as of $10 / 26 / 90$ )}

The following results are based on the responses of 20 local sponsors, with 30 current water resources projects covered. The results provided in this compilation are based on the project number of 30 . In cases where the results fall short of the 30 possible responses, the questions were either found to be unapplicable or simply were unanswered.

1. Since 1986, have you been a potential or are you currently a local sponsor with a flood control project (to be) cost-shared with the U.S. Army Corps of Engineers?

No 25 Current (\# of Projects) 5 Potential

2. If the answer to one is yes, what is the name(s) of the project(s) and where is it (are they) located? (Corps District, Division, City)

3. Omitted.

4. Omitted.

5. If you have an approved local cooperation agreement (LCA) for construction, when was it signed?

14 have signed LCAs, with the earliest being signed in 1986 and the most recent signed on July $30,1990$.

11 No, ICA has yet to be signed.

1 Not Applicable.

LCA

a) At what stage in the Corps approval process was the signed?

Planning (1)

Prior to construction (3)

Plans and specs completed (3)

After first construction appropriation (2) - Phase II

GDM; complete and approved.

Post GDM approval (2)

Beginning of feasibility study

After final approval 
b) Does your LCA include language addressing hazardous and toxic wastes?

$\begin{array}{ll}\frac{7}{10} & \text { Yes } \\ \frac{5}{5} & \text { No (hasn't been signed) } \\ \frac{1}{1} & \text { Expected to }\end{array}$

6. Does your locality qualify under the Ability to Pay provisions of the Water Resources Development Act of 1986, which entitled qualifying localities to limited cost sharing relief for flood control projects?

$\frac{2}{(1}$ Yes $\frac{17}{17}$ No $\frac{2}{2}$ (Don't know) ( 1 probably not) (1 respondent indicated not according to the procedures established by ASA, however, the ASA provisions do not comply with the intent of congress.)

5. PARTNERSHIP QUESTIONS - Percentages of yes to no answers

Yes No

Have you been:

$82 \% 18 \% 1$. Listened to and had your opinion considered? (1 sometime)

$82 \% \quad 18 \%$ 2. Kept informed during the project? (1 sometime)

39\% $61 \% 3$. Provided fiscal documentation on the use of project funds? (3 NA)

76\% 24\% 4. Allowed to attend project related meetings with District project team?

$\underline{30 \%} \underline{70 \%}$ 5. Participating in District Project Review Board meetings? (2 NA)

$12 \%$ 88\% 6. Participating in Division Project Review Board meetings? (2 NA)

37\% 63\% 7. Involved in a Reconnaissance Resolution Conference? (2 NA)

$33 \%$ 67\% 8. Involved in a Feasibility Resolution Conference? (2 NA)

46\% 54\% 9. Involved in a Technical Resolution or Progress Review meeting? ( $1 \mathrm{NA}$ ) 
Yes No

18\% $82 \%$ 10. Allowed to participate at a Washington Level Review meeting? ( 2 NA) ( 1 No added that although they had requested to participate they had been turned down by Chief of Engineers.)

47\% 53\% 11. Given the opportunity to meaningfully participate in decisions about project costs and schedules?

71\% 29\% 12. Allowed to participate in decisions about the type and mix of project objectives?

85\% $15 \%$ 13. Able to influence formulation and selection of alternative plans? ( $1 \mathrm{NA}$ )

76\% 24\% 14. Allowed to affect decisions about project design, including environmental and aesthetic features?

42\% $58 \%$ 15. Able to influence construction phasing? (4 NA)

50\% $50 \%$ 16. Provided the opportunity to assist the corps in preparing project documents: (check blank)

Note: For preliminary analysis, percentages for $a-i$ were taken out of 30 possible responses, this group of responses only may be slanted too much to the negative.

a. Reconnaissance Reports $26 \%$

b. Feasibility Report $43 \%$

c. Environmental Assessments $30 \%$

d. Design Memoranda $37 \%$

e. Plans and Specifications $57 \%$

f. Project Management Plans $30 \%$

g. Project Management Reports $23 \%$

h. Feasibility cost Sharing Agreements $37 \%$

i. Local Cooperation Agreement $40 \%$ 
Yes No

58\% $\underline{42}$ 17. Provided copies of Corps Guidance Documents? (1 No Answer-NA) (2 yes, added "Limited")

$48 \%$ 52\% 18. Requested by the corps to be the project proponent to gain political support?

Can't use 19. Able to meet the local sponsor commitments for the project including:

88\% $12 \%$ - Timely response on issues or documents you have been requested to review? ( 2 yes said "somewhat" for all 4 related questions)

92\% 8\% - Providing financing on time? (1 answered between yes and no)

75\% $\underline{25 \%}$ - Delivered real estate interests on schedule? ( 1 answered between yes and no)

$68 \% 32 \%$ - Insured relocations to meet project schedules? ( 1 answered between yes and no) ( 1 NA)

$66 \% 34 \%$ 20. Provided with a single point of contact throughout the project development?

66\% $34 \%$ 21. Aware of an appropriate conduit in the corps to voice concerns in all areas of project development?

37\% $63 \%$ 22. Given a copy of the corps' draft "Sponsor's Information Kit" for review by your local District? one district reported it had not been received there.

(2 Not sure-got one from NAFSMA)

28\% $72 \%$ 23. Able to observe that your project has been managed in a way to establish and maintain a firm cost estimate and project execution schedule? (2 No answer)

21\% 79\% 24. Satisfied with how the LCA negotiation approval process has been handled for your project?

$39 \% \quad 61 \%$ 25. Able to determine if the corps Division has been an effective participant in the implementation of the project? ( 3 Somewhat) 
Yes No

$68 \%$ 32\% 26. Able to find a way to keep real estate acquisition from holding up your project? (If so, briefly describe how below.) ( 1 NA)

29\% 71\% 27. Faced with any problems in receiving credit for compatible work? (2 NA)

24\% $76 \%$ 28. Forced to hold up or forego seeking credit for local construction you believe was compatible with the project? ( 2 NA)

43\% $57 \%$ 29. In the situation where you had a dispute with the District about a design issue that you were not able to resolve?

52\% $48 \%$ 30. Able to define to your satisfaction what constitutes a project betterment? ( 2 NA)

71\% $29 \%$ 31. Able to achieve sensitivity to local design issues? ( 1 yes added, but it was difficult)

52\% $48 \%$ 32. In a situation where the project being implemented is called the "locally preferred plan" and not the NED plan? (1 NA)

$78 \%$ 22\% 33. Able to get the corps to include changes in the project/contracts to include locally requested additions? ( $2 \mathrm{NA})$

$0 \quad 100 \% 34$. In a situation where the ability to pay regulation was an issue?

58\% $42 \% 35$. Satisfied with escrow agreement arrangement with the corps? ( 3 NA)

(1 respondent answered questions 23-35 between yes and no.)

(1 respondent answered questions 5-35 not applicable, recon just completed.)

(1 respondent pointed out that most of no responses were due to the fact that they are not far enough in the project to have meaningful participation.) 
APPENDIX C

INDEX OF ACRONYMS 


\begin{tabular}{|c|c|}
\hline $\begin{array}{l}\text { ASACW } \\
\text { CEQ }\end{array}$ & $\begin{array}{l}\text { Assistant Secretary of Army for Civil Works } \\
\text { Council on Environmental Quality }\end{array}$ \\
\hline $\mathrm{CW}$ & Civil Works \\
\hline $\mathrm{DA}$ & Department of the Army \\
\hline $\mathrm{DDE}$ (PME) & $\begin{array}{l}\text { Deputy District Engineer for Project } \\
\text { Management }\end{array}$ \\
\hline $\mathrm{DE}$ & District Engineer \\
\hline $\mathrm{DE}$ & Division Engineer \\
\hline DFARS & $\begin{array}{l}\text { Defense Federal Acquisition Regulation } \\
\text { Supplement }\end{array}$ \\
\hline EC & Engineer Circular \\
\hline EFARS & $\begin{array}{l}\text { Engineer Federal Acquisition Regulation } \\
\text { Supplement }\end{array}$ \\
\hline EQ & Environmental Quality \\
\hline ER & Engineer Regulation \\
\hline ETL & Engineering Topographic Laboratories \\
\hline FAR & Federal Acquisition Regulation \\
\hline FCSA & Feasibility cost Sharing Agreement \\
\hline FOIA & Freedom of Information Act \\
\hline FONSI & Finding of No Significant Impact \\
\hline FY & Fiscal Year \\
\hline GAO & General Accounting office \\
\hline GPO & Government Printing office \\
\hline ICWP & Interstate Conference on water Policy \\
\hline HQ & Headquarters \\
\hline HQUSACE & Headquarters, U.S. Army Corps of Engineers \\
\hline ICWP & Interstate Conference on Water Problems \\
\hline
\end{tabular}




\begin{tabular}{|c|c|}
\hline IPMP & Initial Project Management Plan \\
\hline LCA & Local Cooperation Agreement \\
\hline LCPM & Life Cycle Project Management \\
\hline LERD & Lands, Easements, Rights of Way, Relocations \\
\hline LERR & Lands, Easements, Rights of Way, Relocations \\
\hline LERRD & $\begin{array}{l}\text { Lands, Easements, Rights of Way, Relocations, } \\
\text { Disposal }\end{array}$ \\
\hline NAFSMA & National Association of Flood and Stormwater \\
\hline NED Plan & National Economic Development Plan \\
\hline NEPA & National Environmental Policy Act \\
\hline OASA (CW) & $\begin{array}{l}\text { Office of the Assistant secretary of the } \\
\text { Army, Civil Works }\end{array}$ \\
\hline OMB & Office of Management and Budget \\
\hline PED & Preconstruction Engineering and Design \\
\hline PE\&D & Planning, Engineering and Design \\
\hline$P \& G$ & Principles and Guidelines \\
\hline$S A$ & Secretary of the Army \\
\hline SAME & Society of American Military Engineers \\
\hline USACE & United States Army Corps of Engineers \\
\hline USAED & United State Army Engineer District \\
\hline WLRC & Washington Level Review Center \\
\hline WRDA & Water Resources Development Act \\
\hline WTP & Willingness to Pay \\
\hline
\end{tabular}

